\title{
ULTRAVIOLET DISINFECTION PILOT STUDY AT THE FARGO WASTEWATER TREATMENT PLANT
}

\author{
A Thesis \\ Submitted to the Graduate Faculty \\ of the \\ North Dakota State University \\ of Agriculture and Applied Science
}

By

Ursinio Puga Gil
In Partial Fulfillment of the Requirements for the Degree of MASTER OF SCIENCE

Major Department:

Civil Engineering

April 2017

Fargo, North Dakota 


\section{North Dakota State University \\ Graduate School}

Title

Ultraviolet Disinfection Pilot Study at the Fargo Wastewater Treatment

Plant

By

Ursinio Puga Gil

The Supervisory Committee certifies that this disquisition complies with North Dakota

State University's regulations and meets the accepted standards for the degree of

\section{MASTER OF SCIENCE}

SUPERVISORY COMMITTEE:

Dr. Wei Lin

Chair

Dr. Stephanie Day

Dr. Alan Denton

Dr. Robert Zimmerman

Approved:

$\frac{05 / 01 / 2017}{\text { Date }} \quad \frac{\text { Dr. Dinesh Katti }}{\text { Department Chair }}$




\begin{abstract}
A pilot study was carried out at the Fargo wastewater treatment plant to determine the impacts that flow rate, water quality, and system fouling may have on the efficiency of UV disinfection. A second-order model successfully explained the results obtained with the collimated beam. The second-order model was used to study the impact of water quality and initial microorganism concentration on E. coli inactivation rates. Fouling material was mostly made of precipitated metal salts and its impact on UV intensity reduction was explained with the application of the Beer-Lambert law. E. coli inactivation in the pilot unit was found to be dependent on UVT, flow rate, and UV intensity. A first-order plug-flow model successfully explained the inactivation data obtained in the pilot unit. No significant seasonal water quality changes that may affect system operation were identified. However, UVT changes caused by storm events had short-term adverse impacts on system performance.
\end{abstract}




\section{TABLE OF CONTENTS}

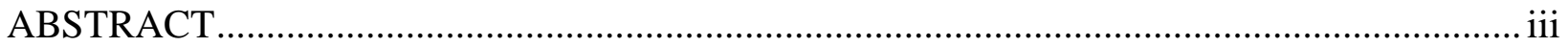

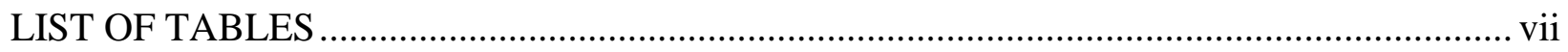

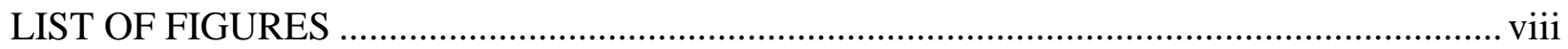

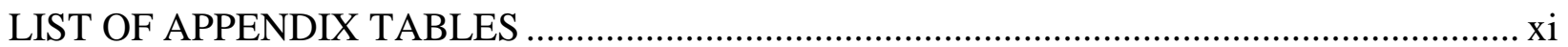

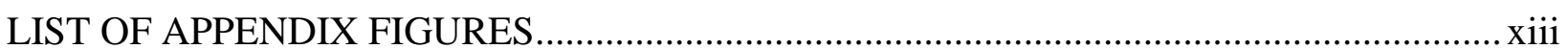

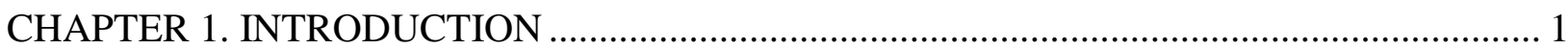

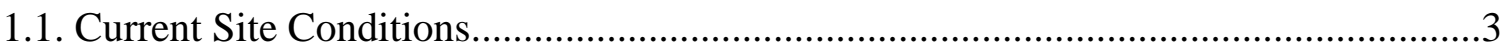

1.2. Research Objectives .....................................................................................6

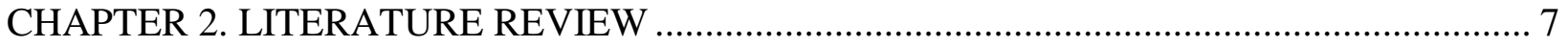

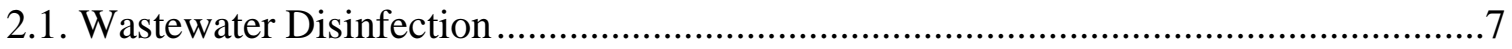

2.1.1. Advantages of UV Light with Respect to Chlorine Disinfection ................. 8

2.1.2. Disadvantages of UV Light with Respect to Chlorine Disinfection............. 9

2.2. UV Light Generation and Lamp Types ...............................................................10

2.3. Transmission of UV Light through Water ................................................................12

2.4. Measurements of Transmitted or Absorbed UV Intensity ..........................................13

2.5. Mechanism of Pathogen Inactivation and Survival .................................................16

2.6. Measurements of Pathogen's Response to UV Light ................................................19

2.6.1. Understanding Microorganism's Response to UV Light.............................. 20

2.6.2. Kinetic Modeling of Microorganism's Response to UV Light .................. 22

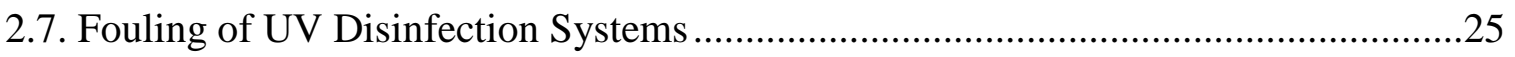

2.7.1. Nature of Fouling Material .................................................................... 26

2.7.2. Intensity Monitoring and Fouling Material Removal ................................. 27

CHAPTER 3. SYSTEM DESCRIPTION AND METHODOLOGY ……………......................... 29 


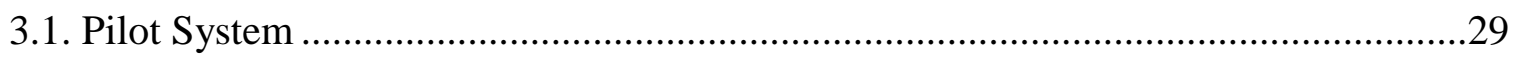

3.1.1. Pilot System Description and Setup............................................................ 29

3.1.2. Pilot System Operation and Control .......................................................... 33

3.1.3. Pilot System Cleaning ................................................................................ 34

3.1.4. Pilot System Sample Collection................................................................. 35

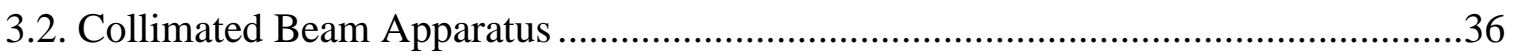

3.2.1. Collimated Beam Apparatus Configuration................................................. 36

3.2.2. Collimated Beam Intensity Calibration Procedure ……............................. 37

3.2.3. Collimated Beam Test Procedure …………………................................... 40

3.2.4. Collimated Beam Sample Analysis ........................................................... 41

3.3. Sample Preparation and Analysis .....................................................................

3.3.1. Microorganism Enumeration ................................................................. 42

3.3.2. Recorded Quality Parameters from SCADA ……………………………... 42

3.3.3. Water Quality Sampling and Reason for Analysis ..................................... 42

3.3.4. Fouling Material Analysis.................................................................... 45

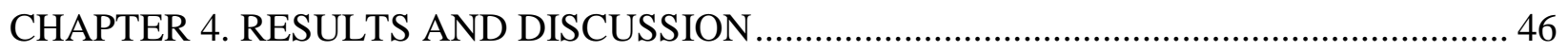

4.1. Evaluation of Fouling of the Quartz Sleeves and Its Impact on UV Intensity ...........46

4.1.1. Initial Test Cycles ..................................................................................... 46

4.1.2. Improved Sensor Cleaning and Intensity Monitoring through SCADA..... 48

4.1.3. Separating Sensor Fouling from the Intensity Data .................................. 51

4.1.4. Fouling Material Analysis....................................................................... 54

4.1.5. Impact of Temperature on Fouling Formation.............................................. 56

4.1.6. Model Simulation of Intensity Loss and Impact of Flow Rate and UVT ... 61

4.2. Impacts of Fouling and Flow Rate Variations on UV Disinfection of E. coli............85

4.2.1. E. coli Inactivation in the Pilot Scale UV Disinfection Unit ....................... 85 
4.2.2. Model Development for E. coli Inactivation Achieved in the Pilot Unit ... 88

4.2.3. Impact of Influent E. coli count on the Disinfection Performance of the Pilot Unit ......................................................................................... 91

4.3. Impact of Influent Water Quality Change on UV Transmittance............................94

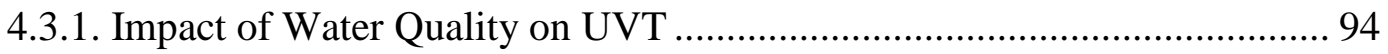

4.3.2. Seasonal Variations of Common Water Quality Parameters ..................... 96

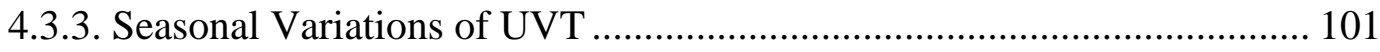

4.4. Relationship between UV Dose and E. coli Inactivation Rate ..............................106

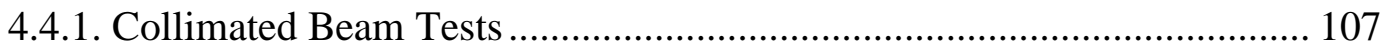

4.4.2. Model Development for E. coli Inactivation Achieved in the Collimated Beam

4.4.3. Impact of Water Quality and Influent E. coli count on Rate of Inactivation .......................................................................... 114

CHAPTER 5. CONCLUSIONS AND RECOMMENDATIONS ........................................ 117

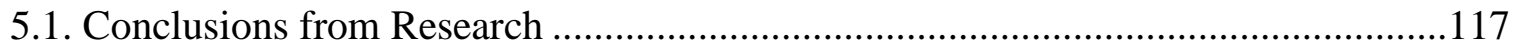

5.5.1. Conclusions drawn from Intensity and Fouling Studies ......................... 117

5.5.2. Conclusions drawn from the Disinfection Achieved in the Pilot Unit ..... 118

5.5.3. Conclusions drawn from the Water Quality and UVT Studies................. 118

5.5.4. Conclusions drawn from the Collimated Beam Study........................... 119

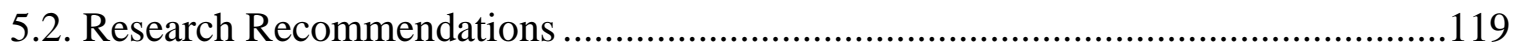

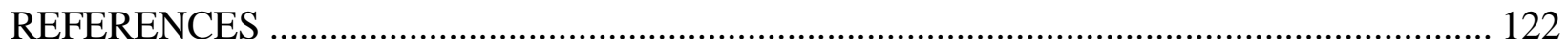

APPENDIX A. INTENSITY AND FOULING DATA .................................................. 130

APPENDIX B. INTENSITY DATA FOR MODELING ................................................. 153

APPENDIX C. PILOT UNIT PERFORMANCE RUNS DATA …....................................... 189

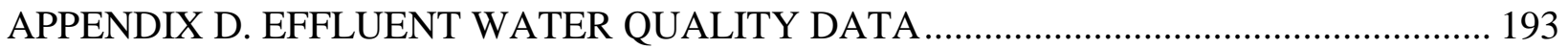

APPENDIX E. CB TEST LOG INACTIVATION DATA .................................................. 202 


\section{LIST OF TABLES}

$\underline{\text { Table }}$

$\underline{\text { Page }}$

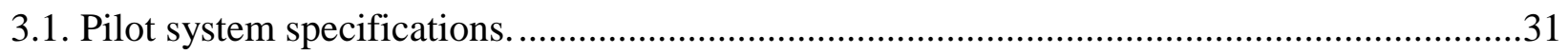

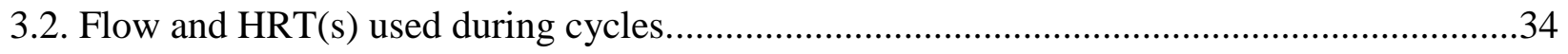

3.3. Filtration procedure and sample classification. ...........................................................45

4.1. Operational conditions for initial eight cycles. ....................................................... 47

4.2. Operational conditions for the initial four cycles monitored through SCADA....................50

4.3. Comparison of intensity loss associated to sleeve fouling and sensor fouling for C13.........52

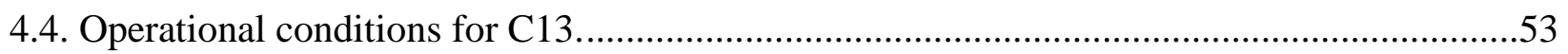

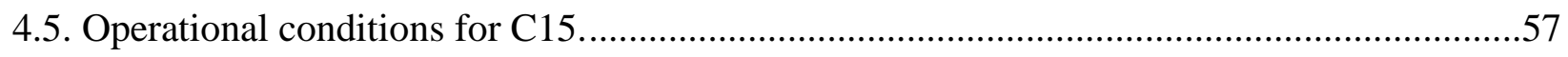

4.6. Comparison of intensity loss associated to sleeve fouling and sensor fouling for C15.........57

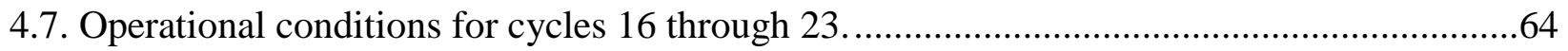

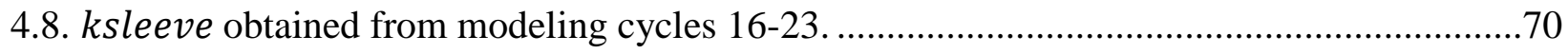

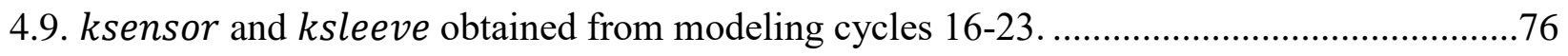

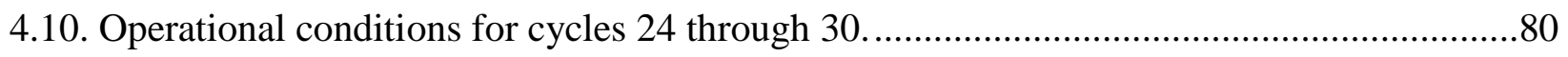

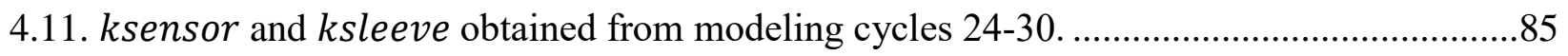

4.12. Operational conditions experienced during the performance runs. ...................................86

4.13. Impact of $\mathrm{N}_{\mathrm{o}}$ on the $\mathrm{D}_{\mathrm{a}}$ needed to achieve Fargo's disinfection discharge standards..........92

4.14. Effects of absorption and scattering on UV Intensity loss........................................95

4.15. Average and standard deviation of UVT experienced during different seasons. ..............103

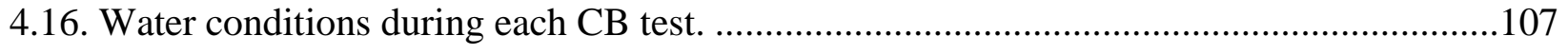

4.17. Counts of surviving E. coli under different UV dose. .............................................108

4.18. Determination of design UV dose from the CB tests performed.................................110

4.19. Second-order rate constants obtained from modeling the experimental data...................113 


\section{LIST OF FIGURES}

Figure

$\underline{\text { Page }}$

1.1. Fargo WWTP flow diagram...........................................................................................

2.1. Electromagnetic spectrum (Source: Ultraviolet Radiation, Government of Canada).............10

2.2. Wavelength spectrum of intensity output of LP and MP UV lamps (Source: USEPA, 2003).

2.3. Typical dose-response curve relationship developed with a CB apparatus for

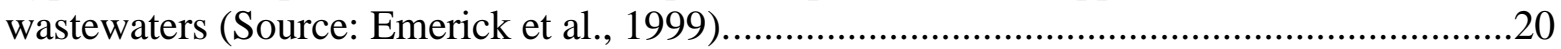

3.1. TrojanUVLogic pilot unit diagram (Source: Trojan Technologies).........................................30

3.2. HRT and flow relationship for the TrojanUVLogic pilot unit.................................................31

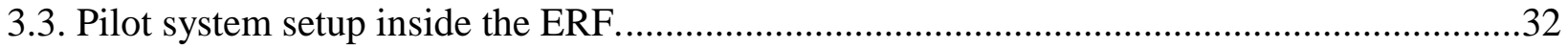

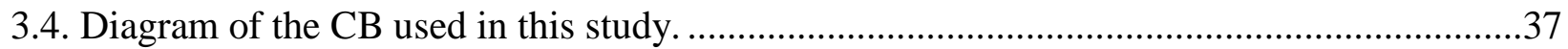

4.1. UV intensity behavior of the initial eight cycles of the study.............................................47

4.2. Magnified picture of the fouled UV intensity sensor. ........................................................49

4.3. UV intensity behavior of the initial four cycles monitored with the SCADA system............50

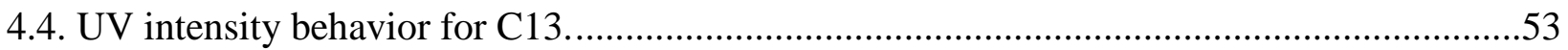

4.5. Distribution of the cations forming the fouling material. ..................................................5

4.6. Visual comparison between fouled and clean quartz sleeve at the end of C14 .....................56

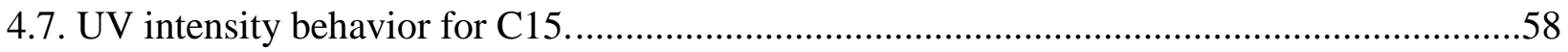

4.8. Intensity behavior with UV lamps off versus on. ……...................................................5

4.9. Visual comparison between fouled and clean quartz sleeve at the end of $\mathrm{C} 15 \ldots \ldots \ldots \ldots \ldots \ldots \ldots \ldots . . .60$

4.10. Modeled UV intensity data collected after cleaning the sensor's lens during C16............65

4.11. Modeled UV intensity data collected after cleaning the sensor's lens during C17 .............66

4.12. Modeled UV intensity data collected after cleaning the sensor's lens during C18 .............66

4.13. Modeled UV intensity data collected after cleaning the sensor's lens during C19.............67 
4.14. Modeled UV intensity data collected after cleaning the sensor's lens during C20.

4.15. Modeled UV intensity data collected after cleaning the sensor's lens during C21............68

4.16. Modeled UV intensity data collected after cleaning the sensor's lens during C22. ...........68

4.17. Modeled UV intensity data collected after cleaning the sensor's lens during C23. ...........69

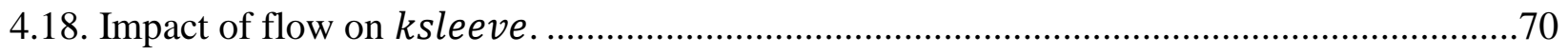

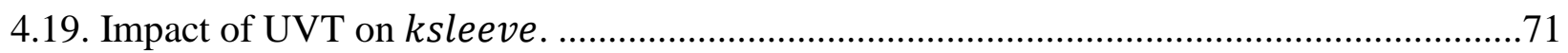

4.20. Modeled UV intensity data collected before cleaning the sensor's lens during C16..........72

4.21. Modeled UV intensity data collected before cleaning the sensor's lens during C17..........73

4.22. Modeled UV intensity data collected before cleaning the sensor's lens during C18..........73

4.23. Modeled UV intensity data collected before cleaning the sensor's lens during C19..........74

4.24. Modeled UV intensity data collected before cleaning the sensor's lens during C20..........74

4.25. Modeled UV intensity data collected before cleaning the sensor's lens during C21..........75

4.26. Modeled UV intensity data collected before cleaning the sensor's lens during C22 ..........75

4.27. Modeled UV intensity data collected before cleaning the sensor's lens during C23..........76

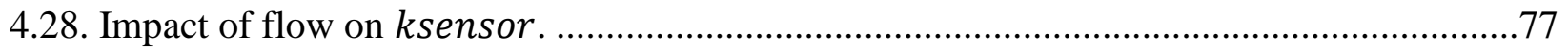

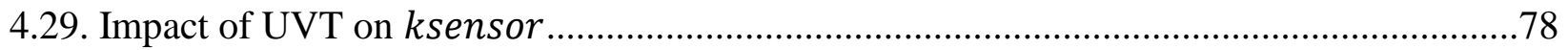

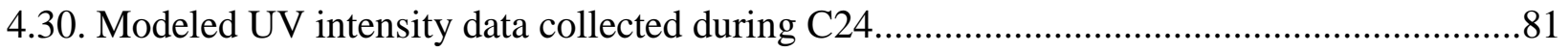

4.31. Modeled UV intensity data collected during C25...............................................82

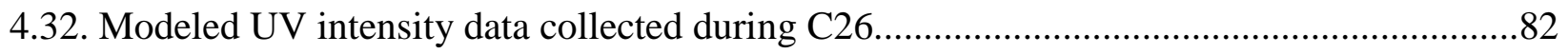

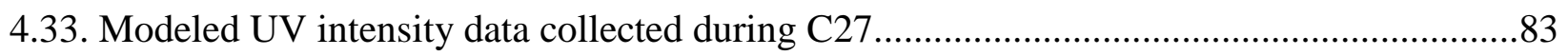

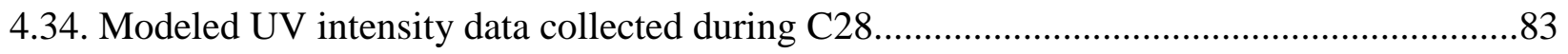

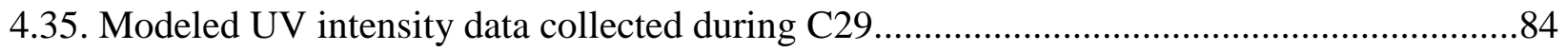

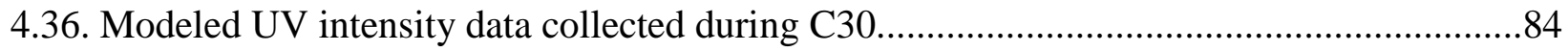

4.37. Intensity loss through the quartz sleeves experienced during performance runs.................86

4.38. Percent surviving E. coli counts experienced during performance tests. .........................87 
4.39. E. coli survival experienced in the pilot unit.

4.40. First-order plug flow kinetic model explaining the E. coli experimental data obtained during performance runs. ......................................................................91

4.41. Impact of $\mathrm{N}_{\mathrm{o}}$ on $\mathrm{D}_{\mathrm{a}}$ needed to achieve disinfection discharge standards. ........................93

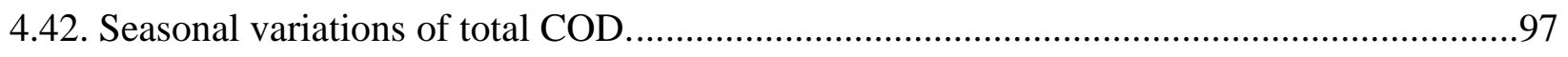

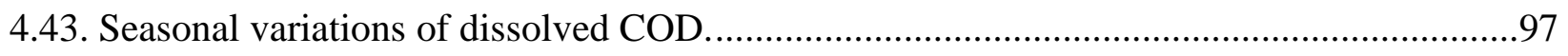

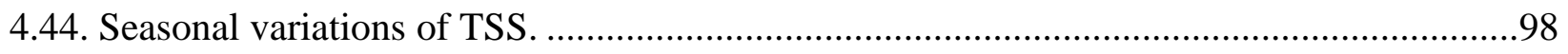

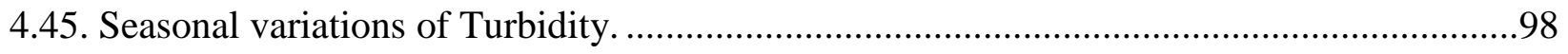

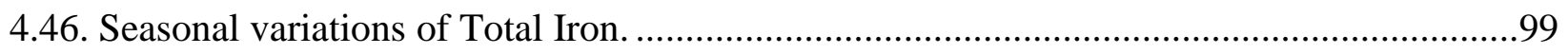

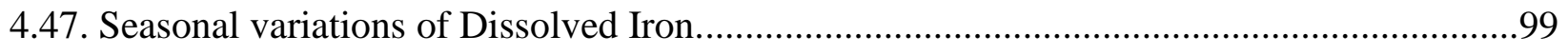

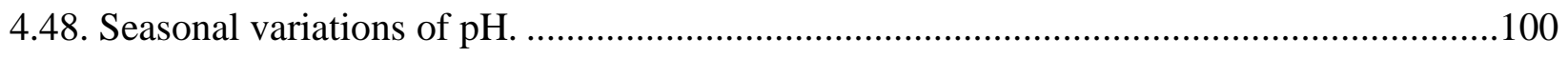

4.49. Seasonal variations of water temperature ............................................................ 101

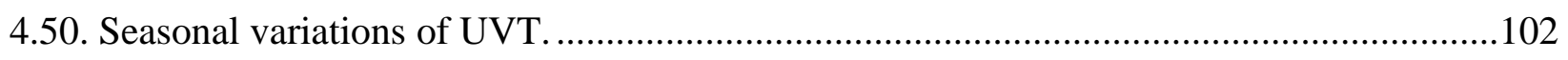

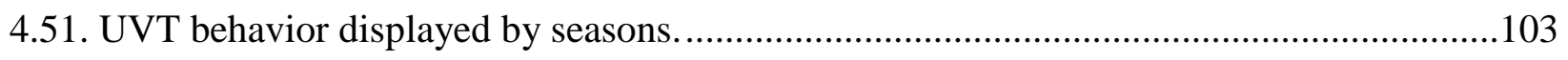

4.52. Single-variable linear relationship between dissolved COD and UVT. .........................105

4.53. Single-variable linear relationship between turbidity and UVT. ..................................105

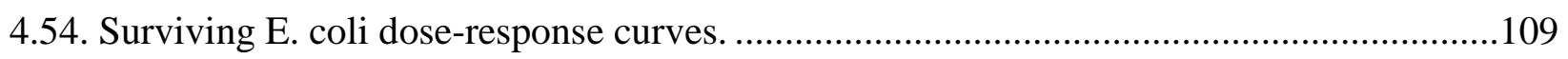

4.55. Determination of UV dose that meets disinfection discharge standards for each $\mathrm{CB}$

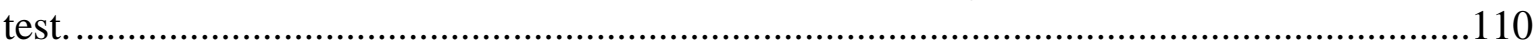

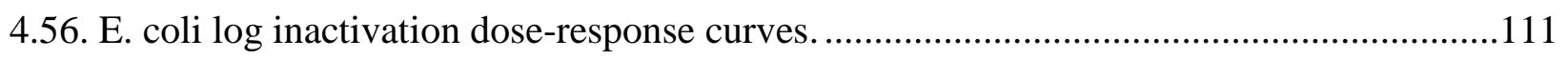

4.57. Use of second-order approach to model dose-response curves. ..................................114

4.58. UVT and second-order rate kinetic constant relationship.......................................115 


\section{LIST OF APPENDIX TABLES}

$\underline{\text { Table }}$

$\underline{\text { Page }}$

A.1. Intensity data collected for initial eight test cycles. 130

A.2. Intensity data collected for cycles 9-12 which was monitored with the SCADA system. . 132

A.3. Fouling material testing results for $\mathrm{C} 14$. 152

B.1. UV intensity data for cycles 16-23. Intensity data collected after cleaning the sensor's lens was modeled to obtain $\mathrm{k}_{\text {sleeve }}$ and the intensity data collected before cleaning the sensor's lens was modeled to obtain $\mathrm{k}_{\text {sesnor. }}$

B.2. RMSE and CVRMSE for cycles C16 through C23. 155

B.3. UV intensity data collected during C24. 156

B.4. UV intensity data collected during C25. 161

B.5. UV intensity data collected during C26. 166

B.6. UV intensity data collected during C27. 171

B.7. UV intensity data collected during C28. 176

B.8. UV intensity data collected during C29. 181

B.9. UV intensity data collected during C30. 184

B.10. RMSE and CVRMSE for cycles C24 through C30. 188

C.1. Intensity data collected after cleaning the sensor's lens during performance runs. 189

C.2. Influent and effluent E. coli data collected during the first performance run. 190

C.3. Influent and effluent E. coli data collected during the second performance run. 190

C.4. Influent and effluent E. coli data collected during the third performance run. 191

C.5. Influent and effluent E. coli data collected during the fourth performance run. 191

C.6. Influent and effluent E. coli data collected during the fifth performance run. 192

C.7. Influent and effluent E. coli data collected during the sixth performance run. 192

D.1. Unfiltered water quality data. 


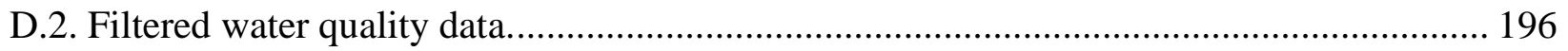

D.3. Total and soluble iron monitoring........................................................................... 198

D.4. Precipitation and plant's flow for days prior to July $13^{\text {th }}$ and July $27^{\text {th }}$ of $2016 \ldots \ldots \ldots \ldots . . . .201$

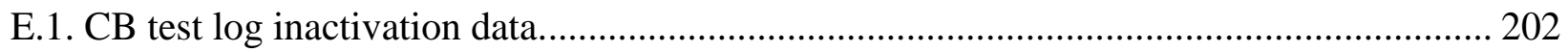




\section{LIST OF APPENDIX FIGURES}

$\underline{\text { Figure }} \quad \underline{\text { Page }}$

D.1. Precipitation data (Source: Record of Climatological Observations)................................. 200 


\section{CHAPTER 1. INTRODUCTION}

The City of Fargo owns and operates the only wastewater treatment plant (WWTP) in Fargo, North Dakota (ND), United States. The WWTP was built in 1934 and it has been expanded several times since its construction. Currently, the WWTP treats an average daily flow of 12 million gallons per day (MGD) and has the ability to handle a peak capacity of 29 MGD. The Fargo WWTP will yet undergo another expansion, increasing its peak capacity from 29 to 50 MGD.

The effluent of the Fargo WWTP is discharged to the Red River of the North. Based on discharge regulations, the Red River is classified as a Class A stream. According to the ND Century Code, class A streams must be suitable for water-related recreational activities during several predetermined months of the year (ND Century Code, 1994). As a result, disinfection of wastewater effluent in Fargo is only required during a period of time referred to as the disinfection season. Based on the regulations set by the ND Century Code, the Fargo WWTP is only required to disinfect its effluent between April $1^{\text {st }}$ and October $31^{\text {st }}$.

The current method used to disinfect the wastewater at the Fargo WWTP is chlorination followed by de-chlorination. This disinfection technique requires chemical handling as well as a large contact basin to provide sufficient contact time for the chlorine to inactivate the microorganisms present in the wastewater. Apex Engineering Group, the consulting company in charge of performing a facility plan, has raised several concerns when it comes to the expansion of the existing chlorine disinfection system in their preliminary engineering report. According to Apex Engineering Group, another contact basin would have to be constructed as well as considerably increasing the amount of chemicals stored on site if chlorination were to be carried over with the plant's expansion (Apex, 2014). 
Due to the close proximity to the Red River of the North, there is extremely limited space for a new contact basin on the existing WWTP's campus. Additionally, the engineering report highlights that the soil near the riverbank is not stable for construction (Apex, 2014), thus expanding the existing disinfection system would be a complicated and costly task to accomplish. Due to these concerns, the consulting firm studied different disinfection alternatives. One of the main objectives of the consulting firm was to find a disinfection technique that would not add any additional footprint to the existing contact basin while being able to handle the additional wastewater flow once the expansion of the plant takes place. After studying several alternatives, Apex Engineering Group recommended switching to a UV disinfection system. According to Apex Engineering Group, retrofitting the existing disinfection contact basin into a UV system will allow the plant to provide adequate disinfection to its wastewater without having to increase the footprint of the existing disinfection contact basin to handle the future flow (Apex, 2014).

Although UV disinfection is a proven technology, its application in wastewater treatment is relatively new in North Dakota and throughout the Midwest. Additionally, past research indicates that there is a need to develop on-site studies to effectively design a full-scale UV disinfection system for a particular plant depending on its flow and water quality characteristics. The management of the Fargo WWTP decided to perform on-site studies to determine the UV disinfection efficiency under different flow conditions, potential seasonal water quality changes, and quartz sleeve fouling prior to the implementation of this technology in a full-scale basis.

It was decided that the best way to perform on-site studies was through a pilot study. Fargo's WWTP management proposed a 7-month pilot study (April $1^{\text {st }}$ through October $31^{\text {st }} 2016$ ) to match the current Fargo's WWTP disinfection season. It was decided that the pilot would be carried out by North Dakota State University (NDSU) researchers with collaboration with the 
scientists and wastewater experts from the City of Fargo, engineers from Apex Engineering Group, and representatives from UV system manufacturers.

\subsection{Current Site Conditions}

A flow diagram of the Fargo WWTP is shown in Figure 1.1. The flow diagram highlights the processes currently being utilized to treat wastewater. The Fargo WWTP uses both mechanical and biological methods to treat its wastewater. Wastewater collected throughout the city's sanitary sewer system makes its way to the plant's influent pumping station through a sequence of lift stations distributed throughout the city. Wastewater flow is then pumped through a series of screens prior to entering the grit removal and pre-aeration basin. Solids collected in the bar screen and grit removal units are hauled to the city's landfill on a weekly basis.

Upon pre-aeration, wastewater goes into the primary clarification stage. The primary clarification stage is equipped with seven clarifiers in charge of performing initial settling. The solids removed from the primary clarifiers are further treated by the primary and secondary digesters followed by dewatering in sand drying beds or filter presses for sludge compaction and volume reduction. The stabilized biosolids are hauled to the city's landfill for disposal on a daily basis. The effluent wastewater exiting primary clarification goes through three trickling filters, followed by two intermediate clarification tanks, and two nitrification trickling filters. Both trickling filters and the clarification tanks are capable of reducing most of the biochemical oxygen demand (BOD), total suspended solids (TSS), and ammonia of the plant's influent.

To achieve further settling, wastewater is then sent to the final clarification tank. A small portion of the wastewater flow, averaging about 325,000 gallons per day (gpd), is returned from the intermediate and final clarifiers to the head of the plant. Flow starts its return to the head of 
the plant at midnight. Return flow is used to maintain proper wetting rates across the tricking filters during the night time.

Flow exiting the final clarifier that is not returned to the head of the plant has two possible routes to continue through the plant's treatment system. A portion of the water treated by the final clarifier is by-passed through the disinfection system and sent to the Effluent Reuse Facility (ERF). The ERF is a tertiary treatment system consisting of three ultra-filtration skids and four two-stage reverse osmosis skids. The ERF has a capacity of producing a permeate flow of $1.4 \mathrm{MGD}$ at $70 \%$ recovery. The water treated by the ERF is then pumped to Casselton, ND and it is used by Tharaldson Ethanol as water supply for their cooling towers. The remaining flow exiting the final clarifier is disinfected using chlorine disinfection prior to discharging it to the Red River of the North. However, if the Red River conditions do not allow for discharge (e.g., flood conditions), the plant has the capability of diverting the flow exiting the final clarifier to a number of stabilization ponds for as long as it may be necessary. These ponds are located in the north-west part of town. 


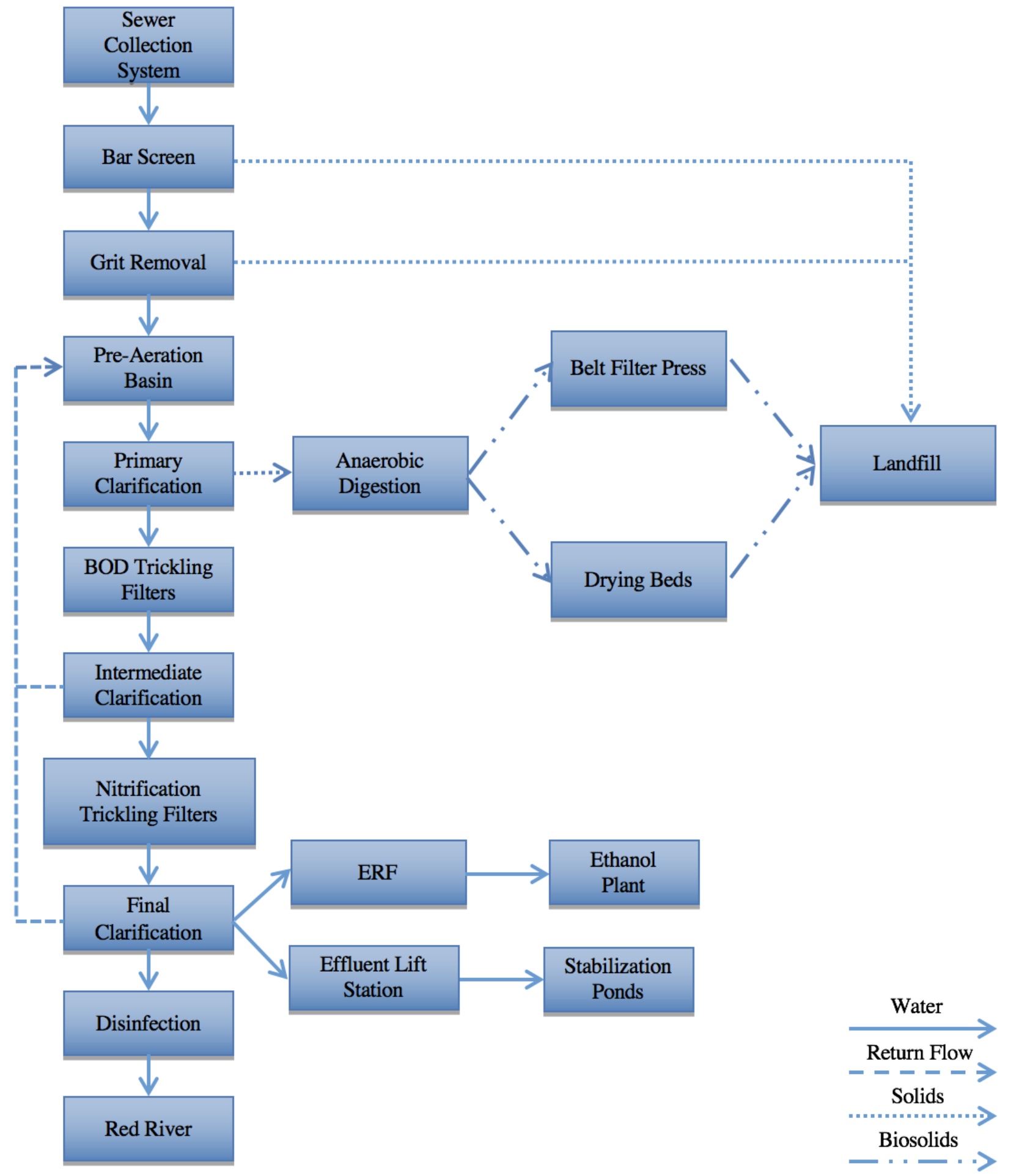

Figure 1.1. Fargo WWTP flow diagram. 


\subsection{Research Objectives}

The main objective of this study is to evaluate the disinfection efficiency of UV light for wastewater applications in Fargo, ND. Another main objective of this research is to provide the City of Fargo with the parameters needed to design the future UV disinfection system. The specific goals of this research study are shown below:

1. To evaluate the impact of effluent water quality changes on UV transmittance (UVT);

2. To evaluate the impact of UVT changes on UV disinfection of E. coli;

3. To evaluate the fouling tendency of quartz sleeves and its impact on intensity loss; and

4. To evaluate the impacts of fouling and flow rate variations on UV disinfection of E. coli.

A review of previous literature, methodologies followed, results found, discussion of the results, research conclusions, and ideas for furthering research are covered in the chapters found in this report. Chapter 2 introduces the readers to the basic understanding of UV technology in addition to providing an in-depth literature review of UV disinfection of wastewater. The methodologies and procedures followed for meeting the above research objectives are displayed in Chapter 3. Results and discussion obtained from the pilot study are addressed in Chapter 4. Lastly, research conclusions and future research recommendations can be found in Chapter 5. 


\section{CHAPTER 2. LITERATURE REVIEW}

An in-depth review of previous literature related to UV disinfection in wastewater applications has been performed. The knowledge found in this chapter highlights the necessary information to attain a comprehensive understanding of UV disinfection. An appropriate understanding of the information found in this chapter is necessary to develop adequate methodologies to achieve the previous established research goals and objectives.

\subsection{Wastewater Disinfection}

Some of the most popular methods that can be successfully used to disinfect wastewater are chlorination, ozonation and UV light. Chlorination has been one of the most common disinfection techniques used in wastewater treatment plants since chlorine gas is relatively inexpensive (Chawla et al. 2015). However, one of the main drawbacks of chlorine is that protozoa and viruses such Cryptosporidium and Giardia are resistant to the chlorine concentrations used in wastewater applications (Carpenter et al., 1999). Additionally, chlorine disinfection results in the production of chlorine residual. If not properly managed, such residual can negatively affect the aquatic life of the receiving body of water.

The other major chemical used in wastewater disinfection is ozone. Unlike chlorine gas, ozone is effective at inactivating a wider variety of viruses and bacteria (Hais \& Venosa, 1978). It is well known that in addition to inactivating a greater variety of pathogens, ozone transforms to oxygen rapidly. Such rapid transformation results in the decrease of chemical residual present in the treated water. One of the main drawbacks of ozone disinfection is that ozone production for wastewater disinfection applications may not be cost-effective due to the high-energy costs associated with ozone generation (Orta de Velasquez et al., 2008). 
Unlike chlorine and ozone, UV light is a physical process. Due to the nature of physical processes, UV disinfection has several benefits and drawbacks when compared to chemical disinfectants. Because the current disinfection method used to disinfect the Fargo's WWTP effluent is chlorine gas, a study of the literature covering the advantages and disadvantages that UV disinfection has when directly compared to chlorine gas was performed. Such study is shown in Sections 2.1.1 and 2.1.2.

\subsubsection{Advantages of UV Light with Respect to Chlorine Disinfection}

- Similar to ozone, UV disinfection was found to be more effective in removing a broader range of pathogens, including Giardia cysts and Cryptosporidium oocysts (Betancourt \& Rose, 2004);

- UV disinfection is a physical process. Physical processes eliminate the need for generation, handling, and storing potentially hazardous chemicals on site (Chang et al., 1985);

- Since chemicals are not used to disinfect the water, UV disinfection poses no known negative impacts to the aquatic life in the receiving body of water (Alyaa et al, 2016). Additionally, Barber et al., (2015) found that the formation of disinfection byproducts is eliminated when wastewater disinfection processes switch from using chemical disinfectants to physical processes (UV light); and

- The detention time required to effectively inactivate pathogens using UV light is only a matter of seconds (USEPA, 1986). Due to the short detention time, UV disinfection systems tend to occupy much less footprint when compared to chemical disinfection methods such chlorine gas (Chang et al., 1985). 


\subsubsection{Disadvantages of $U V$ Light with Respect to Chlorine Disinfection}

- Low doses of UV light were found to ineffectively inactivate several microorganisms (Chang et al., 1985). In addition to ineffective disinfection taking place at low UV doses, some microorganisms have developed mechanisms to repair the damage caused by UV light (Harris et al., 1987; Knudson, 1985; Small \& Greimann, 1977). However, it has been found that the microorganisms' repair capabilities can be eradicated by increasing the UV dose delivered in the reactor (Knudson, 1985);

- UV disinfection performance is affected by fouling material accumulation on the UV lamp's quartz sleeves (Emerick et al., 1999), thus regular cleaning of the quartz sleeves is needed to maintain adequate disinfection. In addition to quartz sleeve fouling, UV disinfection performance can also be severely affected by drastic changes in water quality (Batch et al., 2004; Emerick et al., 1999; Loge et al., 1999). The impact of water quality on disinfection performance is addressed throughout this report;

- Due to the short detention time experienced in UV reactors, flow fluctuations will have a significant impact on the amount of time the microorganisms are exposed to UV light. Thus, reducing the performance of UV systems when large flow fluctuations are experienced. Studies conducted by Flores (et al. 2015) show that UV disinfection efficiency improved when lower flows were used; and

- UV disinfection requires large amounts of electricity to function and it may not be costeffective when directly compared to chlorination (Dyksen et al., 1998; Lazarova et al., 1998). 


\subsection{UV Light Generation and Lamp Types}

UV light is a form of electromagnetic radiation as shown in the electromagnetic spectrum displayed in Figure 2.1. UV light lies between the x-rays and visible light in the electromagnetic spectrum and it covers the wavelength range from 100 to 400 nanometers (nm). However, not all the wavelengths of UV light are equally effective at inactivating microorganisms. It is known that UV light only has germicidal effects in the wavelengths found under the UV-C and UV-B spectrum, more particularly, the maximum germicidal effect of UV light occurs at a the single wavelength of $253.7 \mathrm{~nm}$ (Reed, 2010).

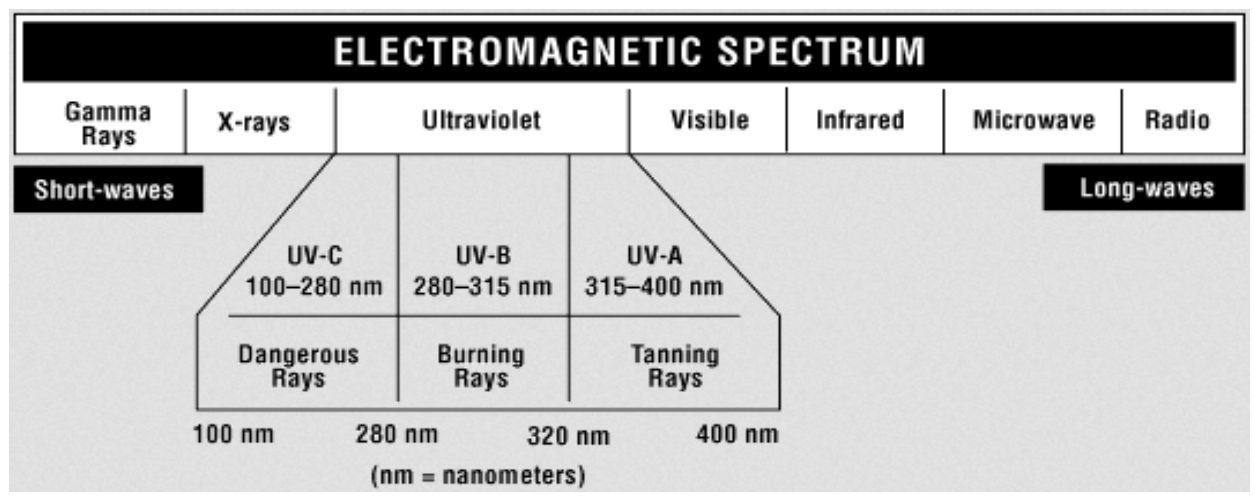

Figure 2.1. Electromagnetic spectrum (Source: Ultraviolet Radiation, Government of Canada).

When a voltage is applied to a UV lamp, some of the liquid mercury located inside the lamp vaporizes. UV light is then produced through the energy released from the mercury gas generated (Germicidal Lamp Basics, Light Sources Inc). The wavelength of UV light produced by any UV lamp is dependent on the mercury vapor pressure maintained inside the lamp (USEPA, 2003). There are two types of UV lamps based on the mercury vapor pressure (USEPA, 2003): (i) low pressure (LP), and (ii) medium pressure (MP). Figure 2.2 displays the wavelength spectrum of LP and MP UV lamps. As seen in Figure 2.2, LP lamps emit UV light at a single wavelength 
of $253.7 \mathrm{~nm}$. Due to that, LP UV lamps are also known as monochromatic lamps in the UV industry. On the other hand, MP lamps are capable of emitting UV light at several wavelengths. In the UV industry, MP UV lamps are also known as polychromatic lamps due to their multiwavelength emitting capabilities. In addition to the mercury pressure classification, UV lamps can also be classified by their quantity of intensity output (USEPA, 2003). The following lamp classification can be made based on mercury pressure and intensity output (USEPA, 2003): (i) low-pressure low-output (LPLO), (ii) low-pressure high-output (LPHO), and (iii) MP.
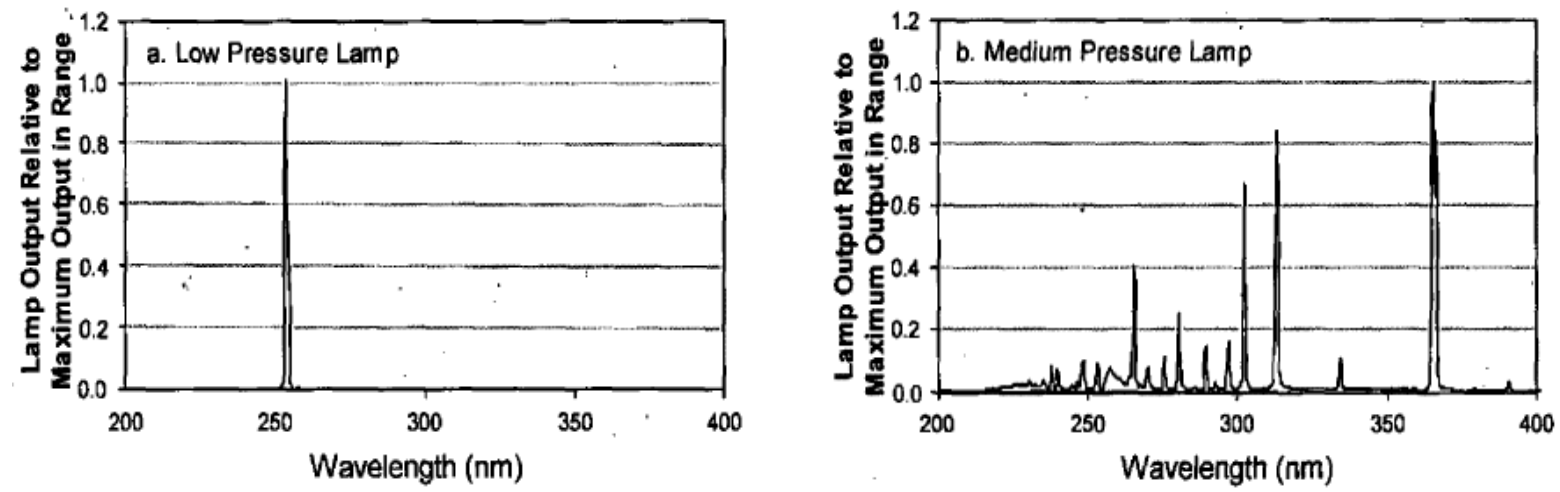

Figure 2.2. Wavelength spectrum of intensity output of LP and MP UV lamps (Source: USEPA, 2003).

Quartz sleeves are installed surrounding UV lamps to protect them from debris that could potentially damage them. Both UV lamps and the quartz sleeves are housed in UV reactors. UV reactors can be divided into two main groups based on their channel configuration (USEPA, 2003): (i) open, and (ii) closed. Closed reactors are commonly used for drinking water treatment while open reactors are used in wastewater applications (USEPA, 2003). Regardless of the channel type, UV reactors should all be equipped with UV intensity sensors, temperature sensors, and flow meters to adequately monitor the performance of the system (USEPA, 2003). Since UV reactors 
provide contact times in the order of seconds, a reactor that has been designed incorrectly will result in an inadequate exposure of UV light to the microorganisms being disinfected (Bryant et al., 1992). Due to that, UV reactors must be designed to eliminate dead zones where UV light cannot reach to avoid inadequate disinfection (USEPA, 1999).

\subsection{Transmission of UV Light through Water}

UV light starts to interact with the substances and particles present in the water subjected to treatment as soon as it exits the quartz sleeves. Several dissolved substances and wastewater particles are capable of reducing UV light's propagation through the water (Loge et al., 1999; Qualls et al., 1985; USAPHC, 2004). Due to that, the amount of UV light successfully transmitted through the reactor is dependent on the concentration of various dissolved substances, the distance the light must travel, and the particle concentration.

A broad range of dissolved substances (organic compounds and metals) found in wastewater effluents are known to absorb UV light (USEPA, 1999). It is important to point out that not only dissolved substances are capable of absorbing UV light. In addition to dissolved substances, wastewater particles can successfully absorb UV light due to their highly porous surface composition (Loge et al., 1999). Nevertheless, absorbing capabilities of wastewater particles are weaker when compared to those of dissolved substances. It is important to note that when UV light is absorbed, it is no longer available to disinfect microorganisms (Mamane, 2008).

The effects of absorption on the propagation of the UV light's intensity through the water can be explained with the scientific principles found in the Beer-Lambert law. The Beer-Lambert law is a combination of two laws developed by August Beer and Johann Lambert. Lambert's law states that the absorbance of light is directly proportional to the length the light has to travel 
through in a homogeneous solution. Thus, UV light will be absorbed as the light travels through the reactor. The longer the distance traveled, the more light will be absorbed. Beer's law states that absorbance of light in a sample is directly proportional to the concentration of the absorbing solution in which the light travels through. A mathematical representation of the Beer-Lambert law is shown in Equation 2.1.

$$
A=\varepsilon L C
$$

$$
\begin{array}{ll}
A & =\text { Absorbance of light } \\
\varepsilon & =\text { Molar extinction coefficient of absorbing substance }\left(\mathrm{Lmol}^{-1} \mathrm{~cm}^{-1}\right) \\
\mathrm{L} & =\text { Depth of light penetration }(\mathrm{cm}) \\
\mathrm{C} & =\text { Concentration absorbing substance in the solution }\left(\mathrm{molL}^{-1}\right)
\end{array}
$$

Propagation of UV light can also be affected by scattering. Scattering of UV light is caused by wastewater particles (suspended and colloidal) present in water (Qualls et al., 1983). However, the degree to which UV light is scattered by particles is influenced by the shape, the size, and the particle concentration (Bohren \& Huffman, 1983). Because of their scattering capabilities, particles will also reduce UV light's depth of penetration through the water being disinfected (Qualls et al., 1983).

\subsection{Measurements of Transmitted or Absorbed UV Intensity}

UVT and UV Absorbance (UVA) are water quality parameters commonly used in the UV disinfection industry for measuring overall water quality conditions. UVT and UVA are important parameters used by the UV industry to determine both the feasibility of UV disinfection and design 
of UV disinfection systems. UVT is defined as the ratio of UV intensity passing through any fluid sample $(I)$ to the UV intensity passing through a deionized (DI) water sample $\left(I_{o}\right)$ since the DI water sample will let 100 percent of the emitted UV intensity pass through it. Equation 2.2 can be used to calculate the UVT of any water sample.

$$
U V T=100 \times \frac{I}{I_{o}}
$$

UVT $=$ UV Transmittance $(\%)$

I = Intensity of the UV light exiting the test sample $\left(\mathrm{mW} / \mathrm{cm}^{2}\right)$

$\mathrm{I}_{\mathrm{o}} \quad=$ Intensity of the UV light exiting the DI water sample $\left(\mathrm{mW} / \mathrm{cm}^{2}\right)$

UVA characterizes the decrease in the amount of incident UV light as it passes through a sample over a 1 centimeter depth. It is important to note that UVT and UVA measure the complete opposite phenomenon. While UVT is a measurement of the amount of UV light transmitted through a fluid sample, the UVA measures the amount of UV light absorbed across the sample's depth. Both parameters can be related using Equation 2.3.

$$
U V A=-\log \left(\frac{U V T}{100}\right)=\log \left(\frac{I_{o}}{I}\right)
$$

UVA $=$ Absorbance $\left(\mathrm{cm}^{-1}\right)$

Both UVT and UVA of an effluent sample can be measured using a spectrophotometer. It is important to note that UVA and UVT readings obtained from measurements performed in a spectrophotometer of unfiltered samples do not distinguish between the effects that both scattering and absorption have on UV intensity (Qualls et al., 1983). Instead, spectrophotometer 
measurements of an unfiltered sample measure the bulk UVA or bulk UVT of it (Qualls et al., 1983). All particles present in the sample must be removed through filtration prior to obtaining a UVA or UVT measurement that can exclusively be associated to absorption or transmission of UV light affected by dissolved substances alone (Qualls et al., 1983). The absorption of dissolved components is associated with the UVA measured for samples filtered through 0.45 micrometer $(\mu \mathrm{m})$ pore size filters since the majority of the particles (both suspended and colloidal) will be successfully retained by the filter (Qualls et al., 1983).

A UV disinfection study in Minnesota performed by Trojan Technologies, a UV lamp manufacturer, only showed minor improvements in the amount of UV light transmitted when the suspended particles were removed through filtration (Trojan UV, 2013). Indicating that dissolved substances may be the major contributor of absorption of UV light. Dissolved substances are a special concern for Fargo WWTP management since the city applies ferrous salts in its sewer system for odor control. It is expected that some of the iron added throughout the collection system may make its way through the plant and end up in the effluent in dissolved or particulate forms hindering UV disinfection performance through absorption of UV light (Apex, 2014).

Efforts in monitoring water quality parameters such chemical oxygen demand (COD), turbidity, total suspended solids (TSS), or total dissolved solids (TDS) to evaluate the impact of effluent water quality on UVT can be found in the literature (Emerick et al., 1999; Harris et al., 1987; Madge \& Jensen, 2006; Qualls et al., 1983; Qualls et al., 1985). These studies observed the impact of water quality on UVT by developing relationships between the above listed water quality parameters and UVT. The relationships developed varied from study to study. Consequently, it can be said that relationships between effluent water quality parameters and UVT as well as UVT seasonal variations may be considered to be plant specific. 


\subsection{Mechanism of Pathogen Inactivation and Survival}

The inactivation of microorganisms by UV light results from the absorption of the radiation by the deoxyribonucleic acid (DNA) of the microorganism (Pfeifer et al., 2005; Reed, 2010). Such absorption distorts the double helix arrangement of the DNA, which disables the microorganism's capability to reproduce (Harris et al., 1987). Although the microorganism still possesses metabolic functions after the exposure to UV light, it cannot reproduce; therefore, the microorganism is incapable of infecting a host. It is well known that the level of pathogen inactivation is affected by the UV intensity delivered to the pathogens and the amount of time the pathogens were exposed to the UV radiation. Calculation of UV dose is shown in Equation 2.4.

$$
D=I \times t
$$

$$
\begin{array}{ll}
\mathrm{D} & =\mathrm{UV} \text { Dose }\left(\mathrm{mJ} / \mathrm{cm}^{2}\right) \\
\mathrm{I} & =\mathrm{UV} \text { Intensity }\left(\mathrm{mW} / \mathrm{cm}^{2}\right) \\
\mathrm{t} & =\text { Exposure time (seconds) }
\end{array}
$$

Microorganisms are capable of surviving UV light exposure by repairing the damage caused by the light or by hiding from it. Certain microorganisms have developed mechanisms to repair the damage caused by UV radiation (Harris et al., 1987). The mechanism typically taking place in wastewater applications is known as photoreactivation (Harris et al., 1987; Knudson, 1985; Small \& Greimann, 1977). Photorepair capabilities of microorganisms vary within strains and typically take place when low UV doses are applied to the water being disinfected (Oguma et al., 2002; Whitby et al., 1984). However, it is known that photorepair capabilities of microorganisms can be eliminated by increasing the UV dose delivered in the reactor (Knudson, 
1985). In particularly, UV doses higher than $21 \mathrm{~mJ} / \mathrm{cm}^{2}$ have been found to be sufficient to eliminate the repair capabilities of E. coli (Kashimada et al., 1996).

As previously mentioned, wastewater particles are highly porous. Such porosity translates in larger surface areas which allows wastewater particles to provide microorganisms' with shelter from UV light (Loge et al., 1999; Qualls et al., 1985), thus hide from UV light exposure. Studies show that the degree to which microorganisms attach to particles varies depending on the type of the upstream treatment processes (Emerick et al. 1999). In their study, Emerick et al. (1999) calculated the percentage of wastewater particles containing at least one attached microorganism for samples collected from different treatment systems. The study was performed for two particle size classes: (i) particles with average diameter between 11 and $80 \mu \mathrm{m}$, and (ii) particles with average diameter greater than $80 \mu \mathrm{m}$. In addition to the degree of attachment, it was also found that different treatment processes produce treated water with different effluent UVT's (Emerick et al. 1999).

As previously mentioned, the concentration of wastewater particles is a concern in UV disinfection systems since particles are capable of scattering UV light and sheltering microorganisms. However, particle concentration may not be the only concern when it comes to assessing the degree of microorganism survival. In addition to the particle concentration, the size of the particles also plays an important role when studying the degree of microorganism attachment (Jolis et al. 2001; Madge \& Jensen, 2006; Qualls et al., 1983). Studies show that larger particles are more effective sheltering microorganisms from UV light since it has been found that particles greater than $20 \mu \mathrm{m}$ can shelter a larger number of microorganisms when compared to smaller particles (Madge \& Jensen, 2006). Similarly, particles smaller than $10 \mu \mathrm{m}$ have been found to be too small to provide a significant level of microorganism protection (Qualls et al., 1983). Jolis et 
al. (2001) studied the effects of filtration on the microorganism's inactivation to analyze the impacts of wastewater particles in the level of inactivation achieved. Jolis et al. (2001) reported that much higher UV doses were needed to obtain the similar inactivation levels for unfiltered samples when compared to filtered samples. Indicating that wastewater particles play an important role in the degree of microorganism protection.

In addition to the concentration and size of the particles, the composition of such particles can determine whether the sheltering effect of particles is successful or not (Azimi et al., 2012; Liao et al., 2002; Yuan \& Farnood 2010). It is known that most of the particles in secondary treated effluents are generated through biological treatment processes (Azimi et al., 2012). Such particles, also referred to in the literature as bioflocs, are typically composed of two layers consisting of a compact core and a shell (Liao et al., 2002). Yuan \& Farnood (2010) found that the outer shell is formed of loose/porous material while the core is dense and non-porous. Yuan \& Farnood (2010) arrived at the previous conclusion by comparing the shear strength of cores and shells. Continuing the same two-layered approach, Azimi et al. (2012) later found that microorganisms embedded inside the core are more resistant to UV light than the microorganisms attached to the loose shell. Azimi et al. (2012) arrived at that conclusion when tests revealed that smaller particles composed mostly of core were more effective at sheltering microorganisms from UV light when compared to larger particles with highly porous characteristics. Thus, affirming that not only the size of the particle matters, but the density and the composition of the particle may also play a major role in the effectiveness of wastewater particles sheltering microorganism. 


\subsection{Measurements of Pathogen's Response to UV Light}

Laboratory bench-scale tests can be performed to study any microorganism's response to a given UV light intensity exposure (UV dose). A bench-scale collimated beam (CB) apparatus can be used to determine any microorganism's inactivation as a function of UV dose under well controlled conditions. The CB unit measures the microorganism's response to UV radiation by delivering UV light to a mixed test sample located in a petri dish (USEPA, 2003). The results obtained from performing CB tests can be displayed in dose-response curves which are used to evaluate the performance of continuous flow UV systems through validation and to perform kinetic studies of the microorganism's response to UV light. Furthermore, one can study the effects that water quality has on microbial inactivation by developing several dose-response curves for varying water qualities and kinetically comparing them (USEPA, 2003). Additionally, dose-response curves can be used to determine the minimum UV dose needed to inactivate a targeted microorganism for a given UVT. The minimum UV dose needed can then be used as a controlling parameter to size full-scale systems.

A proper correction of the intensity output of the lamp(s) used during any CB test is essential to obtain accurate results. Because of that, several correction factors must be applied to the intensity reading taken by the radiometer of the $\mathrm{CB}$ apparatus prior to starting the experiment. The correction factors are used to calculate the average intensity across the test sample located in the petri dish (Bolton \& Linden, 2003; USEPA, 2003). The procedures and calculations needed to obtain the average intensity across the test samples used in this research study are shown in Section 3.2.2. 


\subsubsection{Understanding Microorganism's Response to UV Light}

An example of a representative dose-response curve can be seen in Figure 2.3. Doseresponse curves are obtained by plotting the microorganism's response data (y-axis) with respect to the UV doses (x-axis) used during the $\mathrm{CB}$ test. Microorganism response data can be plotted using either: (i) microbial inactivation, and/or (ii) surviving microbial counts. Figure 2.3 will be used to introduce the standard behavior and shape of the dose-response curves found across the literature.

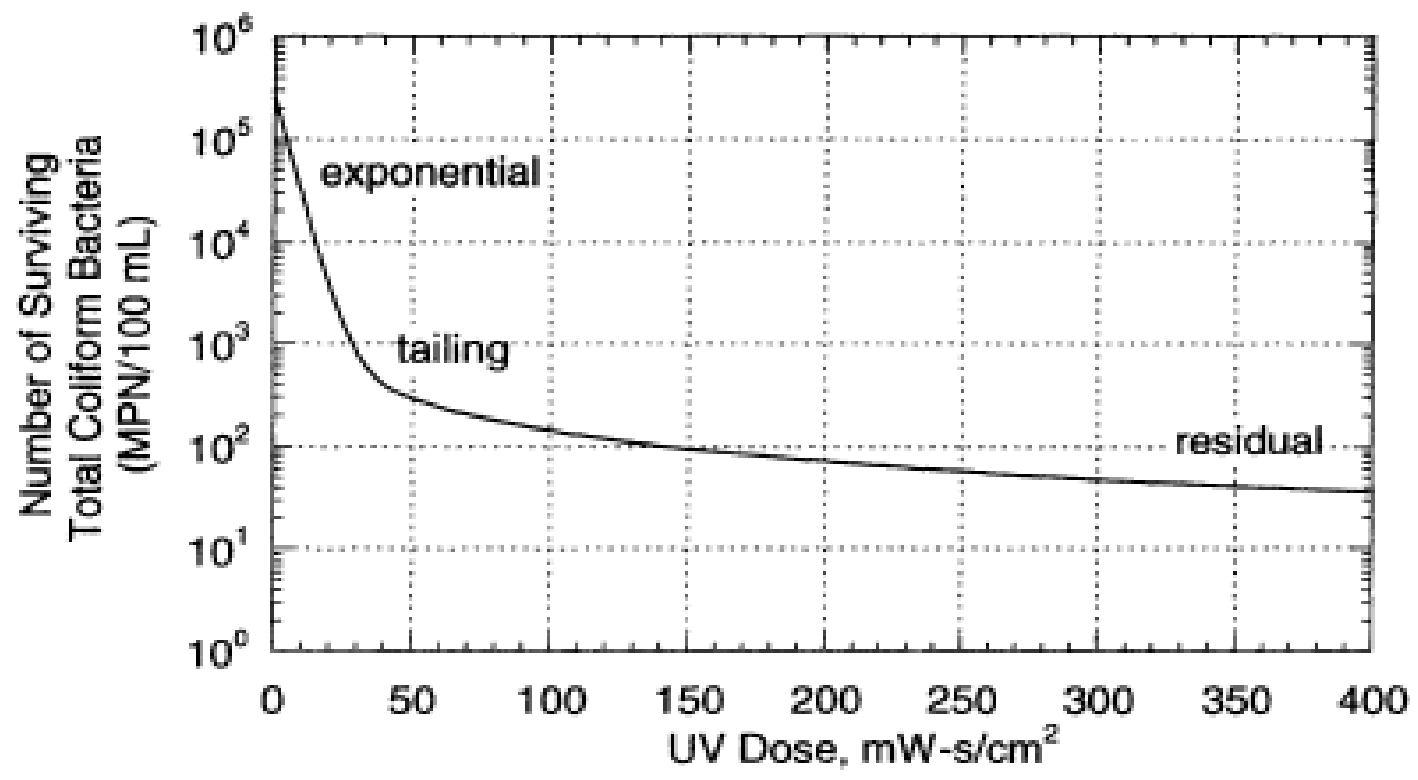

Figure 2.3. Typical dose-response curve relationship developed with a CB apparatus for wastewaters (Source: Emerick et al., 1999).

At low UV doses, microorganisms tend to follow exponential response to UV light when adequate mixing conditions are present (Emerick et al., 2000; Hassen et al., 2000; Mounaouer \& Abdennaceur 2012; USEPA, 2003). Proper mixing conditions are achieved using a magnetic stirrer to constantly stir the sample that is being exposed to UV light (Kuo et al., 2003). By 
providing adequate mixing, the dispersed microorganisms receive a constant amount of UV intensity, thus yielding initial exponential response to UV light translating in a first-order kinetic behavior (Emerick et al., 2000). As UV dose increases, the initial exponential behavior eventually evolves into a tailing response, when this occurs, deviations from first-order kinetic inactivation take place (Emerick et al., 1999; Madge \& Jensen, 2006; Qualls et al., 1985). Tailing response develops when the inactivation slows down at higher doses.

A microorganism embedded in a particle will be exposed to a limited amount of UV light, thus receiving less UV intensity for a given exposure time. Due to that, embedded microorganisms need longer exposure to UV light (higher UV dose) to achieve similar inactivation rates that disperse microorganisms are capable of achieving at lower UV doses. It is believed that the tailing behavior of dose-response curves starts occurring once the majority of the dispersed microorganisms are inactivated and inactivation of embedded microorganisms starts taking place at higher doses (Emerick et al., 2000). Ever since the tailing behavior of the curves has been associated with particles shielding microorganisms, studies have tried to relate the degree of tailing to the suspended particle count and/or concentration present in the water by performing CB tests with filtered and unfiltered samples (Darby et al., 1993; Emerick et al., 2000; Jolis et al., 2001).

As UV dose continues to increase, the microorganisms' tailing response evolves into a plateau. This plateau region defines the surviving microorganism concentration to the UV light, also known as residual (Emerick et al., 1999). The residual microorganism concentration is hypothesized to be caused by one or combination of the following: (i) particles sheltering microorganism from UV light (Azimi et al., 2012), (ii) association of dispersed microorganisms (Blatchley et al., 2001), and/or (iii) possible accuracy issues of enumeration techniques experienced at low microbial concentrations (Mamane, 2008). 


\subsubsection{Kinetic Modeling of Microorganism's Response to UV Light}

Since the initial section of the dose-response curve behaves as first-order kinetics, and it is believed that the majority of the microorganism present in solution are found in a dispersed state (Qualls et al., 1985), a simple first-order kinetic model has been widely used in previous studies to describe microbial response to UV light (Hassen et al., 2000; Jolis et al., 2001; Madge \& Jensen, 2006; Qualls et al., 1985). The first-order kinetic model found in the literature is shown in Equation 2.5.

$$
\frac{N}{N_{o}}=e^{-k D}
$$

$\mathrm{N}=$ Concentration of microorganisms after exposure to UV light (MPN/100ml)

$\mathrm{N}_{\mathrm{o}} \quad=$ Concentration of microorganisms before exposure to UV light (MPN/100ml)

$\mathrm{D} \quad=\mathrm{UV} \operatorname{dose}\left(\mathrm{mJ} / \mathrm{cm}^{2}\right)$

$\mathrm{k}=$ First-order rate constant $\left(\mathrm{cm}^{2} / \mathrm{mJ}\right)$

If the above model is used, deviations between the experimental data and the model occur once the inactivation rate slows down and tailing behavior takes place (Emerick et al., 1999; Madge \& Jensen, 2006; Qualls et al., 1985). In an attempt to study the dose-response curves using this model, some studies omit the data points associated with the non-linear portions of the curve as done by Jolis et al. (2001) and Madge \& Jensen (2006), thus developing rate constants that are only dependent on the linear section of the dose-response curves.

Since the first-order model can only explain the initial section of the dose-response curves, the application of this model poses challenges when studying the tailing effect. Additionally, a proper study of water quality impacts on UV disinfection efficiency cannot be done using this 
approach since the complete behavior of the dose-response curves cannot be modeled correctly. Modifications of this simple first-order kinetic model have been found in the literature (Emerick et al., 2000; Hassen et al., 2000). These modifications strive to incorporate the tailing behavior while still utilizing a first-order kinetic approach to the kinetic analyses.

Modifications have been made to the first-order model by adding a parameter that represents the initial microbial reduction at the contact of water with UV radiation (Hassen et al., 2000). By doing this, the tailing behavior can be modeled. However, the entire set of data of the dose-response curve cannot be successfully modeled at once. To successfully model the entire set of data using this modification of the first-order kinetics, Hassen et al. (2000) broke up the data in two different sets: (i) initial exponential response, and (ii) tailing behavior. The same formula is used to model both sets of data. However, the kinetic parameters used in the model vary from set to set for a single dose-response curve. Equation 2.6 shows the model used by Hassen et al. (2000).

$$
\frac{N}{N_{o}}=A e^{-k D}
$$

$\mathrm{N}=$ Concentration of microorganisms after exposure to UV light (MPN/100ml)

$\mathrm{N}_{\mathrm{o}} \quad=$ Concentration of microorganisms before exposure to UV light (MPN/100ml)

A = Initial microbial reduction at the contact of water with $\mathrm{UV}$ radiation

$\mathrm{D} \quad=\mathrm{UV} \operatorname{dose}\left(\mathrm{mJ} / \mathrm{cm}^{2}\right)$

$\mathrm{k}=$ First-order rate constant $\left(\mathrm{cm}^{2} / \mathrm{mJ}\right)$

Similarly to the previous modeling approach, a proper study of the effects of water quality on UV disinfection performance cannot be accomplished using this approach since the data has to be broken up in separate data sets. Other modifications have been made to the first-order kinetic 
model with the intention of using a single equation to explain the behavior of the entire set of data. This model was developed by Emerick et al. (2000) and has been utilized in other data analysis efforts found in the literature (Mounaouer \& Abdennaceur, 2012). The model developed by Emerick et al. (2000) is displayed in Equation 2.7.

$$
N_{t}=N_{D} e^{-k D}+\frac{N_{P}}{k D}\left(1-e^{-k D}\right)
$$

$\mathrm{N}_{\mathrm{t}} \quad=$ Total concentration of microorganism at given UV dose (MPN/100ml)

$\mathrm{N}_{\mathrm{D}}=$ Initial concentration of disperse microorganisms (MPN/100ml)

$\mathrm{N}_{\mathrm{P}} \quad=$ Total number of particles containing at least one microorganism before exposure of UV Light (MPN/100ml)

$\mathrm{D} \quad=\mathrm{UV}$ dose $\left(\mathrm{mJ} / \mathrm{cm}^{2}\right)$

$\mathrm{k} \quad=$ First-order rate constant $\left(\mathrm{cm}^{2} / \mathrm{mJ}\right)$

This model proposed by Emerick et al. (2000) describes the complete behavior of the doseresponse curves using a single equation. This model relies on the measurement of the number of wastewater particles sheltering at least one microorganism before exposure to UV light $\left(\mathrm{N}_{\mathrm{P}}\right)$. Particle size distribution and in situ hybridization tests were performed by Emerick et al. (2000) to calculate $\mathrm{N}_{\mathrm{P}}$. These tests are tedious to perform and would have to be repeated from site to site, adding more uncertainty to the kinetic modeling study. Additionally, this model cannot be used to develop meaningful relationships with overall water quality since the rate constant of the model depends on the particle counts, not other water quality characteristics of the sample such UVT or UVA. 
Other models can be found in the literature, however, the three introduced by this literature review are the most commonly used in studies to explain the dose-response curve behavior. Effort should be put into developing simple models to describe the full set of dose-response curve data that can be related to common water quality parameters to easily study the impacts that water quality has on the rate of microorganism inactivation by UV light.

\subsection{Fouling of UV Disinfection Systems}

Fouling in a UV disinfection system is the accumulation of water constituents on the external surface of the quartz sleeves. Fouling of the quartz sleeves is considered to be one of the main limitations of UV disinfection systems (Blatchley et al., 1996; Wait \& Blatchley, 2010). Constituents deposited on the quartz sleeves have the ability to absorb the UV light emitted by the UV lamps, thus reducing the transmission of UV light to the water being treated (Blatchley et al. 1996; Peng et al., 2005; USEPA, 2003). By reducing the UV light transmitted through the quartz sleeves, less UV intensity is delivered to the microorganisms, henceforward fouling has a negative impact on UV performance.

Deposition of fouling material on the quartz sleeves is thought to be caused by the transition of the quartz's sleeve surface from a smooth silica-based to a rough one (Lin et al., 1999b). It is important to note that the quartz sleeve's length is longer than the UV lamps to be able to fully protect the lamp from debris. The UV lamp is then located in the middle section of the quartz sleeves. Because of this, the end sections of the quartz sleeves will receive less irradiation when compared to the middle section, where the UV lamp is located. These end sections are also referred to as the non-irradiated zones of the quartz sleeves, while the middle section is known as the irradiated zone. It has been found in the literature that fouling material will have different 
characteristics depending on the zone of the quartz sleeve (Lin et al., 1999b). These findings are explained in the following sections. Several studies were found in the literature regarding the different types of fouling materials, the mechanism of fouling material accumulation onto the quartz sleeves, rate of fouling formation, and the removal of fouling material (Lin et al., 1999a and b; Nessim \& Gehr, 2006; Sheriff \& Gehr, 2001).

\subsubsection{Nature of Fouling Material}

Fouling can be caused by both inorganic and organic constituents present in the water being treated (Gehr \& Sehnaoui, 2001). Inorganic fouling is mainly caused by deposition of metal ions with inverted solubility such iron, aluminum, calcium and magnesium onto the surface of the quartz (Lu et al., 2012; Wait et al., 2004). Metals with inverted solubility become less soluble with an increase of temperature. Due to the high temperatures taking place in the quartz sleeve's surface, metals with inverted solubility tend to precipitate onto the quartz sleeves (Gehr \& Sehnaoui, 2001; Nessim \& Gehr, 2006; Wait et al., 2004). This type of fouling is typically caused by a mechanism referred to as heat-induced precipitation and it is more predominant in the irradiated zone of the quartz sleeve (Gehr \& Sehnaoui 2001, Lin et al., 1999b; Wait et al., 2004). Sodium and potassium are other metal ions that are commonly found in inorganic fouling material. However, they do not follow a heat-induced precipitation mechanism since they do not have inverted solubility.

Total organic carbon (TOC) measured in fouling material revealed that organics also have the ability to deposit onto the quartz sleeves, thus causing organic fouling formation. However, data indicates that UV radiation appears to limit the deposition of organics since higher TOC concentrations were found in the non-irradiated zone versus the irradiated zone of quartz sleeves 
(Lin et al., 1999b). Lin et al. (1999b) concluded that this phenomenon is due to absorption of UV light by organic matter deposited on the irradiated zone of the quartz sleeve. Organic fouling is typically caused by a mechanism referred to as sedimentation of particles (Gehr \& Sehnaoui 2001, Lin et al., 1999b; Wait et al., 2004) and tends to occur in systems with high colloidal particle concentrations (Lin et al., 1999a).

The chemical composition of the fouling material has been found to be affected by the aqueous species present in the water (Gehr \& Sehnaoui, 2001; Lin et al., 1999a; Sheriff \& Gehr, 2001; Wait \& Blatchley, 2010). As result, chemical treatment processes prior to UV disinfection have the ability to influence the chemical composition of the fouling material (Lin et al., 1999a). Overall, studies agree that rapid fouling will take place in the event that high hardness concentrations $\left(350 \mathrm{mg} / \mathrm{L}\right.$ as $\left.\mathrm{CaCO}_{3}\right)$ and/or iron concentrations over $1 \mathrm{mg} / \mathrm{L}$ are present in the water being treated based on experimental observations performed by Blatchley et al. (1996). Fouling material composition has been studied by removing it from the quartz sleeves through scraping or by acid-washing them (Blatchley et al., 1996; Lin et al., 1999 a \& b). X-ray diffraction

analysis revealed that the majority of the fouling material accumulated on the surface of quartz sleeves has an amorphous structure (Blatchley, et al., 1996; Lin et al., 1999a).

\subsubsection{Intensity Monitoring and Fouling Material Removal}

Intensity loss through the quartz sleeves can be studied by locating a UV intensity measuring device inside the reactor and monitoring the intensity drop with respect to time (Gehr \& Wright, 1998). Several studies found that fouling material caused the UV intensity transmitted through the quartz sleeves to decrease rapidly during the initial hours of operation of the system (Lin et al., 1999b; Sheriff \& Gehr, 2001). Lin et al. (1999b) reported that UV intensity 
transmission through the quartz sleeves decreased in almost $80 \%$ during the initial 23 hours of operation while fouling material followed zero-order accumulation behavior.

Some of the studies that monitor the intensity loss through the quartz sleeves were performed using synthetic water in laboratory settings (Sheriff \& Gehr, 2001). Due to that, it could be argued that the scenarios used to develop the models may not be a representation of real world situations experienced in WWTP. An example of that would be using dissolved iron concentrations over $5 \mathrm{mg} / \mathrm{L}$ (Sheriff \& Gehr, 2001), a concentration which is likely not to be experienced in a WWTP effluent. A different approach to modeling is to attempt to explain the fouling material accumulation on the quartz sleeves (Lin et al., 1999c; Wait \& Blatchley, 2010). These models attempt to explain fouling material accumulation based on correlating the transport mass or concentration of fouling constituents present in the water being treated (Lin et al., 1999c; Wait \& Blatchley, 2010). Such approach may pose challenges when applying these models since water characteristics vary from site to site. Effort should be put into developing a simple model that can be easily applicable to a variety of sites with different water compositions and fouling mechanisms.

Fouling material deposited onto the quartz sleeves can be removed through cleaning (Gehr \& Sehnaoui, 2001; Wait et al., 2004). Cleaning methods are divided into two types (Nessim \& Gehr, 2006): (i) mechanical wiping, and (ii) combination of mechanical and chemical wiping. Mechanical methods simply wipe the quartz sleeves while a combination of mechanical and chemical use chemicals such nitric or phosphoric acid during the cleaning process. Previous cleaning efforts found in the literature show that the use of chemicals for cleaning is more effective than mechanical methods without chemicals (Oliver, 2002). 


\section{CHAPTER 3. SYSTEM DESCRIPTION AND METHODOLOGY}

The pilot system and the CB apparatus used as well as the methodologies developed to assess the adequacy of UV disinfection for wastewater applications in Fargo, ND are presented in this chapter.

\subsection{Pilot System}

A pilot system was loaned from Trojan Technologies, Ontario, Canada to perform this research study. The pilot system was operated for the following purposes:

1. To evaluate the fouling tendency of quartz sleeves;

2. To evaluate the effectiveness of several cleaning methods for the quartz sleeves and the intensity sensor;

3. To perform a qualitative analysis of the fouling material composition accumulated on the surface of the quartz sleeves;

4. To evaluate the impact of flow rate and seasonal water quality variations on fouling formation; and

5. To evaluate the impacts of fouling and flow rate variations on UV disinfection of E. coli.

\subsubsection{Pilot System Description and Setup}

The pilot system was located inside the ERF. The system consisted of a UV reactor, a control panel, and an intensity sensor. A detailed diagram of the TrojaUVLogic unit and the setup of the pilot system inside the ERF are shown in Figures 3.1 and 3.3, respectively. 


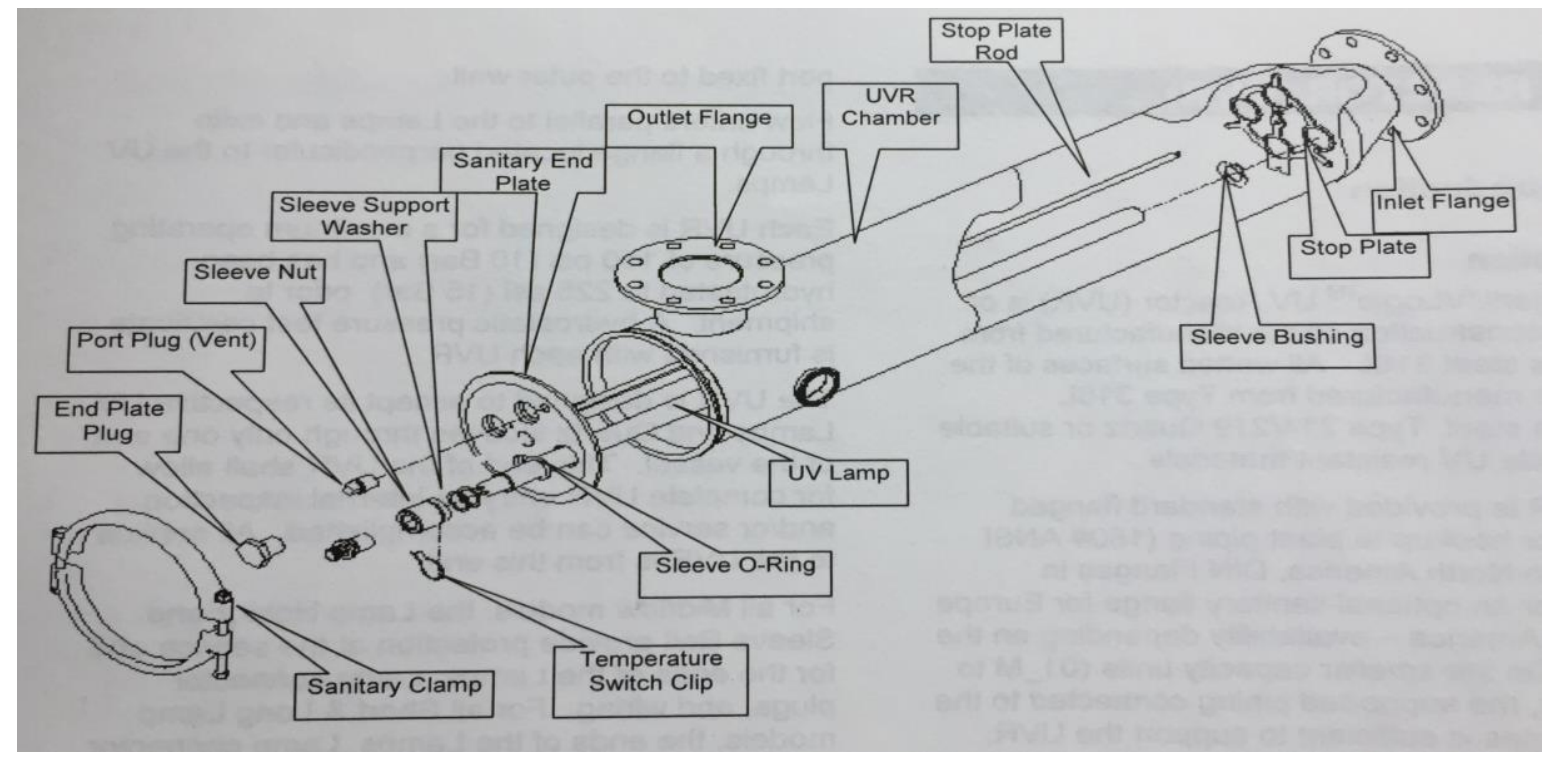

Figure 3.1. TrojanUVLogic pilot unit diagram (Source: Trojan Technologies).

The TrojanUVLogic stainless steel L-shaped UV reactor housed 2 UV lamps enclosed in quartz sleeves. The stop plate and the sanitary end plate supported the quartz sleeves in place inside the reactor's chamber. The pilot unit was equipped with both inlet and outlet sampling ports located in the inlet and outlet flanges. The control panel of the unit provided power supply to the lamps and to the intensity sensor as well as displaying the intensity readings obtained by the sensor. The control panel also allowed for monitoring of the alarm system. The alarm system would go off and the unit would shut down if high temperatures were to occur inside the chamber. The intensity sensor was mounted inside the wall of the UV reactor. General specifications of the pilot unit used can be found in Table 3.1 . 
Table 3.1. Pilot system specifications.

\begin{tabular}{|c|c|}
\hline Lamp Type & LPHO \\
\hline Number of Lamps & 2 \\
\hline Nominal Lamp Length $(\mathrm{cm})$ & 68 \\
\hline Effective Lamp Length $(\mathrm{cm})$ & 57 \\
\hline Chamber Diameter $(\mathrm{cm})$ & 15 \\
\hline Effective Chamber Volume (gal) & 2.6 \\
\hline Maximum Operating Pressure $(\mathrm{psi})$ & 150 \\
\hline Record Setpoint System & Intensity Setpoint \\
\hline Intensity Sensor Type & Photodiode \\
\hline System Power (kVA) & 0.33 \\
\hline
\end{tabular}

A relationship between flow and hydraulic retention time (HRT) was developed for the pilot unit based on the effective volume, retention time and flow formula. Such relationship is shown in Figure 3.2. The effective volume of the reactor was calculated using the diameter of the pilot chamber and the effective lamp length.

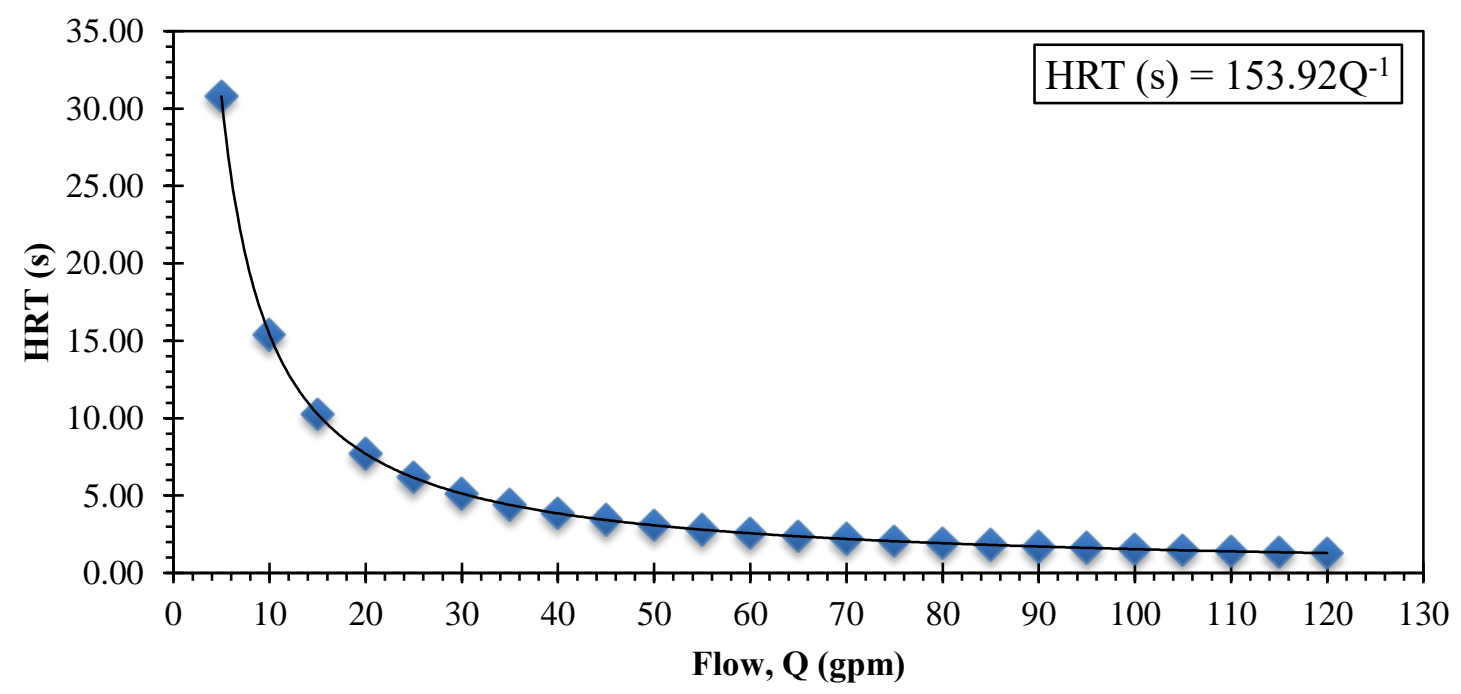

Figure 3.2. HRT and flow relationship for the TrojanUVLogic pilot unit. 
Influent water to the ERF was used as water supply to the pilot system. Once again, it is important to note that influent water to the ERF is diverted from the Fargo's WWTP before reaching the disinfection treatment unit. As indicated in Figure 3.3, influent water to the ERF was pumped through the pilot unit using a submersible pump located in the influent basin of the ERF. Prior to entering the pilot unit, the water was pumped through a strainer to remove large debris that could potentially block or damage the unit. Flow entering the reactor was monitored using an Endress+Hauser Promag flow meter located between the pump and the pilot unit.

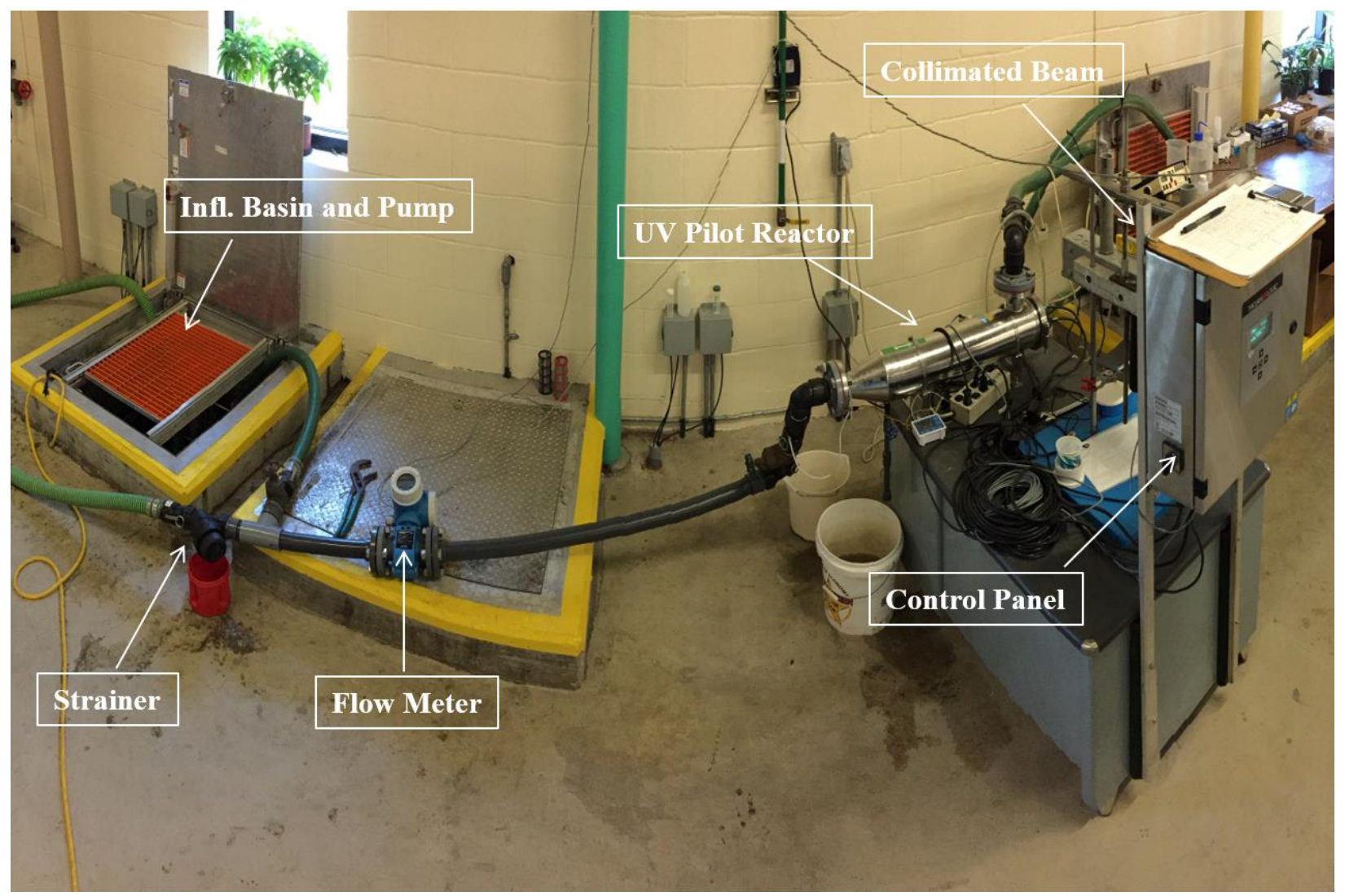

Figure 3.3. Pilot system setup inside the ERF. 


\subsubsection{Pilot System Operation and Control}

The pilot system was operated from April $4^{\text {th }}$ to October $23^{\text {rd }}$ of 2016 . The pilot unit was run for several days at a time before system maintenance took place. This report uses the term "cycle" as the amount of days the pilot unit was used without performing system maintenance. Each cycle lasted a minimum of three and a maximum of seven days to allow the quartz sleeves to collect enough fouling material so the intensity loss experienced through the quartz sleeves was significant. Proper maintenance of the system was performed at the end of each cycle. Maintenance included cleaning of the strainer, the quartz sleeves, and the intensity sensor.

The intensity inside the pilot unit was recorded both automatically and manually. Automatic measurements of the intensity maintained inside the pilot unit were performed by connecting the readings from the UV intensity sensor to the Fargo's WWTP SCADA monitoring system. The SCADA system was programed to document one intensity reading every hour. Manual measurements of the intensity were taken every twenty-four hours by recording the intensity reading displayed in the control panel. The influent flow to the pilot unit was varied at the beginning of every cycle and it was maintained constant throughout the cycle. Intensity readings collected during each cycle were used to study the behavior of the intensity loss experienced in the unit as fouling took place for varying operational conditions (flow and water quality).

Out of all the cycles, six of them were used as test runs to study the disinfection performance of the pilot system. The six test runs were performed from September $19^{\text {th }}$ to October $23^{\text {rd }}$ of 2016. A performance test was carried out every twelve to twenty-four hours during each test run to allow for the UV intensity experienced inside the pilot unit to vary from test to test. Each performance test involved a calculation of the E. coli inactivation achieved by the reactor for 
a given flow, intensity output, and water quality. Specific information regarding the sample collection that took place during each performance test is addressed in Section 3.1.4. The range of flows (with their respective detention times for the pilot unit) used to perform the test runs are shown in Table 3.2.

Table 3.2. Flow and HRT(s) used during cycles.

\begin{tabular}{|c|c|c|c|c|c|}
\hline Flow (gpm) & 10 & 15 & 20 & 25 & 35 \\
\hline HRT (s) & 15.4 & 10.3 & 7.7 & 6.2 & 4.4 \\
\hline
\end{tabular}

\subsubsection{Pilot System Cleaning}

The quartz sleeves, the intensity sensor, and the lamps were removed at the end of each cycle for routine maintenance and cleaning with the goal of recovering the initial intensity output of the UV lamps. Several cleaning methods were tested to assess their effectiveness in recovering the initial intensity output. The quartz sleeves were cleaned using a 10\% phosphoric acid solution while scraping with Kimtech Kim-wipes. Two different methods were used to clean the intensity sensor. The first method is the same one utilized to clean the quartz sleeves. The second method involved the use of a $10 \%$ nitric acid solution and a cotton swab. The surface of the intensity sensor as well as the quartz sleeves were rinsed with DI water prior to placing them back inside the pilot unit. An air compressor was used to remove the material accumulated in the strainer. Following the air compressor, the strainer was rinsed with a hose prior to attaching it back to the system. 


\subsubsection{Pilot System Sample Collection}

To adequately assess the performance of the pilot unit, the following data was collected during each performance test (detailed information regarding E. coli and UVT sampling preparation and analysis is addressed in Section 3.3):

- Grab sample of the E. coli entering the unit $\left(\mathrm{N}_{\mathrm{o}}\right)$;

- Grab sample of the E. coli exiting the unit $(\mathrm{N})$;

- Flow rate measurement;

- Intensity sensor reading; and

- Grab sample tested for UVT of the influent water to the pilot unit.

A series of water quality parameters were sampled two to three times per week throughout the 2016 disinfection season. Water quality parameters were sampled throughout the season for three different purposes: (i) monitor seasonal effluent water quality variations, (ii) study the impacts of water quality changes on UVT, and (iii) study whether water quality had an impact on the rate of intensity loss experienced in the pilot unit. A one liter grab sample was collected in triplicate from the influent sampling port of the pilot unit, allowing ten minutes between each sample collection. Samples collected were tested immediately after collection for the following: Turbidity, TSS, COD, UVT, UVA, temperature, iron, and $\mathrm{pH}$. Collected water quality samples were analyzed at the Fargo WWTP and water treatment plant (WTP) laboratories following the procedures and methodologies addressed in Sections 3.3.2 and 3.3.3.

The fouling material accumulated onto the surface of the quartz sleeves was collected when desired prior to cleaning them at the end of each cycle. A qualitative analysis of the fouling material was performed to study the distribution of the components forming it. By knowing the components forming the fouling material, one can attempt to assess the possible fouling 
mechanism(s) taking place at the Fargo WWTP. Kim-wipes damped in DI water were used to remove the majority of the fouling material by scraping it from the quartz sleeves. Removed material was placed in a clean plastic bottle containing $500 \mathrm{ml}$ of DI water, preserved with nitric acid and stored in a refrigerator prior to testing. Fouling samples were transported to the Fargo WTP for analysis. Analysis procedures of the fouling material are addressed in Section 3.3.4.

\subsection{Collimated Beam Apparatus}

A CB apparatus was loaned from Trojan Technologies for this study. The CB was used to study the impact of water quality on UV disinfection by performing several CB tests at varying water qualities. Procedures specified in "Ultraviolet Disinfection Guidance Manual" (USEPA, 2003) were followed for CB intensity calibration and sample testing.

\subsubsection{Collimated Beam Apparatus Configuration}

The CB unit utilized a single LPLO mercury lamp as a source of UV light. The UV lamp was enclosed in a box suspended parallel to ground level. The box had ventilation channels to prevent it from overheating. A round tube, also known as collimating tube, extended downward from the box and it was used to achieve collimation of UV light. The inside of the collimating tube was painted black to prevent light reflection from the walls of the tube (Bolton \& Linden, 2003). A diagram of the CB apparatus used for this study including its dimensions is shown in Figure 3.4.

The CB unit was also equipped with a magnetic stirrer. The magnetic stirrer was used to mix the wastewater sample while the sample was exposed to UV light to provide equal exposure 
to all microorganisms in suspension (Bolton \& Linden, 2003). To prevent UV light from exiting the collimating tube when desired, an opaque sheet was located between the collimating tube and the petri dish to block the beam of UV light exiting the tube while sample preparation was taking place.

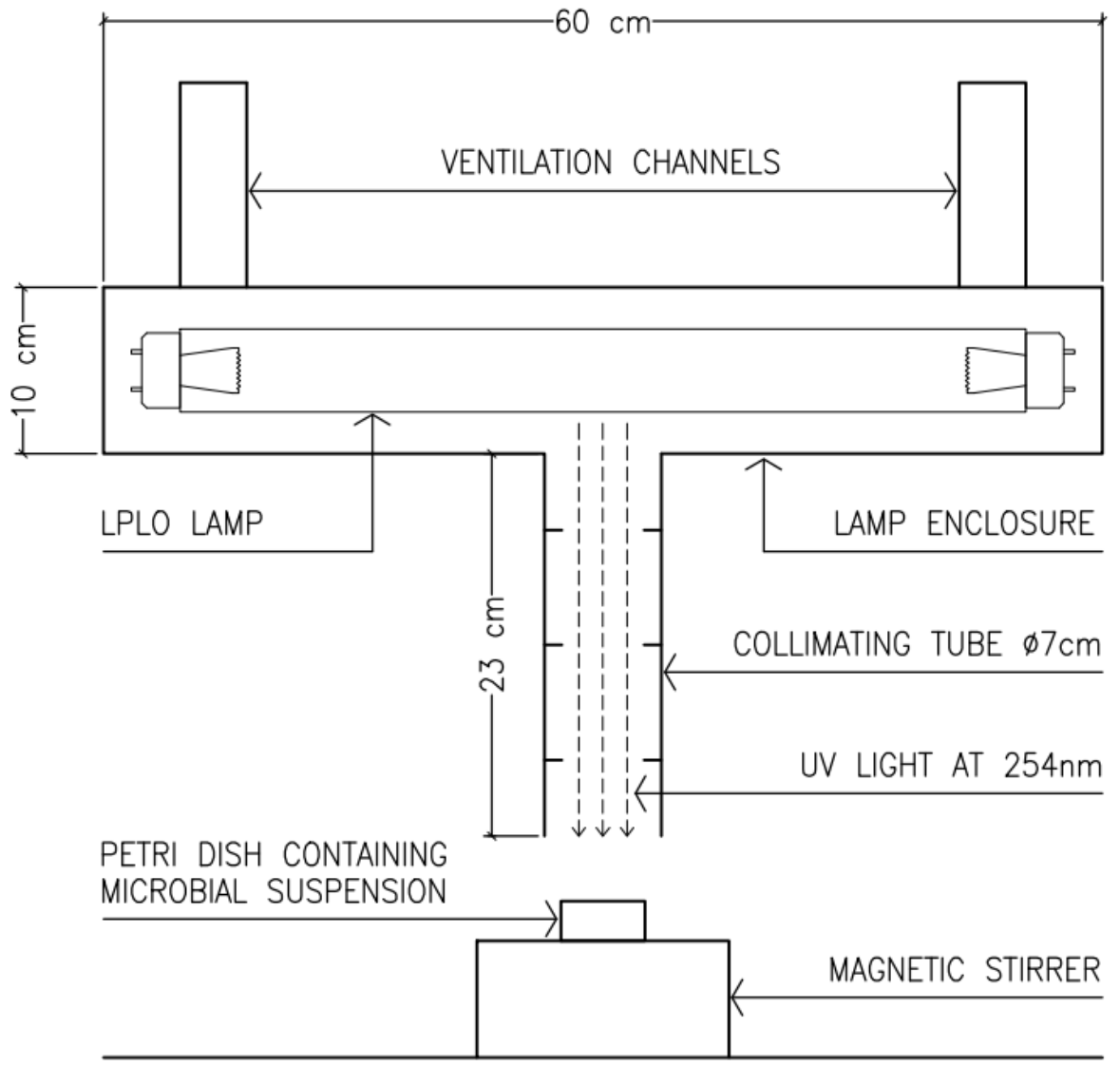

Figure 3.4. Diagram of the CB used in this study.

\subsubsection{Collimated Beam Intensity Calibration Procedure}

Several correction factors have to be determined and applied to the intensity output of the UV lamp prior to performing a CB test. Before calculating the correction factors, the LP lamp of the $\mathrm{CB}$ apparatus was turned on and allowed to stabilize for a period of 60 minutes. After 60 
minutes had passed, the UV light intensity at the surface of the test sample was measured using a calibrated radiometer (International Light IL1700 model, equipped with a diffuser and UV254 filter). It is important to note that the intensity measurement taken by the radiometer measures the intensity of the UV light at the surface of the sample. As mentioned in Chapter 2, absorption and scattering taking place in the test sample will reduce the measured UV intensity at the surface of the sample as the UV rays travel through it. Due to that, to properly perform a CB test, the average UV intensity across the test sample needs to be calculated (Bolton \& Linden, 2003). Several correction factors were applied to the intensity reading taken by the radiometer to obtain the average intensity through the test sample. The correction factors used were: (i) petri factor, (ii) water factor, (iii) divergence factor, and (iv) reflection factor.

Petri factor is defined as the ratio of the average intensity across the sample surface to the intensity measured at the center of the sample surface (Bolton \& Linden, 2003). To determine the petri factor, UV intensity at the center of the UV beam and every $0.5 \mathrm{~cm}$ in the $\mathrm{x}$ and $\mathrm{y}$ directions for a distance of $3 \mathrm{~cm}$ were measured using a radiometer.

The water factor is related to the absorption and/or scattering of UV light by the sample. In this study, a grab sample containing 1 liter of influent water to the pilot unit was collected. The bottle containing the grab sample was mixed for a period of five minutes on a magnetic stirrer prior to performing a measurement of the sample UVA using a spectrophotometer. Separately, fifty millimeters of the same sample were placed in a petri dish to measure the sample's depth. The UVA and the sample's depth were then used to calculate the water factor using Equation 3.1. Equation 3.1 was derived by Morowitz et al. (1950).

$$
W F=\frac{1-10^{-U V A \times d}}{\ln (10) \times U V A \times d}
$$


$\mathrm{WF}=$ Water Factor

UVA $=$ Absorbance $\left(\mathrm{cm}^{-1}\right)$

$\mathrm{d} \quad=$ Sample depth $(\mathrm{cm})$

Following the water factor, the divergence factor was calculated. The divergence factor takes into account the divergence of the UV light as it travels from the lamp to the surface of the test sample and through the sample (USEPA, 2003). At this point, the opaque sheet was used to block the UV light coming out of the collimating tube. The magnetic stirrer and the petri dish containing the 50 millimeter sample were placed right under the collimating tube. The distance between UV lamp and sample's surface was measured and Equation 3.2 was used to calculate the divergence factor.

$$
D F=\frac{L}{L+d}
$$

$\mathrm{DF}=$ Divergence Factor

L = Distance between UV lamp and sample's surface $(\mathrm{cm})$

$\mathrm{d} \quad=$ Sample depth $(\mathrm{cm})$

It is important to note that not all the UV light exiting the collimating tube penetrates through the sample. Due to refractive index changes between different mediums as light travels from air to water, a small percentage of the beam of light is reflected off the sample's surface (Bolton \& Linden, 2003). For a normal incident light, the fraction of light reflected is given by the Fresnel law. Based on the Fresnel law and the types of media (air and water), the reflection 
factor for the $\mathrm{CB}$ test is 0.975 and it represents the portion of light entering the test sample (Bolton \& Linden, 2003).

Once all the previous factors (petri, water, divergence and reflection) were measured, the average germicidal irradiance through the test sample can be calculated using Equation 3.3.

$$
G I=I \times P F \times W F \times D F \times R F
$$

GI = Average germicidal irradiance through the wastewater sample $\left(\mathrm{mW} / \mathrm{cm}^{2}\right)$

I = Intensity measured by the radiometer $\left(\mathrm{mW} / \mathrm{cm}^{2}\right)$

$\mathrm{PF} \quad=$ Petri Factor

$\mathrm{WF}=$ Water Factor

DF $=$ Divergence Factor

RF $\quad=$ Reflection Factor

\subsubsection{Collimated Beam Test Procedure}

Upon calculation of the average germicidal irradiance through the test sample, the exposure times needed to achieve certain UV doses were calculated using Equation 2.4. Exposure times were calculated to obtain UV doses ranging from 0 to $80 \mathrm{~mJ} / \mathrm{cm}^{2}$ based on the average germicidal irradiance calculated for the particular $\mathrm{CB}$ test and the desired UV dose. Fifty millimeters of sample were placed in petri dishes prior to begin testing. These petri dishes were placed under the UV light for the calculated exposure times to obtain the desired UV doses. A chronometer was used to accurately measure the time lapsed during each sample's exposure to UV light. 


\subsubsection{Collimated Beam Sample Analysis}

As indicated throughout the previous sections, 1 liter of influent water to the pilot unit was collected to perform each $\mathrm{CB}$ test. The following data was collected during each $\mathrm{CB}$ test performed in this study:

- E. coli count prior to UV light exposure $\left(\mathrm{N}_{\mathrm{o}}\right)$;

- E. coli count upon different UV light exposures $(\mathrm{N})$; and

- Water quality: UVT, turbidity, TSS, COD, and iron measurements of the 1 liter grab sample.

The above water quality parameters were recorded to assess the impact of water quality on UV the disinfection of E. coli. Information regarding E. coli and water quality sampling preparation and analysis is addressed in Section 3.3.

\subsection{Sample Preparation and Analysis}

E. coli samples were collected throughout the disinfection season to assess the performance of UV disinfection (pilot unit and CB apparatus) for varying conditions (intensity output, flow rate, and water quality). In addition to E. coli sampling, water quality sampling took place two to three times per week to study the seasonal water quality variations experienced the Fargo effluent, and whether these variations had any impacts in the rate of intensity loss through the quartz sleeves. Furthermore, water quality sampling was performed to identify the water quality parameter(s) that has/have the biggest impact on the loss of UVT of the Fargo's WWTP effluent. The following sections contain the different methods to analyze both the water quality conditions and the E. coli enumeration in this research study. 


\subsubsection{Microorganism Enumeration}

All UV irradiated samples were stored in sterilized containers. The sterilized containers containing the irradiated samples were kept in a dark environment with a temperature of 4 degrees Celsius for a maximum holding time of one hour prior to enumerating the positive surviving E. coli colonies. E. coli incubation and enumeration performed in this study followed the Enzyme Substrate Test Method (Standard Methods 9223B) using the Colilert-18/Quanti-Tray/2000 testing procedure. Test values were reported using a MPN chart for positive colonies. All UV dose exposures (pilot unit and CB tests) were performed in duplicate. The geometric mean was used to obtain a single positive surviving E. coli count for each UV dose exposure.

\subsubsection{Recorded Quality Parameters from SCADA}

The Fargo WWTP was functioning while this project was conducted during the disinfection season of 2016. Because of that, the plant's SCADA system was used to record certain continuously monitored parameters by the plant. These recordings were taken at the plant's effluent measuring station. These parameters included turbidity, temperature, and $\mathrm{pH}$. A HACH 1720E online meter was used to measure the turbidity, a Siemens SitransTF2 online meter was used to measure water temperature, and a HACH PC1RIA was used to measure $\mathrm{pH}$.

\subsubsection{Water Quality Sampling and Reason for Analysis}

In addition to the parameters recorded through the SCADA system, additional effluent samples were taken at the times indicated in Sections 3.1.4 and 3.2.4. As already mentioned in previous sections, these parameters included: turbidity, TSS, COD, iron, and UVT. 
COD is a measurement of the oxygen required to oxidize soluble and particulate organic matter in water. Effluents reporting high concentrations of COD will negatively affect UV light's propagations through absorption of UV light. To accurate measure the COD concentration of dissolved substances alone, samples collected were filtered through a $0.45 \mu \mathrm{m}$ pore size filter. COD analysis performed in this study was done in filtered and unfiltered grab samples following the Closed Reflux, Colorimetric Method (Standard Methods 5220D) using the HACH 8000 testing procedure. A HACH DR5000 spectrophotometer and a HACH DRB200 digestion block were used to properly follow the test procedure at the Fargo WWTP.

TSS measurements include all particles suspended in a sample that will not pass through a filter with a pore size of $1.2 \mu \mathrm{m}$. Suspended particles negatively affect UV light's propagation since particles may scatter light and reduce the depth of light penetration in the sample. TSS analysis performed in this study followed the Total Suspended Solids Dried at $103-105^{\circ} \mathrm{C}$ Method (Standard Methods 2540D) using a filtration unit, an oven, and a desiccator following the USGS I3765-85 testing procedure at the Fargo WWTP.

Turbidity is the cloudiness of a fluid sample. Turbidity is caused by individual particles that often times are invisible to the naked eye. In a similar fashion than TSS, cloudiness of a sample reduces the penetration of the UV light into it, thus affecting UV light's depth of propagation. In addition to measuring unfiltered turbidity through the SCADA system, turbidity was also measured for filtered samples following the Nephelometric Method (Standard Methods 2130B) using a HACH $2100 \mathrm{P}$ portable turbidity meter at the Fargo WWTP. Grab samples were filtered through 1.2 and $0.45 \mu \mathrm{m}$ pore size filters to distinguish what contributed to the turbidity of the Fargo effluent (suspended particles, colloidal particles, or dissolved substances). 
Iron concentration is a parameter that is not monitored at the Fargo WWTP on a regular basis. Iron concentrations were only monitored between the months of May through October. Although iron is not a parameter currently tested at the Fargo WWTP, it was decided to include it in this research study since iron affects the performance of UV disinfection systems through fouling of quartz sleeves following a heat-induced precipitation mechanism due to iron's inverted solubility. The role of iron on fouling deposition may be more pronounced for the Fargo WWTP than other plants since the city applies ferrous salts in its sewer system for odor control purposes. It was expected that some of the iron added throughout the collection system may make its way through the plant and end up in the effluent in dissolved or particulate forms accelerating fouling material deposition, thus hindering UV performance. Iron concentrations were measured for both filtered and unfiltered samples. Dissolved iron concentrations were calculated by filtering the grab samples through $0.45 \mu \mathrm{m}$ pore size filter and measuring the iron concentration. Both total and dissolved iron analyses followed the Inductively Coupled Plasma-Atomic Emission Spectrometry Method (Standard Methods 6010C) at the Fargo WTP. Some of the iron samples collected were analyzed at the Fargo WWTP using a HACH DR/890 Colorimeter following the HACH 8000 testing procedure. Samples were preserved with nitric acid if not analyzed for iron immediately after collection.

UVT was never measured at the Fargo WWTP prior to this study. As mentioned in Chapter 2, unfiltered UVT measurements of a grab sample cannot distinguish between absorbed and scattered UV light. Because of that, UVT was also measured for filtered samples to assess the individual impacts that particles and dissolved substances have on the loss of UV Intensity. By doing that, one can analyze which phenomenon (absorption or scattering) affects UV Intensity loss the most. The filtration procedure involved filtering effluent samples through a series of filters 
(1.2 and $0.45 \mu \mathrm{m}$ pore size filters) and taking UVT measurements prior and after filtration. UVT was measured with a HACH DR5000 spectrophotometer following the HACH 10243 Method at the Fargo WWTP. UVA was calculated using the relationship between UVT and UVA shown in Equation 2.3. The filtration procedure and the sample composition present in each type of sample are shown in Table 3.3.

Table 3.3. Filtration procedure and sample classification.

\begin{tabular}{|c|c|c|}
\hline Sample Type & Sample Composition & Reason for UVI loss \\
\hline $\begin{array}{c}\text { Unfiltered Effluent } \\
\text { Sample }\end{array}$ & $\begin{array}{c}\text { Suspended Particles } \\
\text { Colloidal Particles } \\
\text { Dissolved Substances }\end{array}$ & $\begin{array}{c}\text { Combination of absorption } \\
\text { (dissolved substances) and } \\
\text { scattering (colloidal and } \\
\text { suspended particles) }\end{array}$ \\
\hline $\begin{array}{c}\text { GFC Filtered Sample } \\
\text { (filter pore size 1.2 } \mu \mathrm{m})\end{array}$ & $\begin{array}{c}\text { Colloidal Particles } \\
\text { Dissolved Substances }\end{array}$ & $\begin{array}{c}\text { Combination of absorption } \\
\text { (dissolved substances) and } \\
\text { scattering (colloidal } \\
\text { particles) }\end{array}$ \\
\hline $\begin{array}{c}0.45 \mu \mathrm{m} \text { pore size filter } \\
\text { Filtered Sample }\end{array}$ & Dissolved Substances & $\begin{array}{c}\text { Absorption alone (dissolved } \\
\text { substances) }\end{array}$ \\
\hline
\end{tabular}

\subsubsection{Fouling Material Analysis}

Fouling material was removed from the quartz sleeves as stated in Section 3.1.4. Fouling material was analyzed for cation composition. Fouling material analysis took place at the Fargo WTP following the Inductively Coupled Plasma-Atomic Emission Spectrometry Method (Standard Methods 6010C). Fouling samples were preserved with nitric acid if not analyzed immediately after collection. 


\section{CHAPTER 4. RESULTS AND DISCUSSION}

The results of this study regarding the evaluation of UV irradiation as an adequate method

of wastewater disinfection for the Fargo WWTP are presented in the following sections. The intensity and fouling study are provided in Section 4.1. The effects of flow variations and intensity impacts on E. coli inactivation are addressed in Section 4.2. A study of the seasonal water quality variations and impacts of water quality on UVT are provided in Section 4.3. A study pertaining the impacts of UVT on UV disinfection efficiency of E. coli can be found in Section 4.4. Discussion of the results is provided within each section of this chapter. The data collected and the results obtained from this study will be made available to the management of the Fargo WWTP to assist the design process and the operation strategies of the Fargo WWTP UV disinfection system.

\subsection{Evaluation of Fouling of the Quartz Sleeves and Its Impact on UV Intensity}

This section of the report touches on the challenges experienced while operating the pilot system as well as addressing the results for fouling material removal and analysis, the model simulation of the intensity loss behavior, and the effects of temperature and flow variations on the rate of intensity loss experienced in the pilot unit. The pilot system and the methodologies mentioned under Section 3.1 were used to obtain the results for the following sections.

\subsubsection{Initial Test Cycles}

Changes if UV light intensity in the pilot unit during the initial eight operation cycles are presented in Figure 4.1. Raw data for these eight cycles, taking place from April $4^{\text {th }}$ to May $21^{\text {st }}$ 
of 2016, can be found in Appendix A, Table A.1. The duration of the cycles was determined based on the intensity readings collected during each cycle. It was decided to end the cycles when 70 to $90 \%$ of the intensity experienced at the beginning of the cycles was lost. Operational conditions, such as flow rates, water temperature, and influent water quality parameters for these initial eight cycles are shown in Table 4.1.

Table 4.1. Operational conditions for initial eight cycles.

\begin{tabular}{|c|c|c|c|c|c|c|c|c|}
\hline Parameter & C1 & C2 & C3 & C4 & C5 & C6 & C7 & C8 \\
\hline Flow Rate $(\mathrm{gpm})$ & 25.0 & 24.8 & 23.7 & 24.8 & 23.0 & 14.9 & 14.7 & 15.7 \\
\hline Water Temperature $\left({ }^{\circ} \mathrm{C}\right)$ & 14.5 & 14.9 & 15.5 & 16.1 & 16.3 & 15.5 & 17.3 & 18.1 \\
\hline COD $(\mathrm{mg} / \mathrm{L})$ & 54.3 & 54.7 & 53.0 & 42.7 & 49.5 & 34.0 & 56.3 & 68.0 \\
\hline TSS $(\mathrm{mg} / \mathrm{L})$ & 14.9 & 19.7 & 15.3 & 14.0 & 14.1 & 18.4 & 14.1 & 19.9 \\
\hline Turbidity (NTU) & 10.5 & 12.8 & 12.1 & 10.1 & 9.2 & 12.4 & 10.9 & 14.8 \\
\hline UVT $(\%)$ & 54.4 & 51.3 & 54.1 & 54.6 & 54.6 & 53.6 & 51.7 & 50.6 \\
\hline $\mathrm{pH}$ & 7.3 & 7.1 & 7.3 & 7.2 & 7.3 & 7.2 & 7.1 & 7.2 \\
\hline
\end{tabular}

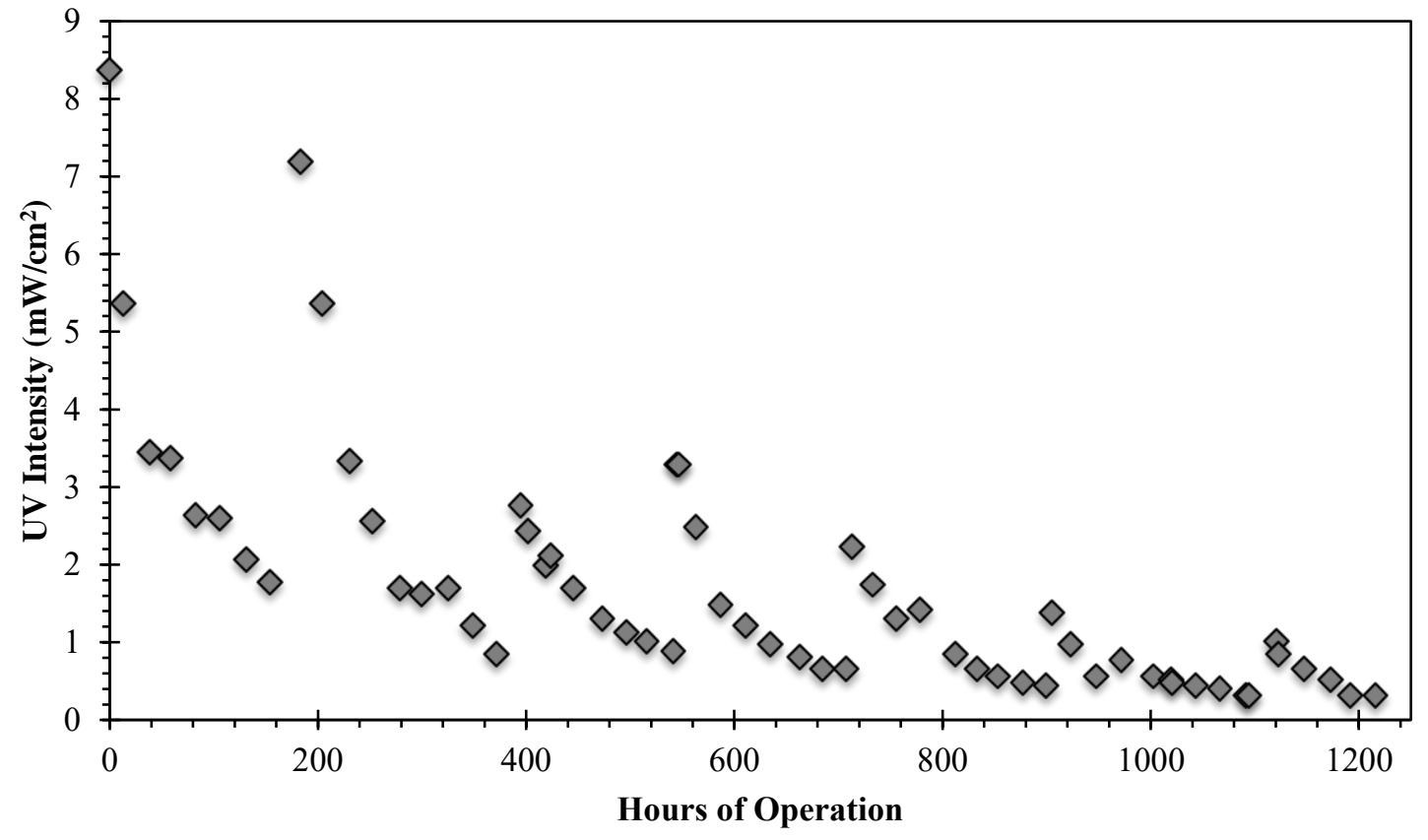

Figure 4.1. UV intensity behavior of the initial eight cycles of the study. 
As seen in Figure 4.1, in each cycle, UV intensity in the pilot unit dropped considerably during the first several hours and the rate of intensity drop decreased with time. Similar behavior was experienced in previous studies performed by Sheriff \& Gehr (2001) and Lin et al. (1999a). In addition to rapid intensity loss, initial intensity was not recovered from previous cycles upon cleaning of the quartz sleeves and the sensor lens. The fact that the initial intensity output was not recovered could be associated to either ineffective cleaning (quartz sleeve and/or sensor lens) or malfunctioning of the equipment (UV lamps and/or sensor).

\subsubsection{Improved Sensor Cleaning and Intensity Monitoring through SCADA}

Several attempts were carried out during the initial weeks of June to investigate the reason why the initial intensity output was not being recovered. The first and second attempt consisted of replacing the UV lamps and quartz sleeves for the backup equipment that came with the pilot system. The initial intensity was still not recovered after these first attempts, leading towards the conclusion that the initial intensity output was not recovered due to issues with the intensity sensor.

The intensity sensor used until that point of the study was removed from the unit and observed visually. Upon visual inspection, the sensor appeared to be in working order. However, a picture of the sensor obtained with a special magnifying camera (shown in Figure 4.2) indicated that the surface of the sensor was not cleaned properly since fouling material was still accumulated on it upon cleaning it. Pictures of the sensor were taken in London, Ontario by Trojan Technologies. 


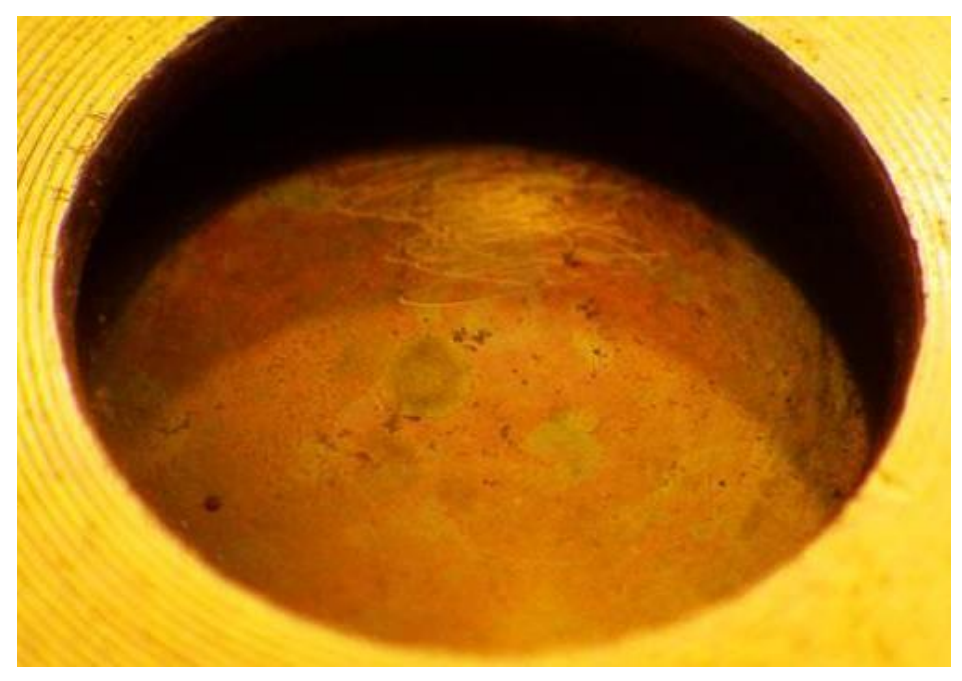

Figure 4.2. Magnified picture of the fouled UV intensity sensor.

Prior to discovering that improper cleaning of the sensor was taking place, the sensor was cleaned using $10 \%$ phosphoric acid, DI water, and Kim-wipes, which had proven successful for quartz sleeve cleaning. However, due to the shape of the sensor's lens, the Kim-wipes were not able to remove the fouling material accumulated. From that point on, the cleaning method of the sensor's lens was changed to using a stronger chemical (10\% nitric acid) in combination with DI water, and a cotton swab. Although inadequate sensor cleaning posed a significant operational concern at the beginning of this study, similar operational challenges have not been found in the literature.

In addition to changing the sensor's lens cleaning method, the UV intensity sensor was connected to the Fargo WWTP SCADA system. The SCADA system allows for a more controlled monitoring of the intensity behavior since the system can be programed to record a reading as frequent as desired. The SCADA system was programed to record a reading every hour. The intensity data collected during the first four cycles monitored with the SCADA system is shown in Figure 4.3. Raw data for these four cycles, taking place from June $15^{\text {th }}$ to July $13^{\text {st }}$ of 2016 , can 
be found in Appendix A, Table A.2. Similar to previous intensity monitoring efforts, the quartz sleeves and the intensity sensor were only cleaned at the end of each cycle. Operational conditions, such as flow rates, water temperature, and influent water quality parameters for these cycles are shown in Table 4.2.

Table 4.2. Operational conditions for the initial four cycles monitored through SCADA.

\begin{tabular}{|c|c|c|c|c|}
\hline Parameter & C9 & C10 & C11 & C12 \\
\hline Flow Rate $(g p m)$ & 16.0 & 25.9 & 24.8 & 23.8 \\
\hline Water Temperature $\left({ }^{\circ} \mathrm{C}\right)$ & 19.5 & 19.3 & 19.0 & 19.4 \\
\hline COD $(\mathrm{mg} / \mathrm{L})$ & 51.8 & 46.7 & 57.0 & 68.5 \\
\hline TSS $(\mathrm{mg} / \mathrm{L})$ & 15.6 & 14.3 & 17.2 & 18.4 \\
\hline Turbidity $(\mathrm{NTU})$ & 9.3 & 8.7 & 8.3 & 14.7 \\
\hline UVT $(\%)$ & 54.3 & 54.1 & 51.2 & 46.1 \\
\hline Total Iron $(\mathrm{mg} / \mathrm{L})$ & 0.73 & 0.71 & 0.72 & 0.86 \\
\hline $\mathrm{pH}$ & 7.3 & 7.4 & 7.2 & 7.4 \\
\hline
\end{tabular}

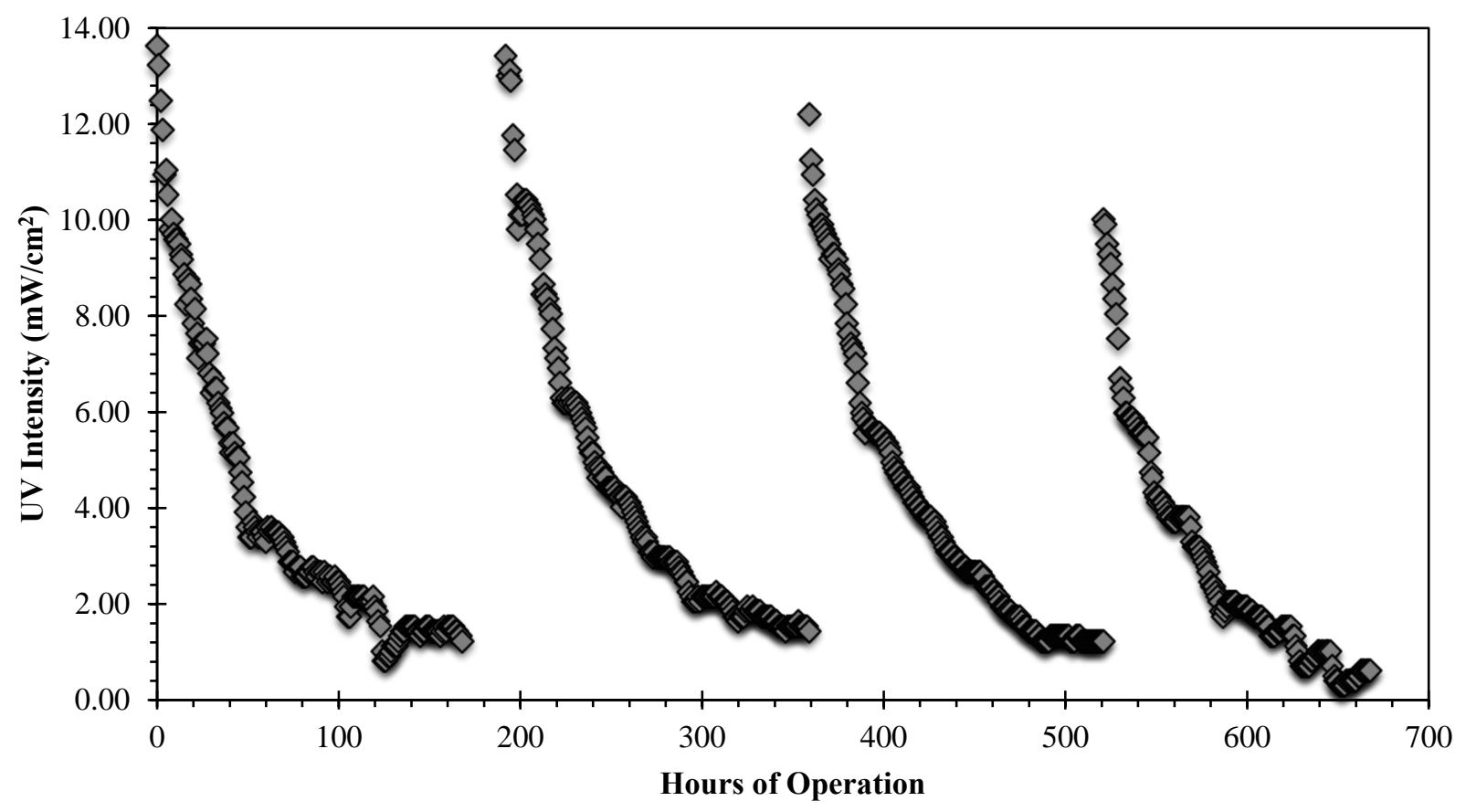

Figure 4.3. UV intensity behavior of the initial four cycles monitored with the SCADA system. 
The data displayed in Figure 4.3 indicates that cleaning of the intensity sensor was now effective since the initial intensity output of the lamps was recovered upon cleaning. It is important to point out that the lower UV intensity at the beginning of the last two cycles were likely due to the drop of influent UVT as shown in Table 4.2. When water quality worsens, the amount of UV intensity propagated from the quartz sleeves to the intensity sensor decreases since more absorption and scattering are taking place. Because of that, a decrease in the initial intensity experienced in cycles \#3 and \#4 was not caused by ineffective cleaning, rather by water quality conditions.

It was intended to simulate the fouling process using an existing model or with a new model developed, and calibrate the model using the pilot data. However, intensity data displayed in Figure 4.3 are affected by combined fouling of both UV lamp sleeves and the sensor's lens. Due to that, the data shown in Figure 4.3 cannot be used to model the behavior of the intensity over time caused by accumulation of fouling material on the quartz sleeves alone since fouling material was accumulated on the sensor's lens while the intensity data is recorded.

\subsubsection{Separating Sensor Fouling from the Intensity Data}

The remaining cycles of this pilot study were monitored by the SCADA system. However, in an effort to eliminate the impact of sensor fouling on studying the quartz sleeve fouling, discrete UV intensity readings were taken every 24 hours after cleaning the sensor. By removing the fouling material from the sensor before collecting a reading, the intensity data collected was only affected by quartz sleeve fouling. In addition to taking an intensity reading after cleaning the sensor, a reading was also taken before. By doing this, the amount of intensity recovered through 
sensor cleaning can be calculated. The amount of intensity recovered by cleaning the sensor's lens can be used to represent the intensity loss caused by fouling material accumulated on the sensor.

Intensity readings collected before and after cleaning the sensor's lens for the $13^{\text {th }}$ cycle (C13) shown in this report are displayed in Table 4.3. The cumulative intensity loss associated to quartz sleeve fouling and sensor's lens fouling are also shown in Table 4.3. There were a total of eleven cycles whose UV intensity was monitored by measuring it before and after cleaning the sensor's lens. C13 was the second cycle ran while performing discrete intensity readings before and after cleaning the sensor. The intensity data collected from the first cycle ran while performing discrete readings was not used to perform this analysis since heavy storm events occurred during that week, which significantly varied the influent water quality experienced during the cycle.

Table 4.3. Comparison of intensity loss associated to sleeve fouling and sensor fouling for C13.

\begin{tabular}{|c|c|c|c|c|}
\hline Time & $\begin{array}{c}\text { UV Intensity } \\
\text { before sensor } \\
\text { cleaning } \\
\left(\mathrm{mW} / \mathrm{cm}^{2}\right)\end{array}$ & $\begin{array}{c}\text { UV Intensity } \\
\text { after sensor } \\
\text { cleaning } \\
\left(\mathrm{mW} / \mathrm{cm}^{2}\right)\end{array}$ & $\begin{array}{c}\text { Cum. Intensity Loss } \\
\text { due to Sensor } \\
\text { Fouling }\end{array}$ & $\begin{array}{c}\text { Cum. Intensity Loss } \\
\text { due to Sleeve } \\
\text { Fouling }\end{array}$ \\
\hline (Hours $)$ & 13.00 & 13.00 & 0.00 & $\left.(\mathrm{~m})^{2}\right)$ \\
\hline 0 & 8.56 & 9.71 & 1.15 & 0.00 \\
\hline 22 & 5.52 & 6.19 & 1.82 & 3.29 \\
\hline 45 & 4.18 & 4.74 & 2.38 & 6.81 \\
\hline 68 & 3.25 & 3.45 & 2.58 & 9.26 \\
\hline 90 & & & \\
\hline
\end{tabular}

As seen in Table 4.3, the intensity loss through the quartz sleeves was much higher than the intensity loss through the sensor when they were allowed to foul for the same period of time. Based on the data displayed in Table 4.3 it could be said that fouling material accumulates at a faster rate on the quartz sleeves than on the surface of the sensor's lens since the UV intensity is lost at a faster rate through the quartz sleeves. This would later be confirmed through modeling 
of the intensity data. C13 took place in between August $1^{\text {st }}$ and August $5^{\text {th }}$ of 2016 . C13 was run with a flow rate of $25 \mathrm{gpm}$. Operational conditions such as water temperature, and influent water quality parameters for $\mathrm{C} 13$ are shown in Table 4.4.

Table 4.4. Operational conditions for C13.

\begin{tabular}{|c|c|c|c|}
\hline Parameter & $\mathbf{8 / 2 / 2 0 1 6}$ & $\mathbf{8 / 4 / 2 0 1 6}$ & Average \\
\hline Water Temperature $\left({ }^{\circ} \mathrm{C}\right)$ & 21.3 & 21.3 & 21.3 \\
\hline COD $(\mathrm{mg} / \mathrm{L})$ & 46.0 & 47.0 & 46.5 \\
\hline TSS $(\mathrm{mg} / \mathrm{L})$ & 15.3 & 17.0 & 16.2 \\
\hline Turbidity (NTU) & 9.2 & 10.5 & 9.8 \\
\hline UVT (\%) & 56.1 & 55.1 & 55.6 \\
\hline Total Iron (mg/L) & 0.7 & 0.6 & 0.67 \\
\hline $\mathrm{pH}$ & 7.3 & 7.4 & 7.3 \\
\hline
\end{tabular}

The intensity data recorded after cleaning the sensor for C13 is shown in Figure 4.4. Once again, it is important to note that the since the intensity data displayed in Figure 4.4 was collected after cleaning the sensor's lens, it is not affected by combined fouling.

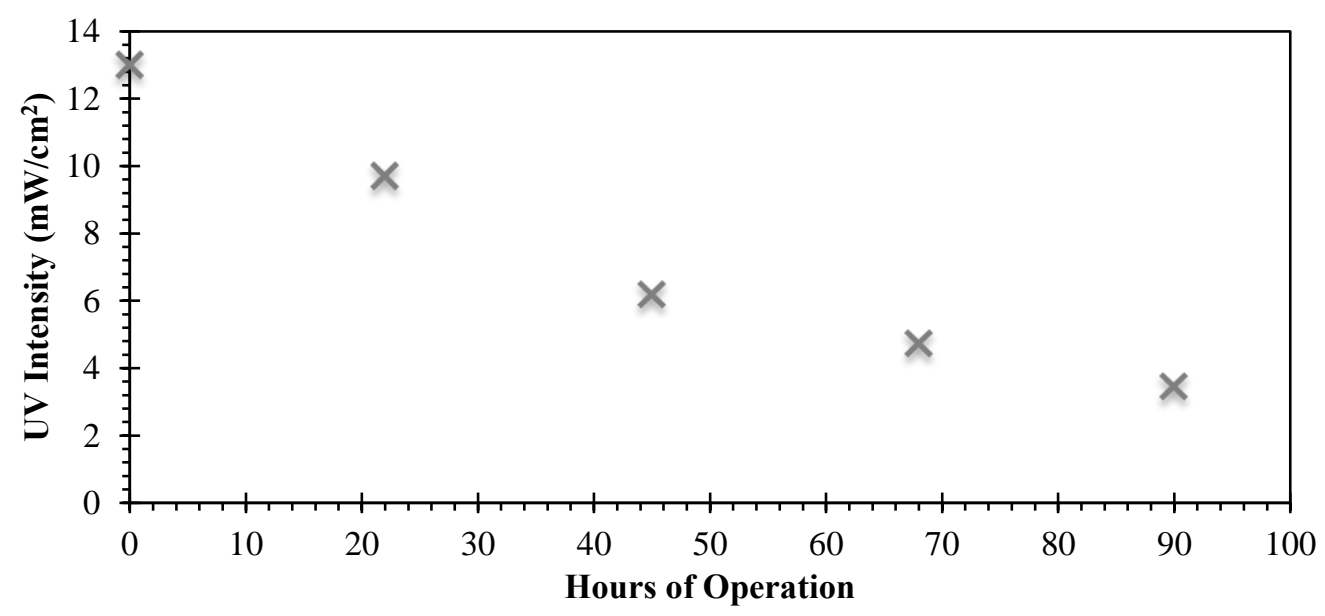

Figure 4.4. UV intensity behavior for C13. 
As seen in Figure 4.4, intensity readings after cleaning the sensor's lens during C13 display similar exponential decrease as seen in earlier cycles. Prior to further investigating why the fouling material accumulated at a faster rate on the quartz sleeves than on the sensor's lens or modeling the intensity behavior, a sample of the fouling material deposited on the surface of the quartz sleeves was removed and tested to study its composition.

\subsubsection{Fouling Material Analysis}

To determine the nature of the quartz sleeve fouling, fouling material was collected from one of the quartz sleeves at the end of C14, which took place between June $13^{\text {th }}$ and June $19^{\text {th }}$ of 2016. An ICP-OES test was performed in this sample at the Fargo WTP laboratory to identify the major cations in the fouling material and their respective abundance. Based on the tests results, a percentage distribution of the cations forming the fouling material was calculated. Figure 4.5 is a diagram representing the distribution of the metal ions deposited on the surface of the sleeve. Results obtained from the test displayed in Figure 4.5 can be found in Appendix A, Table A.3. 


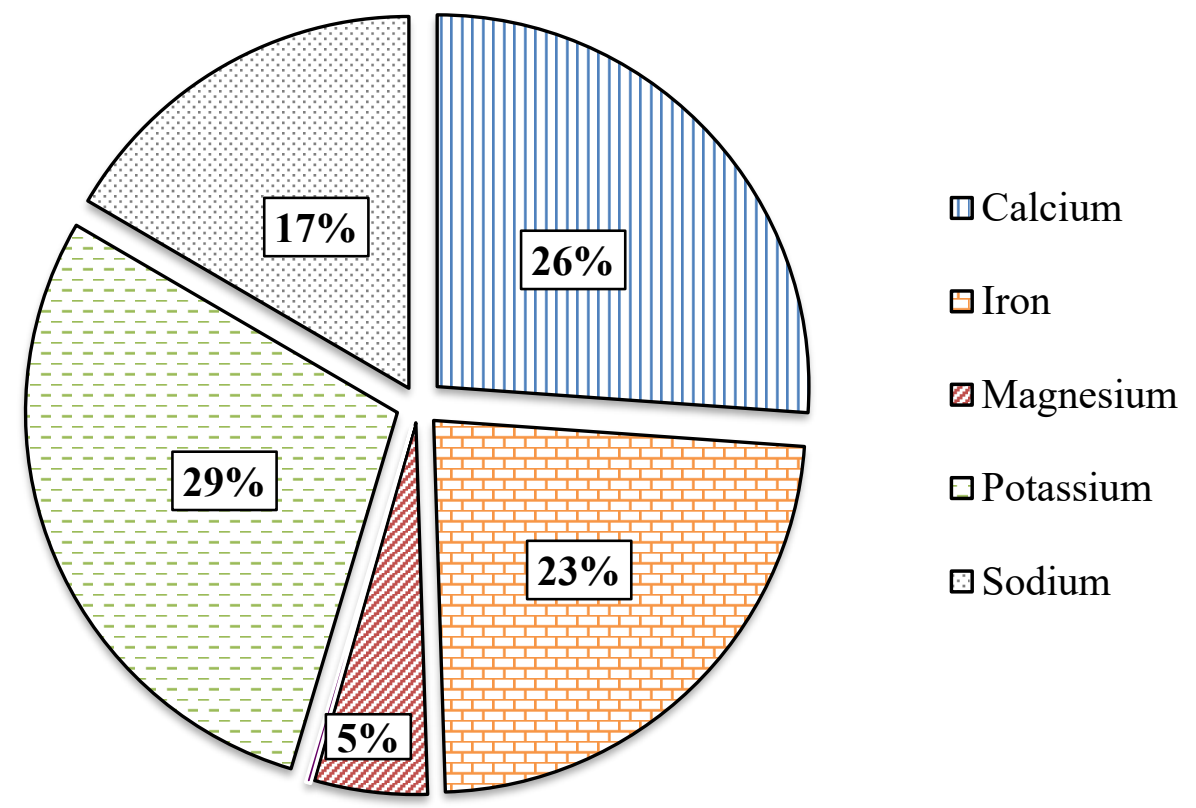

Figure 4.5. Distribution of the cations forming the fouling material.

Fouling material analysis showed that over half of the metal ion distribution (54 percent) is formed by cations which are known to have inverted solubility (calcium, iron, and magnesium). Previous research efforts found in the literature obtained similar fouling composition when analyzing the fouling material accumulated on the quartz sleeves (Blatchley et al., 1996; Gehr \& Sehnaoui, 2001; Lin et al., 1999a). Such studies indicated that fouling material was mostly found in an inorganic form with high concentrations of metals salts known to have inverted solubility. The fact that over half of the ions forming the fouling material have inverted solubility lead to the hypothesis that the majority of the fouling material was accumulated onto the sleeves through a heat-induced precipitation mechanism due to the temperature difference experienced at the quartz sleeve-water interface.

A picture of a fouled quartz sleeve and a clean one is shown in Figure 4.6 to compare the difference between the two. The picture was taken at the end of C14. 


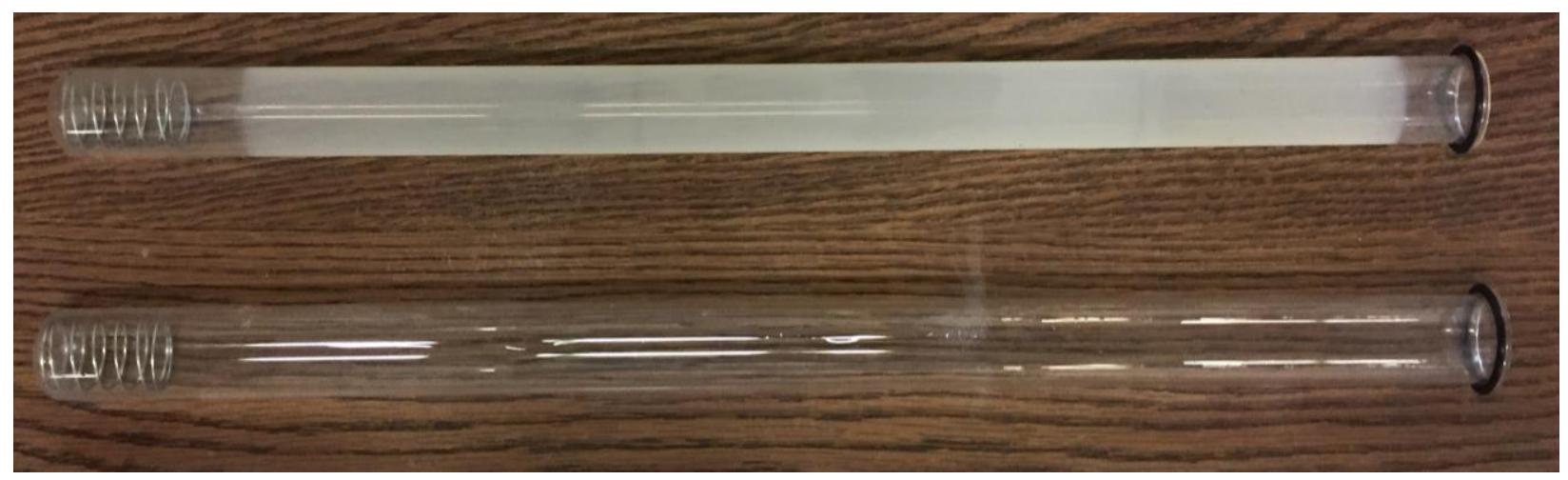

Figure 4.6. Visual comparison between fouled and clean quartz sleeve at the end of C14.

As seen in Figure 4.6, the majority of the fouling material is accumulated on the middle section of the quartz sleeve, also known as the irradiated section. Similar observations have been found in other research efforts. Previous studies found that fouling material deposited under a heat-induced precipitation mechanism tends to accumulate on the irradiated zone of the quartz sleeves (Lin et al., 1999b). Visual inspection of the quartz sleeves support the hypothesis that heat-induced precipitation may have been the main fouling mechanism facilitating the accumulation of fouling material on the quartz sleeves.

\subsubsection{Impact of Temperature on Fouling Formation}

To test the hypothesis that majority of fouling was caused by heat-induced precipitation of metal salts, water was allowed to flow through the pilot unit while the lamps were turned off during a full cycle. By turning the lamps off, the temperature experienced in the quartz sleeve-water interface should be the same as the temperature of the water flowing through the unit and no fouling caused by heat-induced precipitation should occur. To allow proper measurements of the intensity through the quartz sleeves, the UV lamps were turned on when an intensity reading was required (every 24 hours). C15 was used to measure the behavior of the UV intensity when the 
quartz sleeves were at the same temperature than the water. C15 took place in between August $15^{\text {st }}$ and August $20^{\text {th }}$ of 2016 . C15 was run with a flow rate of 25 gpm. Operational conditions such as water temperature and influent water quality parameters for C15 are shown in Table 4.5.

Table 4.5. Operational conditions for C15.

\begin{tabular}{|c|c|c|c|}
\hline Parameter & $\mathbf{8 / 1 6 / 2 0 1 6}$ & $\mathbf{8 / 1 8 / 2 0 1 6}$ & Average \\
\hline Water Temperature $\left({ }^{\circ} \mathrm{C}\right)$ & 21.8 & 21.2 & 21.5 \\
\hline COD $(\mathrm{mg} / \mathrm{L})$ & 46.0 & 48.0 & 47.0 \\
\hline TSS $(\mathrm{mg} / \mathrm{L})$ & 22.3 & 15.0 & 18.7 \\
\hline Turbidity $(\mathrm{NTU})$ & 12.4 & 9.1 & 10.7 \\
\hline UVT $(\%)$ & 53.2 & 53.7 & 53.5 \\
\hline Total Iron $(\mathrm{mg} / \mathrm{L})$ & 0.9 & 0.7 & 0.78 \\
\hline $\mathrm{pH}$ & 7.1 & 7.0 & 7.0 \\
\hline
\end{tabular}

Similar to previous intensity monitoring efforts, a reading of the intensity was obtained before and after cleaning the sensor. Intensity data collected before and after cleaning the sensor was used to measure the intensity loss associated to quartz sleeve fouling and sensor fouling separately. Such intensity measurements for this particular cycle are shown in Table 4.6.

Table 4.6. Comparison of intensity loss associated to sleeve fouling and sensor fouling for C15.

\begin{tabular}{|c|c|c|c|c|}
\hline Time & $\begin{array}{c}\text { UV Intensity } \\
\text { before sensor } \\
\text { cleaning }\end{array}$ & $\begin{array}{c}\text { UV Intensity } \\
\text { after sensor } \\
\text { cleaning }\end{array}$ & $\begin{array}{c}\text { Cum. Intensity Loss } \\
\text { due to Sensor } \\
\text { Fouling }\end{array}$ & $\begin{array}{c}\text { Cum. Intensity Loss } \\
\text { due to Sleeve } \\
\text { Fouling }\end{array}$ \\
\hline (Hours) & $\left(\mathrm{mW} / \mathrm{cm}^{2}\right)$ & $\left(\mathrm{mW} / \mathrm{cm}^{2}\right)$ & $\left(\mathrm{mW} / \mathrm{cm}^{2}\right)$ & $\left(\mathrm{mW} / \mathrm{cm}^{2}\right)$ \\
\hline 0 & 14.45 & 14.65 & 0.00 & 0.00 \\
\hline 22 & 13.09 & 13.62 & 0.53 & 1.03 \\
\hline 45 & 11.58 & 12.15 & 1.10 & 2.50 \\
\hline 68 & 11.30 & 12.19 & 1.99 & 2.46 \\
\hline 90 & 11.38 & 11.97 & 2.58 & 2.68 \\
\hline
\end{tabular}


Based on the data displayed in Table 4.6, it could be concluded that the sensor's lens and the quartz sleeves fouled at similar rates when the lamps were turned off. However, as discussed in Section 4.1.3, the sensor's lens fouled at a much slower rate than the quartz sleeves when the lamps were turned on. The different fouling rates experienced when the lamps were on was caused by the heat released from the UV lamps. When the lamps are on, the quartz of the sleeves and the quartz of the sensor will be at a higher temperature than the water flowing through the reactor. However, since the quartz sleeves are much closer to the source of UV light than the sensor's lens, the quartz of the sleeves were subjected to much higher temperatures. Taking into consideration that over half of the metal salts forming the fouling material were deposited through a heat-induced precipitation mechanism, more fouling material will deposit on the quartz sleeves than the sensor since the quartz sleeves are at a higher temperature than the sensor which results in a larger amount of intensity lost due to quartz sleeve fouling than to sensor fouling for the same hours of operation. The intensity data recorded after cleaning the sensor for C15 is shown in Figure 4.7.

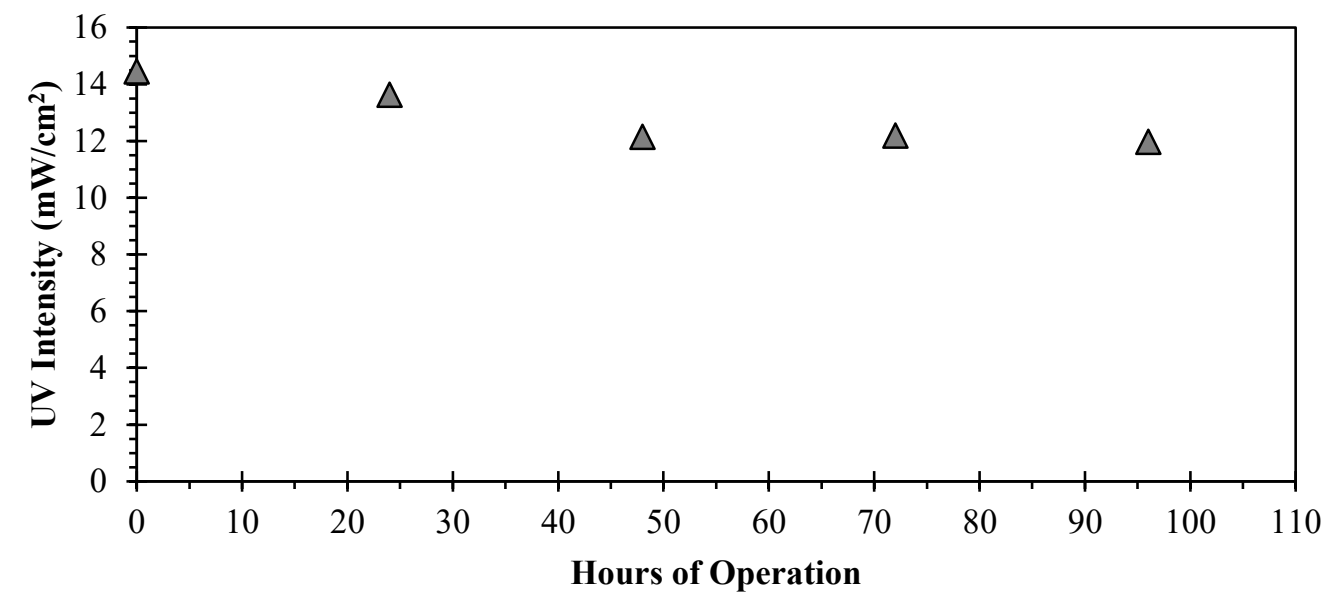

Figure 4.7. UV intensity behavior for C15. 
As seen in Figure 4.7, the intensity loss through the quartz sleeves occurred at a much slower rate in comparison to C13, when the lamps were on (Figure 4.4). Additionally, the exponential intensity drop suffered when the lamps were on was not experienced when the lamps were off. This conclusion coincides with the work done by Lin (et al. 1999a). In their studies, Lin (et al. 1999a) concluded that the intensity was lost at a slower rate when the temperature of the sleeves decreased. Intensity readings collected during C13 and C15 are shown in Figure 4.8. Intensity readings displayed in Figure 4.8 have been normalized to facilitate comparison between cycles.

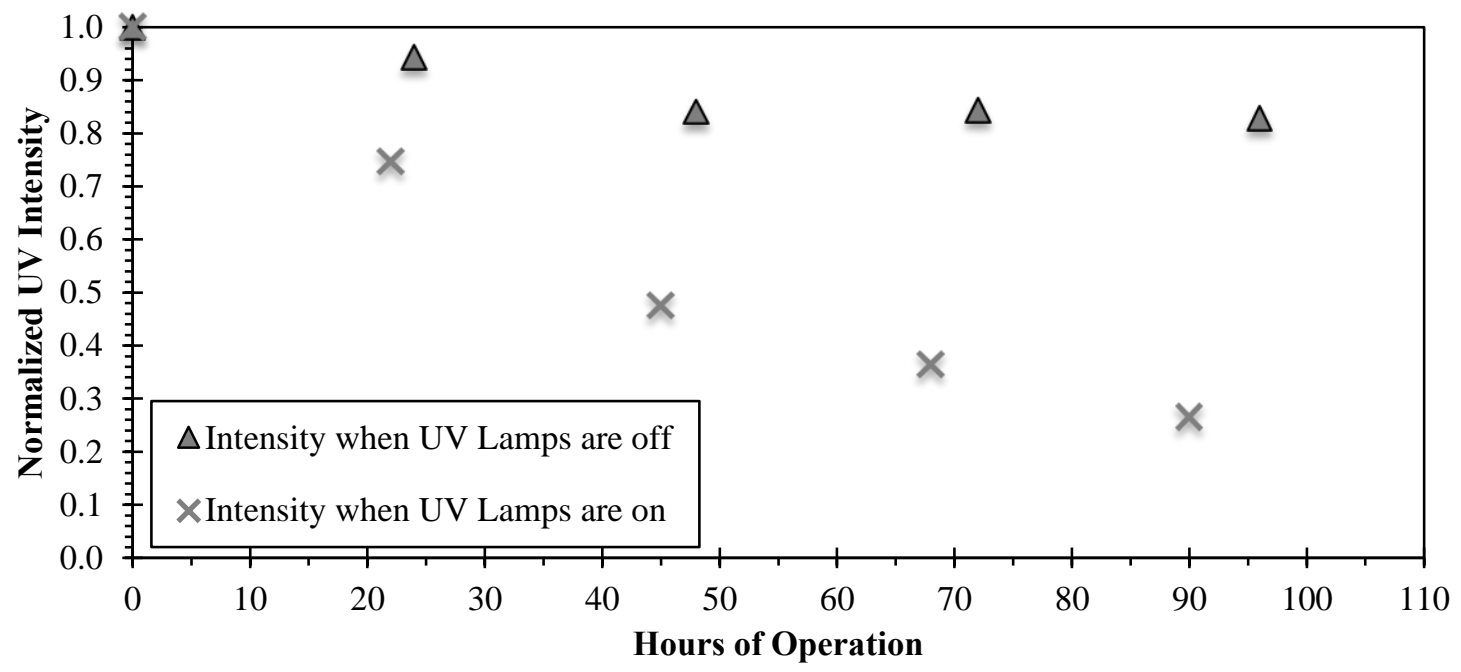

Figure 4.8. Intensity behavior with UV lamps off versus on.

The two cycles displayed in Figure 4.8 were ran at the same flow rate and experienced similar water qualities (see Tables 4.4 and 4.5 for water quality comparison between cycles). Meaning, that although both cycles did not take place simultaneously, the only difference between both sets of intensity data is the temperature that the quartz sleeves experienced. As seen in Figure 
4.8, such temperature difference experienced between the cycles resulted in an additional $57 \%$ loss of intensity through the quartz sleeves by the end of the cycle when the lamps were on.

Similar to C14, a visual inspection of the quartz sleeves was performed at the end of the cycle when the lamps were off $(\mathrm{C} 15)$. A picture of a fouled quartz sleeve and a clean one is shown in Figure 4.9 to compare the difference between the two. A picture of the fouled quartz sleeve (top sleeve in the figure) and the clean one taken at the end of C15 is shown in Figure 4.9.

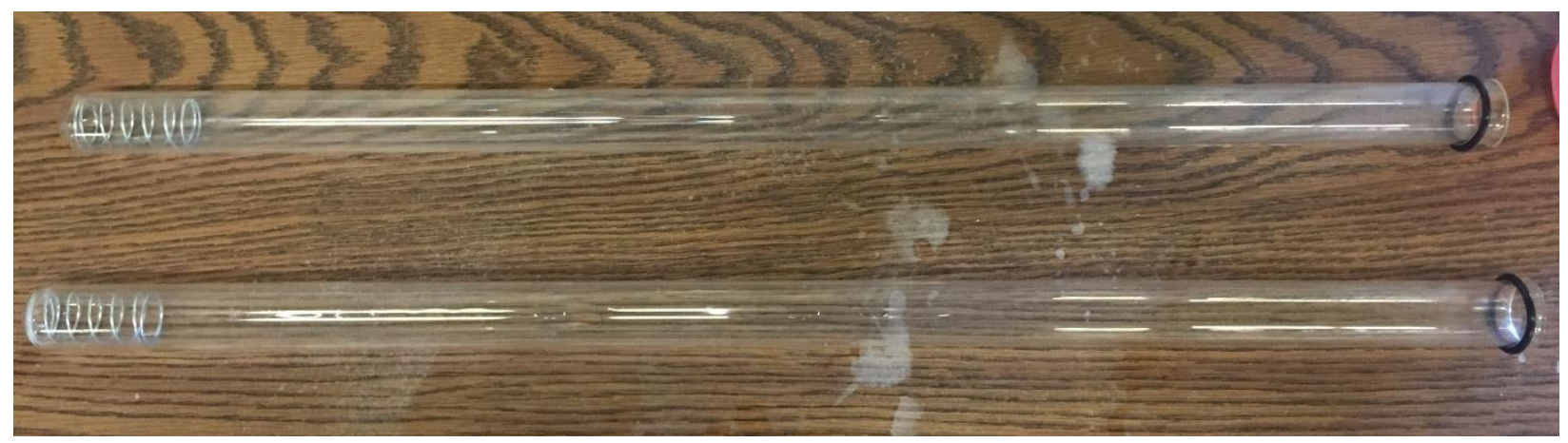

Figure 4.9. Visual comparison between fouled and clean quartz sleeve at the end of C15.

Unlike when the lamps were on, the fouling material accumulated on the surface of the quartz sleeves when the lamps were off was evenly distributed across the entire sleeve, not just located on the irradiated section of the quartz sleeves. Although fouling material accumulation on the quartz sleeves was significantly reduced by decreasing their operating temperature, fouling material was still found on the quartz sleeves at the end of C15. Indicating, that while heat-induced precipitation may be the main fouling mechanism, it is not the only mechanism facilitating fouling material accumulation in the UV system at the Fargo WWTP. 


\subsubsection{Model Simulation of Intensity Loss and Impact of Flow Rate and UVT}

The following sections address the development of a model to simulate the UV intensity drop in the pilot system and to determine the sleeve fouling rate under different operational conditions.

\subsubsection{Model Development}

The Beer-Lambert law was modified to simulate UV intensity loss due to accumulation of fouling materials on the quartz sleeves over time. As mentioned in Section 2.3, the Beer-Lambert law states that the absorbance of light in a homogeneous solution is directly proportional to the length of the sample and the concentration of the solution in which the light passes through. A mathematical representation of the Beer-Lambert law is shown in Equation 2.1. Using the definition of absorbance (shown in Section 2.4) the Beer-Lambert law can be re-written as follows.

$$
\begin{gathered}
A=\ln \left(\frac{I_{o}}{I}\right)=\varepsilon L c \\
I=I_{o} e^{-(\varepsilon L c)}
\end{gathered}
$$

Where $A$ represents the degree of absorbance of the UV intensity as UV light travels through the medium; $I_{o}$ is the incident light intensity to the medium and $I$ is the exiting light intensity of the medium; $L$ is the path length, which was treated as a constant since the distance between the quartz sleeves and the intensity sensor remained unchanged in the pilot system; $\varepsilon$ is the molar extinction coefficient of the absorbing material which was also considered to be a constant since fouling material or materials that cause UV attenuation were considered not changed; and $\mathrm{c}$ is the concentration of the solution. Because most of the UV intensity loss over a period of pilot system operation is caused by accumulation of fouling materials on the quartz 
sleeves over time, $\mathrm{c}$ is treated as amount of fouling material on the quartz sleeves. It is further assumed that fouling material accumulation on the quartz sleeves occurred at a constant rate, or $c=k^{\prime} t$. With the above mentioned conditions and assumptions, Equation 4.2 can be rewritten as,

$$
I=I_{o} e^{-(k t)}
$$

Where,

$\mathrm{t} \quad=$ Time of operation (hours)

$\mathrm{k} \quad=\varepsilon L k^{\prime}=$ rate constant of intensity loss caused by fouling material (hours ${ }^{-1}$ )

As explained in Section 4.1.3, the quartz sleeves and the intensity sensor foul at different rates when the lamps are on. Because of that, the model developed to explain the intensity behavior caused by combined fouling must account for the different intensity loss rates originated from quartz sleeve and sensor fouling. The different intensity loss rates were accounted by adding separate terms to Equation 4.3 representing the rate of intensity attenuated by fouling accumulated onto the sensor and onto the quartz sleeves. The model accounting for the different intensity loss rates originated from the two different types of fouling is shown in Equations 4.4.

$$
\begin{gathered}
\qquad I=I_{0}\left(e^{-\left(k_{\text {sleeve }} t\right)} \times e^{-\left(k_{\text {sensor }} t^{\prime}\right)}\right) \\
k_{\text {sleeve }}=\text { Intensity loss rate constant for quartz sleeve fouling }\left(\text { hours }^{-1}\right) \\
k_{\text {sensor }}=\text { Intensity loss rate constant for sensor's lens fouling }\left(\text { hours }^{-1}\right)
\end{gathered}
$$

The parameter $t$ in Equation 4.4 was used to represent the time elapsed between quartz sleeve cleanings and $t^{\prime}$ was the time elapsed between intensity sensor cleanings. At the beginning of every cycle both $t$ and $t$ ' were set to zero since both the sensor and the quartz sleeves are cleaned. 
As water flows through the pilot unit, $t$ increased cumulatively since the quartz sleeves were never cleaned while the cycle is taking place. However, the parameter $t^{\prime}$ was zeroed every time the intensity sensor's lens was cleaned.

Several steps were taken prior to modeling a full cycle displaying intensity behavior caused by combined fouling. Before modeling combined fouling, the principles put forth by the BeerLambert law were used to model the intensity behavior caused by quartz sleeve fouling and sensor fouling separately. Upon modeling the intensity data, the potential impacts of flow rate and UVT on the rates of intensity loss obtained were studied by developing relationship between the intensity loss rates and UVT and/or flow rate. By doing that, one can study the individual impacts of flow rate and UVT on the $k_{\text {sleeve }}$ and the $k_{\text {sensor }}$ prior to attempting modeling combined fouling. Sections 4.1.6.2 and 4.1.6.3 introduce the steps taken and the results obtained when modeling $k_{\text {sleeve }}$ and the $k_{\text {sensor }}$ individually. Lastly, 4.1.6.4 applies to knowledge gained when

modeling $k_{\text {sleeve }}$ and the $k_{\text {sensor }}$ individually to a full set of intensity data affected by combined fouling.

\subsubsection{Model Simulation to determine $\mathbf{k}_{\text {sleeve }}$}

The data used to model the intensity drop caused by quartz sleeve fouling corresponds to the cycles whose intensity readings were taken right after cleaning the sensor. The duration, average flow rate and average UVT conditions of these cycles are displayed in Table 4.7. Flow for each cycle was monitored through the plant's SCADA system. Additionally, water quality was monitored by collecting grab samples from the influent water to the pilot unit and analyzing them for UVT while the cycles were running. The cycles that suffered from significant water quality 
variations while the intensity data was being recorded were excluded from modeling. No UVT data was recorded while C22 took place.

Table 4.7. Operational conditions for cycles 16 through 23.

\begin{tabular}{|c|c|c|c|c|}
\hline \multirow{2}{*}{$\begin{array}{c}\text { Cycle } \\
\text { Number }\end{array}$} & \multicolumn{2}{|c|}{ Duration } & Flow & UVT \\
\cline { 2 - 5 } & $\mathrm{mm} / \mathrm{dd}-\mathrm{mm} / \mathrm{dd}$ & Hours & gpm & $\%$ \\
\hline C16 & $08 / 01-08 / 05$ & 90 & 25.3 & 55.6 \\
\hline C17 & $08 / 29-09 / 02$ & 93 & 26.5 & 53.0 \\
\hline C18 & $09 / 06-09 / 09$ & 69 & 34.8 & 54.3 \\
\hline C19 & $09 / 09-09 / 14$ & 116 & 11.4 & 54.7 \\
\hline C20 & $09 / 19-09 / 23$ & 87 & 17.2 & 53.3 \\
\hline C21 & $09 / 23-09 / 27$ & 86 & 27.1 & 52.7 \\
\hline C22 & $09 / 29-10 / 03$ & 82 & 34.4 & - \\
\hline C23 & $10 / 04-10 / 09$ & 107 & 11.2 & 52.5 \\
\hline
\end{tabular}

It is important to note that during the 8 cycles displayed in Table 4.7 , the intensity data was recorded both before cleaning the sensor and after cleaning the sensor. However, since this section is attempting to model quartz sleeve fouling, only the intensity data collected after cleaning the sensor was used for modeling purposes. Since the intensity data used for this particular modeling effort was only collected after cleaning the sensor, the data will not be affected by sensor's lens fouling. Because of that, the expression of the Beer-Lambert law shown in Equation 4.4 can be simplified since $k_{\text {sensor }}$ is equal to zero (simplification shown in Equation 4.5).

$$
I=I_{0} e^{-\left(k_{\text {sleeve }} t\right)}
$$

The intensity data collected for the eight cycles displayed in Table 4.7 was simulated using Equation 4.5 by adjusting $I_{o}$ and $k_{\text {sleeve }}$ using a non-linear least squares procedure. The target 
function used for model calibration was the following: $\min \Sigma\left(I_{(\text {experimental data })}-I_{(\text {model })}\right)^{2}$. The intensity data collected after cleaning the sensor for the cycles displayed in Table 4.7 can be found in Appendix B, Table B.1. Modeling results of the impact of quartz sleeve fouling on UV intensity loss are shown in Figures 4.10 through 4.17. The root-mean-square error (RMSE) and the coefficient of variation of RMSE (CVRMSE) for the cycles shown in Figures 4.10 through 4.17 can be found in Table Appendix B, Table B.2. The RMSE represents the sample's standard deviation of the difference between the modeled results and the experimental data and the CVRMSE represents the coefficient of variation of the RMSE. The CVRMSE was calculated to facilitate comparison between data sets. Both parameters can be used to evaluate the accuracy of the model when explaining the experimental results.

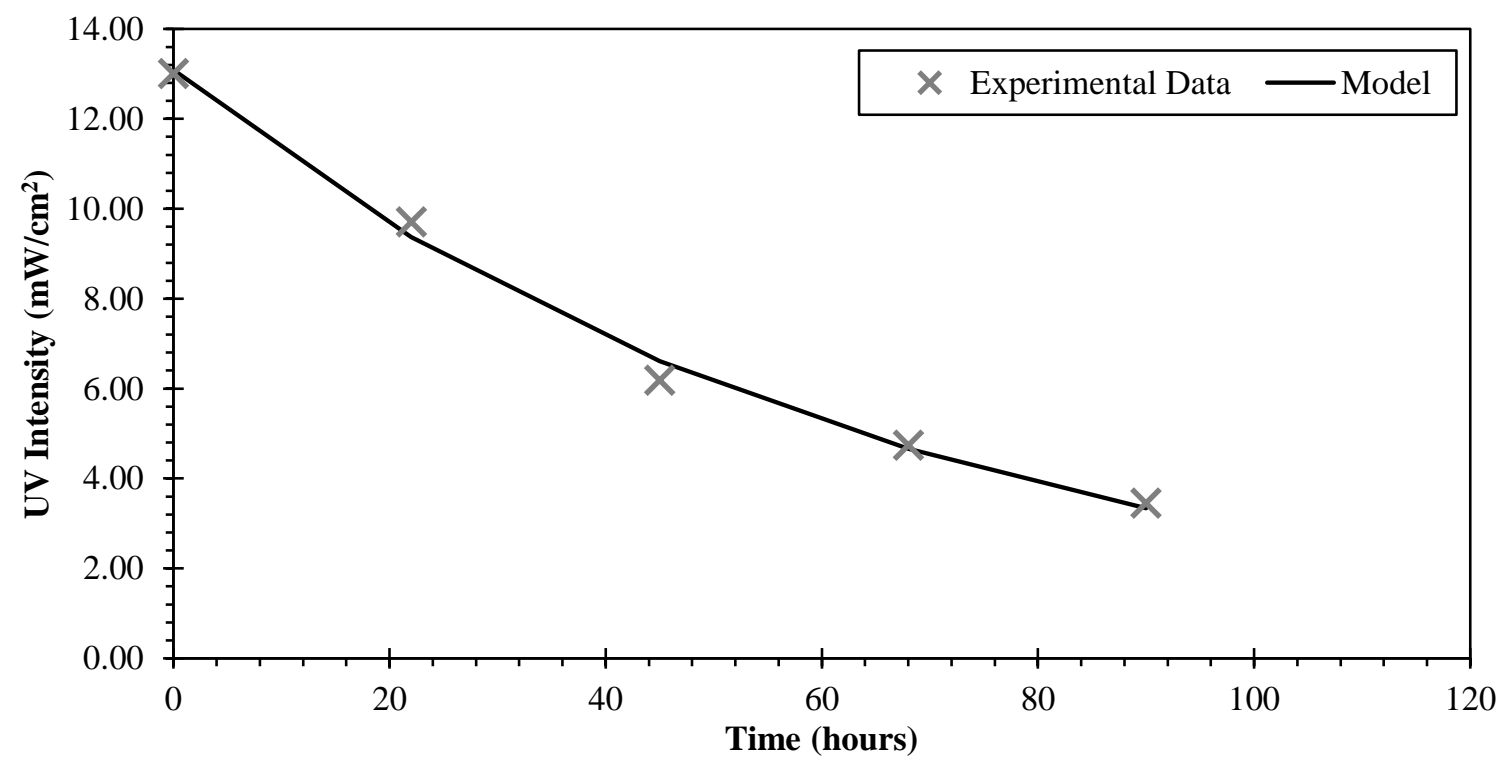

Figure 4.10. Modeled UV intensity data collected after cleaning the sensor's lens during C16. 


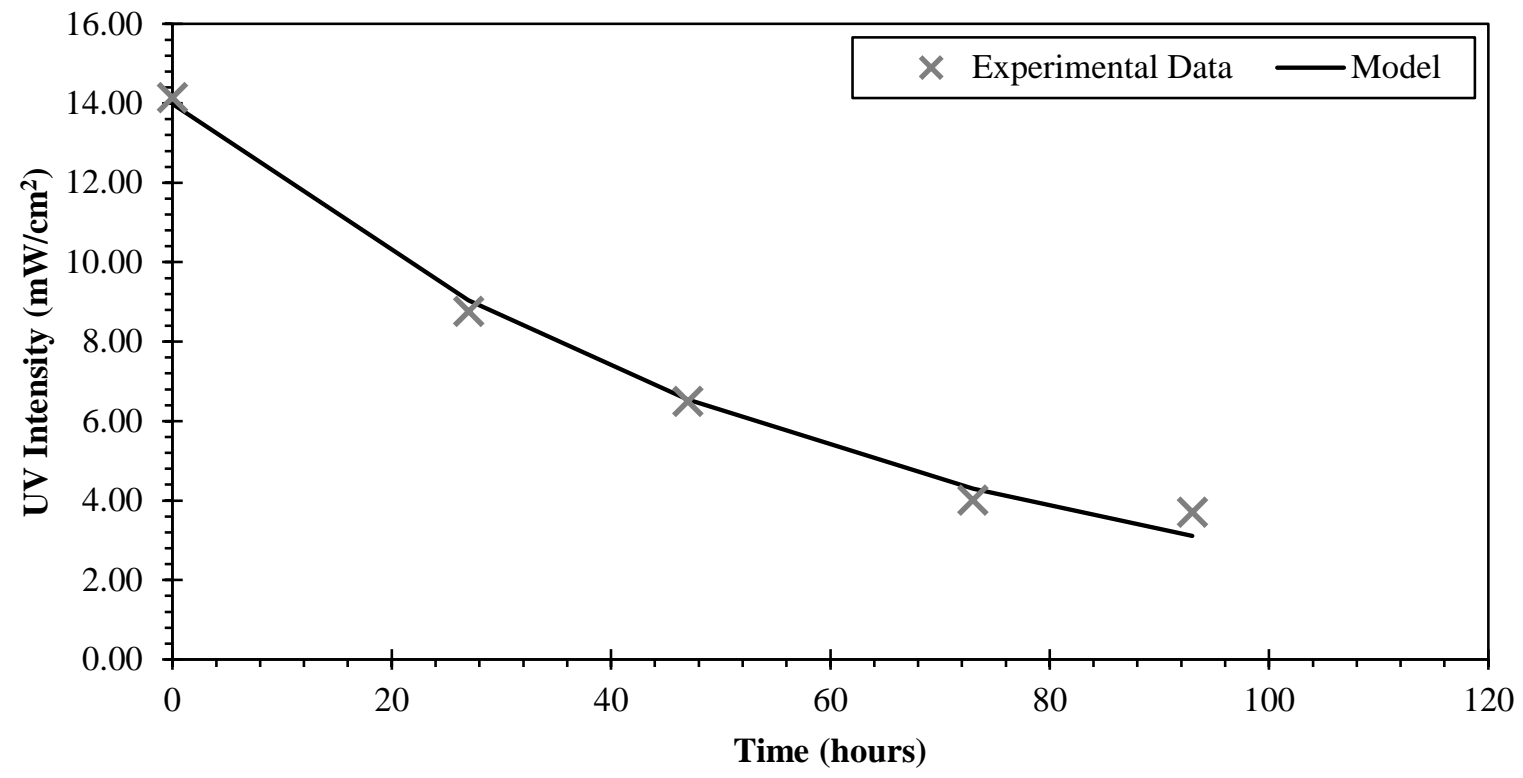

Figure 4.11. Modeled UV intensity data collected after cleaning the sensor's lens during C17.

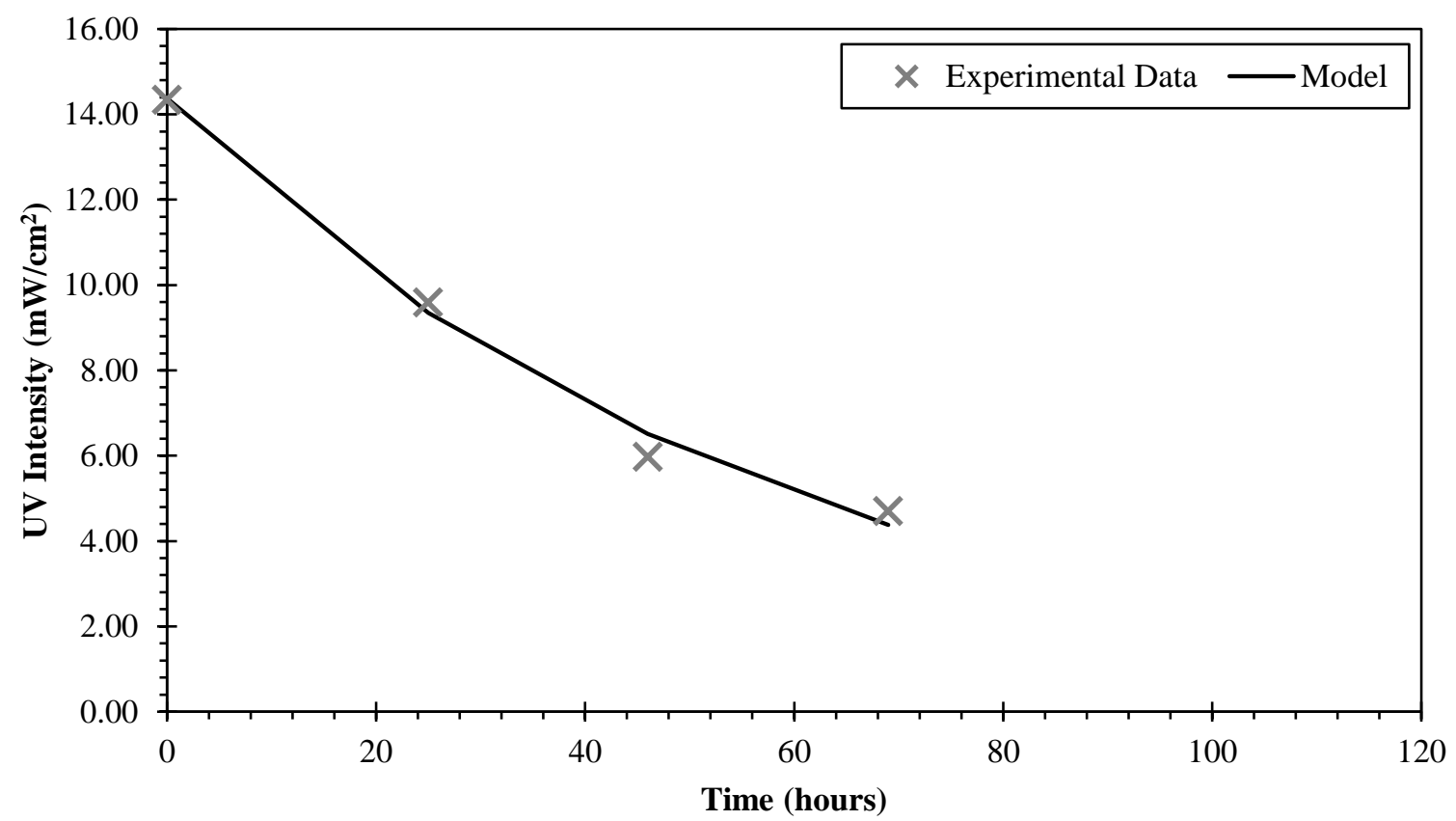

Figure 4.12. Modeled UV intensity data collected after cleaning the sensor's lens during C18. 


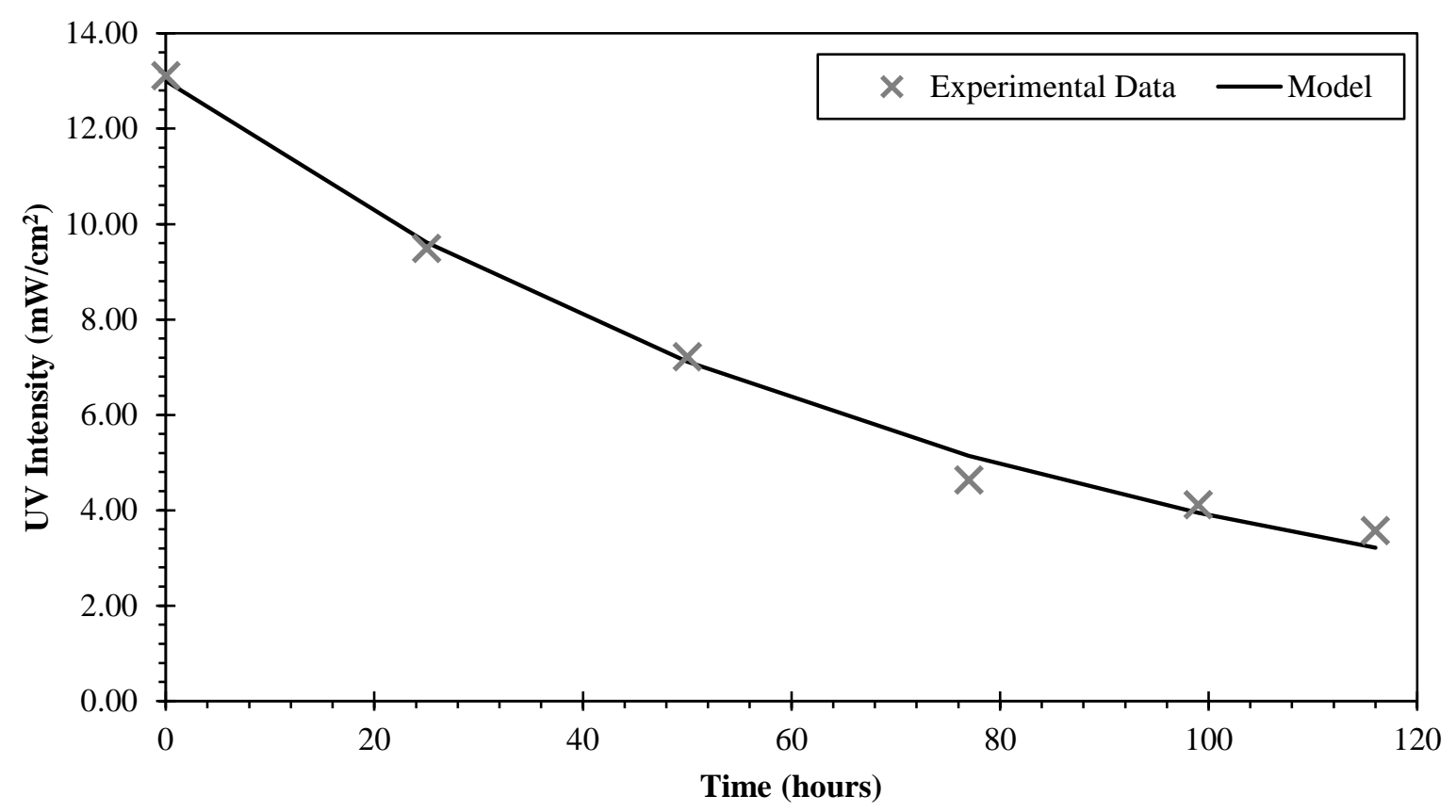

Figure 4.13. Modeled UV intensity data collected after cleaning the sensor's lens during C19.

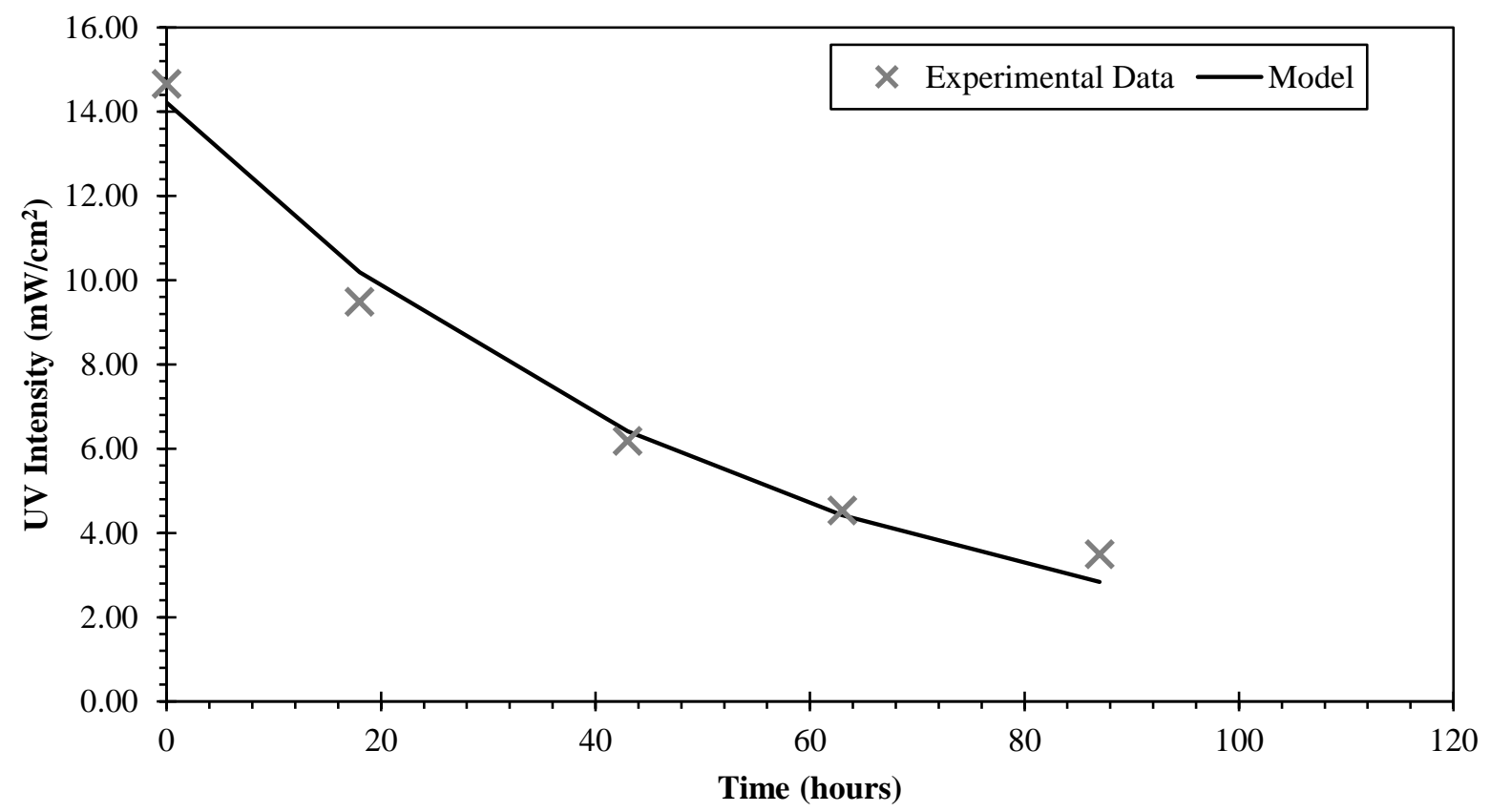

Figure 4.14. Modeled UV intensity data collected after cleaning the sensor's lens during C20. 


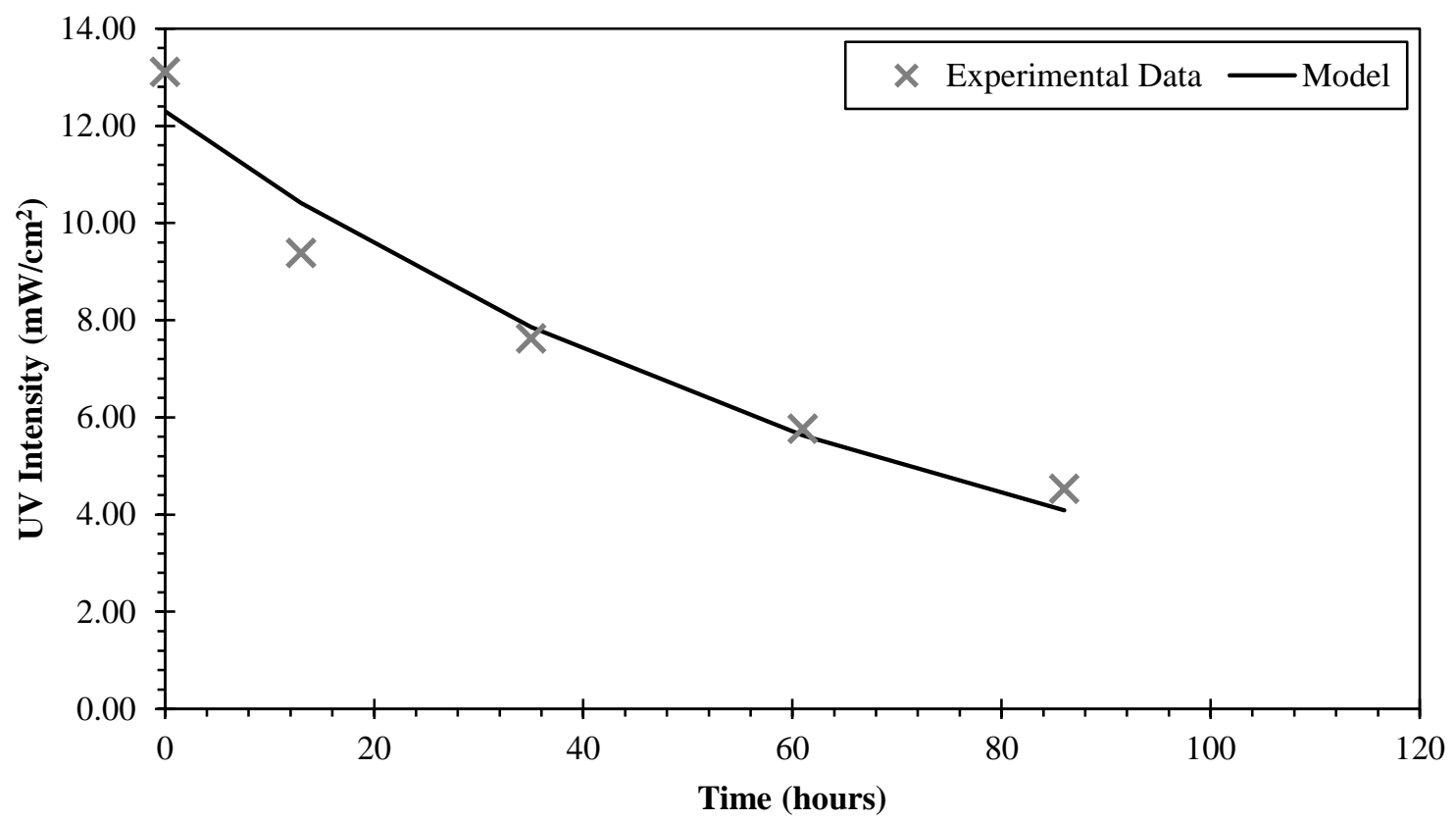

Figure 4.15. Modeled UV intensity data collected after cleaning the sensor's lens during C21.

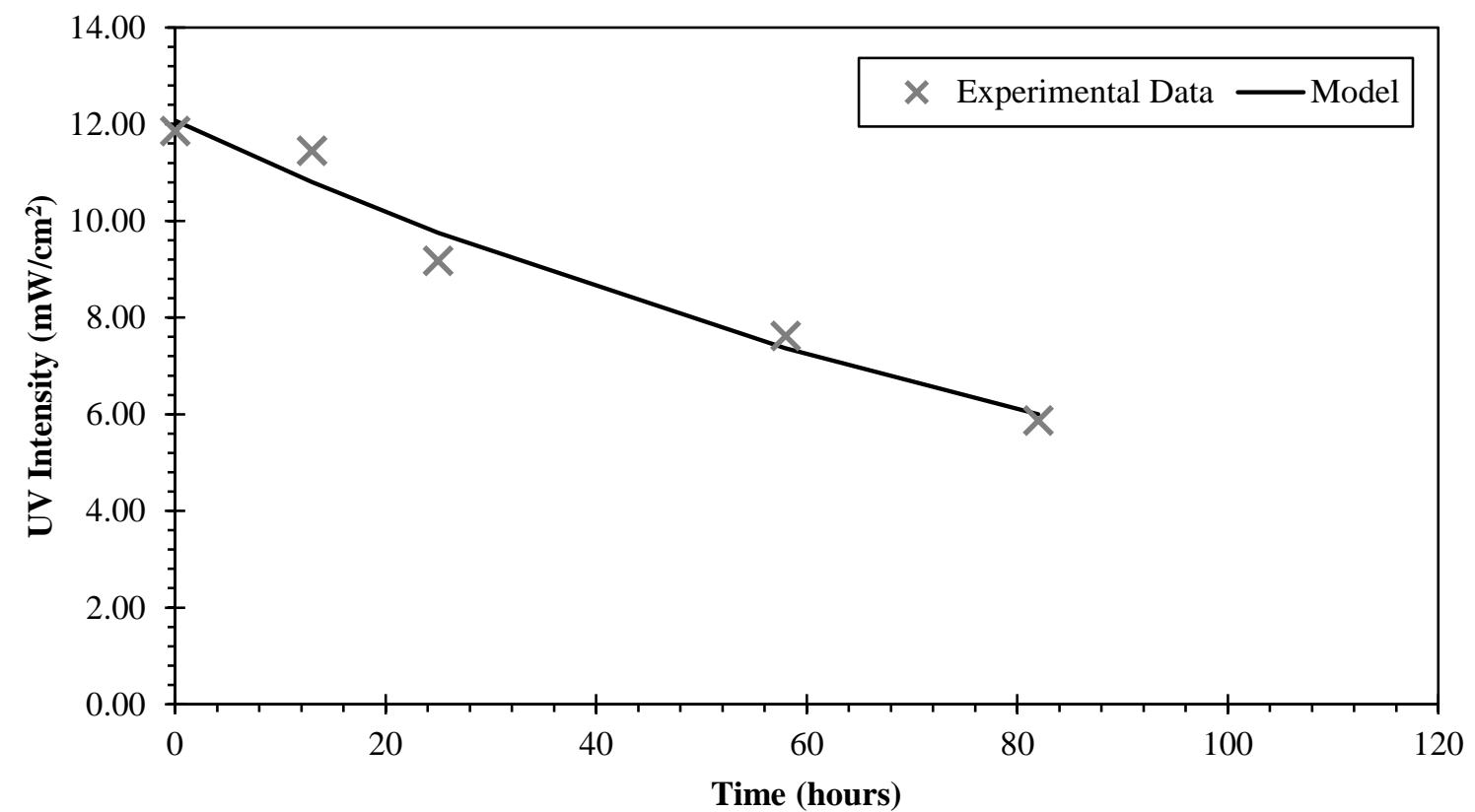

Figure 4.16. Modeled UV intensity data collected after cleaning the sensor's lens during C22. 


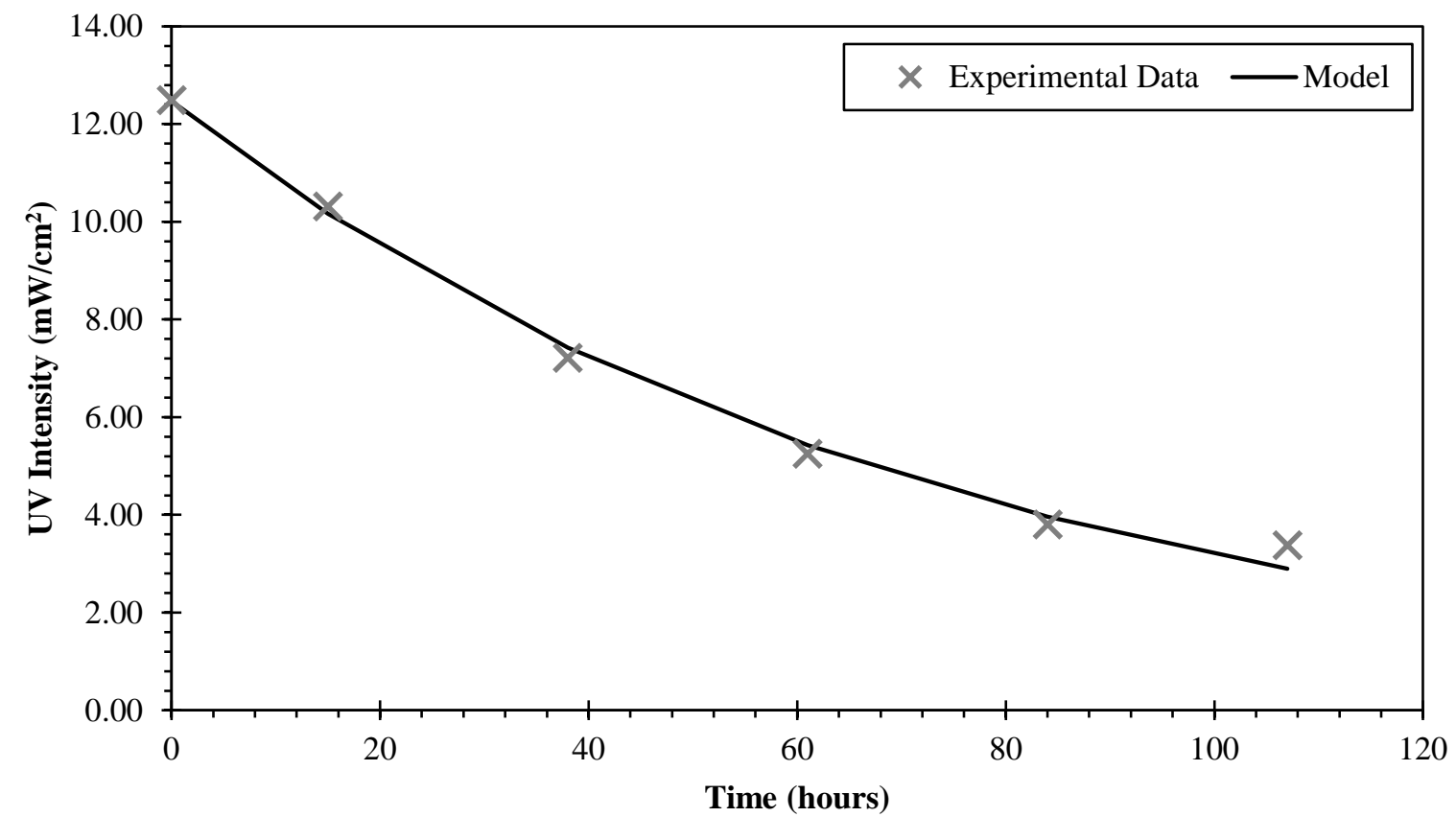

Figure 4.17. Modeled UV intensity data collected after cleaning the sensor's lens during C23.

As seen in Figures 4.10 through 4.17, the modified Beer-Lambert law, Equation 4.5, successfully explains the intensity attenuated over time caused by quartz sleeve fouling. The fact that the model is successful at explaining the experimental data verifies the assumption that fouling material accumulates at a constant rate onto the surface of the quartz sleeves. This deduction agrees with the findings of by Lin et al. (1999b). Based on a study of buildup of fouling materials on the quartz sleeves, Lin et al. (1999b) found that the fouling material deposited on the quartz sleeves followed a zero-order accumulation. The $k_{\text {sleeve }}$ values obtained for the modeled cycles are displayed in Table 4.8 . 
Table 4.8. $k_{\text {sleeve }}$ obtained from modeling cycles $16-23$.

\begin{tabular}{|c|c|} 
Cycle & $\mathbf{k}$ (sleeve) \\
\cline { 2 - 2 } Number & hours $^{-1}$ \\
\hline C16 & 0.0152 \\
\hline C17 & 0.0162 \\
\hline C18 & 0.0172 \\
\hline C19 & 0.0120 \\
\hline C20 & 0.0185 \\
\hline C21 & 0.0128 \\
\hline C22 & 0.0085 \\
\hline C23 & 0.0136 \\
\hline
\end{tabular}

Single-parameter linear relationships were developed between flow, UVT, and the $k_{(\text {sleeve })}$ to study the impact flow rate and UVT on the rate of intensity loss caused by quartz sleeve fouling for each cycle. The relationships developed between flow, UVT, and the $k_{\text {sleeve }}$ obtained from modeling are shown in Figures 4.18 and 4.19.

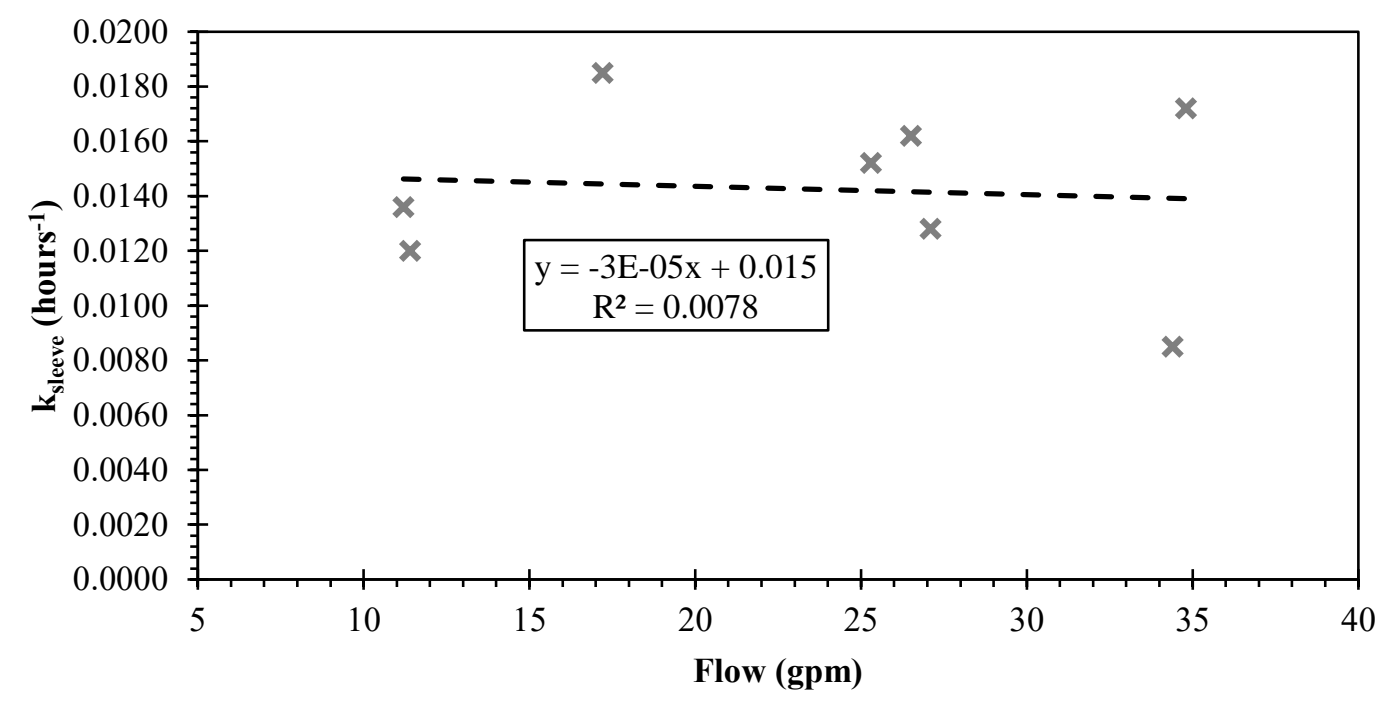

Figure 4.18. Impact of flow on $k_{\text {sleeve }}$. 


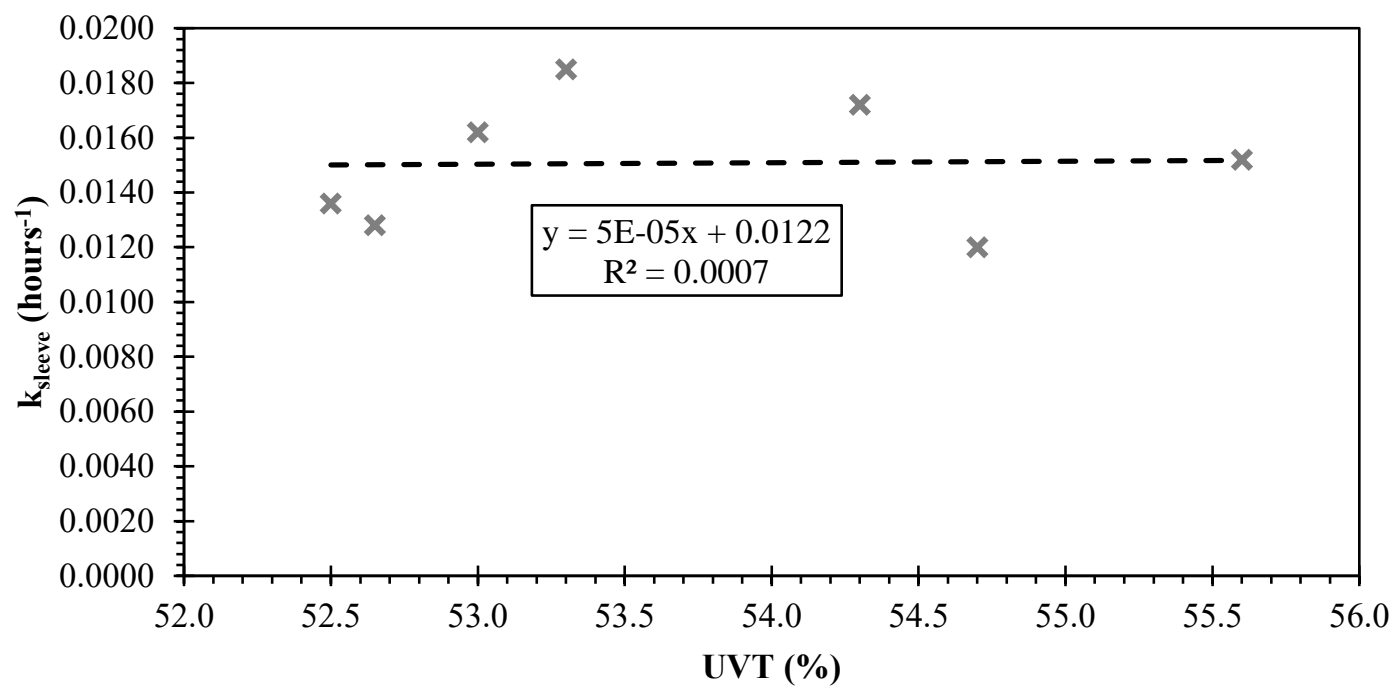

Figure 4.19. Impact of UVT on $k_{\text {sleeve }}$.

As seen in Figures 4.18 and 4.19, the behavior of $k_{\text {sleeve }}$ for each cycle is independent of flow rate and UVT for the operational conditions used during this study. Due to that, it can be said that the main fouling mechanism experienced at the Fargo WWTP (heat-induced precipitation) was also found to be independent of flow rate and UVT for the operational conditions experienced during this study. This could be due to the fact that the higher temperatures causing heat-induced precipitation may overcome the impact of flow and UVT on the intensity loss rates experienced in the sleeves. This conclusion disagrees with previous work found in the literature which indicated that UV intensity was lost at a faster rate when the concentration of the fouling causing constituents in the water increased (Sheriff \& Gehr, 2001). In their study, Sheriff \& Gehr (2001) observed that UV intensity was lost at a faster rate when dissolved iron concentrations in the treated water were increased from 1.2 to $10.8 \mathrm{mg} / \mathrm{L}$. It could be argued that the concentration of dissolved iron, one of the main contributors to fouling at the Fargo WWTP, was maintained fairly constant during the modeled cycles. Indicating that although $k_{\text {sleeve }}$ did not vary with respect with flow rate or UVT 
for this particular study, $k_{\text {sleeve }}$ may have suffered larger variations if the dissolved iron concentrations were to have varied significantly between cycles.

\subsubsection{Model Simulation to determine $\mathbf{k}_{\text {sensor }}$}

To determine $k_{\text {sensor }}$, Equation 4.4 was applied to the intensity data collected before cleaning the sensor's lens during the cycles 16 through 23 . Those same cycles were already modeled in the previous section using the intensity data collected after cleaning the sensor's lens to obtain $k_{\text {sleeve }}$. The $k_{\text {sleeve }}$ values for each modeled cycle were used to determine $k_{\text {sensor }}$. Operational parameters, such flow rate, cycle duration, and UVT for cycles 16 through 23 are shown in Table 4.7 (Section 4.1.6.3). The intensity data collected before cleaning the sensor's lens for the cycles displayed in Table 4.7 can be found in Appendix B, Table B.1. Modeling results of intensity data are shown in Figures 4.20 through 4.27. The RMSE and the CVRMSE for the cycles shown in Figures 4.20 through 4.27 can be found in Table Appendix B, Table B.2.

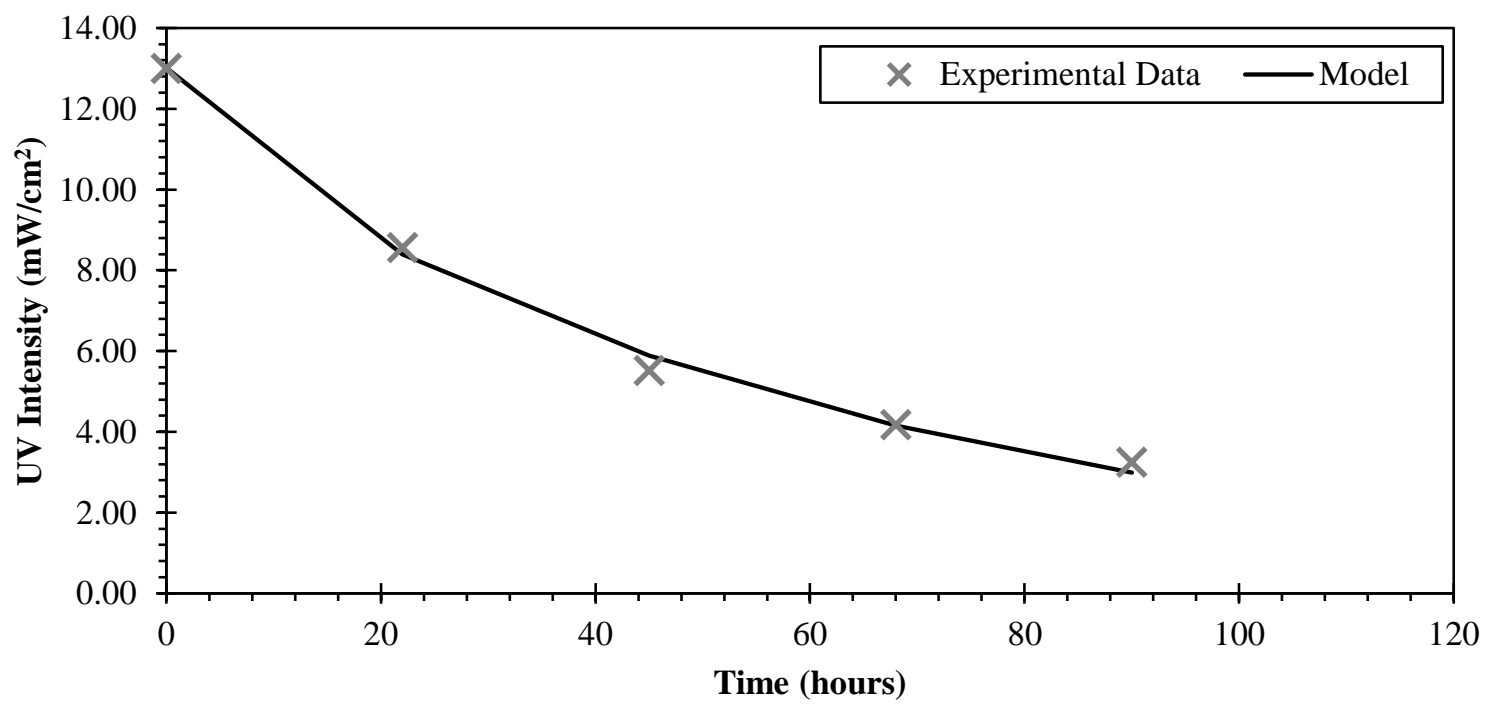

Figure 4.20. Modeled UV intensity data collected before cleaning the sensor's lens during C16. 


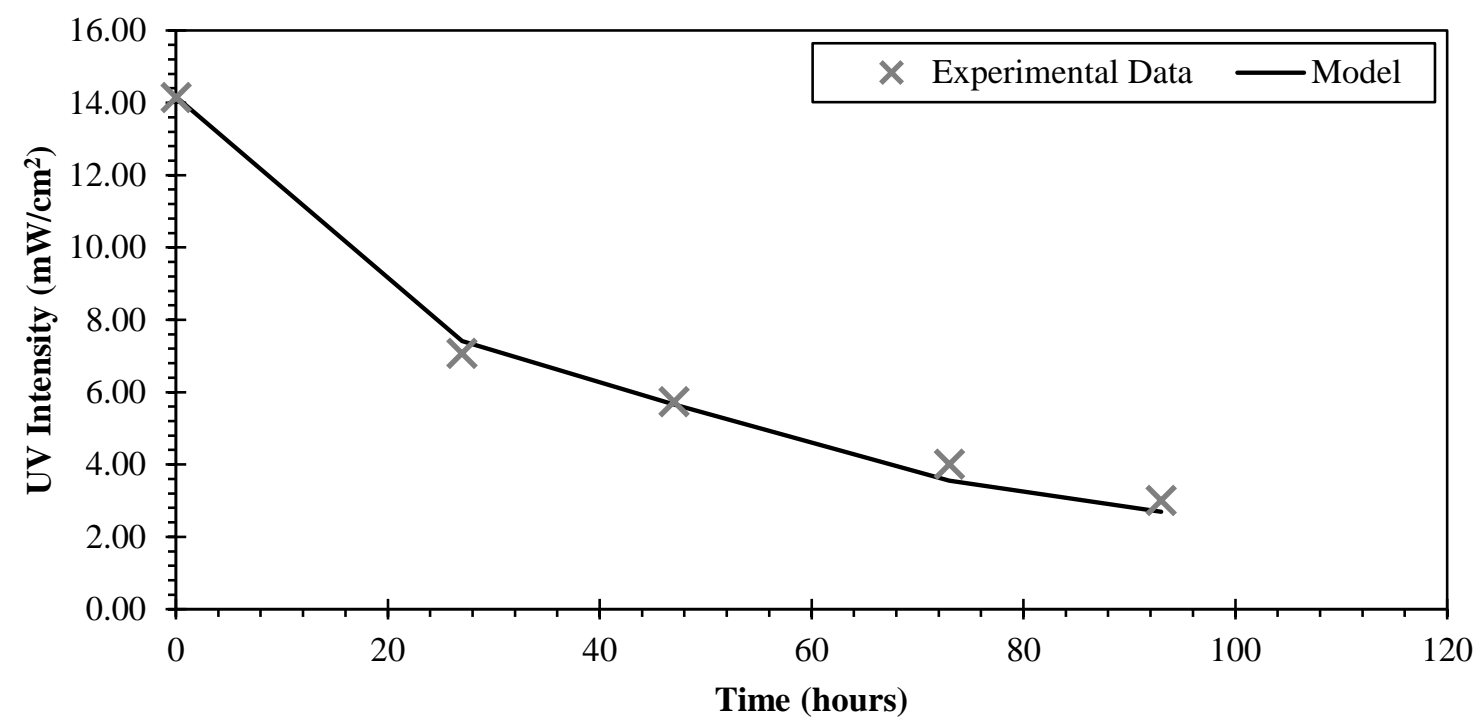

Figure 4.21. Modeled UV intensity data collected before cleaning the sensor's lens during C17.

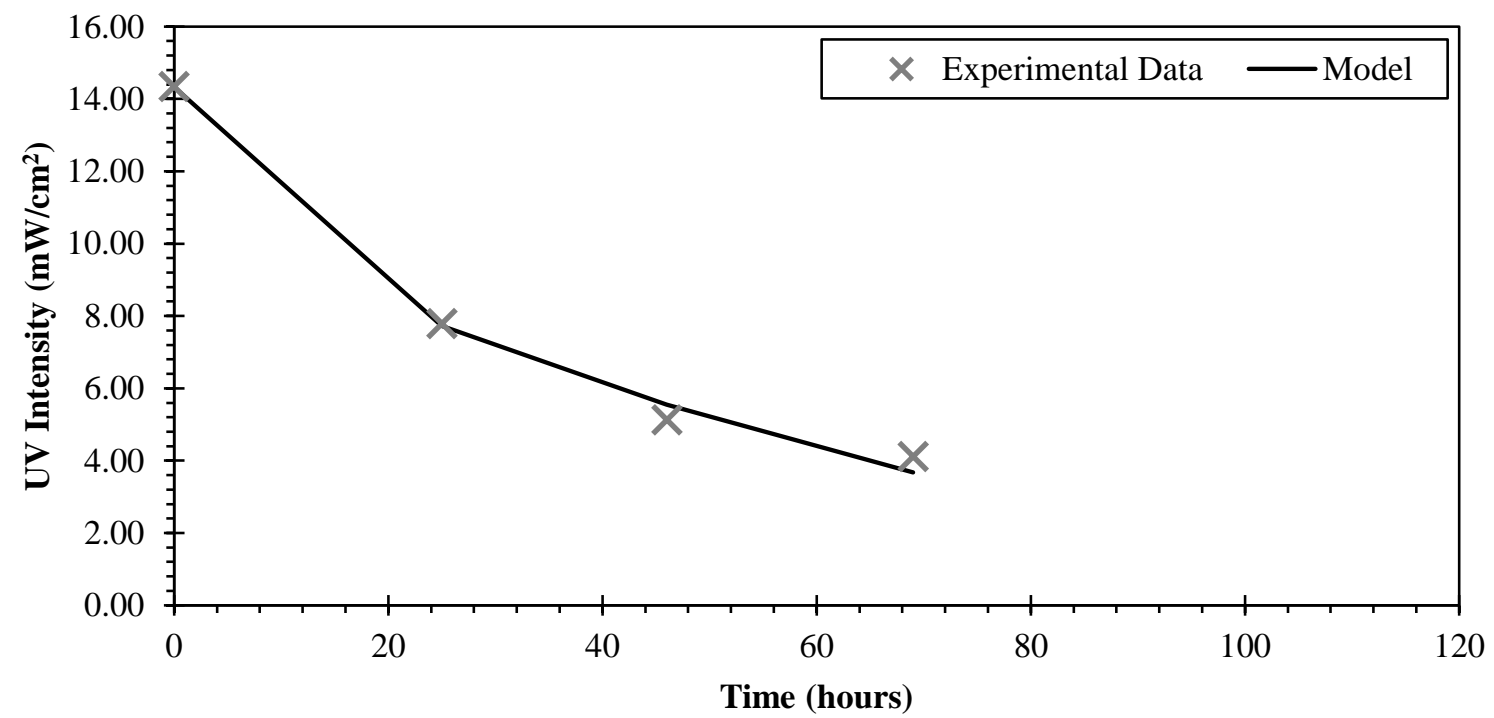

Figure 4.22. Modeled UV intensity data collected before cleaning the sensor's lens during C18. 


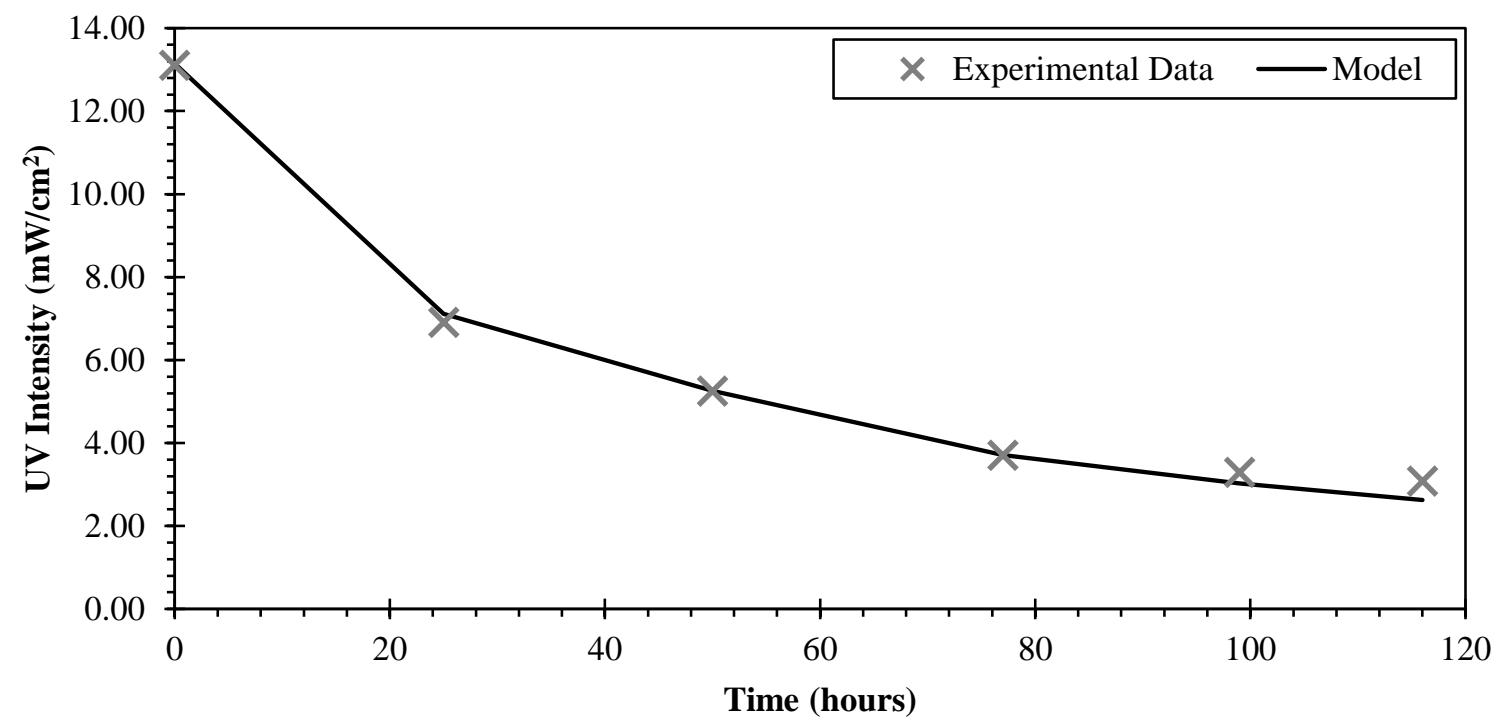

Figure 4.23. Modeled UV intensity data collected before cleaning the sensor's lens during C19.

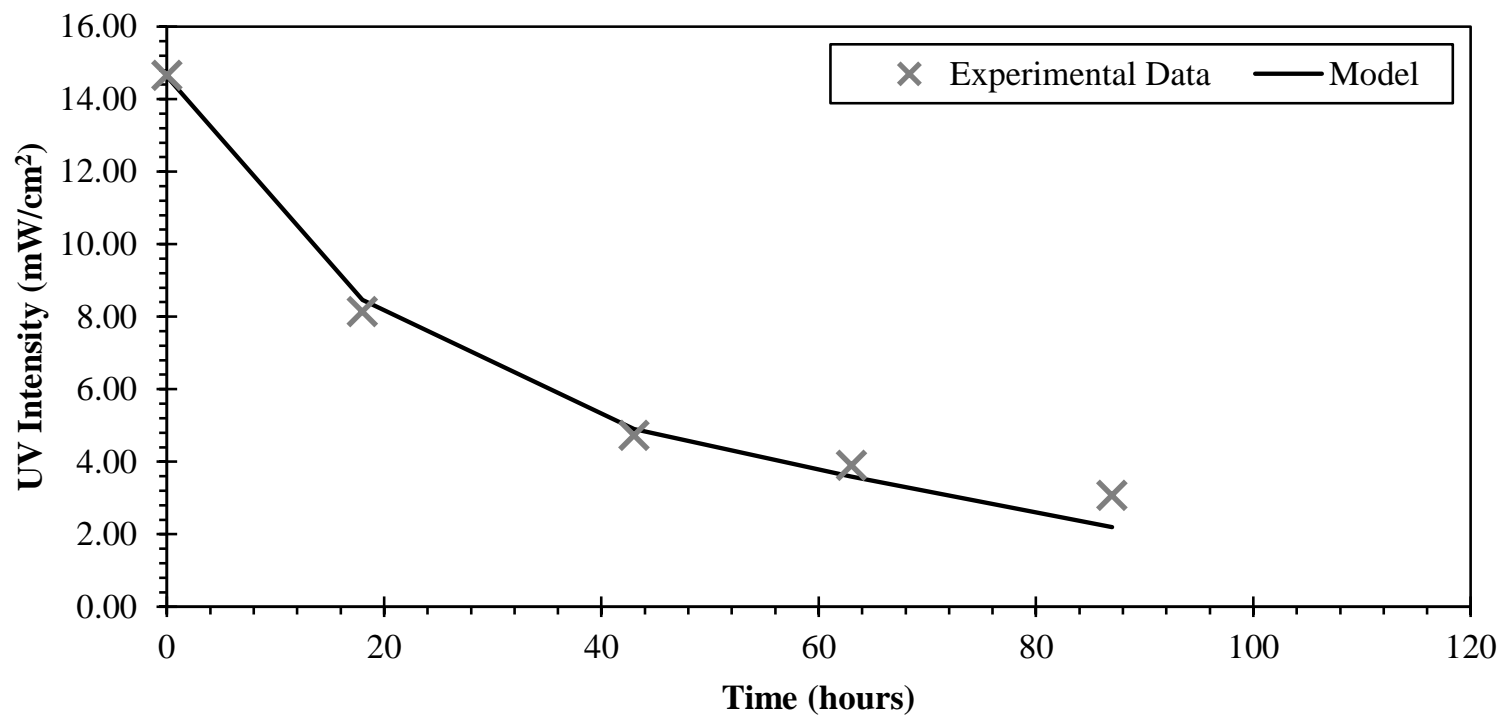

Figure 4.24. Modeled UV intensity data collected before cleaning the sensor's lens during C20. 


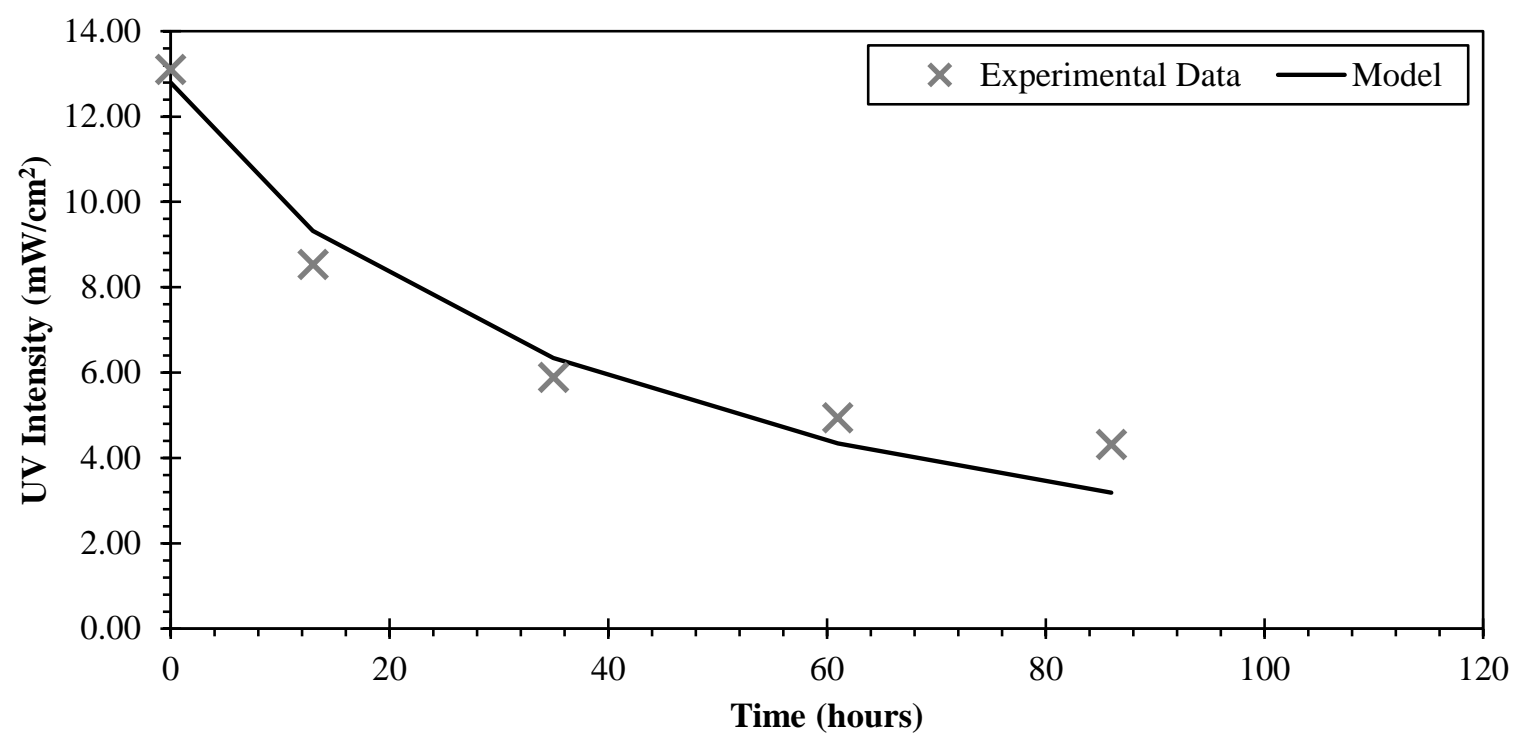

Figure 4.25. Modeled UV intensity data collected before cleaning the sensor's lens during C21.

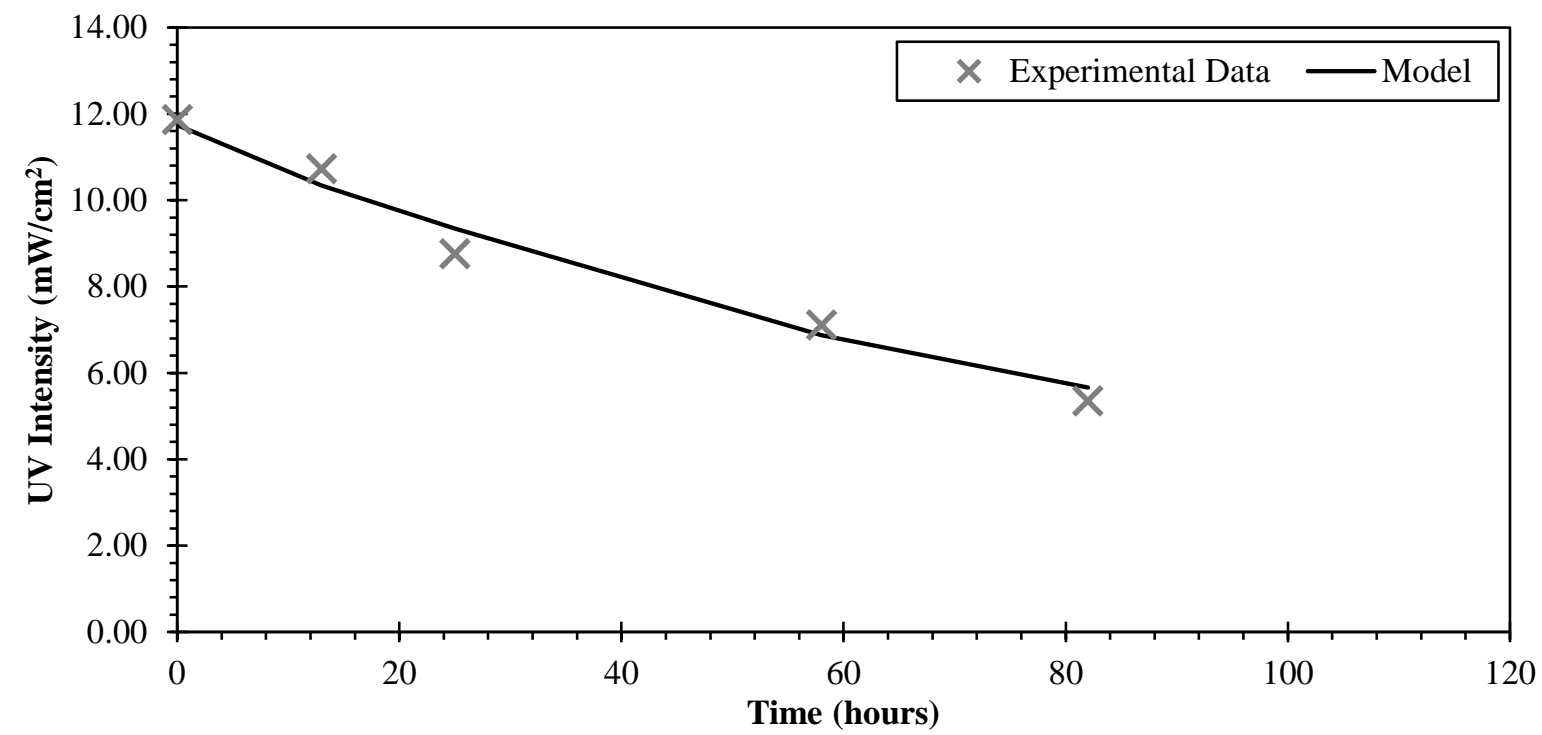

Figure 4.26. Modeled UV intensity data collected before cleaning the sensor's lens during C22. 


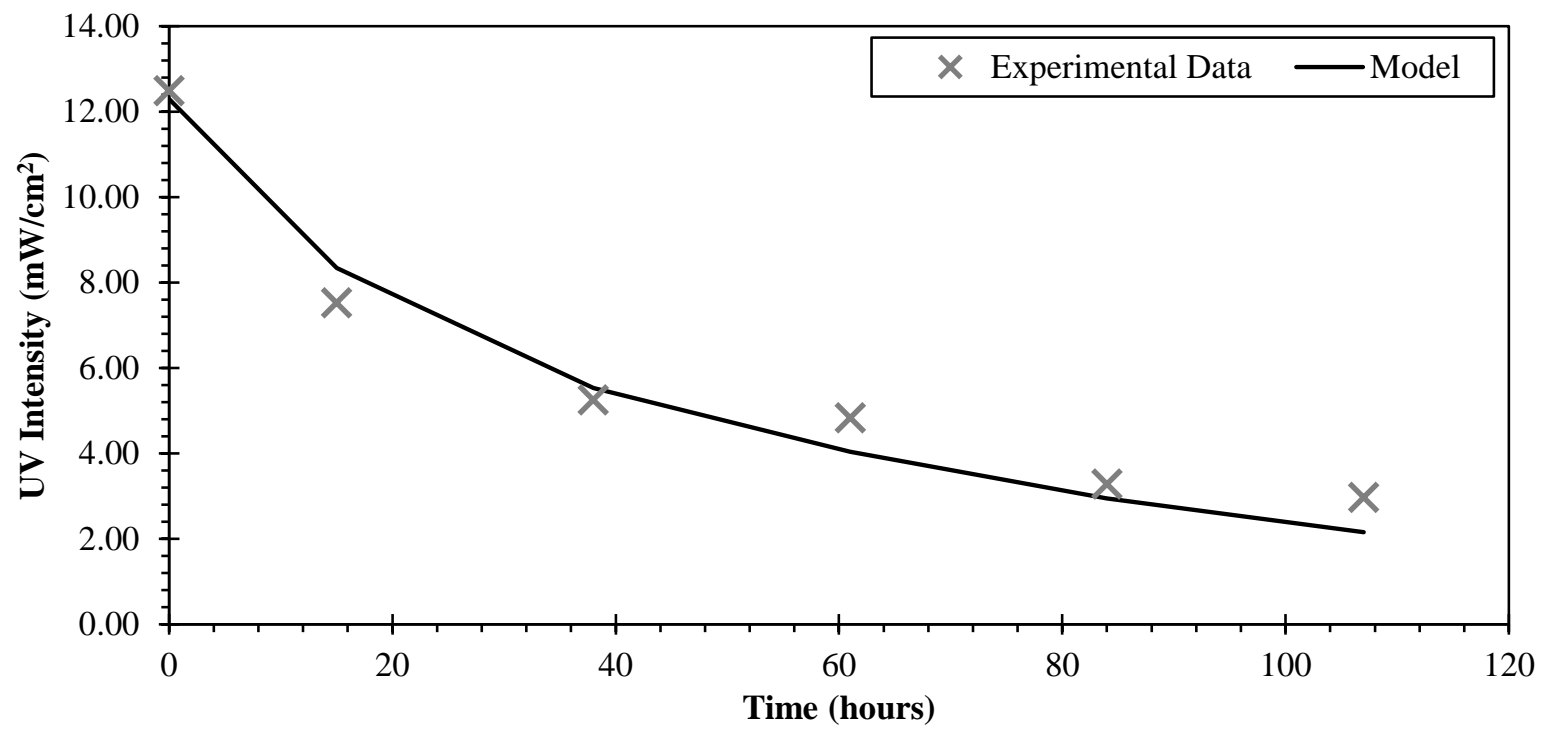

Figure 4.27. Modeled UV intensity data collected before cleaning the sensor's lens during C23.

As seen in Figures 4.20 through 4.27, the modified Beer-Lambert law, Equation 4.4, successfully explains the intensity attenuated over time caused by combined fouling. The $k_{\text {sensor }}$ values obtained for the modeled cycles are displayed in Table 4.9. As seen in Table 4.9, unlike with the $k_{\text {sleeve }}$ values obtained in the previous modeling effort, $k_{\text {sensor }}$ does suffer a significant variation from cycle to cycle.

Table 4.9. $k_{\text {sensor }}$ and $k_{\text {sleeve }}$ obtained from modeling cycles 16-23.

\begin{tabular}{|c|c|c|} 
Cycle & $\mathbf{k}$ (sleeve) & $\mathbf{k}$ (sensor) \\
\cline { 2 - 3 } Number & hours $^{-1}$ & hours $^{-1}$ \\
\hline C16 & 0.0152 & 0.0048 \\
\hline C17 & 0.0162 & 0.0078 \\
\hline C18 & 0.0172 & 0.0075 \\
\hline C19 & 0.0120 & 0.0125 \\
\hline C20 & 0.0185 & 0.0119 \\
\hline C21 & 0.0128 & 0.0116 \\
\hline C22 & 0.0085 & 0.0012 \\
\hline C23 & 0.0136 & 0.0122 \\
\hline
\end{tabular}


The intensity rate constants obtained from modeling confirmed the previous statement made in Section 4.1.3 since the values obtained for $k_{\text {sleeve }}$ are larger than the ones obtained for $k_{\text {sensor }}$ (except for C19). The statement made in Section 4.1.3 mentioned that UV intensity was lost at a faster rate through the quartz sleeves than through the intensity sensor. The fact that intensity is lost at a faster rate through the quartz sleeves means that fouling material accumulates at a faster rate onto the quartz sleeves than to the sensor's lens, which is likely to occur due to the higher temperatures experienced at the surface of the quartz sleeves when compared to the sensor.

Single-parameter linear relationships were developed between flow rate, UVT, and $k_{\text {sensor }}$ to study the impact of flow and UVT on the rate of intensity loss caused by sensor fouling. The relationships developed between flow, UVT, and the $k_{\text {sensor }}$ obtained from modeling are displayed in Figures 4.28 and 4.29.

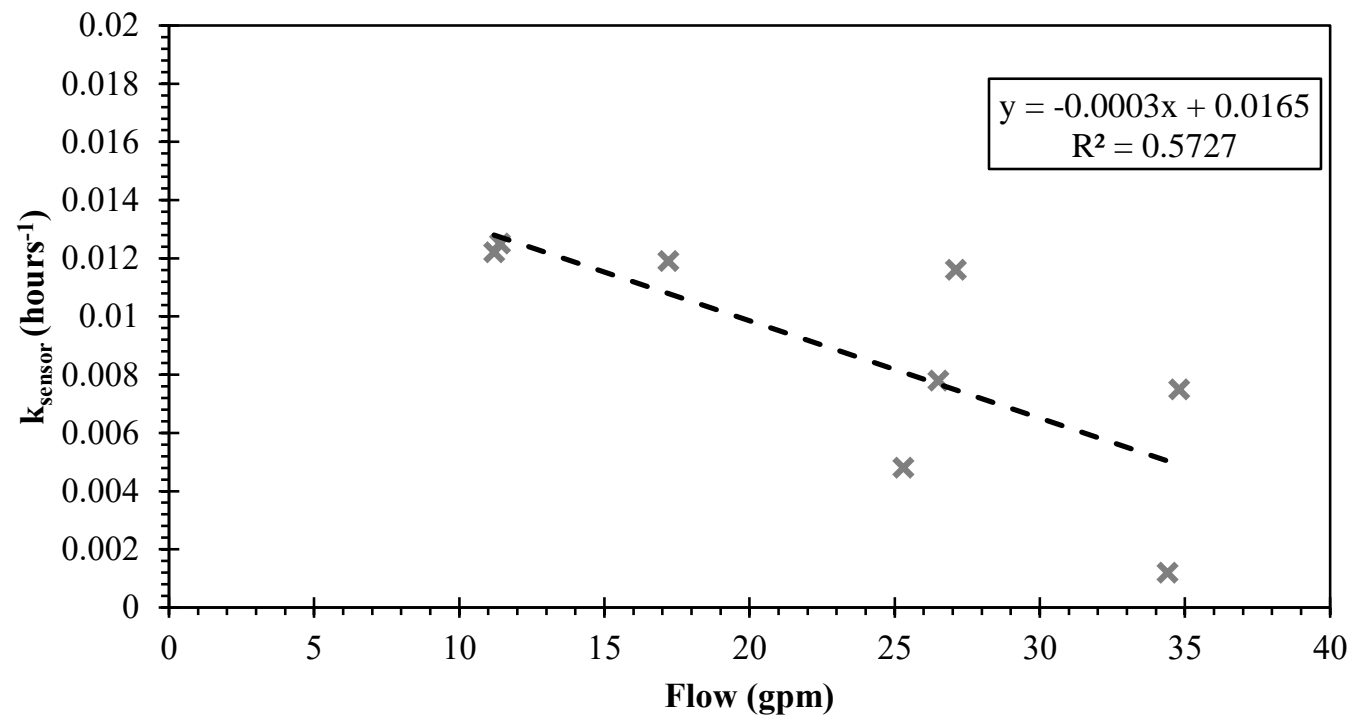

Figure 4.28. Impact of flow on $k_{\text {sensor }}$. 
As seen in Figure 4.28, the rate of intensity loss is reduced when flow is increased for the operational conditions used in this study. This phenomenon could be explained based on the degree of turbulence generated under different flow rates. Higher degree of turbulent flow may have been generated at higher flow rates. Due to that, the higher degrees of turbulent flow generated at higher flows may release some of the particles that are loosely attached to the sensor's lens. By detaching the constituents, fouling material deposited onto the sensor's lens at a slower rate when flow is increased, which translates in a decrease of the rate of intensity loss.

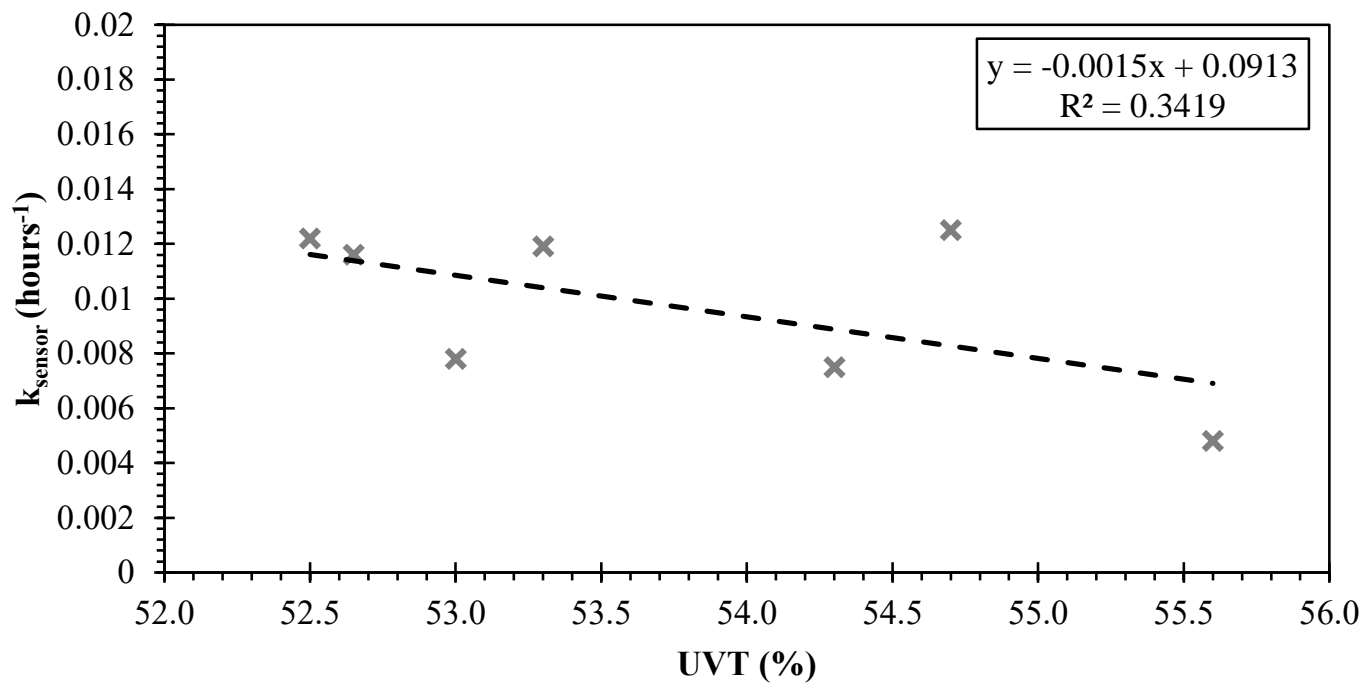

Figure 4.29. Impact of UVT on $k_{\text {sensor }}$.

As seen in Figure 4.29, the rate of intensity loss is reduced when UVT increases for the operational conditions used in this study. This phenomenon could be explained by the fact that fouling formation on the sensor's lens is a concentration dependent process since intensity is lost at a faster rate when lower UVTs are experienced. Information regarding the impact of flow rate 
and UVT on the rate of fouling material accumulation on the intensity sensor was not found in previous literature.

\subsubsection{Model Simulation of Intensity Affected by Combined Fouling}

As mentioned in Section 4.1.2 the UV intensity monitored through the SCADA system displayed combined fouling since the sensor's lens was never cleaned at any point during the cycle's duration. It was also discovered in Section 4.1.3 that the accumulation of fouling material on the quartz sleeves and the sensor's lens did not occur at the same rate. Because of that, before attempting to model the impact of combined fouling on the intensity loss, efforts were put into understanding the impact of quartz sleeve and sensor's lens fouling on the intensity loss separately. Information gained through modeling the impact of quartz sleeve and sensor's lens fouling separately was used to model the intensity loss caused by combined fouling.

The cycles whose intensity was monitored through the SCADA system and display combined fouling were used for this modeling effort. The duration, average flow rate and average UVT conditions of these cycles are displayed in Table 4.10. Flow for each cycle was monitored through the plant's SCADA system. Water quality was monitored by collecting grab samples from the influent water to the pilot unit and analyzing them for UVT while the cycles were running. The cycles that suffered from significant water quality variations while the intensity data was being recorded were excluded from modeling. 
Table 4.10. Operational conditions for cycles 24 through 30.

\begin{tabular}{|c|c|c|c|c|}
\hline \multirow{2}{*}{$\begin{array}{c}\text { Cycle } \\
\text { Number }\end{array}$} & \multicolumn{2}{|c|}{ Duration } & Flow & UVT \\
\cline { 2 - 5 } & $\mathrm{mm} / \mathrm{dd}-\mathrm{mm} / \mathrm{dd}$ & Hours & gpm & $\%$ \\
\hline C24 & $06 / 15-06 / 22$ & 168 & 16.9 & 53.7 \\
\hline C25 & $06 / 23-06 / 30$ & 167 & 26.2 & 55.6 \\
\hline C26 & $06 / 30-07 / 07$ & 144 & 25.2 & 51.2 \\
\hline C27 & $07 / 07-07 / 13$ & 144 & 23.7 & 40.8 \\
\hline C28 & $07 / 19-07 / 26$ & 166 & 33.3 & 57.2 \\
\hline C29 & $09 / 02-09 / 06$ & 91 & 30.2 & 54.3 \\
\hline C30 & $09 / 09-09 / 14$ & 120 & 34.1 & 54.7 \\
\hline
\end{tabular}

It is important to note that during the 7 cycles displayed in Table 4.10, the sensor's lens was never cleaned while the intensity data was collected. Because of that, the expression of the Beer-Lambert law shown in Equation 4.4 can be simplified since $t$ ' is equal to $t$ (simplification shown in Equations 4.6-4.8).

$$
\begin{gathered}
I=I_{0}\left(e^{-\left(k_{\text {sleeve }} t\right)} \times e^{-\left(k_{\text {sensor }} t\right)}\right) \\
I=I_{0} e^{-\left(\left(k_{\text {sleeve }}+k_{\text {sensor }}\right) \times t\right)} \\
I=I_{0} e^{-\left(k_{\text {total }} t\right)}
\end{gathered}
$$

The intensity data collected for the cycles displayed in Table 4.10 was modeled using the expression of the Beer-Lambert law shown in Equation 4.7 by adjusting $k_{\text {sleeve }}, k_{\text {sensor }}$, and $I_{o}$ using a non-linear least squares procedure. Since modeling the impact of quartz sleeve fouling on the intensity loss revealed that $k_{\text {sleeve }}$ was not affected by flow rate or UVT, it was decided to adjust a common value of $k_{\text {sleeve }}$ to all 7 cycles simultaneously. In doing this, a single value for $k_{\text {sleeve }}$ will be obtained upon modeling cycles C24 through C30. However, since modeling the impact of sensor's lens fouling on the intensity loss revealed that $k_{\text {sensor }}$ is affected by flow rate 
and UVT, it was decided to model the intensity data by adjusting $k_{\text {sensor }}$ for each individual cycle. Consequently, $k_{(t o t a l)}$ was calculated by adding the obtained values of $k_{(\text {sensor) }}$ and $k_{(\text {(sleeve) }}$ through modeling. In addition to $k_{\text {sensor }}, I_{o}$ was also adjusted for each individual cycle.

The intensity data collected during the cycles displayed in Table 4.10 can be found in Appendix B, Table B.3-B.9. Modeling results of the intensity data affected by combined fouling without sensor cleaning are shown in Figures 4.30 through 4.36. The root-mean-square error (RMSE) and the coefficient of variation of RMSE (CVRMSE) for the cycles shown in Figures 4.30 through 4.36 can be found in Table Appendix B, Table B.10.

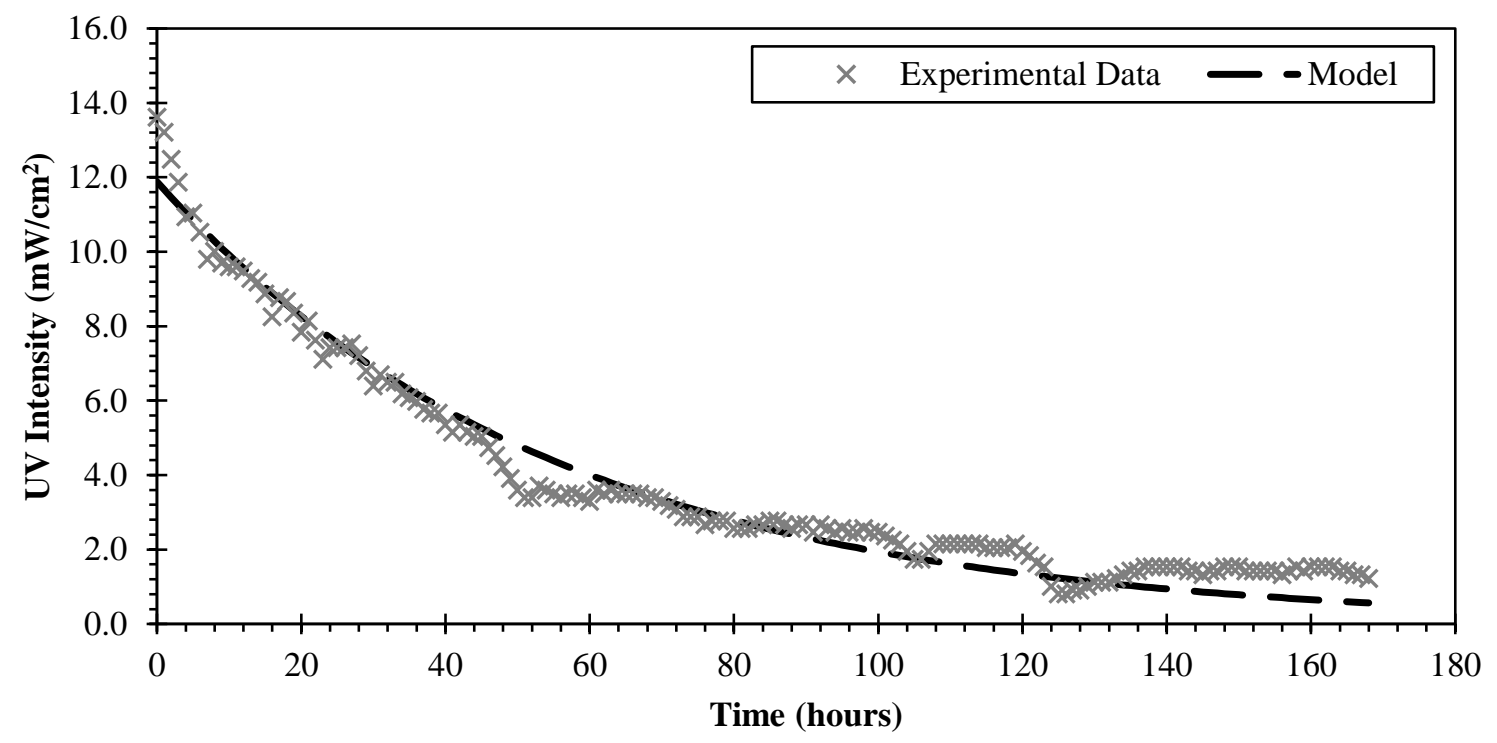

Figure 4.30. Modeled UV intensity data collected during C24. 


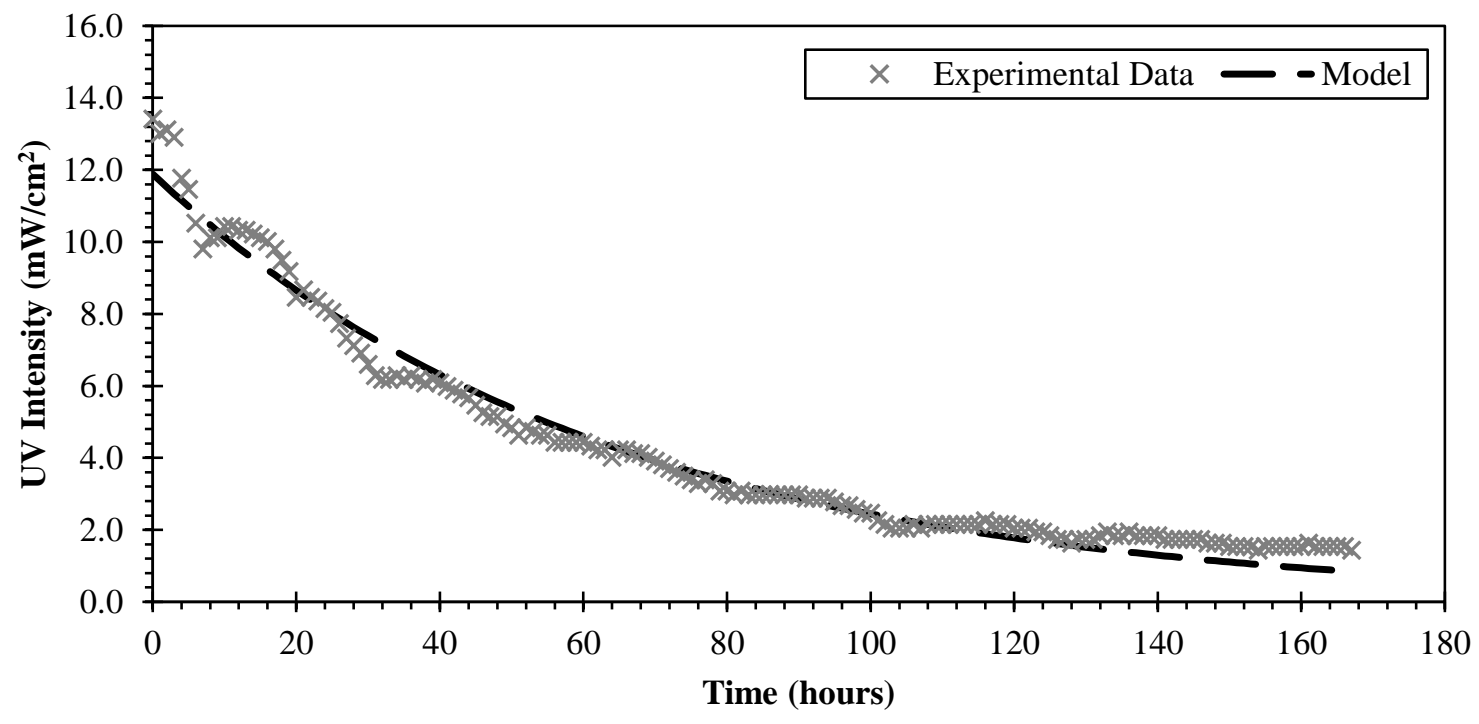

Figure 4.31. Modeled UV intensity data collected during C25.

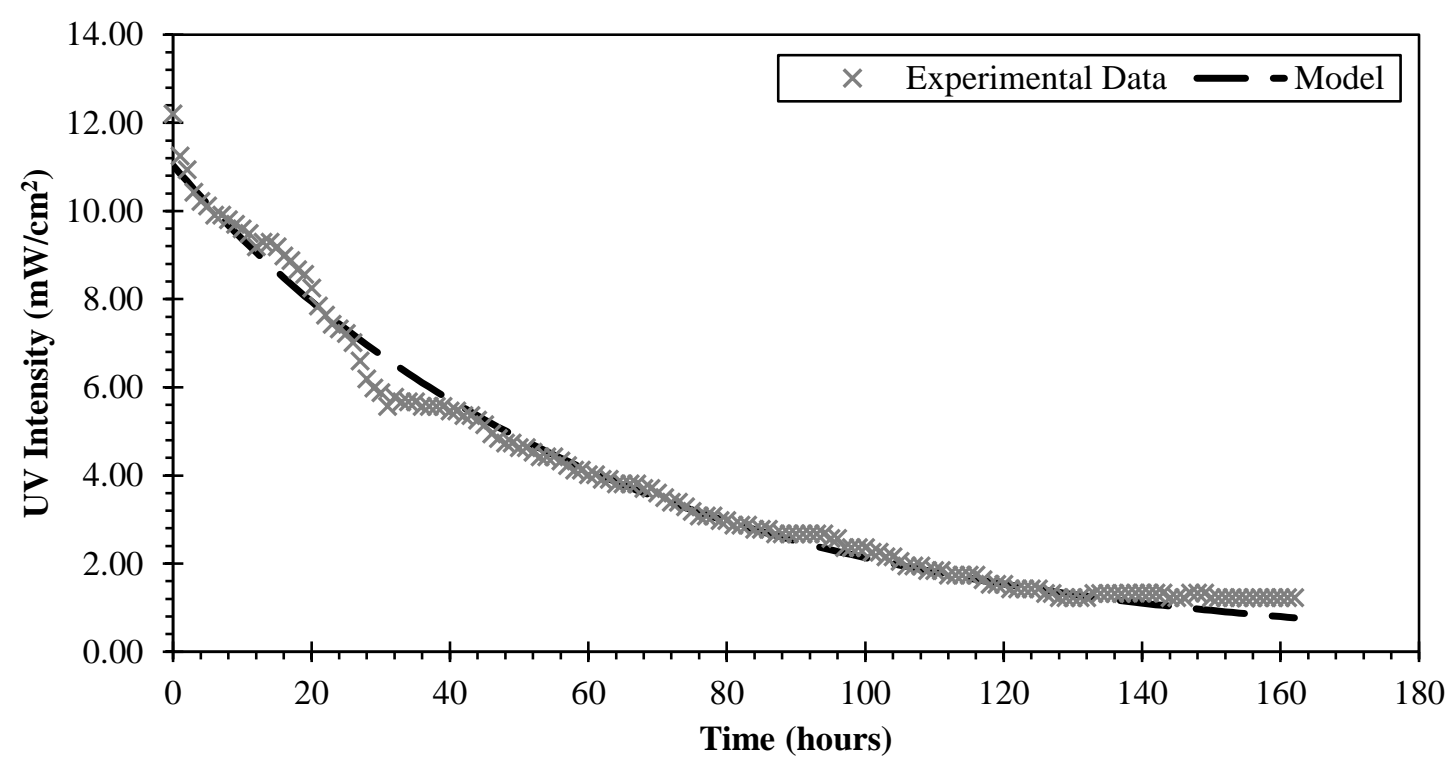

Figure 4.32. Modeled UV intensity data collected during C26. 


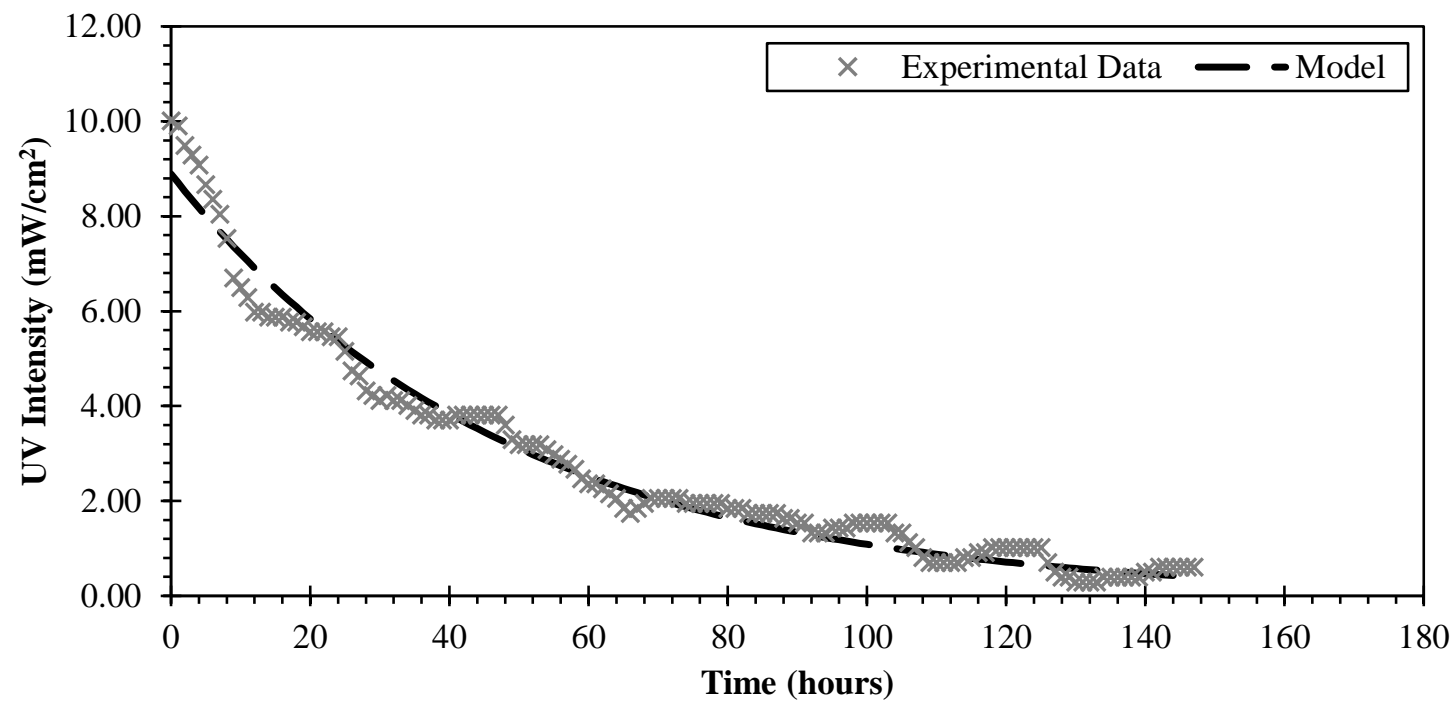

Figure 4.33. Modeled UV intensity data collected during C27.

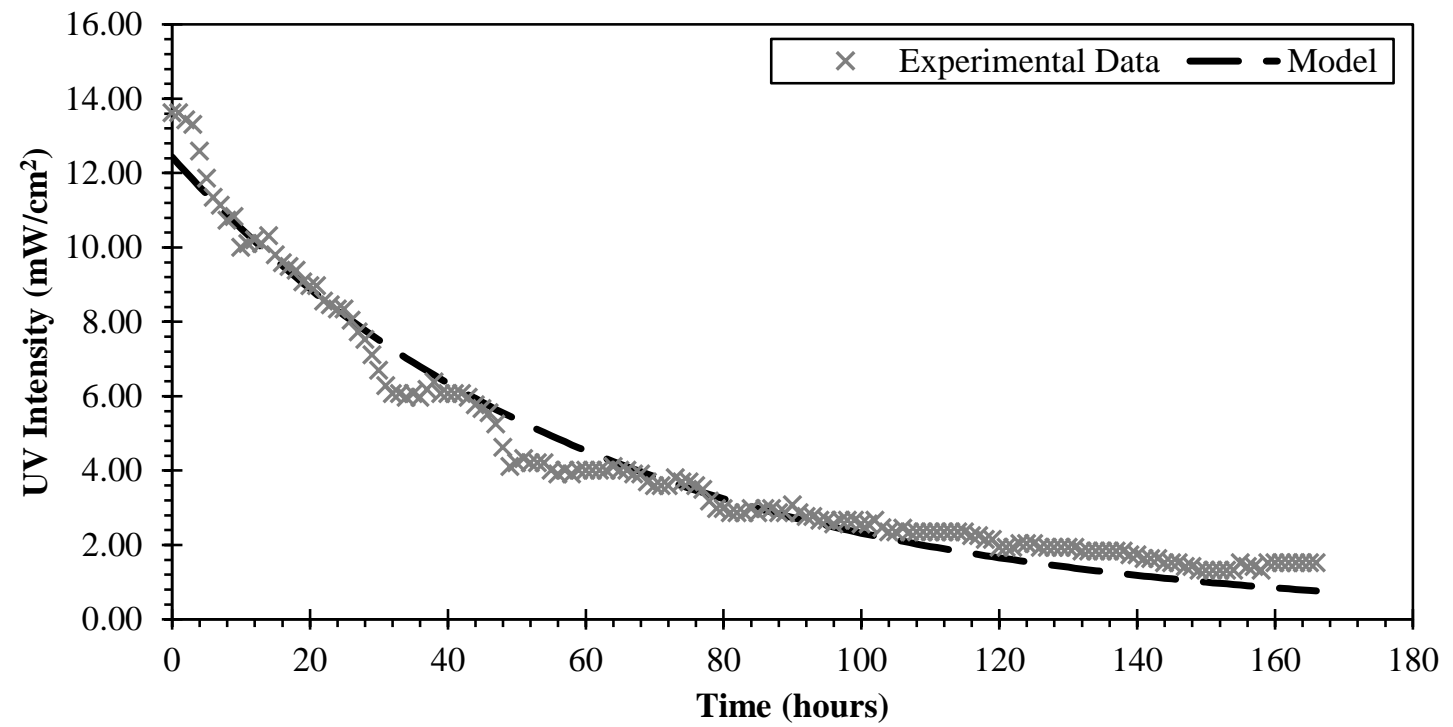

Figure 4.34. Modeled UV intensity data collected during C28. 


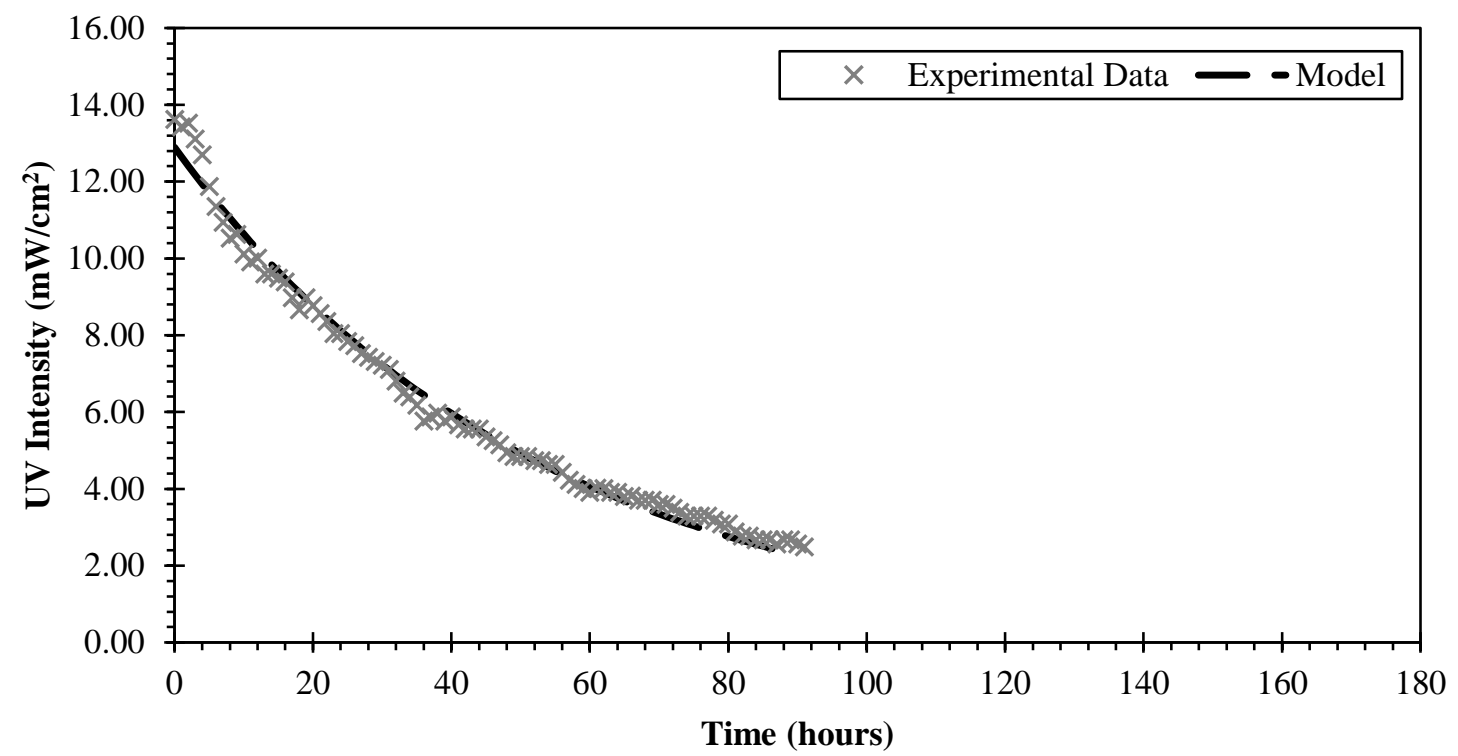

Figure 4.35. Modeled UV intensity data collected during C29.

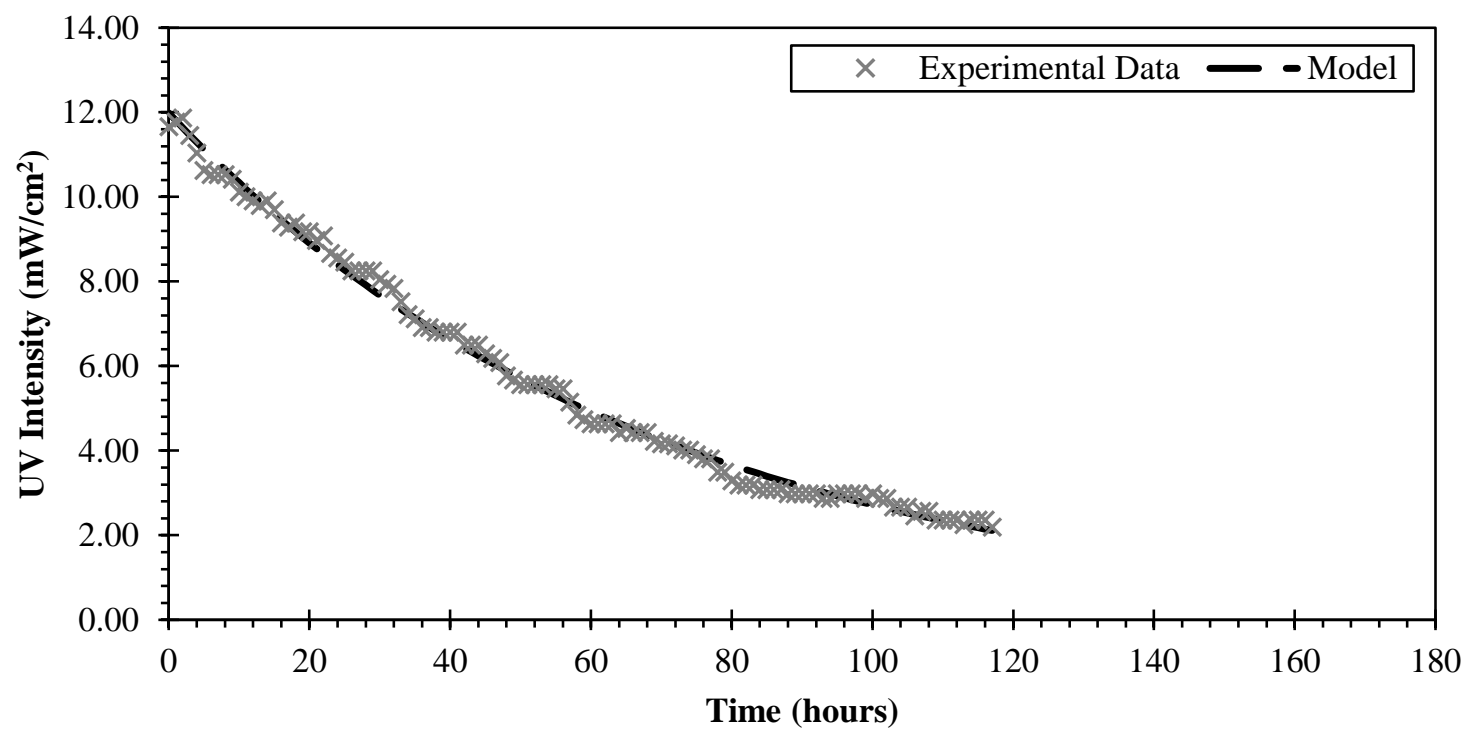

Figure 4.36. Modeled UV intensity data collected during C30.

As seen in Figures 4.30 through 4.36, the modified Beer-Lambert law, Equation 4.7, successfully explains the intensity attenuated over time caused by combined fouling. Once again, the values obtained for $k_{(\text {(sleeve) }}$ are larger than $k_{(\text {sensor) }}$ for each cycle, indicating that fouling 
material deposits at a faster rate onto the surface of the quartz sleeve than the sensor. The $k_{\text {sensor }}$ and $k_{\text {sleeve }}$ values for the modeled cycles are displayed in Table 4.11.

Table 4.11. $k_{\text {sensor }}$ and $k_{\text {sleeve }}$ obtained from modeling cycles 24-30.

\begin{tabular}{|c|c|c|} 
Cycle & $\mathbf{k}_{\text {(sleeve) }}$ & $\mathbf{k}_{\text {(sensor) }}$ \\
\cline { 2 - 3 } Number & hours $^{-1}$ & hours $^{-1}$ \\
\hline C24 & 0.0143 & 0.0038 \\
\hline C25 & 0.0143 & 0.0015 \\
\hline C26 & 0.0143 & 0.0021 \\
\hline C27 & 0.0143 & 0.0067 \\
\hline C28 & 0.0143 & 0.0025 \\
\hline C29 & 0.0143 & 0.0050 \\
\hline C30 & 0.0143 & 0.0005 \\
\hline
\end{tabular}

\subsection{Impacts of Fouling and Flow Rate Variations on UV Disinfection of E. coli}

In this section of the thesis, results obtained from studying E. coli inactivation in the pilot unit are presented and discussed. Six runs were carried out to study the impacts of flow rate, influent water quality and fouling on the E. coli inactivation efficiency. Influent flow rates were controlled at 10 to $35 \mathrm{gpm}$.

\subsubsection{E. coli Inactivation in the Pilot Scale UV Disinfection Unit}

Performance runs took place towards the end of the disinfection season (September $19^{\text {th }}$ to October $23^{\text {rd }}$ ). Six performance runs were completed during that period of time. Operational conditions, such flow rate and UVT for these runs are shown in Table 4.12. As seen in Table 4.12, UVT remained fairly constant during this period of the study. 
Table 4.12. Operational conditions experienced during the performance runs.

\begin{tabular}{|c|c|c|c|c|c|c|}
\hline Parameter & R1 & R2 & R3 & R4 & R5 & R6 \\
\hline Flow Rate (gpm) & 15 & 25 & 35 & 10 & 20 & 15 \\
\hline UVT (\%) & 54.3 & 53.7 & 53.8 & 54.1 & 52.4 & 53.5 \\
\hline
\end{tabular}

It is important to note that as flow increases, the HRT experienced inside the pilot unit will decrease. Because of that, an increase of flow through the pilot unit should decrease the UV dose delivered to the microorganisms. Thus, increasing the surviving microorganisms upon UV light's exposure. Furthermore, a decrease in performance of UV systems will also result from a loss of intensity through the quartz sleeves due to fouling accumulation on them. UV intensity data collected after cleaning the sensor's lens during the 6 performance runs displayed in Table 4.12 is shown in Figure 4.37. Raw data for these 6 runs can be found in Appendix C, Table C.1.

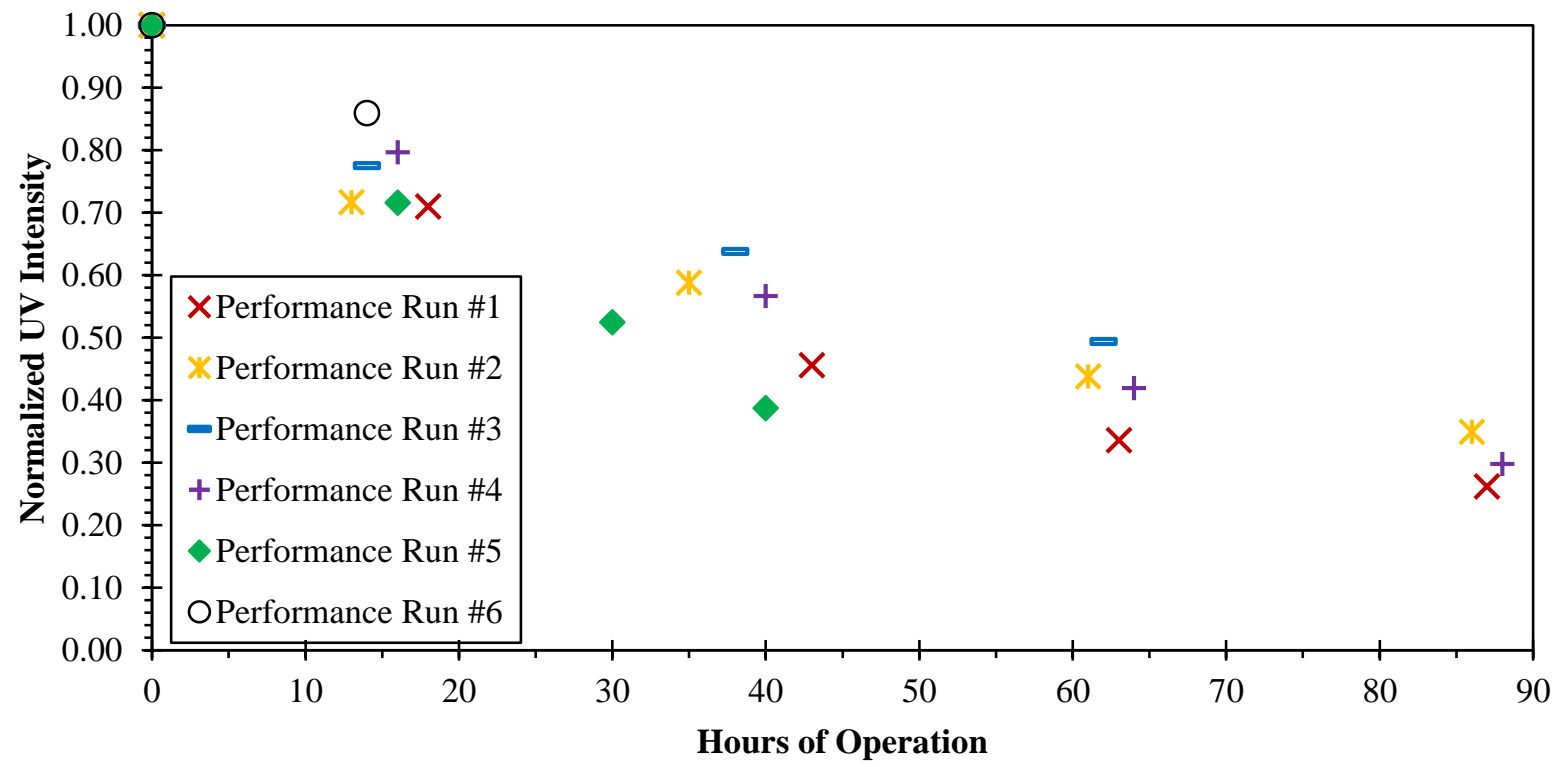

Figure 4.37. Intensity loss through the quartz sleeves experienced during performance runs. 
Intensity readings obtained during these performance runs display similar exponential decrease as seen in earlier cycles. It was intended that runs lasted for a period of 4 to 5 days with daily influent and effluent samples taken for E. coli analysis. It is important to note that run \#6 only displays 2 intensity measurements instead of 4 or 5 . This run had to be terminated short because there were no more available materials to perform additional E. coli tests that could be used for this study on site.

E. coli counts obtained during each performance tests are shown in Figure 4.38 as percent surviving E. coli. Percent surviving E. coli was calculated for each performance test by dividing the E. coli count exiting the unit by the E. coli count entering the unit and multiplying it by 100 . As mentioned in Section 3.1.2, each performance test was conducted in duplicate and an individual E. coli count was obtained from applying the geometric mean to the E. coli counts achieved during each performance test. E. coli data displayed in Figure 4.38 is shown Appendix C, Tables C.2C.7.

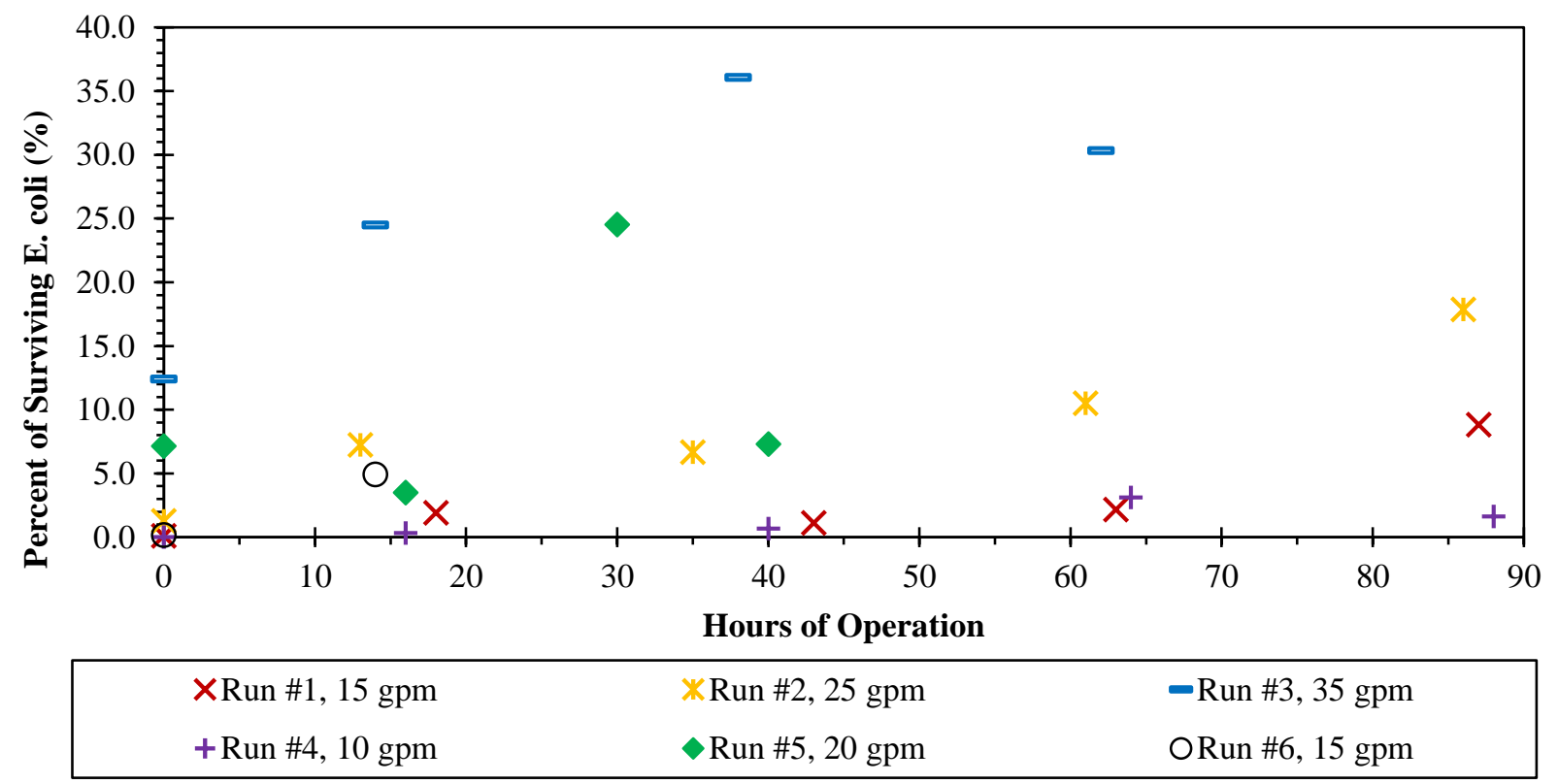

Figure 4.38. Percent surviving E. coli counts experienced during performance tests. 
As seen in Figure 4.38, the percent of surviving E. coli increased with respect increasing flow rate through the pilot unit. As already mentioned in Section 3.1.1, an increase in flow rate translates in a decrease in the time the microorganisms are exposed to UV light. Moreover, the percent of surviving E. coli also increased with an increase of the hours of operation of every run. That is because the UV intensity also decreased with time since the quartz sleeves were not cleaned during the runs (seen in Figure 4.37). All in all, the data displayed in Figure 4.38 confirms the expectations that the percent of surviving E. coli would increase with respect to decreasing hydraulic retention time and UV intensity through the quartz sleeves.

\subsubsection{Model Development for E. coli Inactivation Achieved in the Pilot Unit}

The HRT and the UV intensity recorded during each performance test was used to estimate the Apparent UV Dose $\left(\mathrm{D}_{\mathrm{a}}\right)$ experienced in the reactor at the time of the test using Equation 2.4. The HRT was calculated based on the flow rate and HRT relationship developed for the pilot unit shown in Figure 3.2. The $\mathrm{D}_{\mathrm{a}}$ experienced in the pilot unit varied for each performance test since the flow rate was different during each performance run, and each performance test was conducted at different UV intensity outputs. The experimental E. coli survival data obtained for different $\mathrm{D}_{\mathrm{a}}$ 's is shown in Figure 4.39. E. coli survival data displayed in Figure 4.39 can be found in Appendix C, Tables C.2-C.7. 


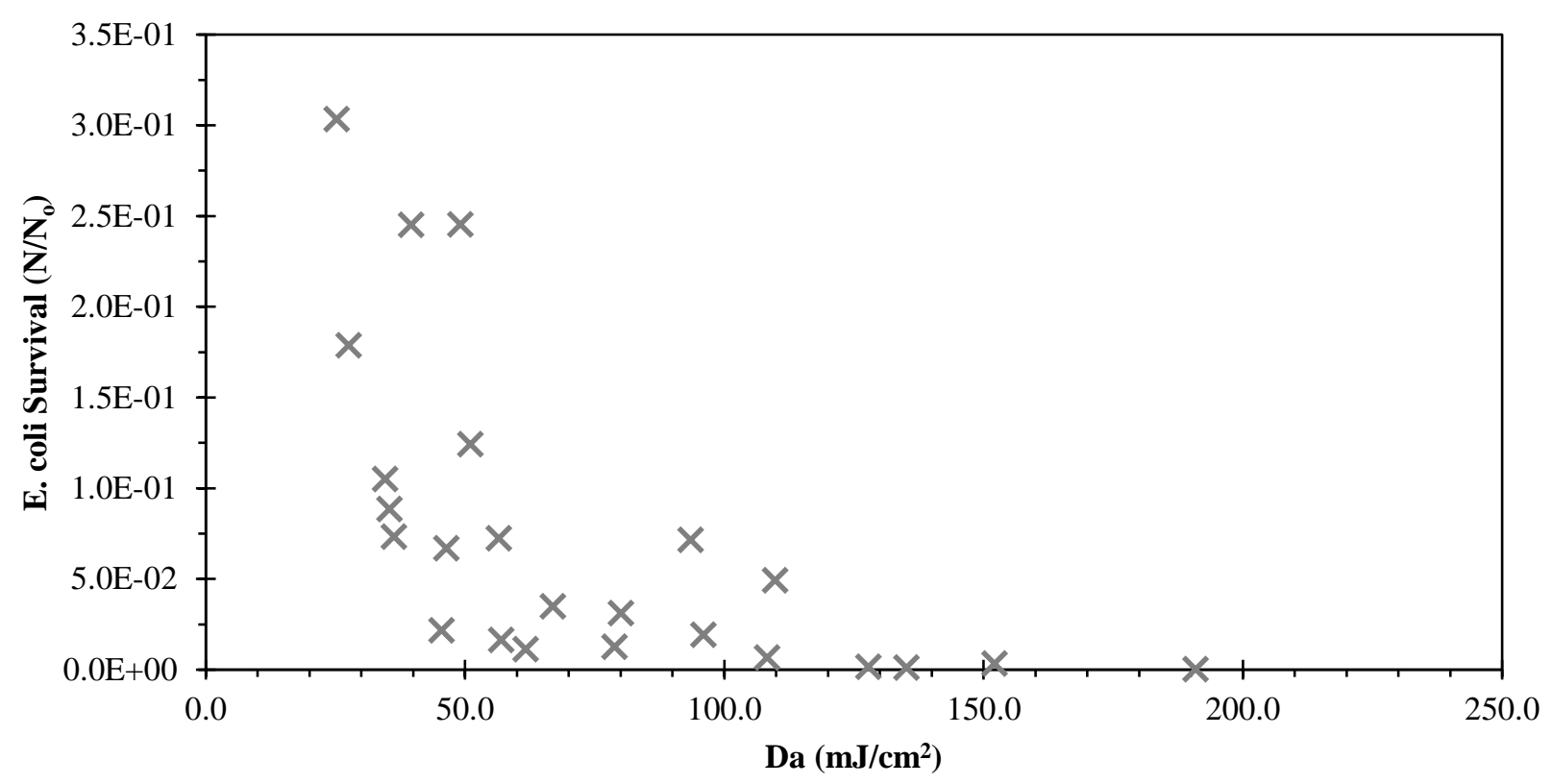

Figure 4.39. E. coli survival experienced in the pilot unit.

A kinetic study of the E. coli survival in the pilot unit was performed for the six performance runs. Several models were tested using $D_{a}$ as a parameter to describe the E. coli survival experienced in the pilot unit. The E. coli survival data was modeled by adjusting the model's rate constants using a non-linear least squares method procedure. Upon modeling, the first-order plug flow model was found to be most successful when interpreting the experimental data. Derivation of the first-order plug flow model used to interpret the experimental data is shown in Equations 4.9 through 4.12.

$$
\frac{d N}{d t}=-K N I
$$

Where $N$ represents the E. coli count; $t$ represents the detention time calculated for a given flow rate; I represents the UV intensity reading taken after cleaning the sensor; and $\mathrm{K}$ is the firstorder rate constant. Intensity of UV radiation decreases with time due to fouling material 
accumulation on the surface of the quartz sleeves. However, since hydraulic detention time in the pilot unit is only 4.4 to 15.4 seconds, intensity change can be considered negligible in this period. Therefore, $I$ was assumed to be constant in solving this rate equation.

$$
\begin{gathered}
\int_{N_{o}}^{N} \frac{1}{N} d N=-K I \int_{0}^{t} d t \\
\ln \left(N / N_{o}\right)=-K I t \\
\frac{N}{N_{o}}=e^{-\left(k D_{a}\right)}
\end{gathered}
$$

$\mathrm{N}=\mathrm{E}$. coli count after UV exposure (MPN/100ml)

$\mathrm{N}_{\mathrm{o}} \quad=$ E. coli count prior to UV exposure (MPN/100ml)

$\mathrm{D}_{\mathrm{a}} \quad=$ Apparent $\mathrm{UV}$ dose $\left(\mathrm{mJ} / \mathrm{cm}^{2}\right)$

$\mathrm{k}=$ First-order rate constant $\left(\mathrm{cm}^{2} / \mathrm{mJ}\right)$

The E. coli experimental data displayed in Figure 4.39 was simulated using Equation 4.12. Modeling results of the E. coli survival experienced in the pilot units are shown in Figure 4.40. 


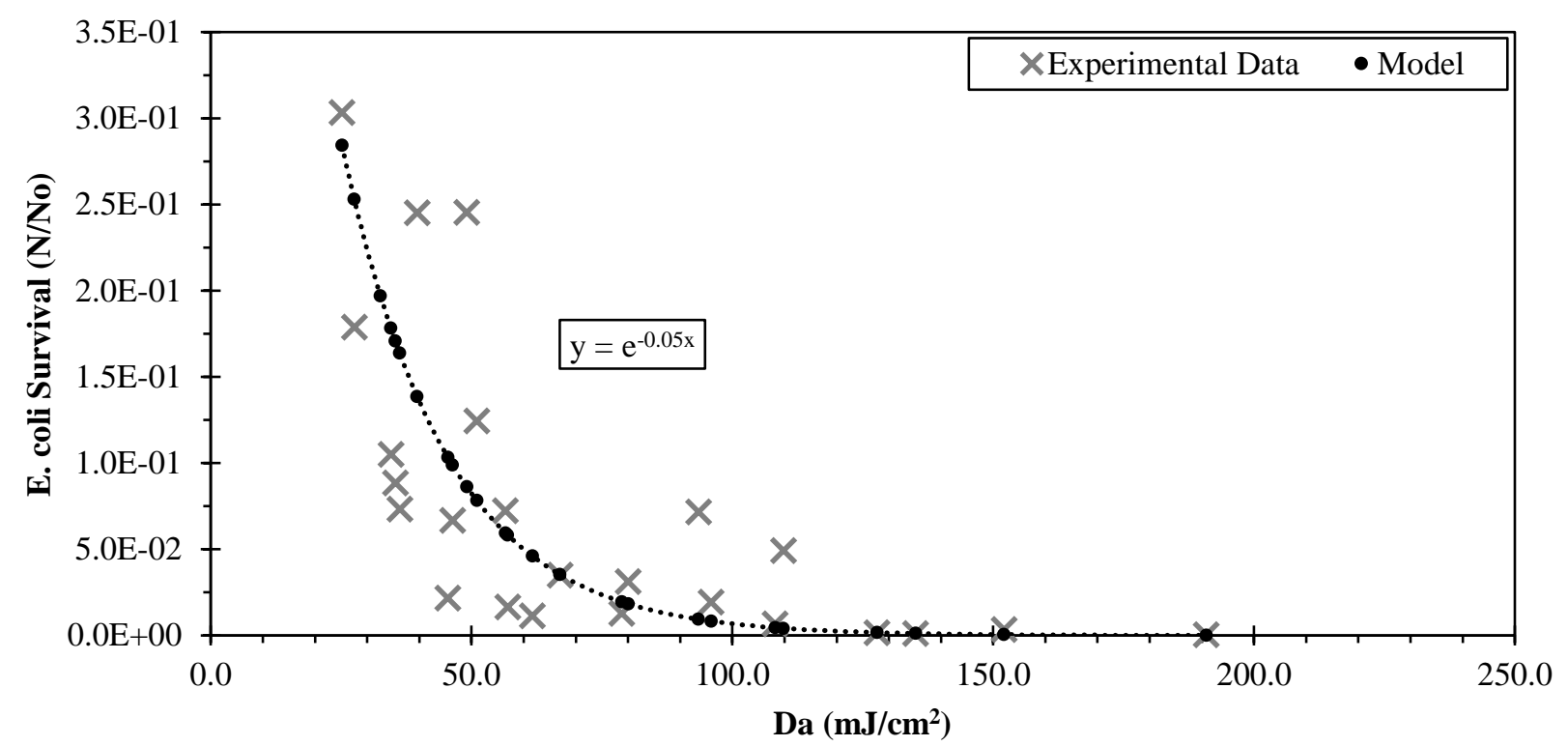

Figure 4.40. First-order plug flow kinetic model explaining the E. coli experimental data obtained during performance runs.

As seen in Figure 4.40, the first-order plug flow model describes the microbial data well. As mentioned in Chapter 2, first-order models have been widely used in previous studies to describe microbial response to UV light (Mounaouer \& Abdennaceur, 2016; Jolis et al., 2001; Severin et al., 1984).

\subsubsection{Impact of Influent E. coli count on the Disinfection Performance of the Pilot Unit}

Unlike in the water treatment industry, wastewater discharge regulations do not set standards for log inactivation achieved, rather, standards are set on final microorganisms count. As previously mentioned in this report, the Fargo's WWTP E. coli discharge standards have been set to a value of $126 \mathrm{MPN} / 100 \mathrm{ml}$. Since discharge standards are set on a final microorganism count, influent microorganism count will be one of the main parameters controlling the performance of the UV system. Having said that, the performance of this pilot unit may suffer if 
installed in facilities whose range of influent of E. coli counts $\left(\mathrm{N}_{\mathrm{o}}\right)$ is rather large. The first-order model introduced in Section 4.2.2 was used to perform scenario analysis to study the impact of $\mathrm{N}_{\mathrm{o}}$ the disinfection performance of the pilot unit.

To estimate the impact of $\mathrm{N}_{\mathrm{o}}$, a simulation was performed using the first-order plug flow kinetic model to calculate the required $D_{a}$ needed to achieve proper disinfection $(\mathrm{N}=126$ MPN/100ml) based on $\mathrm{N}_{\mathrm{o}}$ variations. Influent E. coli counts were varied from 4,000 to 25,000 MPN/100ml and the apparent dose needed to achieve proper disinfection was calculated. Results from this simulation are shown in Table 4.13, and Figure 4.41. The different $\mathrm{N}_{\mathrm{o}}$ 's used to perform this simulation were a representation of the initial E. coli concentration experienced during the 2016 disinfection season at the Fargo WWTP.

Table 4.13. Impact of $\mathrm{N}_{\mathrm{o}}$ on the $\mathrm{D}_{\mathrm{a}}$ needed to achieve Fargo's disinfection discharge standards.

\begin{tabular}{|c|c|c|}
\hline $\mathbf{N}_{\mathbf{o}}$ & $\mathbf{N} / \mathbf{N}_{\mathbf{o}}$ & Required $\mathbf{D}_{\mathbf{a}}$ \\
\hline 4000 & 0.0315 & 69.3 \\
\hline 6000 & 0.021 & 77.4 \\
\hline 10000 & 0.0126 & 87.6 \\
\hline 15000 & 0.0084 & 95.7 \\
\hline 20000 & 0.0063 & 101.5 \\
\hline 25000 & 0.00504 & 105.9 \\
\hline
\end{tabular}




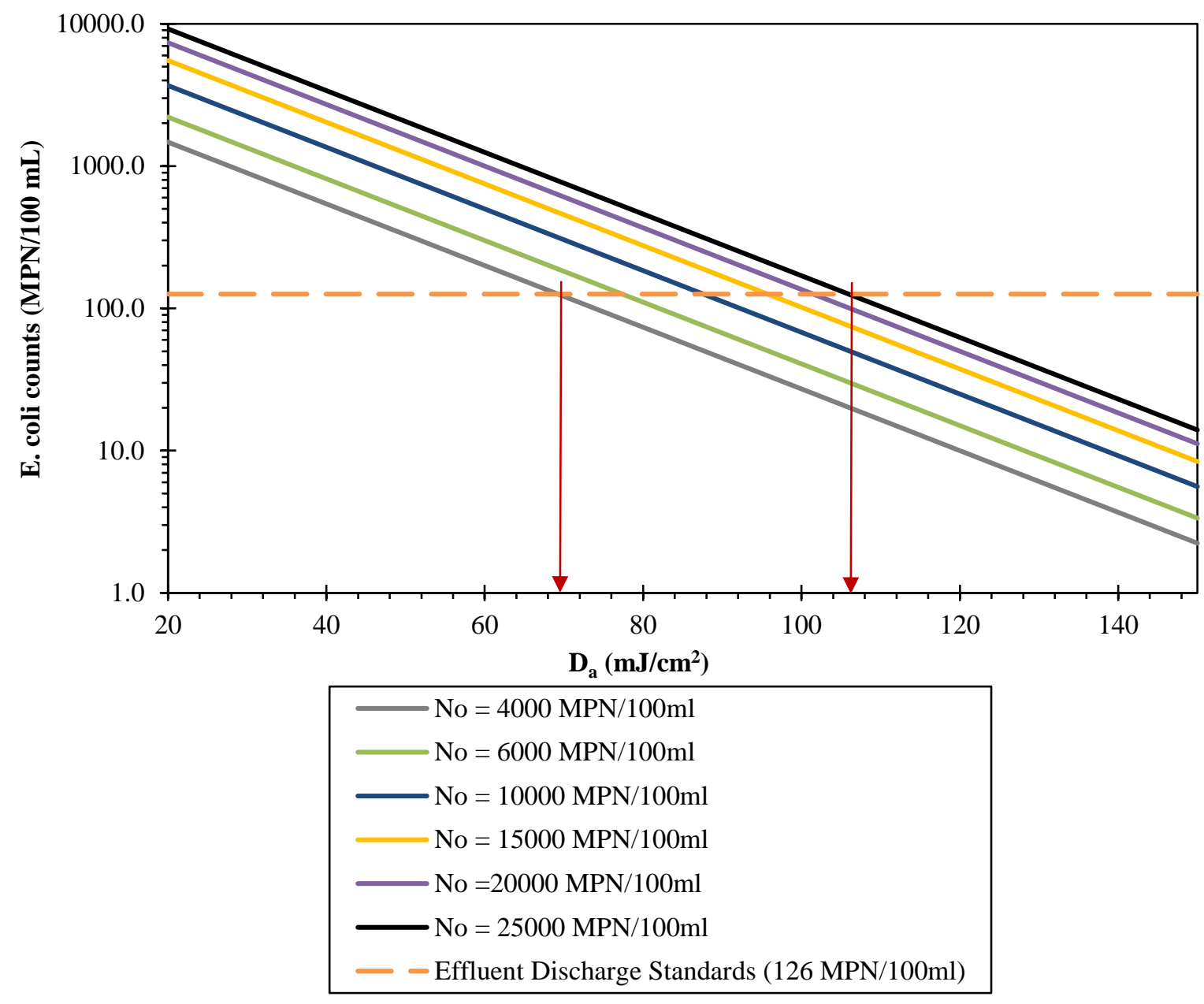

Figure 4.41. Impact of $\mathrm{N}_{\mathrm{o}}$ on $\mathrm{D}_{\mathrm{a}}$ needed to achieve disinfection discharge standards.

As seen in Table 4.13 and Figure 4.41, the influent microorganism count has a significant impact in the $D_{a}$ required to achieve proper disinfection. Having said that, if a similar model were to be used for a full-scale system, the system's operational procedures would have to be planned in a way to ensure $D_{a}$ is maintained large enough that influent water containing high E. coli counts can still be properly disinfected at all times. 


\subsection{Impact of Influent Water Quality Change on UV Transmittance}

The pilot system influent water was sampled and analyzed for various water quality parameters through the period of this research. Results of these tests are analyzed in this section to study the seasonal water quality variations and potential impact of water quality changes on UV disinfection, with a focus on relationship between UVT and other water quality parameters. All the effluent water quality data collected can be found under Appendix D.

\subsubsection{Impact of Water Quality on UVT}

Since UVT was never monitored at the Fargo WWTP before this study, it was not clear which phenomenon (scattering or absorption) would have the greatest impact on the UV intensity loss at the plant. Because of this, it is convenient to understand what was the major cause of UV intensity loss at the Fargo WWTP before studying the seasonal variations of the water quality parameters monitored during the 2016 disinfection season. UVT measurements of unfiltered effluent samples are affected by a combination of scattering (caused by both suspended and colloidal particles) and absorption (mostly caused by dissolved substances). However, the scattering component of the UVT loss can be eliminated if the sample is filtered through a 0.45 $\mu \mathrm{m}$ pore size filter. Such filter size is capable of removing all particles present in solution (suspended and colloidal). Thus, allowing to study the effect of dissolved substances on the UV intensity loss. In a similar way, when an effluent sample is filtered through a $1.2 \mu \mathrm{m}$ pore size filter, the impact of suspended particles on the filtered UVT is eradicated and the combined effect of dissolved substances and colloidal particles on UV intensity loss can be studied. Furthermore, the individual impact of suspended particles on UV intensity loss can be studied based on the UVT measurements obtained for unfiltered samples and $1.2 \mu \mathrm{m}$ pore size filtered samples. 
The UVT measurements of all collected samples (both unfiltered and filtered) can be found in Appendix D, Tables D1-D2. UVT was measured 64 times for unfiltered samples, and 57 times for $1.2 \mu \mathrm{m}$ and $0.45 \mu \mathrm{m}$ filtered samples. The average and standard deviation of the UVT for each sample type is displayed in Table 4.14. Once the average UVT for each sample type is known, one can calculate the percent of UV intensity loss that is associated with each sample type.

Table 4.14. Effects of absorption and scattering on UV Intensity loss.

\begin{tabular}{|c|c|c|c|c|c|}
\hline \multirow{2}{*}{$\begin{array}{l}\text { Sample } \\
\text { Type }\end{array}$} & \multicolumn{2}{|c|}{ Sample } & \multicolumn{2}{|c|}{ UVT } & \multirow{2}{*}{$\begin{array}{l}\text { Percent of } \\
\text { UVI Loss }\end{array}$} \\
\hline & Composition & \# of Samples & Average & St. Deviation & \\
\hline Effluent & $\begin{array}{l}\text { Suspended Particles } \\
\text { Colloidal Particles } \\
\text { Dissolved Substances }\end{array}$ & 64 & $53.1 \%$ & $3.28 \%$ & $46.9 \%$ \\
\hline $\begin{array}{c}1.2 \mu \mathrm{m} \\
\text { Filtered } \\
\text { Effluent }\end{array}$ & $\begin{array}{l}\text { Colloidal Particles } \\
\text { Dissolved Substances }\end{array}$ & 57 & $60.0 \%$ & $3.80 \%$ & $40.0 \%$ \\
\hline $\begin{array}{l}0.45 \mu \mathrm{m} \\
\text { Filtered } \\
\text { Effluent }\end{array}$ & Dissolved Substances & 57 & $62.7 \%$ & $4.06 \%$ & $37.3 \%$ \\
\hline
\end{tabular}

As seen in Table 4.14, removal of suspended particles from solution only resulted in a $6.9 \%$ increase in the average UVT of the sample. Moreover, the removal of colloidal particles resulted in a $2.7 \%$ increase of the average UVT. A similar UVT percent increase associated with the removal of suspended solids from solution has been found in previous work (Certificate of Analysis - Trojan, 2013). In their study performed in Minnesota, filtration of suspended particles only accounted for a $5 \%$ increase in overall UVT.

Based on the UVT and the percent of UV intensity loss data displayed in Table 4.14, the UV Intensity loss associated to dissolved substances, suspended particles, and colloidal particles can be calculated. First, the percent of UV intensity loss associated to unfiltered samples can be 
found by subtracting $53.1 \%$ from $100 \%$. As shown in Table 4.14, this measurement came out to be $46.9 \%$ and it represents the total UV intensity loss in Fargo due to a combination of absorption and scattering. Based on this measurement and the percent UVT increase experienced after each filtration, one can calculate the percent of UV intensity loss associated with each component of the water separately. Upon performing these calculations, it was found that a large portion of the UV intensity loss in Fargo was caused by absorption of UV light by dissolved substances (79\% of the loss). The remaining UV intensity loss, $21 \%$, was caused by particles. Within the UV intensity loss due to particles, suspended particles had a larger impact (15\% of the loss) when compared to colloidal particles ( $6 \%$ of the loss) due to their overall larger size. It was assumed that the majority of the UV intensity loss caused by particles was due to scattering. The UV intensity loss associated to scattering and absorbance found in this study coincides with previous efforts found in the literature (Qualls et al., 1983). In their study, Qualls et al. (1983) found that $88 \%$ of the UVT loss was caused by absorption and $12 \%$ by scattering. Similar to this study, Qualls et al. (1983) arrived at this conclusion by measuring the absorbance of filtered and unfiltered samples.

\subsubsection{Seasonal Variations of Common Water Quality Parameters}

Seasonal variations of COD are shown in Figure 4.42 and 4.43. Seasonal water quality data analyzed for COD in total and dissolved form did not follow a clear seasonal trend throughout the 2016 disinfection season. Total and dissolved COD were tested 63 and 52 times respectively during the months of March through October. Dissolved COD analysis did not start until April $28^{\text {th }}$ since the $0.45 \mu \mathrm{m}$ pore size filters were not available on site until that date. Total and dissolved COD varied throughout the season with an average ratio of 1.7:1 (total:dissolved). 


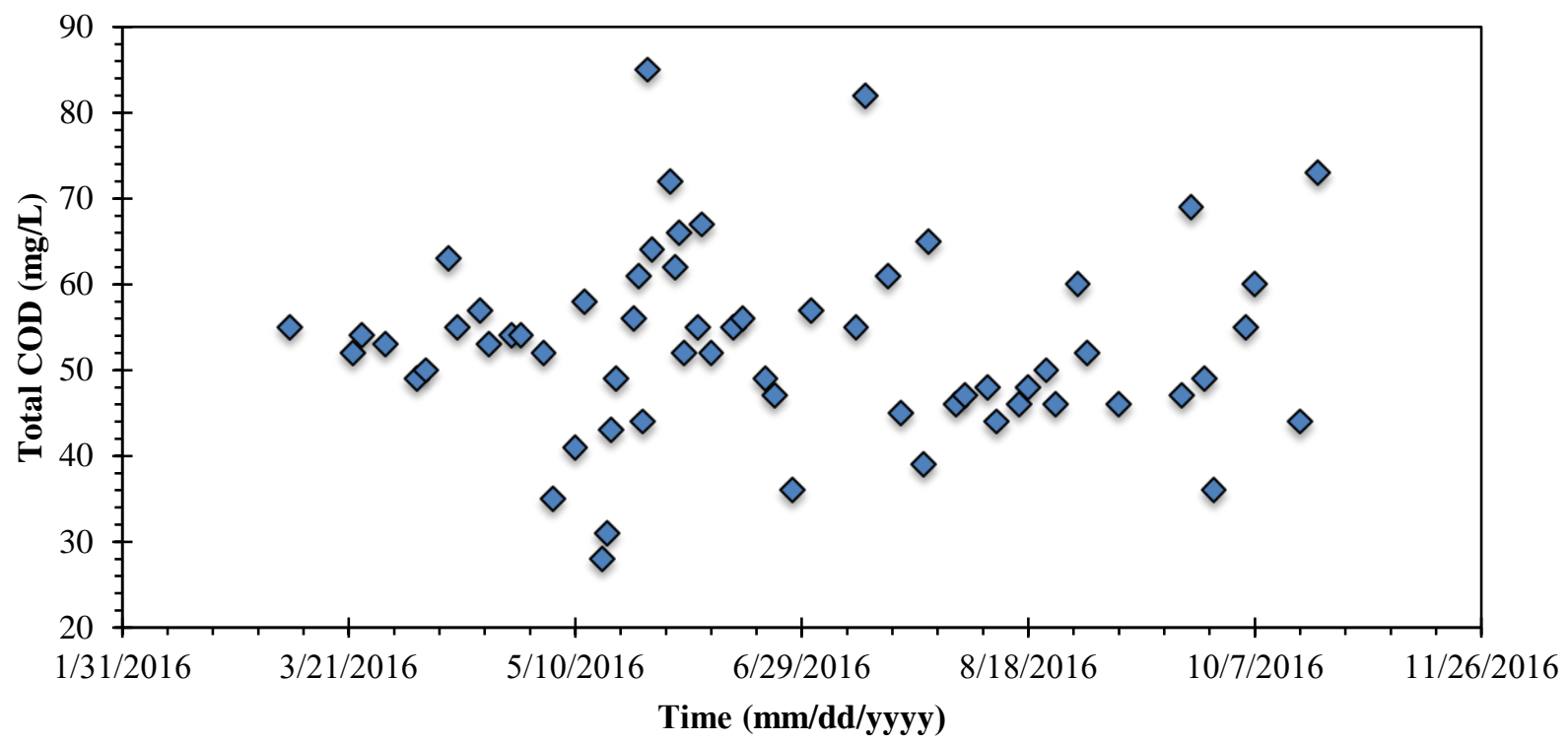

Figure 4.42. Seasonal variations of total COD.

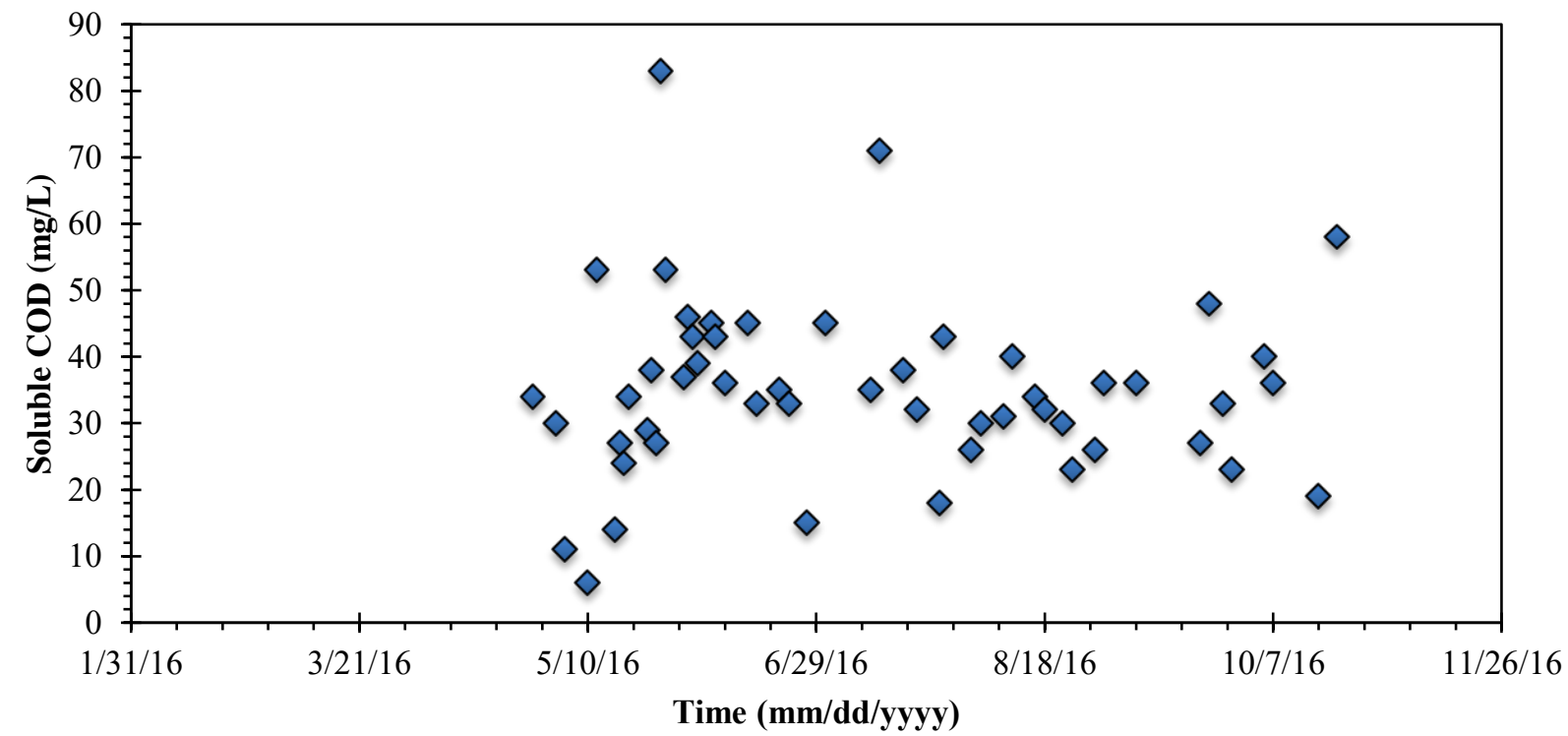

Figure 4.43. Seasonal variations of dissolved COD.

A total of 63 TSS analyses were completed in between March $8^{\text {th }}$ through October $22^{\text {nd }}$. Variation of TSS is shown in Figure 4.44. As seen in Figure 4.44, TSS shows a slight decreasing trend through the 2016 disinfection season. 


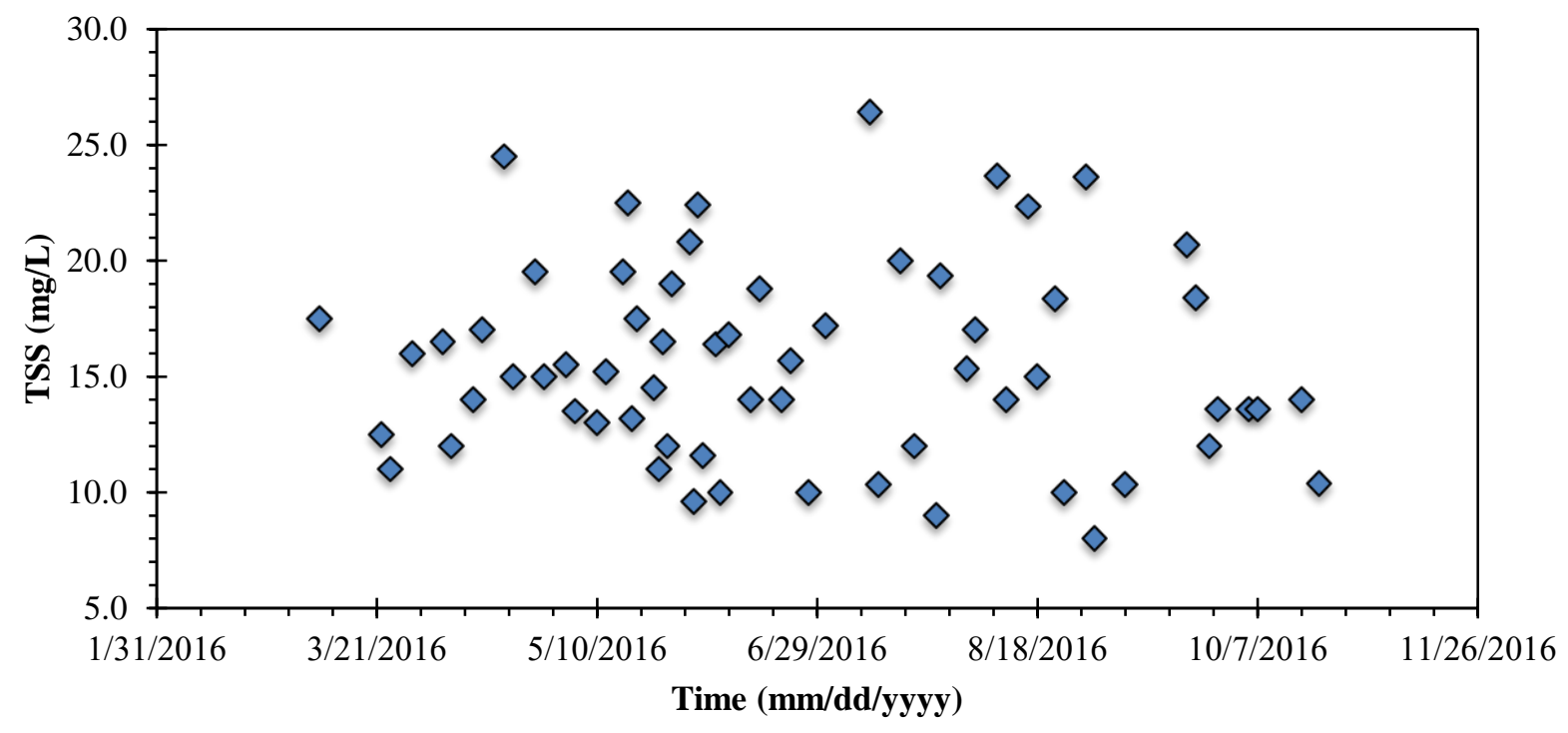

Figure 4.44. Seasonal variations of TSS.

A total of 64 turbidity measurements were conducted between March $8^{\text {th }}$ and October $22^{\text {nd }}$. Results of these analyses are shown in Figure 4.55. Unlike with the previous parameters, turbidity does show a clear decreasing trend throughout the 2016 disinfection season as seen in Figure 4.45.

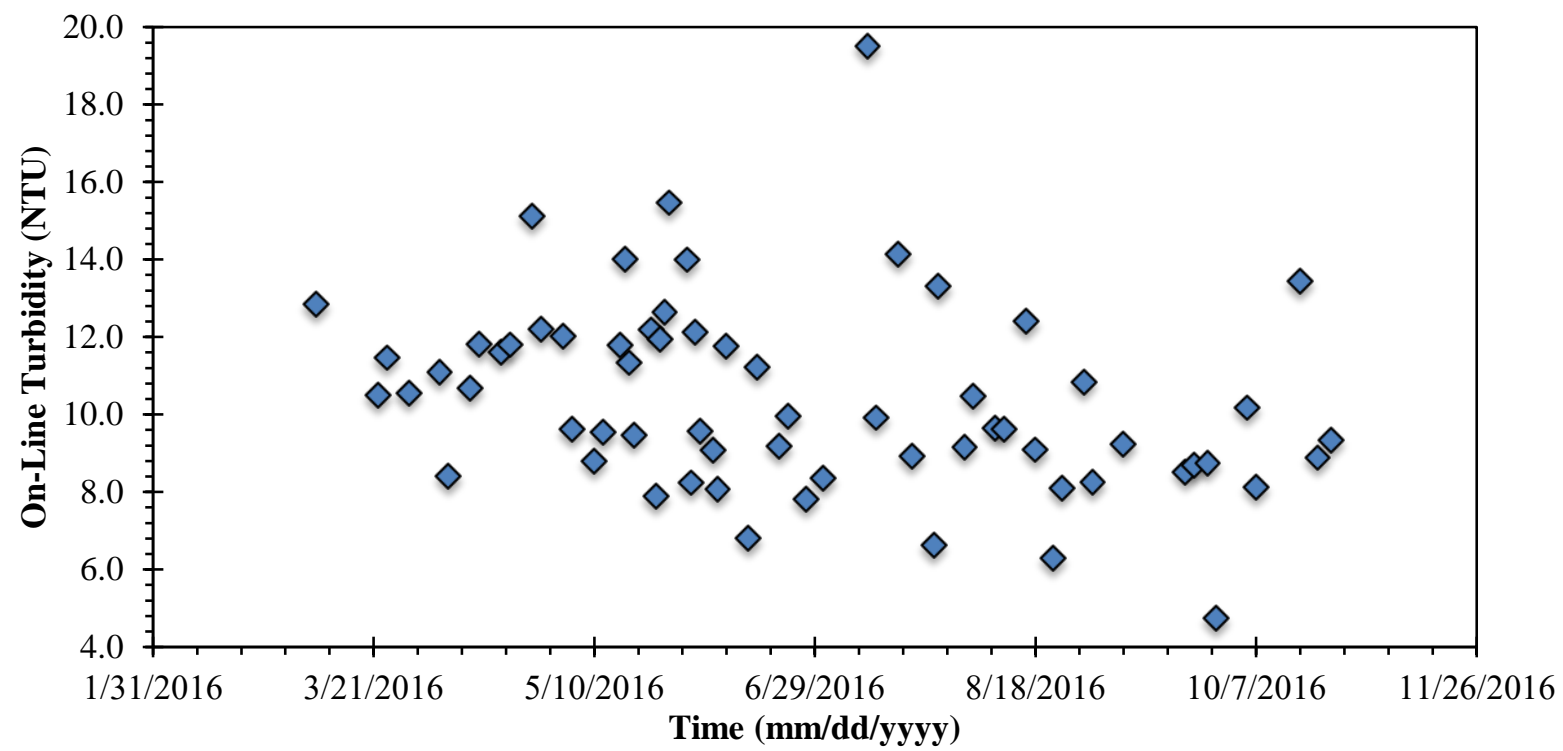

Figure 4.45. Seasonal variations of Turbidity. 
Total and dissolved iron were tested 54 and 19 times respectively during the months of June through October. Seasonal variations of iron are shown in Figures 4.46, and 4.47.

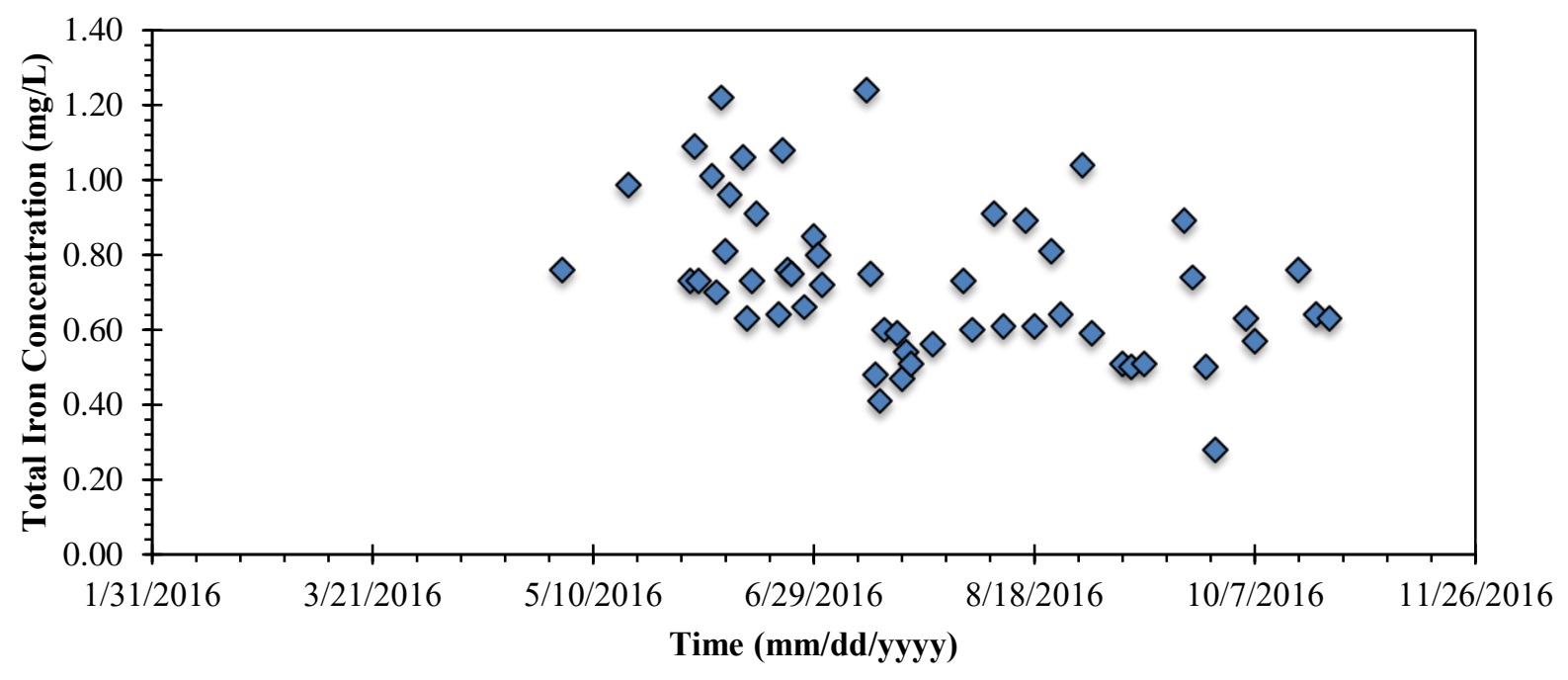

Figure 4.46. Seasonal variations of Total Iron.

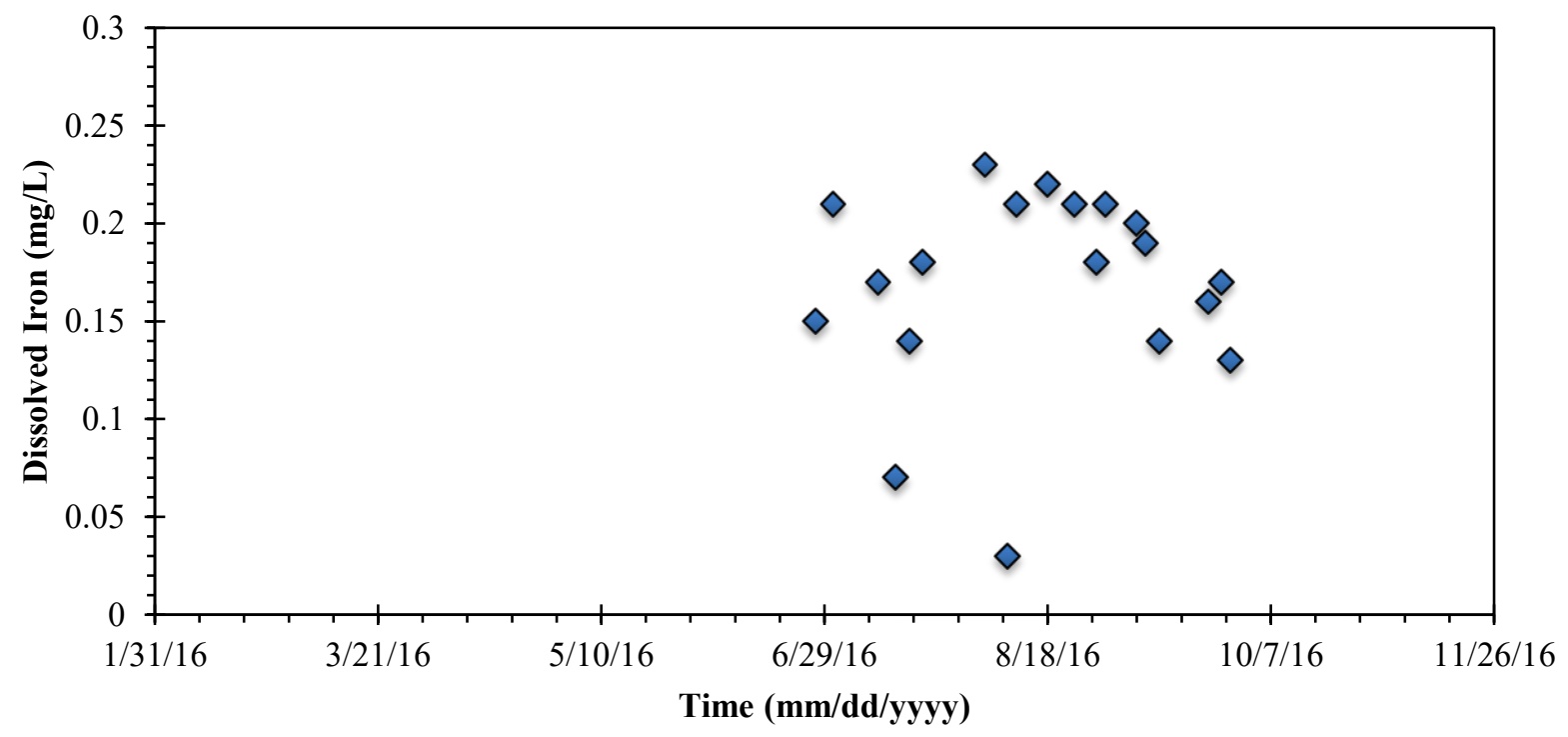

Figure 4.47. Seasonal variations of Dissolved Iron. 
Besides UVT, iron was the only parameter tested during this research that is not monitored at the Fargo WWTP on a regular basis. Iron was monitored during the 2016 disinfection season since previous studies found in the literature indicated that it is one of the main components of fouling material in UV systems installed in wastewater treatment facilities (Lin et al., 1999b; Lu et al., 2012; Nessim \& Gehr, 2006; Sheriff \& Gehr, 2001; Wait et al., 2004). It was hypothesized that the role of iron on fouling deposition would have been more pronounced the Fargo WWTP than other plants since the city applies ferrous salts in its sewer system for odor control purposes. However, as indicated in Section 4.1, although intensity was lost at a fast rate through the quartz sleeves, fouling material analysis displayed similar percentage of metal salts distribution than those found in the literature (Blatchley et al., 1996; Gehr \& Sehnaoui, 2001; Lin et al., 1999a). Indicating that the impact of iron on the rate intensity loss through the quartz sleeves at the Fargo WWTP may not have been as significant as it was initially expected.

The $\mathrm{pH}$ data collected for this study is shown in Figure 4.48. The $\mathrm{pH}$ of the water did not suffer seasonal variations and it was maintained within 7.6 and 6.8.

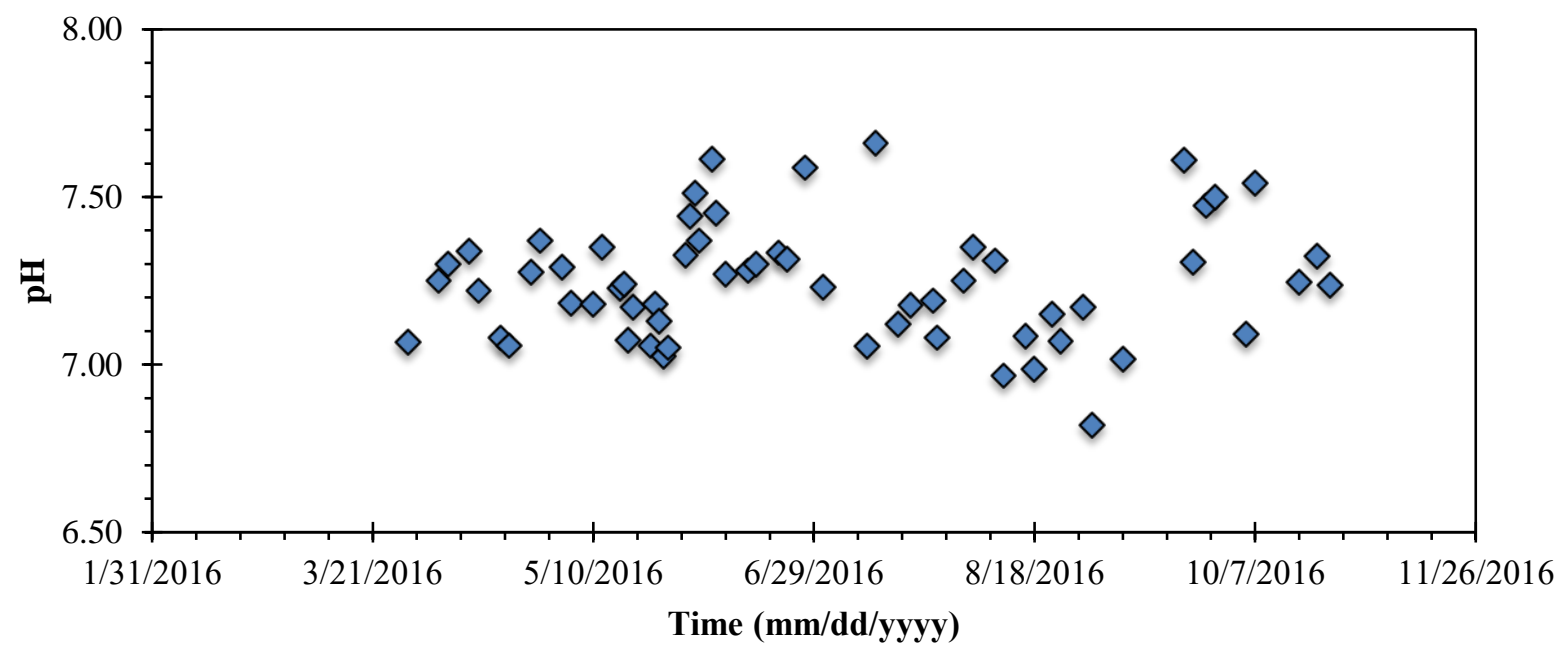

Figure 4.48. Seasonal variations of $\mathrm{pH}$. 
Temperature data collected during study is shown in Figure 4.49. Water temperature was monitored from April through October of 2016. Water temperature suffered the expected seasonal changes, colder in the winter months and warmer in the summer months with a transitional period in May and early June.

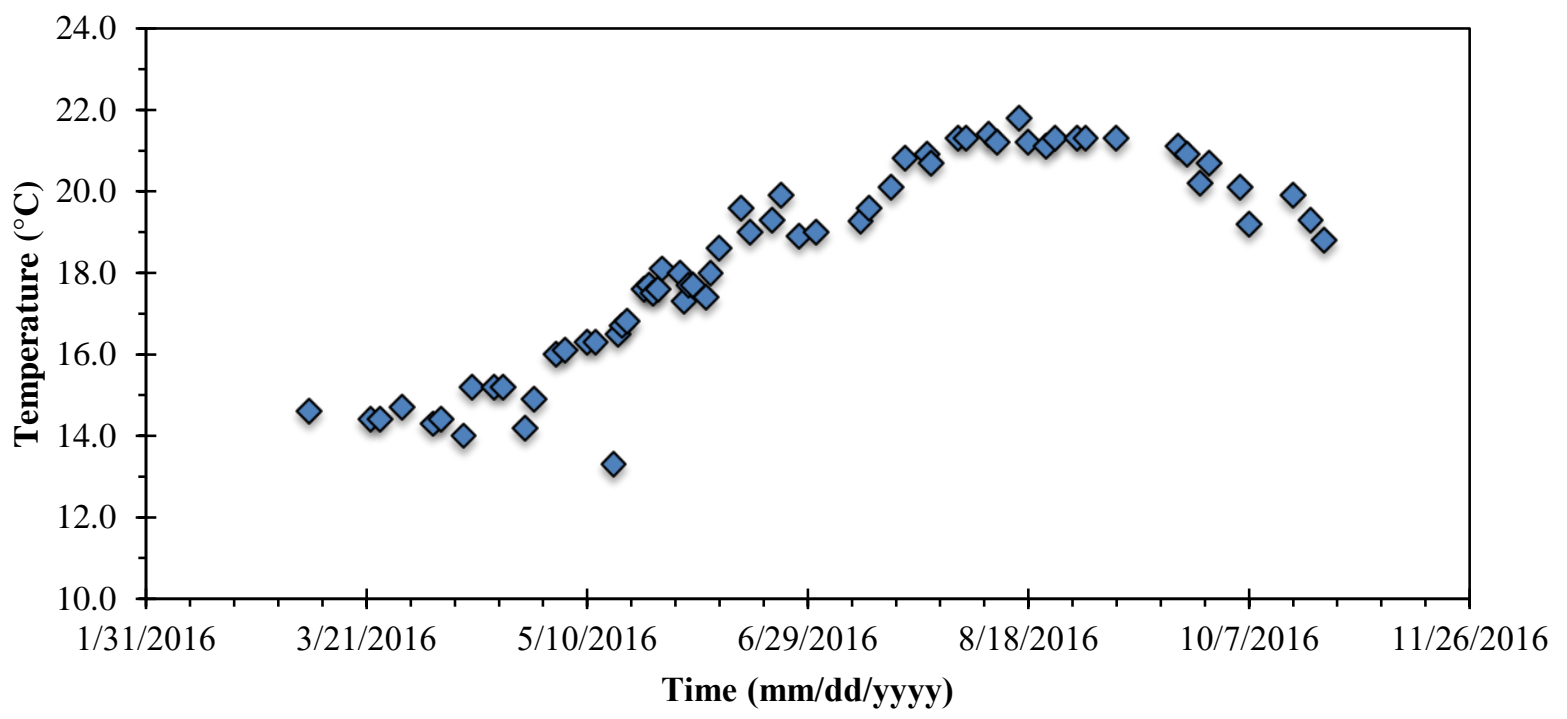

Figure 4.49. Seasonal variations of water temperature.

\subsubsection{Seasonal Variations of UVT}

Seasonal variations of UVT are shown in Figure 4.50. A total of 64 UVT measurements were conducted between March $8^{\text {th }}$ and October $24^{\text {th }}$. 


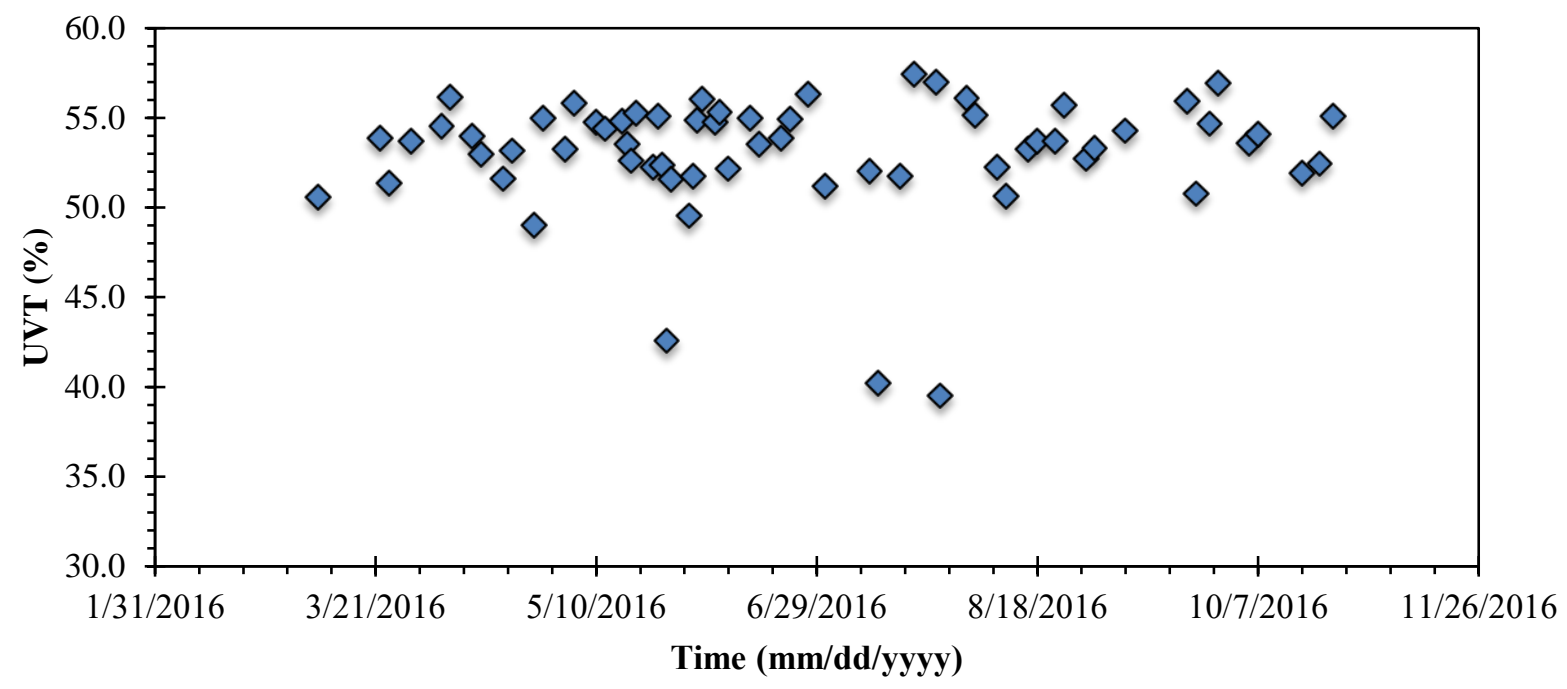

Figure 4.50. Seasonal variations of UVT.

UVT was never monitored at the Fargo WWTP before. Due to that, UVT variations experienced during the 2016 season cannot be compared to data collected in previous years. The first thing that needs to be pointed out is that the UVT measurements taken at the Fargo WWTP effluent are lower than the ones reported in other studies for trickling filter plants (Emerick et al., 1999; Gilley et al., 2008; Loge et al., 1999), which reported UVT values ranging in the sixties. Secondly, the slight increase of water quality throughout the disinfection season (decrease of turbidity, TSS, and iron) did not translate in a consistent increase of the effluent UVT. As seen in Figure 4.50, significant daily UVT variations were experienced in this study. Although no seasonal variation in terms of average UVT was identified during the 2016 disinfection season, the degree of fluctuation of the UVT data collected did vary with the seasons. The average UVT and the standard deviation experienced during this study are shown in Table 4.15. The calculations of the average UVT and standard deviation were divided in three different data sets representing spring, summer, and fall months. Additionally, the seasonal variations of UVT divided in the three periods: spring, summer, and fall; are shown in Figure 4.51. 
Table 4.15. Average and standard deviation of UVT experienced during different seasons.

\begin{tabular}{|c|c|c|}
\hline Season & Average UVT (\%) & St. Deviation \\
\hline Overall & 53.1 & 3.32 \\
\hline Spring (March-May) & 52.8 & 2.79 \\
\hline Summer (June-August) & 52.9 & 4.04 \\
\hline Fall (September-October) & 54.0 & 1.87 \\
\hline
\end{tabular}

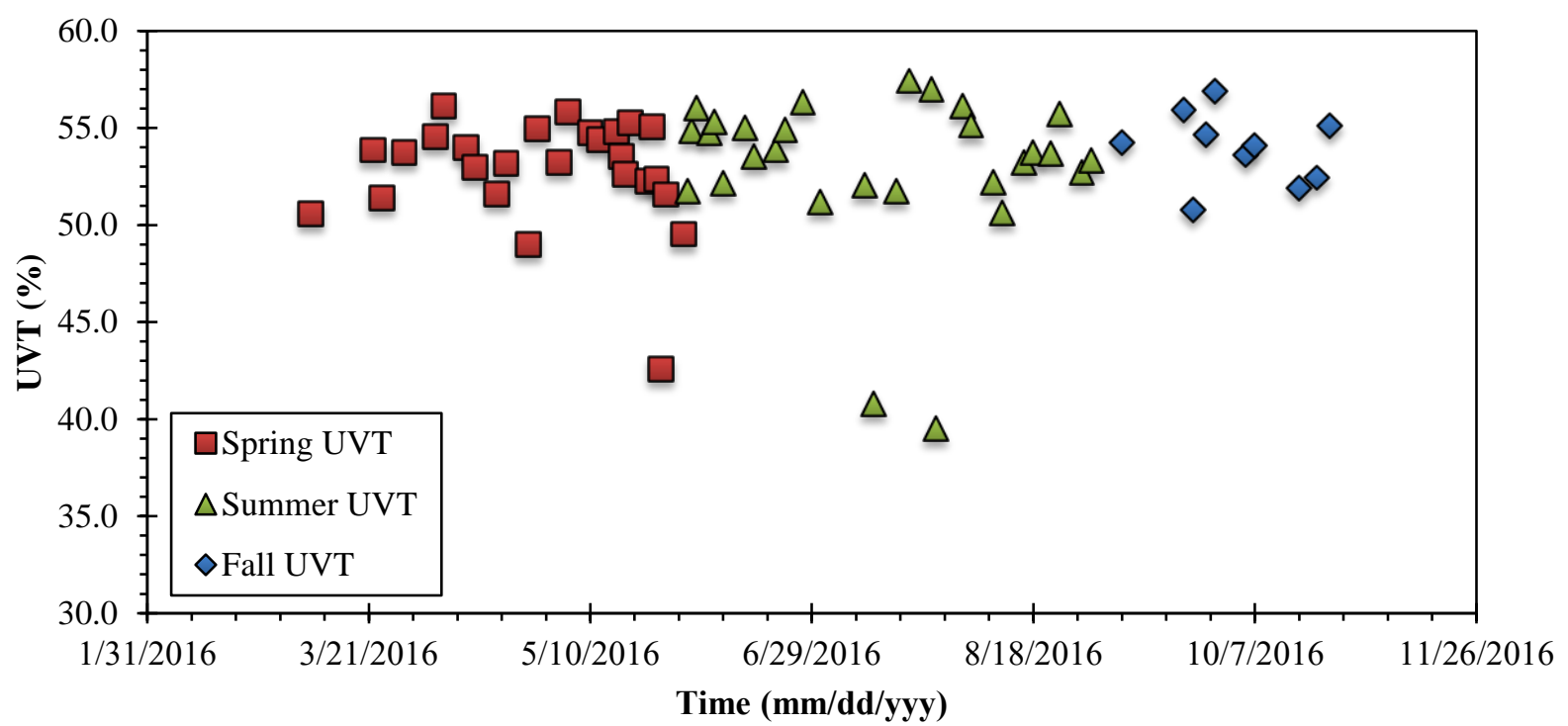

Figure 4.51. UVT behavior displayed by seasons.

Although the average of the UVT between all sets of data is only within $1.1 \%$, the standard deviation of the summer data is significantly larger when compared to other seasons. The two lowest UVT measurements (39.5\% sampled in 07/27/2016, and 40.2\% sampled in 07/13/2016) were experienced during the summer months. Both UVT measurements were taken after major storm events had occurred. Additionally, the plant's flow was significantly higher during those dates. Thus, there could be a relationship between precipitation, the plant's flow, and the water quality. 
To study the impact of precipitation on the plant's flow, precipitation data was retrieved from a monitoring station located close to the Fargo WWTP through the Record of Climatological Observations (National Oceanic \& Atmospheric Administration). Precipitation data obtained for the month of July can be found in Appendix D, Figure D.1. In addition to the precipitation data, the plant's flow during the month of July is also shown in Table D.4. Before starting the analysis, it is important to point out that the average flow experienced at the Fargo's WWTP during the 2016 disinfection season was 13.23 MGD. However, when the two lowest UVT's were experienced, the plant's flow had risen to 15.4 MGD in July $13^{\text {th }}$ and 15.83 MGD in July $27^{\text {th }}$ and rain events of over 1 inch of precipitation were experienced at the monitoring station one or two days prior to the UVT measurement. Indicating that the short-term adverse UVT impacts may be associated to significant storm events taking place in Fargo.

The fact that the plant's flow increases when significant storm events take place could be associated to the possible infiltration and inflow occurring throughout the Fargo's sanitary collection system. When flow increases significantly, the HRT of the treatment processes decreases. Due to that, water spends less time in the treatment units, thus not allowing proper settlement of wastewater particles to take place. This improper settlement causes the UVT of the effluent to drop since parameters such TSS or turbidity increase in concentration in the effluent. WWTP personnel in charge of operating the future UV disinfection system in Fargo must be familiar with the effects that large storm events have on UVT to adjust the operational parameters of the UV disinfection system accordingly. Although UVT did suffer from major storm events, the impacts were short-term and the water quality recovered to its normal conditions within a day or two. 
Single-parameter regression relationships were developed between water quality parameters shown in Section 4.3.2 and UVT as a way to identify the parameters that have the greatest impact on UVT change. The two best single-parameter regression relationships developed in this study are shown in Figures 4.52 and 4.53.

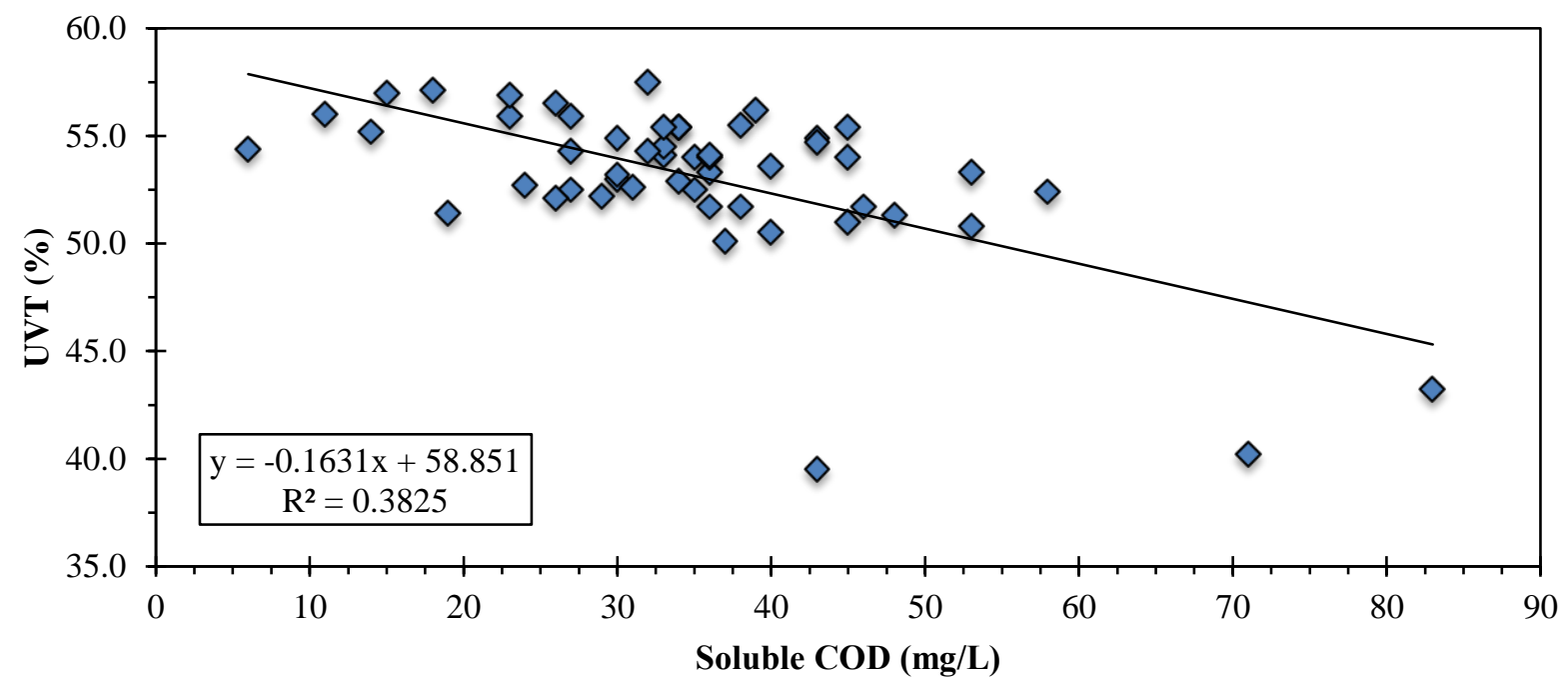

Figure 4.52. Single-variable linear relationship between dissolved COD and UVT.

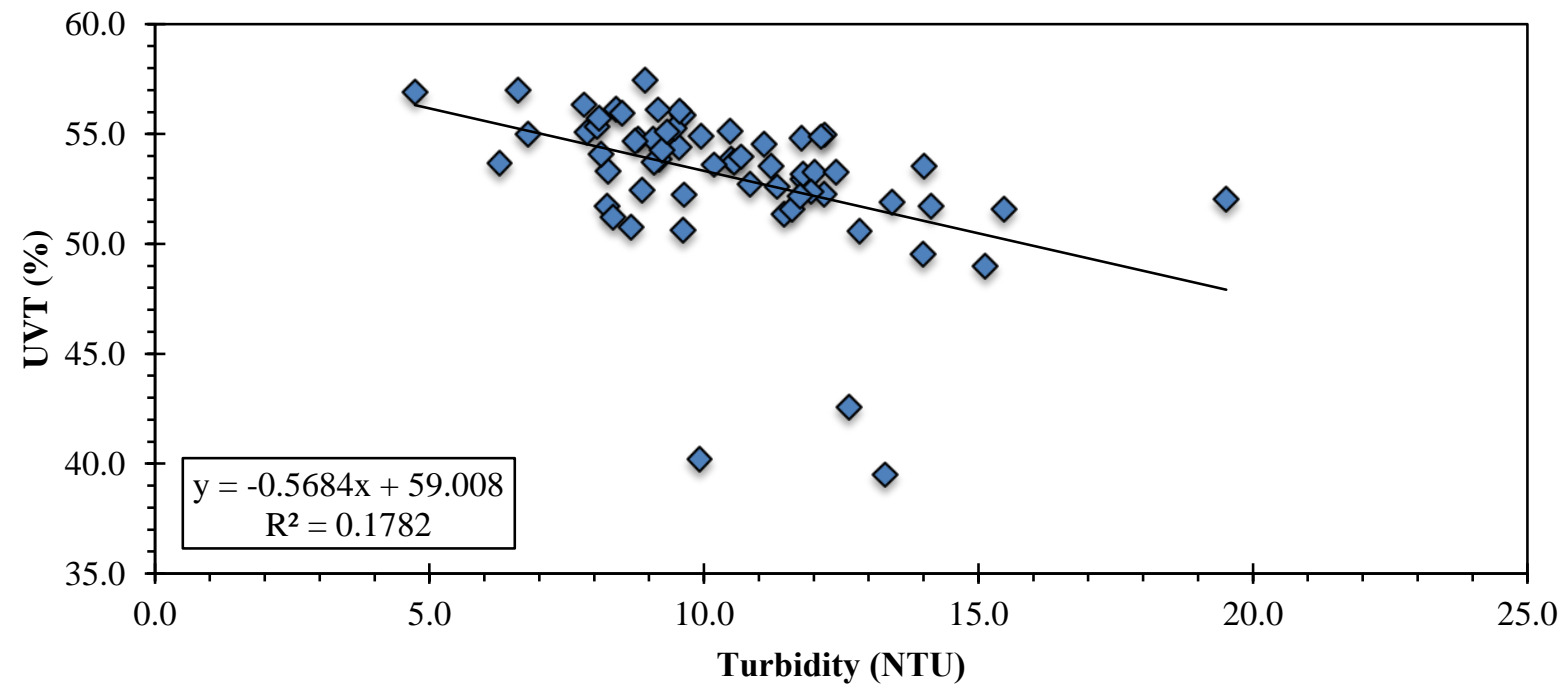

Figure 4.53. Single-variable linear relationship between turbidity and UVT. 
As seen in Figures 4.52 and 4.53, UVT variations were found to be closely related to the effluent concentrations of COD and turbidity. COD (both in total and dissolved form) was the parameter that had the largest impact on UVT, followed by turbidity. Although total COD also correlated well with UVT, it is not shown since dissolved COD correlated slightly better. It is not surprising to see that the individual water quality parameter that has the biggest impact on UVT is dissolved COD since it was found that $79 \%$ of the total UV intensity loss is caused by dissolved substances. Turbidity concentrations also correlated well with UVT variations. Once again, it is not surprising to see turbidity correlating well with UVT since $21 \%$ of the UV intensity loss is caused by particles and turbidity is one the parameters closely related to particles in solution. The knowledge attained through the UVT study will be transferred to the Fargo's WWTP personnel. Based on this knowledge, the plant's management may modify their operational procedures to reduce the concentration of the parameters that affect UVT the most in hopes of increasing UV disinfection performance with time.

\subsection{Relationship between UV Dose and E. coli Inactivation Rate}

E. coli disinfection efficiency in response to UV dose and water quality changes are studied using the CB method. Results obtained from this study are presented in this section. A secondorder kinetic model was successfully used to describe the relationship between E. coli inactivation and UV dose. 


\subsubsection{Collimated Beam Tests}

Four CB tests were performed throughout the 2016 disinfection season at varying water qualities. The water quality conditions experienced during each test are shown in Table 4.16.

Table 4.16. Water conditions during each CB test.

\begin{tabular}{|c|c|c|c|c|}
\hline Parameter & T1 & T2 & T3 & T4 \\
\hline Date & $05 / 03 / 2016$ & $05 / 18 / 2016$ & $06 / 07 / 2016$ & $07 / 27 / 216$ \\
\hline UVT (\%) & 52.5 & 54.5 & 56.6 & 39.5 \\
\hline Turbidity (NTU) & 9.11 & 9.07 & 8.04 & 13.5 \\
\hline TSS (mg/L) & 15.5 & 13.2 & 10 & 19.5 \\
\hline Total COD (mg/L) & 52 & 43 & 57 & 65 \\
\hline Dissolved COD (mg/L) & 30 & 24 & 36 & 43 \\
\hline Iron (mg/L) & 0.76 & 0.98 & 0.70 & 1.2 \\
\hline
\end{tabular}

No UV light inhibitor was added to the water to artificially modify the UVT to a desired value. The UVT's used to perform the CB tests were caused by naturally occurring substances and/or particles present in the effluent. As seen in Table 4.16, test \#1 and \#2 were performed with UVT's of 52.5 and $54.5 \%$ respectively (representing average effluent water quality conditions). Test \#3 was used to represent best water quality conditions with an UVT of $56.5 \%$ while test \#4 was used to represent worst water quality conditions with an UVT of 39.5\%. Tests \#1, \#3, and \#4 were performed with UV doses of $0,5,10,20,40$, and $80 \mathrm{~mJ} / \mathrm{cm}^{2}$ while test \#2 was performed with UV doses of $0,5,7.5,10,30$, and $80 \mathrm{~mJ} / \mathrm{cm}^{2}$. The surviving E. coli counts obtained for each CB test performed are shown in Table 4.17. 
Table 4.17. Counts of surviving E. coli under different UV dose.

\begin{tabular}{|c|c|c|c|c|}
\hline $\begin{array}{c}\text { Dose } \\
\left(\mathbf{m} \mathbf{J} / \mathbf{c m}^{2}\right)\end{array}$ & $\begin{array}{c}\text { T1 } \\
(\mathbf{M P N} / \mathbf{1 0 0 m L})\end{array}$ & $\begin{array}{c}\text { T2 } \\
(\mathbf{M P N} / \mathbf{1 0 0 m L})\end{array}$ & $\begin{array}{c}\text { T3 } \\
(\mathbf{M P N} / \mathbf{1 0 0 m L})\end{array}$ & $\begin{array}{c}\text { T4 } \\
(\mathbf{M P N} / 100 m L)\end{array}$ \\
\hline 0 & 8,369 & 4,950 & 7,053 & 16,737 \\
\hline 5 & 869 & 286 & 263 & 4,385 \\
\hline 7.5 & - & 99 & - & - \\
\hline 10 & 112 & 85 & 68 & 1,159 \\
\hline 20 & 80 & - & 42 & - \\
\hline 30 & - & 28 & - & 239 \\
\hline 40 & 40 & - & 15 & 115 \\
\hline 80 & 8 & 10 & 7 & 66 \\
\hline
\end{tabular}

As seen in Table 4.17, initial E. coli counts varied significantly from test to test. Test \#4, which was used to represent worst-case water quality conditions (UVT of 39.5\%) coincides with the highest initial E. coli count of the four CB tests. Turbidity and TSS were also the highest during test \#4. That particular test took place on the day after a significant storm event had occurred. Because of that, a larger amount of wastewater particles may have ended up in the plant's effluent due to the reduced HRT through the plant. As mentioned in Chapter 2, E. coli are capable of attaching to wastewater particles (Loge et al., 1999; Qualls et al., 1985). The fact that the reduction of the HRT hinders settling of wastewater particles in upstream treatment processes could explain the fact that during rain events, E. coli survival through upstream treatment increases due to their attachment capabilities to wastewater particles.

E. coli data displayed in Table 4.17 was used to develop surviving E. coli counts doseresponse curves for this research study. These dose-response curves are shown in Figure 4.54. 


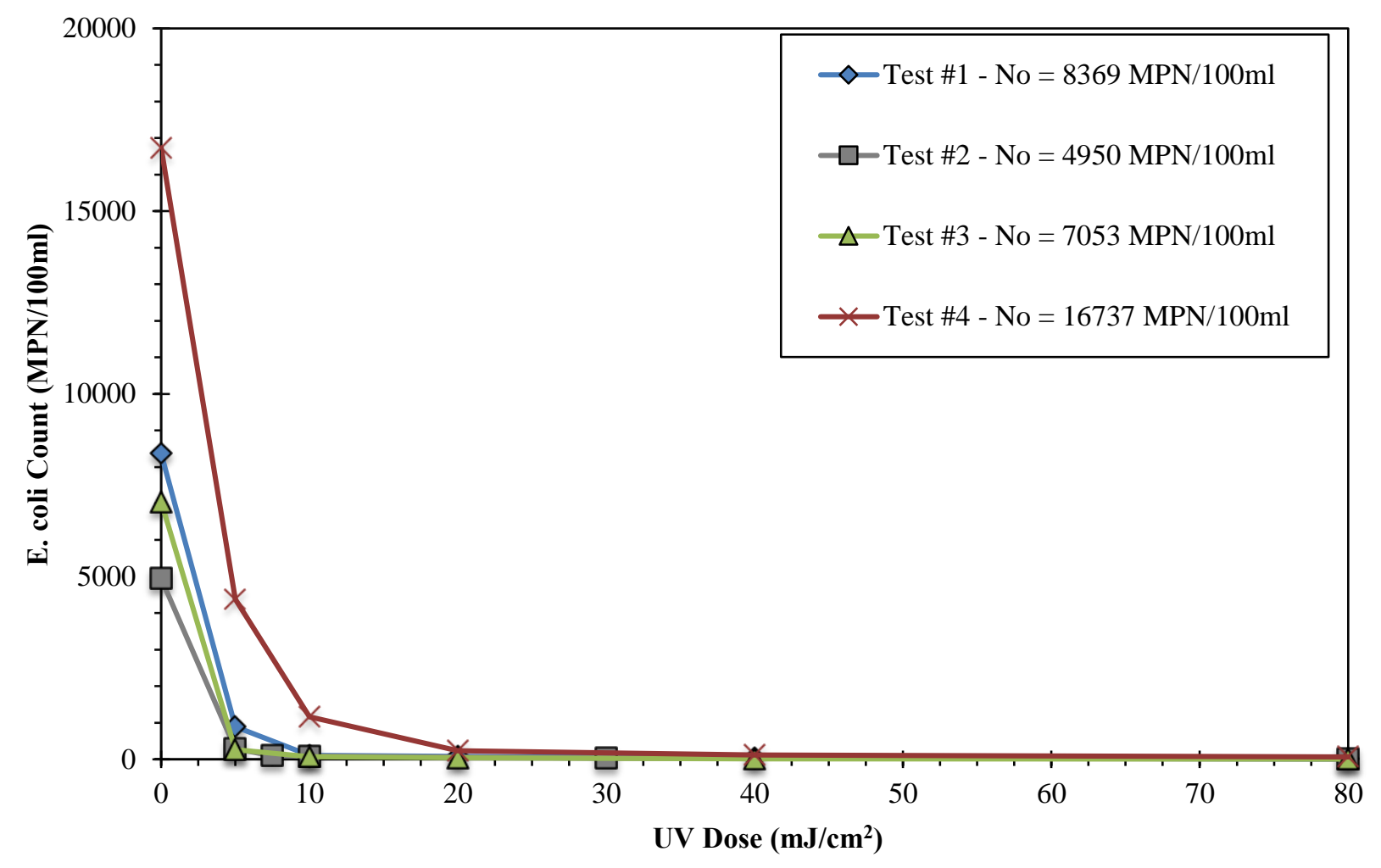

Figure 4.54. Surviving E. coli dose-response curves.

The dose-response curves shown in Figure 4.54 display similar characteristics of those found in previous research studies by Emerick et al. (1999), linear microorganism response at low doses and slowdown of the microorganism's response at higher UV doses. It is essential to highlight once again the importance of designing a UV disinfection system around a minimum or design UV dose capable of disinfecting the water for worst-case water quality conditions to meet disinfection discharge standards. The impact of water quality on the UV dose needed to meet discharge standards can be studied by analyzing carefully the dose-response curves displayed in Figure 4.55.

The E. coli data displayed in Figure 5.55 is the same as in Figure 4.54. However, the range of the y-axis has been reduced to be able to identify the UV dose needed to meet discharge 
standards for each CB test. The red arrows shown in Figure 4.55 highlight such dose for each test performed. Additionally, the UV doses obtained for each test are shown in Table 4.18.

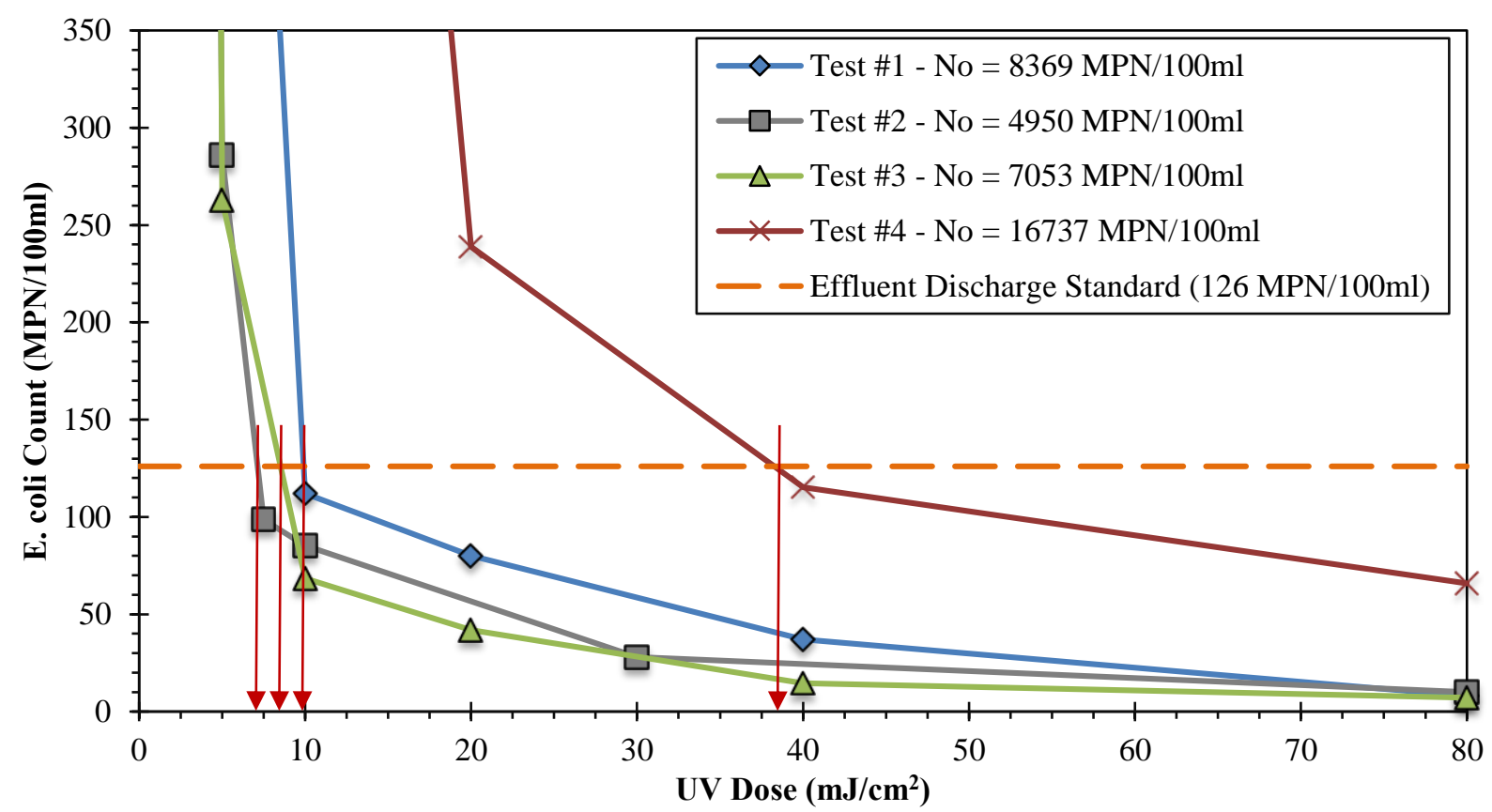

Figure 4.55. Determination of UV dose that meets disinfection discharge standards for each CB test.

Table 4.18. Determination of design UV dose from the CB tests performed.

\begin{tabular}{|c|c|c|c|c|}
\hline Parameter & T1 & T2 & T3 & T4 \\
\hline UV Dose $\left(\mathrm{mJ} / \mathrm{cm}^{2}\right)$ & 9.9 & 7.1 & 8.5 & 38.3 \\
\hline
\end{tabular}

As seen in Figure 4.55 and Table 4.18, the UV dose needed to meet discharge standards increases significantly when water quality worsens, highlighting once again the importance of performing a $\mathrm{CB}$ for worst-water quality conditions expected to be experienced on site. As seen in Table 4.18, the design UV dose of the future disinfection system based on water quality conditions must be equal or greater than $38.3 \mathrm{~mJ} / \mathrm{cm}^{2}$. 


\subsubsection{Model Development for E. coli Inactivation Achieved in the Collimated Beam}

Although the dose-response curves shown in Figures 4.55 can be used to determine the design UV dose for the full-scale system based on water quality conditions, the curves cannot be used to perform a proper kinetic study of the E. coli's response to UV light. Log inactivation doseresponse curves were developed using the surviving E. coli count data displayed in Table 4.17 to study kinetic behavior. The E. coli log inactivation dose-response curves developed are shown in Figure 4.56. Log inactivation data shown in Figure 4.56 can be found in Appendix E, Table E.1.

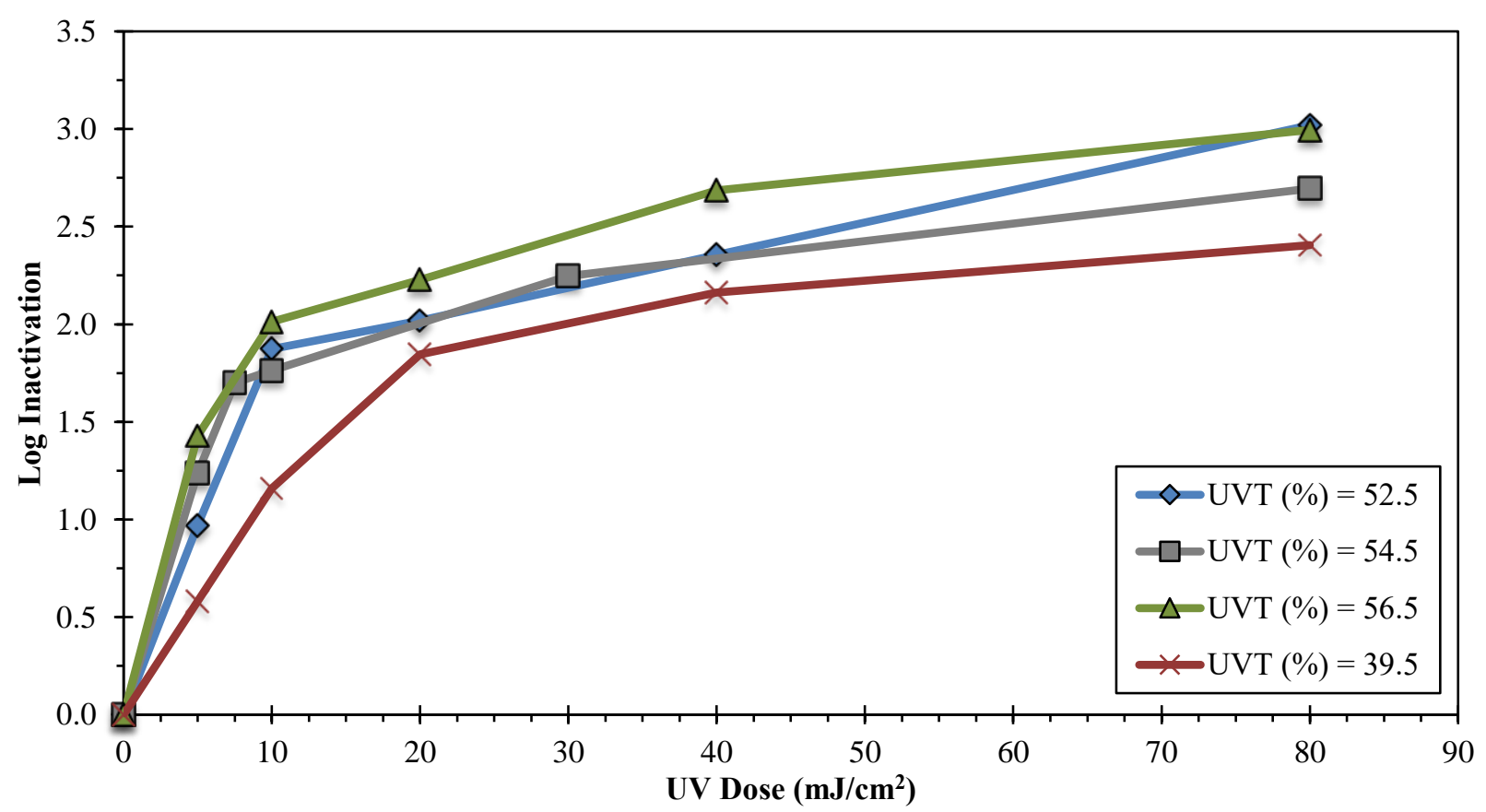

Figure 4.56. E. coli log inactivation dose-response curves.

The $\log$ E. coli inactivation dose-response curves shown in Figure 4.56 are not straight lines. At higher UV doses, E. coli inactivation rate decreased. This tailing phenomenon was observed by many researchers (Emerick et al., 1999; Madge \& Jensen, 2006; Qualls et al., 1985). Since the dose-response curves exhibit tailing response, the first-order model widely applied to 
relate inactivation rate to UV dose cannot be used in this study to explain the full set of experimental results. As mentioned in Chapter 2, it has been hypothesized that tailing of the doseresponse curves is likely due to the sheltering effect of wastewater particles present in the sample subjected to UV light (Azimi et al., 2012; Emerick et al., 2000). Because of the sheltering and shading effects, not all the microorganisms are exposed to the same intensity of UV light. That is the reason why dispersed microorganisms tend to experience exponential first-order kinetics at low UV doses followed by a slowdown of the rate of inactivation at higher UV doses (Emerick et al., 2000).

Kinetic studies performed on the log inactivation dose-response curves resulted in a second-order batch model successfully explaining the non-linearity of the curves. Derivation of the second-order batch model used to interpret the experimental data is shown in Equations 4.13 through 4.15 .

$$
\frac{d N}{d t}=-K N^{2} I
$$

Where $N$ represents the E. coli count; $t$ represents the amount of time the microorganisms were exposed to UV light; I represents the average germicidal irradiance across the petri dish during each test; and $K$ is the second-order rate constant. The intensity of UV radiation, $I$, was assumed to be constant in solving this rate equation.

$$
\begin{gathered}
\int_{N_{o}}^{N} \frac{1}{N^{2}} d N=-K I \int_{0}^{t} d t \\
\frac{N}{N_{o}}=\frac{1}{1+K N_{o} D}
\end{gathered}
$$


$\mathrm{N}_{\mathrm{o}} \quad=$ E. coli count without any exposure to UV light (MPN/100ml)

$\mathrm{N}=\mathrm{E}$. coli count after exposure to a given UV dose D (MPN/100ml)

$\mathrm{D} \quad=\mathrm{UV}$ dose $\left(\mathrm{mJ} / \mathrm{cm}^{2}\right)$

$\mathrm{k}=$ Second-order kinetic rate constant $\left(100 \mathrm{mlcm}^{2} / \mathrm{MPNmJ}\right)$

The E. coli experimental data displayed in Table 4.17 was simulated using Equation 4.15. E. coli inactivation data was modeled by adjusting the second-order rate constant $(k)$ using a nonlinear least squares method procedure. Modeling results of the E. coli inactivation achieved with the CB apparatus are shown in Figure 4.57. The second-order rate constant values obtained from modeling each CB test are shown in Table 4.19.

Table 4.19. Second-order rate constants obtained from modeling the experimental data.

\begin{tabular}{|c|c|}
\hline \multirow{2}{*}{ CB Test } & $\begin{array}{r}\text { Second-Order Rate Constant } \\
\left(100 \mathrm{mlc}^{2} / \mathrm{MPNmJ}\right)\end{array}$ \\
\cline { 2 - 2 } T1 & 0.000661 \\
\hline T2 & 0.001088 \\
\hline T3 & 0.001312 \\
\hline T4 & 0.000125 \\
\hline
\end{tabular}




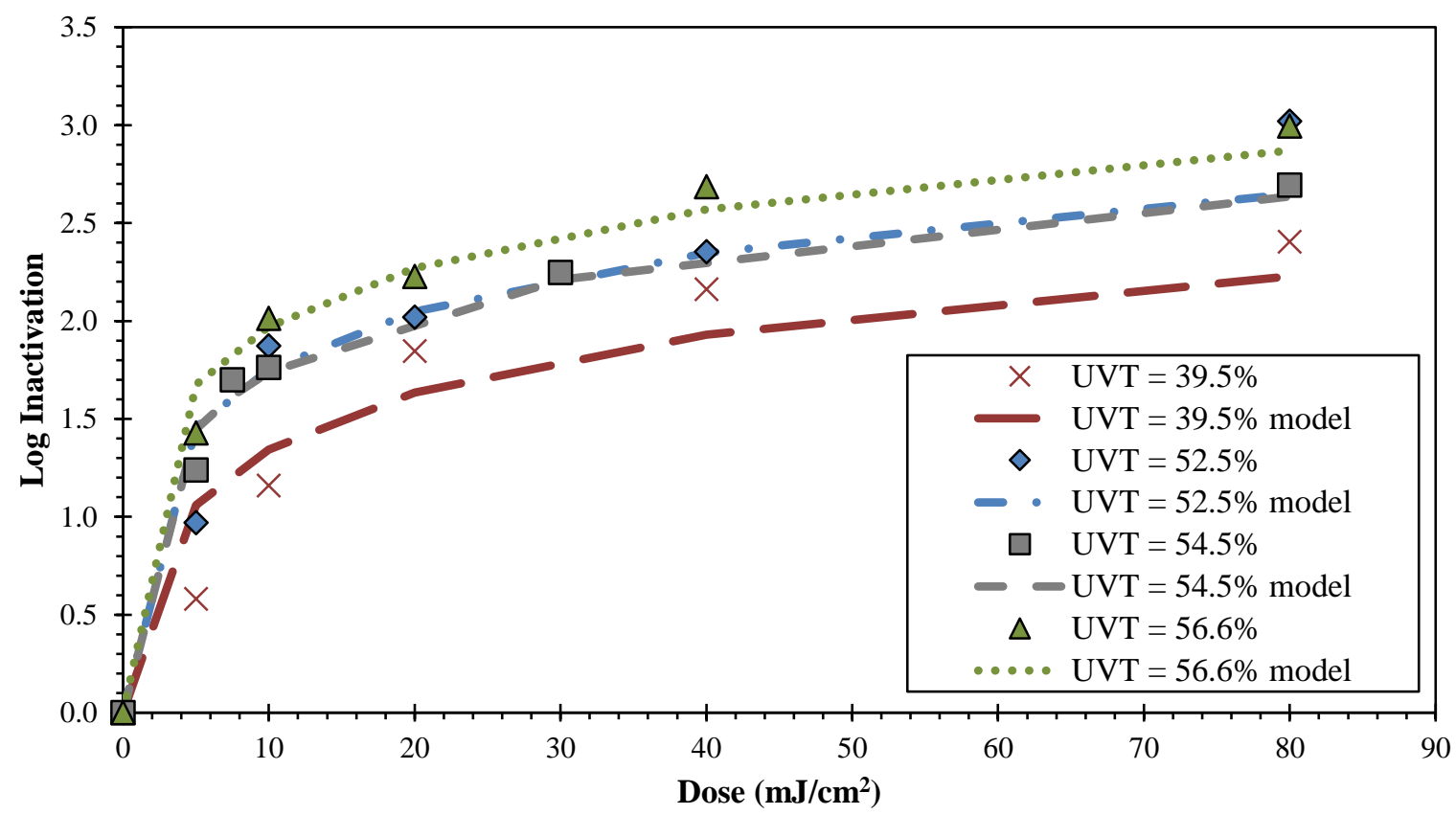

Figure 4.57. Use of second-order approach to model dose-response curves.

As seen in Figure 4.57, the kinetic model is successful at explaining the tailing response of the dose-response curves for any given water quality conditions. Utilization of a simple secondorder kinetic model to explain the response of E. coli to UV light has not been found in previous research studies. Instead, previous literature studies focus on the development of modified firstorder kinetic models to explain the dose-response curve behavior.

\subsubsection{Impact of Water Quality and Influent E. coli count on Rate of Inactivation}

Several research efforts found in the literature are capable of modeling the tailing response of the dose-response curves by making modifications of the first-order kinetic equation (Emerick et al., 2000; Hassen et al., 2000). However, as mentioned in Chapter 2, these modifications often 
result in complicated models. Additionally, due to the complexity of such approaches, clear relationships between water quality conditions and rate of inactivation cannot usually be made.

In addition to modeling the E. coli inactivation behavior correctly, the second-order kinetic model proposed in this study can also be successfully related to water quality conditions. As seen in Figure 4.58, an exponential relationship exists between the second-order kinetic rate constant (k) of the second-order kinetic model (shown in Table 4.19) and UVT.

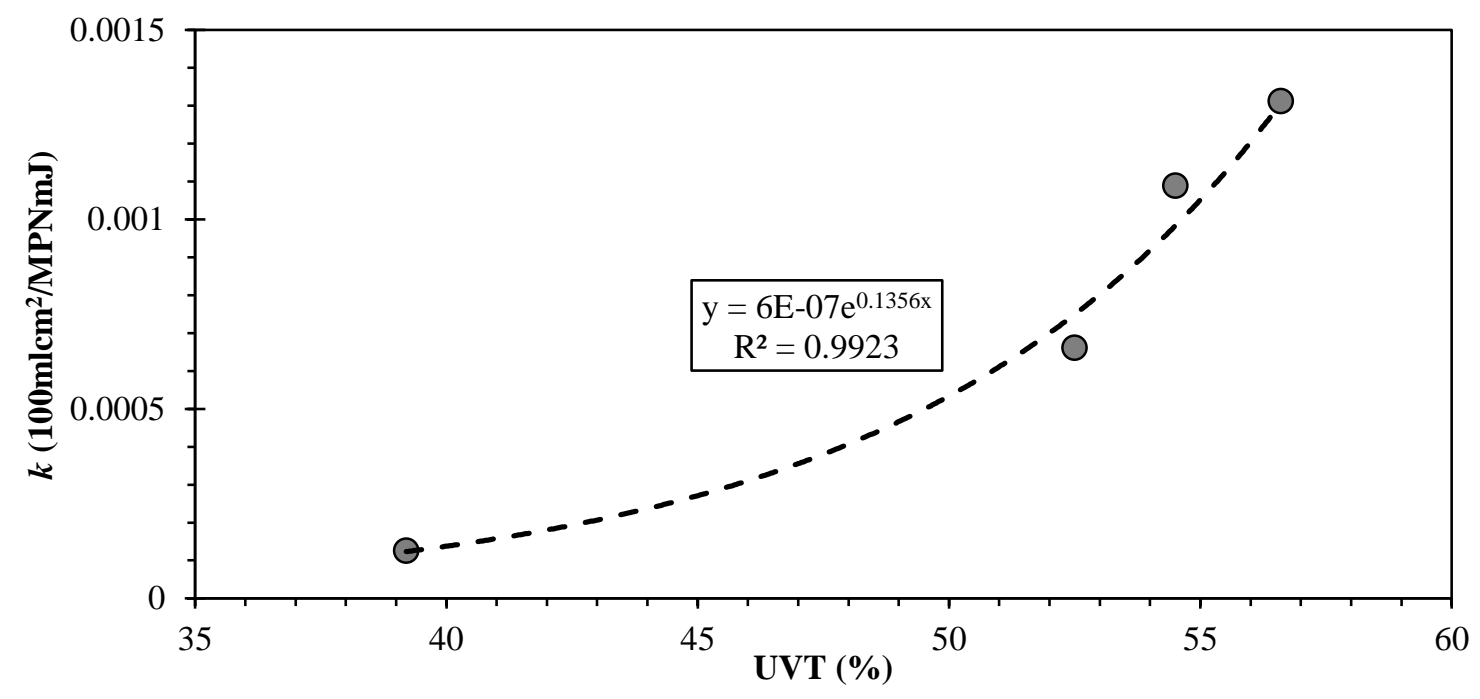

Figure 4.58. UVT and second-order rate kinetic constant relationship.

This relationship can be used to predict the impact that UVT has on the rate of the inactivation of the reaction. Higher UVT's will yield larger second-order kinetic rate constants, thus increasing the rate of the inactivation response of E. coli to UV light. In addition to UVT affecting the rate of the reaction, the use of a second-order model also accounts for the impact of the initial E. coli count on the inactivation rate, which means that the performance of UV light is also controlled by initial E. coli count. The model shown in Equation 4.15 and the relationship displayed in Figure 4.58, allows for calculation of the desired UV dose needed to disinfect an 
effluent based on three key parameters: (i) E. coli discharge standard count, (ii) initial E. coli count, (iii) and UVT of the water being treated. 


\section{CHAPTER 5. CONCLUSIONS AND RECOMMENDATIONS}

The conclusions drawn from this research conducted at the Fargo WWTP and future research recommendations to further assess the applicability of UV disinfection for wastewater applications in Fargo, ND are addressed in this chapter.

\subsection{Conclusions from Research}

The final conclusions drawn from the results obtained for this study are shown in the following sections.

\subsubsection{Conclusions drawn from Intensity and Fouling Studies}

- Heat-induced precipitation of metal salts was the main mechanism by which fouling material deposits on the quartz sleeves. This was proven by performing fouling material analysis, comparing the intensity loss rates experienced in the quartz sleeves and the sensor, and testing the effects of quartz sleeve temperature on intensity behavior.

- UV intensity drop over time due to fouling material accumulation was successfully modeled by the application of the Beer-Lambert law with the assumption that fouling material accumulation on the quartz sleeves occurred at a constant rate.

- Upon modeling, it was found that under the experimental conditions of this study, the intensity loss rate of the quartz sleeves was not affected by flow rate and UVT. However, intensity loss rate of the sensor, which was significantly lower than the one experienced in the quartz sleeve, was affected by flow rate and UVT. Indicating, that the fouling mechanisms experienced in this study may not be limited to heat-induced precipitation. 


\subsubsection{Conclusions drawn from the Disinfection Achieved in the Pilot Unit}

- E. coli inactivation rate achieved in the pilot system used for this research study was directly related to the UV intensity maintained inside the chamber and the hydraulic residence time of the water being treated.

- A first-order plug flow kinetic model was successfully used to interpret the E. coli inactivation data of the pilot system. The proposed kinetic model can be used to calculate the UV dose required to meet effluent discharge standards based on initial microorganism count.

\subsubsection{Conclusions drawn from the Water Quality and UVT Studies}

- It was found that most of the UVT loss (79\% of the loss) was caused by absorption of UV light from dissolved substances. The remaining portion of the UVT loss (21\%) was triggered by the scattering of UV light from particles present in the water (both suspended and colloidal). Within the UVT loss due to scattering, suspended particles were more successful at scattering UV light when compared to colloidal particles due to their overall larger size.

- UVT variation was found closely related to the concentration of COD. In addition to COD, turbidity correlated well with UVT. However, the relationships developed between COD concentrations and UVT are stronger than the one developed with turbidity.

- No seasonal variation in terms of average UVT was identified. However, significant short term UVT variations were found during the summer season caused by large storm events. 


\subsubsection{Conclusions drawn from the Collimated Beam Study}

- Tailing, which represents the slowdown of the inactivation rate at higher UV doses, can be observed in the dose-response curves developed in this study. Due to the impacts of tailing on the inactivation rate, a first-order kinetic model cannot be used to successfully explain the behavior of the dose-response curves. Instead, a second-order kinetic model was successfully applied to explain the experimental data obtained with the CB apparatus.

- In addition to explaining the behavior or the dose-response curves correctly, the secondorder model was able to account for the impact of initial microorganism count on the E. coli inactivation rate. Furthermore, the second-order model's reaction rate constant was found to be exponentially affected by UVT. The higher the UVT, the larger the rate constant, the faster the inactivation rate occurs.

\subsection{Research Recommendations}

This section of the report presents several areas of improvement to further evaluate the application of UV disinfection for wastewater applications in North Dakota. Such opportunities include:

- Monitor iron concentrations at different locations throughout the Fargo sanitary sewer system during two different scenarios: (i) normal operating conditions (ferrous being added throughout the system), and (ii) ferrous not being added. Comparison of iron concentrations obtained under both scenarios would ultimately allow a study of the impact of ferrous addition on the iron concentrations experienced in the influent and effluent of the Fargo WWTP. Furthermore, the individual impact of iron in fouling material formation 
can be more accurately assessed by studying the different fouling rates that would have been experienced under both operational scenarios.

- Since both calcium and iron formed the majority of the fouling material deposited onto the quartz sleeves, it would have been productive to incorporate calcium sampling and testing to study the combined role of calcium and iron on fouling material formation and rate of intensity lost through the quartz sleeves.

- Improve understanding of fouling material composition by incorporating total organic carbon and total carbon tests to the fouling material analyses. Incorporating these tests to the fouling material analyses would allow to estimate the percentage of fouling material associated to organic and inorganic constituents. By knowing the distribution of organic and inorganic fouling material one could provide a more accurate conclusion of the type of fouling mechanism taking place at the Fargo WWTP.

- As mentioned in Section 4.1.5, heat-induced precipitation may not be the only fouling mechanism promoting the deposition of fouling material on the quartz sleeves. Due to that, a study could have been performed to investigate what other fouling mechanism may be contributing to fouling material formation at the Fargo WWTP.

- Previous studies found in the literature suggest that the UVT experienced in plant's effluents is affected by the type of upstream treatment processes (Emerick et al., 1999). A parallel study could have been done between the Moorhead WWTP (treatment type: activated sludge) and the Fargo WWTP (treatment type: trickling filter) to test the impacts of upstream treatment type conditions on effluent UVT. 
- Further investigate the reason why E. coli inactivation behaved as second-order when exposed to UV light under the CB apparatus but it behaved as first-order when exposed to UV light in the pilot unit. 


\section{REFERENCES}

Alyaa M., Eila, T., Veijalainen, A., \& Helvi, H. (2016). The effect of UV and combined chlorine/UV treatment on Coliphages in drinking water disinfection. Journal of Applied Microbiology, 8(130), 1-9.

Azimi, Y., Allen, D. G., \& Farnood, R. R. (2012). Kinetics of UV inactivation of wastewater bioflocs. Water Research, 46(12), 3827-3836.

Barber, L. B., Hladik, M. L., Vajda, A. M., Fitzgerald, K. C., \& Douville, C. (2015). Impact of wastewater infrastructure upgrades on the urban water cycle: Reduction in halogenated reaction byproducts following conversion from chlorine gas to ultraviolet light disinfection. Science of The Total Environment, 529, 264-274.

Batch, L. F., Schulz, C. R., \& Linden, K. G. (2004). Evaluating water quality effects on UV disinfection of MS2 Coliphage. Journal - American Water Works Association Journal, $96(7), 75-87$

Betancourt, W. Q., \& Rose, J. B. (2004). Drinking water treatment processes for removal of Cryptosporidium and Giardia. Veterinary Parasitology, 126(1-2), 219-234.

Beer, A. (1852). Determination of the absorption of red light, in colored liquids. Annalen der Physik, 168(5), 78-88.

Blatchley, E. R., Bastian, C., Duggirala, R. K., Alleman, J. E., Moore, M., \& Schuerch, P. (1996). Ultraviolet irradiation and chlorination/dechlorination for municipal wastewater disinfection. Water Environment Research, 68(2), 194-204.

Blatchley, E. R., Dumoutier, N., Halaby, T. N., Levi, Y., \& Laine, J. M. (2001). Bacterial Responses to Ultraviolet Irradiation. Water Science and Technology, 43(10), 179-186. 
Bohren, C. F., \& Huffman, D. R. (1983). Absorption and Scattering of Light by Small Particles. Weinheim: Wiley-VCH Verlag.

Bohrerova, Z., \& Linden, K. G. (2006). Assessment of DNA damage and repair in Mycrobacterium terrae after exposure to UV radiation. Journal of Applied Microbiology, 101(5), 995-1001.

Bolton, J. R., \& Linden K. G. (2003). Standardization of Methods for Fluence (UV Dose) Determination in Bench-Scale UV Experiments. Journal of Environmental Engineering, 129(3), 209-215.

Bryant, E. A., Fulton, G. P., \& Budd, G. C. (1992). Disinfection Alternatives for Safe Drinking Water. New York: Van Nostrand Reinhold.

Carpenter, C., Fayer, R., Trout, J., \& Beach, M. J. (1999). Chlorine disinfection of recreational water for Cryptosporidium parvum. Emerging Infectious Diseases, 5(4), 579-584.

Certificate of Analysis - Final Report, Trojan UV, 2013.

City of Fargo, North Dakota, Wastewater Treatment Facility Plan, Apex Engineering Group, Inc., 2014.

Chang, J. C., Ossoff, S. F., Lobe, D. C., Dorfman, M. H., Dumais, C. M., Qualls, R. G., \& Johnson, J. D. (1985). UV inactivation of pathogenic and indicator microorganisms. Applied and Environmental Microbiology, 49(6), 1361-1365.

Chawla S., Parashar, R., \& Parashar, P. (2015). Is estimation of residual free chlorine in water by drop number titration method reliable? Investigation of statistical, pragmatic, psychological and philosophical reasons. International Journal of Pharmaceutical Sciences and Research, 2, 11-18. 
Darby, J. L., Snider, K. E., \& Tchobanoglous G. (1993). Ultraviolet Disinfection for Wastewater Reclamation and Reuse Subject to Restrictive Standards. Water Environment Research, 65(2), 169-180.

Emerick, R. W., Loge, F. J., Ginn, T., \& Darby, J. L. (2000). Modeling the Inactivation of ParticleAssociated Coliform Bacteria. Water Environment Research, 72(4), 432-438.

Emerick, R. W., Loge, F. J., Thompson, D., \& Darby, J. L. (1999). Factors Influencing Ultraviolet Disinfection Performance Part II: Association of Coliform Bacteria with Wastewater Particles. Water Environment Research, 71(6), 1178-1187.

Final Report - Evaluation of Ultraviolet Radiation Disinfection Technologies for Wastewater Treatment Plant Effluent, New York State Energy Research and Development Authority (NYSERDA), 2004.

Flores, R. J., Terres-Pena, H. Vaca, M. M., Lopez, C. R., Lazardi-Ramos, A., \& Rojas-Valencia, M. N. (2015). Disinfection of an activated primary effluent using peracetic acid or ultraviolet radiation for its reuse in public services. Journal of Water and Health, 13(1), $118-124$.

Gilley, A., Foster, J., Hunter, G., Cambridge, D., Botero, L. (2008). UV Process and Fouling Testing at Trickling Filter Plant: Key Factors in UV Design for Trickling Filter Effluent. IUVA News, 10(3), 19-22.

Gehr, R., \& Wright, H. (1998). UV disinfection of wastewater coagulated with ferric chloride: Recalcitrance and fouling problems. Water Science and Technology, 38(3), 15-23.

Gehr, R. \& Sehnaoui, K. (2001). Fouling of UV Lamp Sleeves: Exploring Inconsistencies in the Role of Iron. Presented at the First International Congress on Ultraviolet Technologies, Washington D.C., June 14-16; International UV Association: Ayr, Ontario, Canada 
Germicidal Lamp Basics, Light Sources Inc., 2013.

Hais, A. B., \& Venosa A. D. (1978). EPA Overview of Municipal Wastewater Disinfection. Journal of Water Pollution Control Federation, 50(11), 2470-2476.

Harris, G. D., Adams, D. V., Sorensen, D. L., \& Dupont, R. R. (1987). The Influence of Photoreactivation and Water Quality on Ultraviolet Disinfection of Secondary Municipal Wastewater. Journal of Water Pollution Control Federation, 59(8), 781-787.

Hassen, A., Mahrouk, M., Ouzai, H., Cherif, M., Boudabous, A., \& Damelincourt, J. J. (2000). UV disinfection of treated wastewater in a large-scale pilot plant and inactivation of selected bacteria in a laboratory UV device. Bioresource Technology, 74(2), 141-150.

Jolis, D., Lam, C., \& Pitt, P. (2001). Particle effects of ultraviolet disinfection of coliform bacteria in recycled water. Water Environment Research, 73(2), 233-236.

Kashimada, K., Kamiko, N., Yamamoto, K., \& Ohgaki, S. (1996). Assessment of photoreactivation following ultraviolet light disinfection. Water Science and Technology, 33(10-11), 261-269.

Knudson, G. B. (1985). Photoreactivation of UV-irradiated Legionella pneumophila and other Legionella species. Applied and Environmental Microbiology, 49(4), 975-980.

Kuo, J., Chen, C., \& Nellor, M. (2003). Standardized collimated beam testing protocol for water/wastewater ultraviolet disinfection. Journal of Environmental Engineering, 129(8), 774-779.

Lazarova, V., Janex, M. L., Fiksdal, L., Oberg, C., Barcina, I., \& Pommepuy, M. (1998). Advanced wastewater disinfection technologies: Short and long term efficiency. Water Science and Technology, 32(12), 109-117. 
Liao, B. Q., Allen, D. G., Leppard, G. G., Droppo, I. G., \& Liss, S. N. (2002). Interparticle Interactions Affecting the Stability of Sludge Flocs. Journal of Colloid and Interface Science, 249(2), 372-380.

Lin, L., Johnston, C. T., \& Blatchley, E. R. (1999a). Inorganic fouling at quartz: water interfaces in ultraviolet photoreactors-I. Chemical characterization. Water Research, 33(15), 33213329.

Lin, L., Johnston, C. T., \& Blatchley, E. R. (1999b). Inorganic fouling at quartz: water interfaces in ultraviolet photoreactors-II. Temporal and spatial distributions. Water Research, 33(15), 3330-3338.

Lin, L., Johnston, C. T., \& Blatchley, E. R. (1999c). Inorganic fouling at quartz: water interfaces in ultraviolet photoreactors-III. Numerical modeling. Water Research, 33(15), 3339-3347.

Loge, F. J., Emerick, R. W., Thompson, D. E., Nelson, D. N., \& Darby, J. L. (1999). Factors Influencing Ultraviolet Disinfection Performance Part I: Light Penetration to Wastewater Particles. Water Environment Research, 71(3), 377-381.

Lu, G., Li, C., Zheng, Y., \& Deng, A. (2012). Effect of different coagulants on the ultraviolet light intensity attenuation. Desalination and Water Treatment, 37(1-3), 302-307.

Madge, B., \& Jensen, J. (2006). UV Disinfection of fecal coliform in municipal wastewater: effects of particle size. Water Environment Research, 78(3), 294-304.

Mamane, H. (2008). Impact of particles in UV disinfection of water and wastewater effluents: a review. Reviews in Chemical Engineering, 24(2-3), 67-157.

Morowitz, H. J. (1950). Absorption Effects in Volume Irradiation Dosimetry. Science, 111, 229230. 
Mounaouer, B., \& Abdennaceur, H. (2012). Ultraviolet Radiation for Microorganism Inactivation in Wastewater. Journal of Environmental Protection, 3, 194-202.

Mounaouer, B., \& Abdennaceur, H. (2016). Modeling and kinetic characterization of wastewater disinfection using chlorine and UV radiation. Environmental Science and Pollution Research, 23, 19861-19875.

Nessim, Y., \& Gehr, R. (2006). Fouling mechanisms in a laboratory-scale UV disinfection system. Water Environment Research, 78(12): 2311-2323.

North Dakota Century Code. (1994). Certification of Water and Wastewater Systems Operations. Article 33-19.

Oguma, K., Katayama, H., \& Ohgaki, S. (2002). Photoreactivation of Escherichia coli after lowor medium-pressure UV disinfection determined by an endonuclease sensitive site assay. Applied and Environmental Microbiology, 68(12), 6029-6035.

Oliver, M. (2002). Validation of Cleaning Methods of UV Disinfection Systems. Proceedings of Disinfection 2002 Specialty Conference, St. Petersburg. Florida, February 17-20; Water Environment Federation: Alexandria, Virginia.

Orta de Velasquez, M. T., Rojas-Valencia, M. N., \& Ayala, A. (2008). Wastewater Disinfection Using Ozone to Remove Free-Living, Highly Pathogenic Bacteria and Amoebae. Ozone: Science \& Engineering, 30(5), 367-375.

Peng, J., Qiu, Y., \& Gehr, R. (2005). Characterization of permanent fouling on surfaces of UV lamps used for wastewater disinfection. Water Environment Research, 77(4), 309-322.

Pfeifer, G. P., You, Y., \& Besaratinia, A. (2005). Mutations induced by ultraviolet light. Mutation Research - Fundamental and Molecular Mechanisms of Mutagenesis, 571(1-2): 19-31. 
Qualls, R. G., Flynn, M. P., \& Johnson, D. J. (1983). The Role of Suspended Particles on Ultraviolet Disinfection. Water Pollution Control Federation, 55(10), 1280-1285.

Qualls, R. G., Ossoff S. F., Chang, J. C., Dorfman, M. H., Dumais, C. M., Lobe, D. C., \& Johnson, D. J. (1985). Factors Controlling Sensitivity in UV disinfection of Secondary Effluents. Water Pollution Control Federation, 57(10), 1006-1011.

Record of Climatological Observations for July - United States Department of Commerce, Station: Fargo Hector International Airport, 2016.

Reed, N. G. (2010). The history of ultraviolet germicidal irradiation for air disinfection. Public Health Reports, 125(1), 15-27.

Sheriff, M., \& Gehr, R. (2001). Laboratory Investigation of Inorganic Fouling of Low Pressure UV Disinfection Lamps. Journal of Water Quality Research, 36(1), 71-92.

Small, G. D., \& Greimann C. S. (1977). Photoreactivation and dark repair of ultraviolet lightinduced pyrimidine dimers in chloroplast DNA. Nucleic Acids Research, 4(8), 2893-2902.

Ultraviolet Radiation. (2016, November $23^{\text {rd }}$ ). Retrieved from Government of Canada, Canadian Centre for Occupational Health and Safety: https://www.ccohs.ca/

U.S. Army Public Health Command (USAPHC). (2004). Ultraviolet Light Disinfection in the Use of Individual Water Purification Devices. Technical Information Paper \#31-006-0211

U.S. Environmental Protection Agency (USEPA) (1986). Design Manual: Municipal Wastewater Disinfection. D.C. Office of Water.

U.S. Environmental Protection Agency (USEPA) (2003). Ultraviolet Disinfection Guidance Manual. D.C. Office of Water.

U.S. Environmental Protection Agency (USEPA) (1999). Ultraviolet Radiation. D.C. Office of Water. 
Wait, I. W., \& Blatchley, E. R. (2010). Model of Radiation Transmittance by Inorganic Fouling on UV Reactor Lamp Sleeves. Water Environment Research, 82(11), 2272-2278.

Wait, I. W., Johnston, C. T., \& Blatchley, E. R. (2004). Fouling of Quartz Surfaces in Potable Water Ultraviolet Disinfection Systems: Effect of Phosphate Addition. American Society of Civil Engineers. 1-12.

Whitby, G. E., Palmateer, G., Cook, W. G., Maarschalkerweerd, J., Huber, D., \& Flood, K. (1984). Ultraviolet Disinfection of Secondary Effluent. Water Pollution Control Federation, 56(7), 844-850.

Yuan, Y., \& Farnood, R. R. (2010). Strength and breakage of activated sludge flocs. Powder Technology, 199(2), 111-119. 


\section{APPENDIX A. INTENSITY AND FOULING DATA}

Table A.1. Intensity data collected for initial eight test cycles.

\begin{tabular}{|c|c|c|c|}
\hline $\begin{array}{l}\text { Cycle } \\
\text { Number }\end{array}$ & $\begin{array}{c}\text { Hours of Operation } \\
\text { (hours) }\end{array}$ & $\begin{array}{l}\text { Flow } \\
\text { (gpm) }\end{array}$ & $\begin{array}{c}\text { UV Intensity } \\
\left(\mathrm{mW} / \mathrm{cm}^{2}\right)\end{array}$ \\
\hline \multirow{8}{*}{$\mathrm{C} 1$} & 0 & 25.0 & 8.37 \\
\hline & 13 & 25.0 & 5.36 \\
\hline & 39 & 25.0 & 3.45 \\
\hline & 58 & 25.0 & 3.37 \\
\hline & 82 & 25.0 & 2.64 \\
\hline & 106 & 25.0 & 2.6 \\
\hline & 131 & 25.0 & 2.07 \\
\hline & 154 & 25.0 & 1.78 \\
\hline \multirow{9}{*}{$\mathrm{C} 2$} & 183 & 25.3 & 7.19 \\
\hline & 204 & 24.3 & 5.36 \\
\hline & 230 & 24.9 & 3.33 \\
\hline & 252 & 25.2 & 2.56 \\
\hline & 278 & 25.6 & 1.7 \\
\hline & 299 & 25.1 & 1.62 \\
\hline & 325 & 24.8 & 1.7 \\
\hline & 348 & 26.8 & 1.21 \\
\hline & 371 & 21.2 & 0.85 \\
\hline \multirow{9}{*}{$\mathrm{C} 3$} & 394 & 23.8 & 2.76 \\
\hline & 401 & 24.5 & 2.43 \\
\hline & 418 & 22.4 & 1.99 \\
\hline & 423 & 25.4 & 2.11 \\
\hline & 445 & 23.5 & 1.7 \\
\hline & 473 & 23.0 & 1.3 \\
\hline & 496 & 22.0 & 1.13 \\
\hline & 515 & 25.3 & 1.01 \\
\hline & 541 & 23.4 & 0.89 \\
\hline \multirow{6}{*}{$\mathrm{C} 4$} & 544 & 25.0 & 3.29 \\
\hline & 546 & 26.3 & 3.29 \\
\hline & 562 & 24.5 & 2.48 \\
\hline & 586 & 22.4 & 1.48 \\
\hline & 610 & 23.7 & 1.21 \\
\hline & 634 & 25.3 & 0.97 \\
\hline
\end{tabular}


Table A.1. Intensity data collected for initial eight test cycles (continued).

\begin{tabular}{|c|c|c|c|}
\hline $\begin{array}{l}\text { Cycle } \\
\text { Number }\end{array}$ & $\begin{array}{c}\text { Hours of Operation } \\
\text { (hours) }\end{array}$ & $\begin{array}{l}\text { Flow } \\
\text { (gpm) }\end{array}$ & $\begin{array}{l}\text { UV Intensity } \\
\left(\mathrm{mW} / \mathrm{cm}^{2}\right)\end{array}$ \\
\hline \multirow{3}{*}{$\mathrm{C} 4$} & 663 & 25.2 & 0.81 \\
\hline & 684 & 25.4 & 0.65 \\
\hline & 707 & 25.3 & 0.65 \\
\hline \multirow{3}{*}{ C5 } & 712 & 25.5 & 2.23 \\
\hline & 732 & 22.0 & 1.74 \\
\hline & 755 & 21.5 & 1.3 \\
\hline \multirow{6}{*}{ C6 } & 778 & 15.8 & 1.42 \\
\hline & 812 & 14.6 & 0.85 \\
\hline & 833 & 13.8 & 0.65 \\
\hline & 853 & 14.9 & 0.56 \\
\hline & 877 & 15.2 & 0.48 \\
\hline & 899 & 15.1 & 0.44 \\
\hline \multirow{10}{*}{ C7 } & 905 & 15.1 & 1.38 \\
\hline & 923 & 15.1 & 0.97 \\
\hline & 947 & 13.9 & 0.56 \\
\hline & 971 & 15.3 & 0.77 \\
\hline & 1002 & 14.5 & 0.56 \\
\hline & 1019 & 14.6 & 0.52 \\
\hline & 1020 & 15.6 & 0.48 \\
\hline & 1043 & 13.9 & 0.44 \\
\hline & 1066 & 14.5 & $\begin{array}{l}0.4 \\
\end{array}$ \\
\hline & 1091 & 15.1 & 0.32 \\
\hline \multirow{6}{*}{ C8 } & 1120 & 15.0 & 1.01 \\
\hline & 1122 & 16.5 & 0.85 \\
\hline & 1147 & 16.2 & 0.65 \\
\hline & 1172 & 15.8 & 0.52 \\
\hline & 1191 & 15.5 & 0.32 \\
\hline & 1216 & 15.2 & 0.32 \\
\hline
\end{tabular}


Table A.2. Intensity data collected for cycles 9-12 which was monitored with the SCADA system.

\begin{tabular}{|c|c|c|c|}
\hline $\begin{array}{c}\text { Cumulative Time of } \\
\text { Operation }\end{array}$ & $\begin{array}{c}\text { Time of Operation of } \\
\text { per Cycle }\end{array}$ & Flow & Intensity \\
\hline (Hours) & (Hours) & (gpm) & $\left(\mathrm{mW} / \mathrm{cm}^{2}\right)$ \\
\hline 0 & 0 & 20.0 & 13.62 \\
\hline 1 & 1 & 16.3 & 13.22 \\
\hline 2 & 2 & 16.1 & 12.49 \\
\hline 3 & 3 & 16.0 & 11.87 \\
\hline 4 & 4 & 15.9 & 10.94 \\
\hline 5 & 5 & 15.7 & 11.04 \\
\hline 6 & 6 & 16.0 & 10.53 \\
\hline 7 & 7 & 15.8 & 9.80 \\
\hline 8 & 8 & 15.8 & 10.01 \\
\hline 9 & 9 & 15.7 & 9.70 \\
\hline 10 & 10 & 15.2 & 9.60 \\
\hline 11 & 11 & 15.1 & 9.60 \\
\hline 12 & 12 & 15.1 & 9.49 \\
\hline 13 & 13 & 14.7 & 9.28 \\
\hline 14 & 14 & 14.8 & 9.18 \\
\hline 15 & 15 & 14.7 & 8.87 \\
\hline 16 & 16 & 14.4 & 8.25 \\
\hline 17 & 17 & 14.0 & 8.77 \\
\hline 18 & 18 & 13.5 & 8.66 \\
\hline 19 & 19 & 13.4 & 8.35 \\
\hline 20 & 20 & 13.6 & 7.84 \\
\hline 21 & 21 & 16.4 & 8.15 \\
\hline 22 & 22 & 16.0 & 7.63 \\
\hline 23 & 23 & 15.9 & 7.11 \\
\hline 24 & 24 & 15.9 & 7.42 \\
\hline 25 & 25 & 15.8 & 7.42 \\
\hline 26 & 26 & 15.6 & 7.42 \\
\hline 27 & 27 & 15.6 & 7.53 \\
\hline 28 & 28 & 15.4 & 7.22 \\
\hline 29 & 29 & 15.9 & 6.80 \\
\hline 30 & 30 & 15.7 & 6.39 \\
\hline 31 & 31 & 15.6 & 6.70 \\
\hline
\end{tabular}


Table A.2. Intensity data collected for cycles 9-12 which was monitored with the SCADA system (continued).

\begin{tabular}{|c|c|c|c|}
\hline $\begin{array}{c}\text { Cumulative Time of } \\
\text { Operation }\end{array}$ & $\begin{array}{c}\text { Time of Operation of } \\
\text { per Cycle }\end{array}$ & Flow & Intensity \\
\hline (Hours) & (Hours) & (gpm) & $\left(\mathrm{mW} / \mathrm{cm}^{2}\right)$ \\
\hline 32 & 32 & 15.4 & 6.49 \\
\hline 33 & 33 & 15.2 & 6.49 \\
\hline 34 & 34 & 14.2 & 6.18 \\
\hline 35 & 35 & 13.9 & 6.08 \\
\hline 36 & 36 & 14.0 & 5.98 \\
\hline 37 & 37 & 13.8 & 5.77 \\
\hline 38 & 38 & 13.7 & 5.67 \\
\hline 39 & 39 & 13.7 & 5.67 \\
\hline 40 & 40 & 13.6 & 5.36 \\
\hline 41 & 41 & 13.4 & 5.15 \\
\hline 42 & 42 & 13.3 & 5.36 \\
\hline 43 & 43 & 13.2 & 5.15 \\
\hline 44 & 44 & 13.3 & 5.05 \\
\hline 45 & 45 & 18.8 & 5.05 \\
\hline 46 & 46 & 18.6 & 4.74 \\
\hline 47 & 47 & 18.6 & 4.53 \\
\hline 48 & 48 & 18.5 & 4.22 \\
\hline 49 & 49 & 18.1 & 3.91 \\
\hline 50 & 50 & 18.0 & 3.60 \\
\hline 51 & 51 & 18.2 & 3.39 \\
\hline 52 & 52 & 18.2 & 3.39 \\
\hline 53 & 53 & 18.0 & 3.70 \\
\hline 54 & 54 & 18.0 & 3.60 \\
\hline 55 & 55 & 17.8 & 3.50 \\
\hline 56 & 56 & 18.0 & 3.39 \\
\hline 57 & 57 & 17.6 & 3.50 \\
\hline 58 & 58 & 17.5 & 3.50 \\
\hline 59 & 59 & 17.4 & 3.39 \\
\hline 60 & 60 & 17.3 & 3.29 \\
\hline 61 & 61 & 17.1 & 3.60 \\
\hline 62 & 62 & 17.3 & 3.50 \\
\hline 63 & 63 & 17.2 & 3.60 \\
\hline
\end{tabular}


Table A.2. Intensity data collected for cycles 9-12 which was monitored with the SCADA system (continued).

\begin{tabular}{|c|c|c|c|}
\hline $\begin{array}{c}\text { Cumulative Time of } \\
\text { Operation }\end{array}$ & $\begin{array}{c}\text { Time of Operation of } \\
\text { per Cycle }\end{array}$ & Flow & Intensity \\
\hline (Hours) & (Hours) & (gpm) & $\left(\mathrm{mW} / \mathrm{cm}^{2}\right)$ \\
\hline 64 & 64 & 16.9 & 3.50 \\
\hline 65 & 65 & 16.6 & 3.50 \\
\hline 66 & 66 & 16.7 & 3.50 \\
\hline 67 & 67 & 16.7 & 3.50 \\
\hline 68 & 68 & 16.8 & 3.39 \\
\hline 69 & 69 & 16.5 & 3.39 \\
\hline 70 & 70 & 16.5 & 3.29 \\
\hline 71 & 71 & 16.7 & 3.19 \\
\hline 72 & 72 & 16.6 & 3.08 \\
\hline 73 & 73 & 16.7 & 2.88 \\
\hline 74 & 74 & 16.6 & 2.88 \\
\hline 75 & 75 & 16.7 & 2.88 \\
\hline 76 & 76 & 16.7 & 2.67 \\
\hline 77 & 77 & 16.6 & 2.77 \\
\hline 78 & 78 & 16.2 & 2.77 \\
\hline 79 & 79 & 16.4 & 2.77 \\
\hline 80 & 80 & 16.2 & 2.57 \\
\hline 81 & 81 & 16.3 & 2.57 \\
\hline 82 & 82 & 16.5 & 2.57 \\
\hline 83 & 83 & 15.9 & 2.67 \\
\hline 84 & 84 & 16.2 & 2.67 \\
\hline 85 & 85 & 16.0 & 2.77 \\
\hline 86 & 86 & 15.9 & 2.77 \\
\hline 87 & 87 & 16.0 & 2.67 \\
\hline 88 & 88 & 15.9 & 2.57 \\
\hline 89 & 89 & 15.4 & 2.67 \\
\hline 90 & 90 & 15.5 & 2.67 \\
\hline 91 & 91 & 15.4 & 2.46 \\
\hline 92 & 92 & 15.5 & 2.67 \\
\hline 93 & 93 & 15.6 & 2.57 \\
\hline 94 & 94 & 15.2 & 2.46 \\
\hline 95 & 95 & 15.7 & 2.57 \\
\hline 96 & 96 & 15.5 & 2.46 \\
\hline
\end{tabular}


Table A.2. Intensity data collected for cycles 9-12 which was monitored with the SCADA system (continued).

\begin{tabular}{|c|c|c|c|}
\hline $\begin{array}{c}\text { Cumulative Time of } \\
\text { Operation }\end{array}$ & $\begin{array}{c}\text { Time of Operation of } \\
\text { per Cycle }\end{array}$ & Flow & Intensity \\
\hline (Hours) & (Hours) & (gpm) & $\left(\mathrm{mW} / \mathrm{cm}^{2}\right)$ \\
\hline 97 & 97 & 15.6 & 2.46 \\
\hline 98 & 98 & 15.8 & 2.57 \\
\hline 99 & 99 & 15.7 & 2.46 \\
\hline 100 & 100 & 15.4 & 2.46 \\
\hline 101 & 101 & 15.4 & 2.36 \\
\hline 102 & 102 & 15.3 & 2.26 \\
\hline 103 & 103 & 15.6 & 2.15 \\
\hline 104 & 104 & 15.6 & 1.95 \\
\hline 105 & 105 & 15.3 & 1.74 \\
\hline 106 & 106 & 15.3 & 1.74 \\
\hline 107 & 107 & 15.2 & 1.95 \\
\hline 108 & 108 & 15.6 & 2.15 \\
\hline 109 & 109 & 15.1 & 2.15 \\
\hline 110 & 110 & 14.7 & 2.15 \\
\hline 111 & 111 & 14.6 & 2.15 \\
\hline 112 & 112 & 14.5 & 2.15 \\
\hline 113 & 113 & 14.4 & 2.15 \\
\hline 114 & 114 & 14.6 & 2.15 \\
\hline 115 & 115 & 14.6 & 2.05 \\
\hline 116 & 116 & 17.0 & 2.05 \\
\hline 117 & 117 & 16.8 & 2.05 \\
\hline 118 & 118 & 17.0 & 2.05 \\
\hline 119 & 119 & 17.1 & 2.15 \\
\hline 120 & 120 & 17.2 & 1.95 \\
\hline 121 & 121 & 17.0 & 1.84 \\
\hline 122 & 122 & 16.9 & 1.64 \\
\hline 123 & 123 & 17.0 & 1.53 \\
\hline 124 & 124 & 16.8 & 1.02 \\
\hline 125 & 125 & 16.9 & 0.81 \\
\hline 126 & 126 & 17.0 & 0.81 \\
\hline 127 & 127 & 16.9 & 0.91 \\
\hline 128 & 128 & 16.9 & 0.91 \\
\hline 129 & 129 & 16.7 & 1.02 \\
\hline
\end{tabular}


Table A.2. Intensity data collected for cycles 9-12 which was monitored with the SCADA system (continued).

\begin{tabular}{|c|c|c|c|}
\hline $\begin{array}{c}\text { Cumulative Time of } \\
\text { Operation }\end{array}$ & $\begin{array}{c}\text { Time of Operation of } \\
\text { per Cycle }\end{array}$ & Flow & Intensity \\
\hline (Hours) & (Hours) & (gpm) & $\left(\mathrm{mW} / \mathrm{cm}^{2}\right)$ \\
\hline 130 & 130 & 16.7 & 1.12 \\
\hline 131 & 131 & 16.8 & 1.12 \\
\hline 132 & 132 & 16.5 & 1.12 \\
\hline 133 & 133 & 16.6 & 1.22 \\
\hline 134 & 134 & 16.3 & 1.33 \\
\hline 135 & 135 & 16.4 & 1.43 \\
\hline 136 & 136 & 16.4 & 1.43 \\
\hline 137 & 137 & 16.4 & 1.53 \\
\hline 138 & 138 & 16.3 & 1.53 \\
\hline 139 & 139 & 16.4 & 1.53 \\
\hline 140 & 140 & 16.3 & 1.53 \\
\hline 141 & 141 & 16.4 & 1.53 \\
\hline 142 & 142 & 16.5 & 1.53 \\
\hline 143 & 143 & 16.5 & 1.43 \\
\hline 144 & 144 & 16.6 & 1.43 \\
\hline 145 & 145 & 16.4 & 1.33 \\
\hline 146 & 146 & 16.3 & 1.43 \\
\hline 147 & 147 & 15.8 & 1.43 \\
\hline 148 & 148 & 15.8 & 1.53 \\
\hline 149 & 149 & 15.8 & 1.53 \\
\hline 150 & 150 & 16.0 & 1.53 \\
\hline 151 & 151 & 16.2 & 1.43 \\
\hline 152 & 152 & 16.0 & 1.43 \\
\hline 153 & 153 & 15.7 & 1.43 \\
\hline 154 & 154 & 15.6 & 1.43 \\
\hline 155 & 155 & 15.6 & 1.43 \\
\hline 156 & 156 & 15.3 & 1.33 \\
\hline 157 & 157 & 15.6 & 1.43 \\
\hline 158 & 158 & 15.5 & 1.53 \\
\hline 159 & 159 & 15.4 & 1.43 \\
\hline 160 & 160 & 15.4 & 1.53 \\
\hline 161 & 161 & 15.0 & 1.53 \\
\hline 162 & 162 & 15.4 & 1.53 \\
\hline
\end{tabular}


Table A.2. Intensity data collected for cycles 9-12 which was monitored with the SCADA system (continued).

\begin{tabular}{|c|c|c|c|}
\hline $\begin{array}{c}\text { Cumulative Time of } \\
\text { Operation }\end{array}$ & $\begin{array}{c}\text { Time of Operation of } \\
\text { per Cycle }\end{array}$ & Flow & Intensity \\
\hline (Hours) & (Hours) & (gpm) & $\left(\mathrm{mW} / \mathrm{cm}^{2}\right)$ \\
\hline 163 & 163 & 15.4 & 1.53 \\
\hline 164 & 164 & 15.3 & 1.43 \\
\hline 165 & 165 & 15.5 & 1.43 \\
\hline 166 & 166 & 15.5 & 1.33 \\
\hline 167 & 167 & 15.7 & 1.33 \\
\hline 168 & 168 & 15.3 & 1.22 \\
\hline 192 & 0 & 25.9 & 13.42 \\
\hline 193 & 1 & 26.5 & 13.01 \\
\hline 194 & 2 & 26.2 & 13.11 \\
\hline 195 & 3 & 26.2 & 12.90 \\
\hline 196 & 4 & 26.3 & 11.77 \\
\hline 197 & 5 & 26.4 & 11.46 \\
\hline 198 & 6 & 26.1 & 10.53 \\
\hline 199 & 7 & 26.2 & 9.80 \\
\hline 200 & 8 & 25.9 & 10.11 \\
\hline 201 & 9 & 25.9 & 10.11 \\
\hline 202 & 10 & 25.8 & 10.42 \\
\hline 203 & 11 & 26.1 & 10.42 \\
\hline 204 & 12 & 25.9 & 10.32 \\
\hline 205 & 13 & 25.8 & 10.32 \\
\hline 206 & 14 & 25.8 & 10.22 \\
\hline 207 & 15 & 25.7 & 10.11 \\
\hline 208 & 16 & 26.0 & 10.01 \\
\hline 209 & 17 & 25.4 & 9.80 \\
\hline 210 & 18 & 25.5 & 9.49 \\
\hline 211 & 19 & 25.0 & 9.18 \\
\hline 212 & 20 & 24.8 & 8.46 \\
\hline 213 & 21 & 25.1 & 8.67 \\
\hline 214 & 22 & 24.7 & 8.46 \\
\hline 215 & 23 & 26.4 & 8.36 \\
\hline 216 & 24 & 26.8 & 8.15 \\
\hline 217 & 25 & 26.2 & 8.05 \\
\hline 218 & 26 & 26.7 & 7.73 \\
\hline
\end{tabular}


Table A.2. Intensity data collected for cycles 9-12 which was monitored with the SCADA system (continued).

\begin{tabular}{|c|c|c|c|}
\hline $\begin{array}{c}\text { Cumulative Time of } \\
\text { Operation }\end{array}$ & $\begin{array}{c}\text { Time of Operation of } \\
\text { per Cycle }\end{array}$ & Flow & Intensity \\
\hline (Hours) & (Hours) & (gpm) & $\left(\mathrm{mW} / \mathrm{cm}^{2}\right)$ \\
\hline 219 & 27 & 26.0 & 7.32 \\
\hline 220 & 28 & 26.2 & 7.11 \\
\hline 221 & 29 & 26.5 & 6.91 \\
\hline 222 & 30 & 26.4 & 6.60 \\
\hline 223 & 31 & 26.3 & 6.29 \\
\hline 224 & 32 & 26.4 & 6.18 \\
\hline 225 & 33 & 26.4 & 6.18 \\
\hline 226 & 34 & 26.2 & 6.29 \\
\hline 227 & 35 & 26.4 & 6.18 \\
\hline 228 & 36 & 26.3 & 6.29 \\
\hline 229 & 37 & 26.9 & 6.18 \\
\hline 230 & 38 & 26.3 & 6.08 \\
\hline 231 & 39 & 26.6 & 6.18 \\
\hline 232 & 40 & 26.3 & 6.08 \\
\hline 233 & 41 & 26.6 & 5.98 \\
\hline 234 & 42 & 26.7 & 5.87 \\
\hline 235 & 43 & 26.7 & 5.77 \\
\hline 236 & 44 & 26.9 & 5.67 \\
\hline 237 & 45 & 26.4 & 5.46 \\
\hline 238 & 46 & 26.9 & 5.25 \\
\hline 239 & 47 & 27.1 & 5.15 \\
\hline 240 & 48 & 26.6 & 5.15 \\
\hline 241 & 49 & 26.5 & 4.94 \\
\hline 242 & 50 & 26.5 & 4.84 \\
\hline 243 & 51 & 26.4 & 4.63 \\
\hline 244 & 52 & 26.3 & 4.84 \\
\hline 245 & 53 & 26.4 & 4.74 \\
\hline 246 & 54 & 26.4 & 4.63 \\
\hline 247 & 55 & 26.3 & 4.63 \\
\hline 248 & 56 & 25.9 & 4.43 \\
\hline 249 & 57 & 26.6 & 4.43 \\
\hline 250 & 58 & 26.0 & 4.43 \\
\hline 251 & 59 & 25.8 & 4.43 \\
\hline
\end{tabular}


Table A.2. Intensity data collected for cycles 9-12 which was monitored with the SCADA system (continued).

\begin{tabular}{|c|c|c|c|}
\hline $\begin{array}{c}\text { Cumulative Time of } \\
\text { Operation }\end{array}$ & $\begin{array}{c}\text { Time of Operation of } \\
\text { per Cycle }\end{array}$ & Flow & Intensity \\
\hline (Hours) & (Hours) & (gpm) & $\left(\mathrm{mW} / \mathrm{cm}^{2}\right)$ \\
\hline 252 & 60 & 25.8 & 4.43 \\
\hline 253 & 61 & 25.7 & 4.32 \\
\hline 254 & 62 & 25.8 & 4.22 \\
\hline 255 & 63 & 25.8 & 4.22 \\
\hline 256 & 64 & 25.8 & 4.01 \\
\hline 257 & 65 & 25.8 & 4.22 \\
\hline 258 & 66 & 25.1 & 4.22 \\
\hline 259 & 67 & 25.3 & 4.12 \\
\hline 260 & 68 & 25.2 & 4.12 \\
\hline 261 & 69 & 25.1 & 4.01 \\
\hline 262 & 70 & 25.2 & 3.91 \\
\hline 263 & 71 & 25.4 & 3.81 \\
\hline 264 & 72 & 24.8 & 3.70 \\
\hline 265 & 73 & 24.5 & 3.60 \\
\hline 266 & 74 & 24.7 & 3.50 \\
\hline 267 & 75 & 24.5 & 3.39 \\
\hline 268 & 76 & 24.4 & 3.29 \\
\hline 269 & 77 & 24.3 & 3.39 \\
\hline 270 & 78 & 24.5 & 3.29 \\
\hline 271 & 79 & 24.3 & 3.08 \\
\hline 272 & 80 & 24.1 & 3.08 \\
\hline 273 & 81 & 24.0 & 2.98 \\
\hline 274 & 82 & 23.9 & 3.08 \\
\hline 275 & 83 & 24.0 & 2.98 \\
\hline 276 & 84 & 24.1 & 2.98 \\
\hline 277 & 85 & 23.2 & 2.98 \\
\hline 278 & 86 & 23.5 & 2.98 \\
\hline 279 & 87 & 23.5 & 2.98 \\
\hline 280 & 88 & 22.9 & 2.98 \\
\hline 281 & 89 & 22.7 & 2.98 \\
\hline 282 & 90 & 22.5 & 2.98 \\
\hline 283 & 91 & 23.1 & 2.88 \\
\hline 284 & 92 & 22.9 & 2.88 \\
\hline
\end{tabular}


Table A.2. Intensity data collected for cycles 9-12 which was monitored with the SCADA system (continued).

\begin{tabular}{|c|c|c|c|}
\hline $\begin{array}{c}\text { Cumulative Time of } \\
\text { Operation }\end{array}$ & $\begin{array}{c}\text { Time of Operation of } \\
\text { per Cycle }\end{array}$ & Flow & Intensity \\
\hline (Hours) & (Hours) & (gpm) & $\left(\mathrm{mW} / \mathrm{cm}^{2}\right)$ \\
\hline 285 & 93 & 25.8 & 2.88 \\
\hline 286 & 94 & 26.0 & 2.88 \\
\hline 287 & 95 & 25.5 & 2.77 \\
\hline 288 & 96 & 25.2 & 2.67 \\
\hline 289 & 97 & 25.3 & 2.67 \\
\hline 290 & 98 & 25.1 & 2.57 \\
\hline 291 & 99 & 24.5 & 2.46 \\
\hline 292 & 100 & 24.8 & 2.46 \\
\hline 293 & 101 & 24.8 & 2.26 \\
\hline 294 & 102 & 24.7 & 2.15 \\
\hline 295 & 103 & 24.4 & 2.05 \\
\hline 296 & 104 & 24.1 & 2.05 \\
\hline 297 & 105 & 23.6 & 2.05 \\
\hline 298 & 106 & 23.9 & 2.15 \\
\hline 299 & 107 & 24.0 & 2.05 \\
\hline 300 & 108 & 23.5 & 2.15 \\
\hline 301 & 109 & 23.0 & 2.15 \\
\hline 302 & 110 & 23.2 & 2.15 \\
\hline 303 & 111 & 22.8 & 2.15 \\
\hline 304 & 112 & 22.5 & 2.15 \\
\hline 305 & 113 & 24.5 & 2.15 \\
\hline 306 & 114 & 24.8 & 2.15 \\
\hline 307 & 115 & 24.8 & 2.15 \\
\hline 308 & 116 & 28.5 & 2.26 \\
\hline 309 & 117 & 29.0 & 2.15 \\
\hline 310 & 118 & 28.5 & 2.15 \\
\hline 311 & 119 & 28.0 & 2.15 \\
\hline 312 & 120 & 27.8 & 2.05 \\
\hline 313 & 121 & 28.3 & 2.05 \\
\hline 314 & 122 & 28.2 & 2.05 \\
\hline 315 & 123 & 28.1 & 1.95 \\
\hline 316 & 124 & 27.9 & 1.95 \\
\hline 317 & 125 & 28.6 & 1.84 \\
\hline
\end{tabular}


Table A.2. Intensity data collected for cycles 9-12 which was monitored with the SCADA system (continued).

\begin{tabular}{|c|c|c|c|}
\hline $\begin{array}{c}\text { Cumulative Time of } \\
\text { Operation }\end{array}$ & $\begin{array}{c}\text { Time of Operation of } \\
\text { per Cycle }\end{array}$ & Flow & Intensity \\
\hline (Hours) & (Hours) & (gpm) & $\left(\mathrm{mW} / \mathrm{cm}^{2}\right)$ \\
\hline 318 & 126 & 28.2 & 1.74 \\
\hline 319 & 127 & 27.8 & 1.74 \\
\hline 320 & 128 & 28.0 & 1.64 \\
\hline 321 & 129 & 27.0 & 1.74 \\
\hline 322 & 130 & 27.5 & 1.74 \\
\hline 323 & 131 & 26.8 & 1.74 \\
\hline 324 & 132 & 27.1 & 1.84 \\
\hline 325 & 133 & 26.8 & 1.95 \\
\hline 326 & 134 & 26.8 & 1.84 \\
\hline 327 & 135 & 26.0 & 1.84 \\
\hline 328 & 136 & 26.5 & 1.95 \\
\hline 329 & 137 & 27.0 & 1.84 \\
\hline 330 & 138 & 26.9 & 1.84 \\
\hline 331 & 139 & 26.9 & 1.84 \\
\hline 332 & 140 & 26.7 & 1.84 \\
\hline 333 & 141 & 26.9 & 1.74 \\
\hline 334 & 142 & 26.9 & 1.74 \\
\hline 335 & 143 & 26.5 & 1.74 \\
\hline 336 & 144 & 26.6 & 1.74 \\
\hline 337 & 145 & 26.8 & 1.74 \\
\hline 338 & 146 & 24.8 & 1.74 \\
\hline 339 & 147 & 27.4 & 1.64 \\
\hline 340 & 148 & 27.2 & 1.64 \\
\hline 341 & 149 & 27.0 & 1.64 \\
\hline 342 & 150 & 27.3 & 1.53 \\
\hline 343 & 151 & 27.2 & 1.53 \\
\hline 344 & 152 & 27.4 & 1.53 \\
\hline 345 & 153 & 26.8 & 1.53 \\
\hline 346 & 154 & 26.5 & 1.43 \\
\hline 347 & 155 & 26.3 & 1.53 \\
\hline 348 & 156 & 26.6 & 1.53 \\
\hline 349 & 157 & 26.5 & 1.53 \\
\hline 350 & 158 & 26.7 & 1.53 \\
\hline
\end{tabular}


Table A.2. Intensity data collected for cycles 9-12 which was monitored with the SCADA system (continued).

\begin{tabular}{|c|c|c|c|}
\hline $\begin{array}{c}\text { Cumulative Time of } \\
\text { Operation }\end{array}$ & $\begin{array}{c}\text { Time of Operation of } \\
\text { per Cycle }\end{array}$ & Flow & Intensity \\
\hline (Hours) & (Hours) & (gpm) & $\left(\mathrm{mW} / \mathrm{cm}^{2}\right)$ \\
\hline 351 & 159 & 26.2 & 1.53 \\
\hline 352 & 160 & 26.5 & 1.53 \\
\hline 353 & 161 & 26.3 & 1.64 \\
\hline 354 & 162 & 26.2 & 1.53 \\
\hline 355 & 163 & 26.6 & 1.53 \\
\hline 356 & 164 & 25.7 & 1.53 \\
\hline 357 & 165 & 25.6 & 1.53 \\
\hline 358 & 166 & 25.8 & 1.53 \\
\hline 359 & 167 & 25.9 & 1.43 \\
\hline 359 & 0 & 25.5 & 12.20 \\
\hline 360 & 1 & 25.4 & 11.25 \\
\hline 361 & 2 & 25.1 & 10.94 \\
\hline 362 & 3 & 25.0 & 10.42 \\
\hline 363 & 4 & 25.0 & 10.22 \\
\hline 364 & 5 & 25.4 & 10.11 \\
\hline 365 & 6 & 24.9 & 9.91 \\
\hline 366 & 7 & 24.7 & 9.91 \\
\hline 367 & 8 & 25.1 & 9.80 \\
\hline 368 & 9 & 24.7 & 9.70 \\
\hline 369 & 10 & 24.9 & 9.60 \\
\hline 370 & 11 & 24.5 & 9.49 \\
\hline 371 & 12 & 24.4 & 9.18 \\
\hline 372 & 13 & 24.7 & 9.28 \\
\hline 373 & 14 & 24.6 & 9.29 \\
\hline 374 & 15 & 24.2 & 9.18 \\
\hline 375 & 16 & 24.0 & 8.97 \\
\hline 376 & 17 & 24.1 & 8.87 \\
\hline 377 & 18 & 24.4 & 8.66 \\
\hline 378 & 19 & 23.8 & 8.56 \\
\hline 379 & 20 & 24.0 & 8.25 \\
\hline 380 & 21 & 28.2 & 7.84 \\
\hline 381 & 22 & 28.4 & 7.63 \\
\hline 382 & 23 & 28.3 & 7.43 \\
\hline
\end{tabular}


Table A.2. Intensity data collected for cycles 9-12 which was monitored with the SCADA system (continued).

\begin{tabular}{|c|c|c|c|}
\hline $\begin{array}{c}\text { Cumulative Time of } \\
\text { Operation }\end{array}$ & $\begin{array}{c}\text { Time of Operation of } \\
\text { per Cycle }\end{array}$ & Flow & Intensity \\
\hline (Hours) & (Hours) & (gpm) & $\left(\mathrm{mW} / \mathrm{cm}^{2}\right)$ \\
\hline 383 & 24 & 28.4 & 7.32 \\
\hline 384 & 25 & 27.8 & 7.22 \\
\hline 385 & 26 & 28.0 & 7.01 \\
\hline 386 & 27 & 27.7 & 6.60 \\
\hline 387 & 28 & 28.2 & 6.18 \\
\hline 388 & 29 & 27.1 & 5.98 \\
\hline 389 & 30 & 27.6 & 5.87 \\
\hline 390 & 31 & 27.8 & 5.56 \\
\hline 391 & 32 & 28.0 & 5.77 \\
\hline 392 & 33 & 27.6 & 5.67 \\
\hline 393 & 34 & 27.2 & 5.67 \\
\hline 394 & 35 & 27.8 & 5.67 \\
\hline 395 & 36 & 28.0 & 5.56 \\
\hline 396 & 37 & 27.1 & 5.56 \\
\hline 397 & 38 & 27.2 & 5.56 \\
\hline 398 & 39 & 27.7 & 5.56 \\
\hline 399 & 40 & 26.8 & 5.46 \\
\hline 400 & 41 & 26.9 & 5.46 \\
\hline 401 & 42 & 27.1 & 5.36 \\
\hline 402 & 43 & 27.3 & 5.36 \\
\hline 403 & 44 & 27.1 & 5.25 \\
\hline 404 & 45 & 27.1 & 5.15 \\
\hline 405 & 46 & 27.5 & 4.94 \\
\hline 406 & 47 & 27.0 & 4.84 \\
\hline 407 & 48 & 27.5 & 4.74 \\
\hline 408 & 49 & 27.6 & 4.74 \\
\hline 409 & 50 & 27.4 & 4.63 \\
\hline 410 & 51 & 27.8 & 4.63 \\
\hline 411 & 52 & 27.5 & 4.53 \\
\hline 412 & 53 & 27.1 & 4.43 \\
\hline 413 & 54 & 27.5 & 4.43 \\
\hline 414 & 55 & 27.3 & 4.43 \\
\hline 415 & 56 & 27.4 & 4.32 \\
\hline
\end{tabular}


Table A.2. Intensity data collected for cycles 9-12 which was monitored with the SCADA system (continued).

\begin{tabular}{|c|c|c|c|}
\hline $\begin{array}{c}\text { Cumulative Time of } \\
\text { Operation }\end{array}$ & $\begin{array}{c}\text { Time of Operation of } \\
\text { per Cycle }\end{array}$ & Flow & Intensity \\
\hline (Hours) & (Hours) & (gpm) & $\left(\mathrm{mW} / \mathrm{cm}^{2}\right)$ \\
\hline 416 & 57 & 27.2 & 4.22 \\
\hline 417 & 58 & 27.4 & 4.12 \\
\hline 418 & 59 & 27.4 & 4.12 \\
\hline 419 & 60 & 26.9 & 4.01 \\
\hline 420 & 61 & 26.8 & 4.01 \\
\hline 421 & 62 & 27.1 & 3.91 \\
\hline 422 & 63 & 27.0 & 3.91 \\
\hline 423 & 64 & 26.3 & 3.81 \\
\hline 424 & 65 & 26.4 & 3.81 \\
\hline 425 & 66 & 26.4 & 3.81 \\
\hline 426 & 67 & 26.0 & 3.81 \\
\hline 427 & 68 & 26.2 & 3.70 \\
\hline 428 & 69 & 26.4 & 3.70 \\
\hline 429 & 70 & 26.3 & 3.60 \\
\hline 430 & 71 & 26.3 & 3.50 \\
\hline 431 & 72 & 23.4 & 3.39 \\
\hline 432 & 73 & 24.3 & 3.39 \\
\hline 433 & 74 & 24.5 & 3.29 \\
\hline 434 & 75 & 24.5 & 3.19 \\
\hline 435 & 76 & 24.6 & 3.08 \\
\hline 436 & 77 & 25.7 & 3.08 \\
\hline 437 & 78 & 25.7 & 3.08 \\
\hline 438 & 79 & 26.0 & 2.98 \\
\hline 439 & 80 & 25.6 & 2.98 \\
\hline 440 & 81 & 26.2 & 2.88 \\
\hline 441 & 82 & 25.9 & 2.88 \\
\hline 442 & 83 & 25.4 & 2.88 \\
\hline 443 & 84 & 25.5 & 2.77 \\
\hline 444 & 85 & 25.5 & 2.77 \\
\hline 445 & 86 & 25.8 & 2.77 \\
\hline 446 & 87 & 25.3 & 2.67 \\
\hline 447 & 88 & 25.1 & 2.67 \\
\hline 448 & 89 & 25.2 & 2.67 \\
\hline
\end{tabular}


Table A.2. Intensity data collected for cycles 9-12 which was monitored with the SCADA system (continued).

\begin{tabular}{|c|c|c|c|}
\hline $\begin{array}{c}\text { Cumulative Time of } \\
\text { Operation }\end{array}$ & $\begin{array}{c}\text { Time of Operation of } \\
\text { per Cycle }\end{array}$ & Flow & Intensity \\
\hline (Hours) & (Hours) & (gpm) & $\left(\mathrm{mW} / \mathrm{cm}^{2}\right)$ \\
\hline 449 & 90 & 24.9 & 2.67 \\
\hline 450 & 91 & 25.0 & 2.67 \\
\hline 451 & 92 & 24.9 & 2.67 \\
\hline 452 & 93 & 24.7 & 2.67 \\
\hline 453 & 94 & 24.9 & 2.67 \\
\hline 454 & 95 & 24.8 & 2.57 \\
\hline 455 & 96 & 24.7 & 2.57 \\
\hline 456 & 97 & 24.4 & 2.36 \\
\hline 457 & 98 & 24.7 & 2.36 \\
\hline 458 & 99 & 24.4 & 2.36 \\
\hline 459 & 100 & 24.3 & 2.36 \\
\hline 460 & 101 & 24.0 & 2.26 \\
\hline 461 & 102 & 23.9 & 2.26 \\
\hline 462 & 103 & 24.0 & 2.15 \\
\hline 463 & 104 & 24.0 & 2.15 \\
\hline 464 & 105 & 23.8 & 2.05 \\
\hline 465 & 106 & 24.0 & 1.95 \\
\hline 466 & 107 & 23.8 & 1.95 \\
\hline 467 & 108 & 23.3 & 1.95 \\
\hline 468 & 109 & 23.0 & 1.84 \\
\hline 469 & 110 & 23.2 & 1.84 \\
\hline 470 & 111 & 23.3 & 1.84 \\
\hline 471 & 112 & 22.6 & 1.74 \\
\hline 472 & 113 & 22.9 & 1.74 \\
\hline 473 & 114 & 22.5 & 1.74 \\
\hline 474 & 115 & 22.7 & 1.74 \\
\hline 475 & 116 & 22.9 & 1.74 \\
\hline 476 & 117 & 22.3 & 1.64 \\
\hline 477 & 118 & 22.6 & 1.53 \\
\hline 478 & 119 & 23.2 & 1.53 \\
\hline 479 & 120 & 25.1 & 1.53 \\
\hline 480 & 121 & 24.8 & 1.43 \\
\hline 481 & 122 & 24.9 & 1.43 \\
\hline
\end{tabular}


Table A.2. Intensity data collected for cycles 9-12 which was monitored with the SCADA system (continued).

\begin{tabular}{|c|c|c|c|}
\hline $\begin{array}{c}\text { Cumulative Time of } \\
\text { Operation }\end{array}$ & $\begin{array}{c}\text { Time of Operation of } \\
\text { per Cycle }\end{array}$ & Flow & Intensity \\
\hline (Hours) & (Hours) & (gpm) & $\left(\mathrm{mW} / \mathrm{cm}^{2}\right)$ \\
\hline 482 & 123 & 25.0 & 1.43 \\
\hline 483 & 124 & 24.5 & 1.43 \\
\hline 484 & 125 & 25.1 & 1.43 \\
\hline 485 & 126 & 24.9 & 1.33 \\
\hline 486 & 127 & 24.4 & 1.33 \\
\hline 487 & 128 & 24.6 & 1.22 \\
\hline 488 & 129 & 24.1 & 1.22 \\
\hline 489 & 130 & 23.6 & 1.22 \\
\hline 490 & 131 & 23.6 & 1.22 \\
\hline 491 & 132 & 23.1 & 1.22 \\
\hline 492 & 133 & 23.1 & 1.33 \\
\hline 493 & 134 & 23.1 & 1.33 \\
\hline 494 & 135 & 23.1 & 1.33 \\
\hline 495 & 136 & 22.2 & 1.33 \\
\hline 496 & 137 & 22.7 & 1.33 \\
\hline 497 & 138 & 22.4 & 1.33 \\
\hline 498 & 139 & 22.7 & 1.33 \\
\hline 499 & 140 & 22.0 & 1.33 \\
\hline 500 & 141 & 21.8 & 1.33 \\
\hline 501 & 142 & 21.1 & 1.33 \\
\hline 502 & 143 & 21.6 & 1.33 \\
\hline 503 & 144 & 22.3 & 1.22 \\
\hline 504 & 145 & 21.9 & 1.22 \\
\hline 505 & 146 & 22.0 & 1.22 \\
\hline 506 & 147 & 21.6 & 1.33 \\
\hline 507 & 148 & 22.2 & 1.33 \\
\hline 508 & 149 & 21.9 & 1.33 \\
\hline 509 & 150 & 22.0 & 1.22 \\
\hline 510 & 151 & 21.6 & 1.22 \\
\hline 511 & 152 & 21.2 & 1.22 \\
\hline 512 & 153 & 21.4 & 1.22 \\
\hline 513 & 154 & 21.0 & 1.22 \\
\hline 514 & 155 & 20.4 & 1.22 \\
\hline
\end{tabular}


Table A.2. Intensity data collected for cycles 9-12 which was monitored with the SCADA system (continued).

\begin{tabular}{|c|c|c|c|}
\hline $\begin{array}{c}\text { Cumulative Time of } \\
\text { Operation }\end{array}$ & $\begin{array}{c}\text { Time of Operation of } \\
\text { per Cycle }\end{array}$ & Flow & Intensity \\
\hline (Hours) & (Hours) & (gpm) & $\left(\mathrm{mW} / \mathrm{cm}^{2}\right)$ \\
\hline 515 & 156 & 21.2 & 1.22 \\
\hline 516 & 157 & 20.6 & 1.22 \\
\hline 517 & 158 & 20.3 & 1.22 \\
\hline 518 & 159 & 19.9 & 1.22 \\
\hline 519 & 160 & 19.9 & 1.22 \\
\hline 520 & 161 & 19.6 & 1.22 \\
\hline 521 & 162 & 19.3 & 1.22 \\
\hline 521 & 0 & 25.0 & 10.01 \\
\hline 522 & 1 & 25.6 & 9.91 \\
\hline 523 & 2 & 25.2 & 9.49 \\
\hline 524 & 3 & 25.3 & 9.28 \\
\hline 525 & 4 & 25.3 & 9.08 \\
\hline 526 & 5 & 25.2 & 8.67 \\
\hline 527 & 6 & 25.4 & 8.36 \\
\hline 528 & 7 & 25.7 & 8.05 \\
\hline 529 & 8 & 25.1 & 7.53 \\
\hline 530 & 9 & 25.3 & 6.70 \\
\hline 531 & 10 & 25.2 & 6.49 \\
\hline 532 & 11 & 25.1 & 6.29 \\
\hline 533 & 12 & 25.4 & 5.98 \\
\hline 534 & 13 & 24.9 & 5.98 \\
\hline 535 & 14 & 24.6 & 5.87 \\
\hline 536 & 15 & 24.7 & 5.87 \\
\hline 537 & 16 & 24.7 & 5.87 \\
\hline 538 & 17 & 24.4 & 5.77 \\
\hline 539 & 18 & 24.6 & 5.77 \\
\hline 540 & 19 & 23.9 & 5.67 \\
\hline 541 & 20 & 23.8 & 5.56 \\
\hline 542 & 21 & 24.3 & 5.56 \\
\hline 543 & 22 & 23.9 & 5.56 \\
\hline 544 & 23 & 24.0 & 5.46 \\
\hline 545 & 24 & 23.9 & 5.46 \\
\hline 546 & 25 & 24.1 & 5.15 \\
\hline
\end{tabular}


Table A.2. Intensity data collected for cycles 9-12 which was monitored with the SCADA system (continued).

\begin{tabular}{|c|c|c|c|}
\hline $\begin{array}{c}\text { Cumulative Time of } \\
\text { Operation }\end{array}$ & $\begin{array}{c}\text { Time of Operation of } \\
\text { per Cycle }\end{array}$ & Flow & Intensity \\
\hline (Hours) & (Hours) & (gpm) & $\left(\mathrm{mW} / \mathrm{cm}^{2}\right)$ \\
\hline 547 & 26 & 24.4 & 4.74 \\
\hline 548 & 27 & 24.1 & 4.63 \\
\hline 549 & 28 & 24.2 & 4.32 \\
\hline 550 & 29 & 24.7 & 4.22 \\
\hline 551 & 30 & 24.4 & 4.12 \\
\hline 552 & 31 & 24.2 & 4.22 \\
\hline 553 & 32 & 24.7 & 4.12 \\
\hline 554 & 33 & 24.0 & 4.12 \\
\hline 555 & 34 & 24.4 & 4.01 \\
\hline 556 & 35 & 24.1 & 3.91 \\
\hline 557 & 36 & 23.9 & 3.81 \\
\hline 558 & 37 & 24.0 & 3.81 \\
\hline 559 & 38 & 24.0 & 3.70 \\
\hline 560 & 39 & 23.9 & 3.70 \\
\hline 561 & 40 & 23.6 & 3.70 \\
\hline 562 & 41 & 24.3 & 3.81 \\
\hline 563 & 42 & 23.9 & 3.81 \\
\hline 564 & 43 & 23.6 & 3.81 \\
\hline 565 & 44 & 24.1 & 3.81 \\
\hline 566 & 45 & 23.6 & 3.81 \\
\hline 567 & 46 & 23.6 & 3.81 \\
\hline 568 & 47 & 24.0 & 3.81 \\
\hline 569 & 48 & 23.4 & 3.60 \\
\hline 570 & 49 & 23.3 & 3.29 \\
\hline 571 & 50 & 23.5 & 3.19 \\
\hline 572 & 51 & 23.8 & 3.19 \\
\hline 573 & 52 & 23.3 & 3.19 \\
\hline 574 & 53 & 23.5 & 3.19 \\
\hline 575 & 54 & 23.8 & 3.08 \\
\hline 576 & 55 & 23.7 & 2.98 \\
\hline 577 & 56 & 23.6 & 2.88 \\
\hline 578 & 57 & 23.5 & 2.77 \\
\hline 579 & 58 & 23.5 & 2.67 \\
\hline
\end{tabular}


Table A.2. Intensity data collected for cycles 9-12 which was monitored with the SCADA system (continued).

\begin{tabular}{|c|c|c|c|}
\hline $\begin{array}{c}\text { Cumulative Time of } \\
\text { Operation }\end{array}$ & $\begin{array}{c}\text { Time of Operation of } \\
\text { per Cycle }\end{array}$ & Flow & Intensity \\
\hline (Hours) & (Hours) & (gpm) & $\left(\mathrm{mW} / \mathrm{cm}^{2}\right)$ \\
\hline 580 & 59 & 23.5 & 2.46 \\
\hline 581 & 60 & 23.3 & 2.36 \\
\hline 582 & 61 & 23.7 & 2.36 \\
\hline 583 & 62 & 23.9 & 2.26 \\
\hline 584 & 63 & 23.7 & 2.15 \\
\hline 585 & 64 & 24.4 & 2.05 \\
\hline 586 & 65 & 24.3 & 1.84 \\
\hline 587 & 66 & 24.2 & 1.74 \\
\hline 588 & 67 & 23.9 & 1.84 \\
\hline 589 & 68 & 23.4 & 1.95 \\
\hline 590 & 69 & 23.1 & 2.05 \\
\hline 591 & 70 & 23.0 & 2.05 \\
\hline 592 & 71 & 22.9 & 2.05 \\
\hline 593 & 72 & 22.8 & 2.05 \\
\hline 594 & 73 & 22.9 & 2.05 \\
\hline 595 & 74 & 23.1 & 1.95 \\
\hline 596 & 75 & 22.9 & 1.95 \\
\hline 597 & 76 & 22.9 & 1.95 \\
\hline 598 & 77 & 22.8 & 1.95 \\
\hline 599 & 78 & 23.1 & 1.95 \\
\hline 600 & 79 & 22.7 & 1.95 \\
\hline 601 & 80 & 22.8 & 1.84 \\
\hline 602 & 81 & 22.8 & 1.84 \\
\hline 603 & 82 & 23.2 & 1.84 \\
\hline 604 & 83 & 23.2 & 1.74 \\
\hline 605 & 84 & 23.0 & 1.74 \\
\hline 606 & 85 & 23.0 & 1.74 \\
\hline 607 & 86 & 22.8 & 1.74 \\
\hline 608 & 87 & 24.8 & 1.74 \\
\hline 609 & 88 & 24.5 & 1.64 \\
\hline 610 & 89 & 24.7 & 1.64 \\
\hline 611 & 90 & 24.4 & 1.53 \\
\hline 612 & 91 & 24.6 & 1.53 \\
\hline
\end{tabular}


Table A.2. Intensity data collected for cycles 9-12 which was monitored with the SCADA system (continued).

\begin{tabular}{|c|c|c|c|}
\hline $\begin{array}{c}\text { Cumulative Time of } \\
\text { Operation }\end{array}$ & $\begin{array}{c}\text { Time of Operation of } \\
\text { per Cycle }\end{array}$ & Flow & Intensity \\
\hline (Hours) & (Hours) & (gpm) & $\left(\mathrm{mW} / \mathrm{cm}^{2}\right)$ \\
\hline 613 & 92 & 24.7 & 1.33 \\
\hline 614 & 93 & 24.2 & 1.33 \\
\hline 615 & 94 & 24.1 & 1.33 \\
\hline 616 & 95 & 23.9 & 1.43 \\
\hline 617 & 96 & 24.4 & 1.43 \\
\hline 618 & 97 & 24.3 & 1.43 \\
\hline 619 & 98 & 24.0 & 1.53 \\
\hline 620 & 99 & 23.8 & 1.53 \\
\hline 621 & 100 & 23.8 & 1.53 \\
\hline 622 & 101 & 24.1 & 1.53 \\
\hline 623 & 102 & 23.7 & 1.53 \\
\hline 624 & 103 & 23.7 & 1.53 \\
\hline 625 & 104 & 24.0 & 1.33 \\
\hline 626 & 105 & 23.1 & 1.33 \\
\hline 627 & 106 & 23.5 & 1.12 \\
\hline 628 & 107 & 23.4 & 1.02 \\
\hline 629 & 108 & 23.5 & 0.81 \\
\hline 630 & 109 & 23.3 & 0.71 \\
\hline 631 & 110 & 23.3 & 0.71 \\
\hline 632 & 111 & 23.2 & 0.71 \\
\hline 633 & 112 & 23.8 & 0.71 \\
\hline 634 & 113 & 23.3 & 0.71 \\
\hline 635 & 114 & 22.5 & 0.81 \\
\hline 636 & 115 & 22.6 & 0.81 \\
\hline 637 & 116 & 22.5 & 0.91 \\
\hline 638 & 117 & 22.9 & 0.91 \\
\hline 639 & 118 & 22.4 & 1.02 \\
\hline 640 & 119 & 22.4 & 1.02 \\
\hline 641 & 120 & 23.1 & 1.02 \\
\hline 642 & 121 & 22.8 & 1.02 \\
\hline 643 & 122 & 22.4 & 1.02 \\
\hline 644 & 123 & 22.3 & 1.02 \\
\hline 645 & 124 & 22.0 & 1.02 \\
\hline
\end{tabular}


Table A.2. Intensity data collected for cycles 9-12 which was monitored with the SCADA system (continued).

\begin{tabular}{|c|c|c|c|}
\hline $\begin{array}{c}\text { Cumulative Time of } \\
\text { Operation }\end{array}$ & $\begin{array}{c}\text { Time of Operation of } \\
\text { per Cycle }\end{array}$ & Flow & Intensity \\
\hline (Hours) & (Hours) & (gpm) & $\left(\mathrm{mW} / \mathrm{cm}^{2}\right)$ \\
\hline 646 & 125 & 22.3 & 1.02 \\
\hline 647 & 126 & 22.1 & 0.71 \\
\hline 648 & 127 & 24.5 & 0.50 \\
\hline 649 & 128 & 24.4 & 0.40 \\
\hline 650 & 129 & 24.3 & 0.40 \\
\hline 651 & 130 & 24.5 & 0.29 \\
\hline 652 & 131 & 24.3 & 0.29 \\
\hline 653 & 132 & 24.2 & 0.29 \\
\hline 654 & 133 & 24.0 & 0.29 \\
\hline 655 & 134 & 23.7 & 0.40 \\
\hline 656 & 135 & 23.9 & 0.40 \\
\hline 657 & 136 & 24.1 & 0.40 \\
\hline 658 & 137 & 23.8 & 0.40 \\
\hline 659 & 138 & 23.8 & 0.40 \\
\hline 660 & 139 & 22.8 & 0.40 \\
\hline 661 & 140 & 22.3 & 0.50 \\
\hline 662 & 141 & 22.5 & 0.50 \\
\hline 663 & 142 & 22.8 & 0.60 \\
\hline 664 & 143 & 23.0 & 0.60 \\
\hline 665 & 144 & 23.1 & 0.60 \\
\hline 666 & 145 & 22.5 & 0.60 \\
\hline
\end{tabular}


Table A.3. Fouling material testing results for C14.

\begin{tabular}{|c|c|c|c|}
\hline \multirow{2}{*}{ Constituent } & Concentration & Sample Volume & $\begin{array}{c}\text { Percent } \\
\text { Distribution }\end{array}$ \\
\cline { 2 - 4 } & $(\mathrm{mg} / \mathrm{L})$ & $(\mathrm{L})$ & $(\%)$ \\
\hline Calcium & 3.62 & 0.5 & $26.1 \%$ \\
\hline Iron & 3.24 & 0.5 & $23.4 \%$ \\
\hline Magnesium & 0.679 & 0.5 & $4.9 \%$ \\
\hline Manganese & 0.031 & 0.5 & $0.2 \%$ \\
\hline Potassium & 3.99 & 0.5 & $28.8 \%$ \\
\hline Sodium & 2.3 & 0.5 & $16.6 \%$ \\
\hline Total Hardness & 11.8 & 0.5 & - \\
\hline
\end{tabular}




\section{APPENDIX B. INTENSITY DATA FOR MODELING}

Table B.1. UV intensity data for cycles 16-23. Intensity data collected after cleaning the sensor's lens was modeled to obtain $\mathrm{k}_{\text {sleeve }}$ and the intensity data collected before cleaning the sensor's lens was modeled to obtain $\mathrm{k}_{\text {sesnor }}$.

\begin{tabular}{|c|c|c|c|c|c|}
\hline \multirow[t]{2}{*}{$\begin{array}{l}\text { Cycle } \\
\text { Number }\end{array}$} & $\begin{array}{c}\text { Time of } \\
\text { Operation } \\
(\mathbf{t})\end{array}$ & $\begin{array}{c}\text { Time between } \\
\text { Sensor Cleaning } \\
\left(t^{\prime}\right)\end{array}$ & Flow & $\begin{array}{l}\text { Intensity Before } \\
\text { Sensor Cleaning }\end{array}$ & $\begin{array}{l}\text { Intensity After } \\
\text { Sensor Cleaning }\end{array}$ \\
\hline & (Hours) & (Hours) & gpm & $\mathrm{mW} / \mathrm{cm}^{2}$ & $\mathrm{~mW} / \mathrm{cm}^{2}$ \\
\hline \multirow{5}{*}{$\mathrm{C} 16$} & 0 & 0 & 27.1 & 13.01 & 13.01 \\
\hline & 22 & 22 & 26.8 & 8.56 & 9.71 \\
\hline & 45 & 23 & 27.8 & 5.52 & 6.19 \\
\hline & 68 & 23 & 23.8 & 4.18 & 4.74 \\
\hline & 90 & 22 & 21.1 & 3.25 & 3.45 \\
\hline \multirow{5}{*}{$\mathrm{C} 17$} & 0 & 0 & 26.1 & 14.14 & 14.14 \\
\hline & 27 & 27 & 25.1 & 7.07 & 8.77 \\
\hline & 47 & 20 & 30.3 & 5.74 & 6.49 \\
\hline & 73 & 26 & 25.8 & 4.01 & 4.01 \\
\hline & 93 & 20 & 25.0 & 3.00 & 3.70 \\
\hline \multirow{4}{*}{$\mathrm{C} 18$} & 0 & 0 & 36.0 & 14.35 & 14.35 \\
\hline & 25 & 25 & 35.0 & 7.79 & 9.60 \\
\hline & 46 & 21 & 34.0 & 5.13 & 5.98 \\
\hline & 69 & 23 & 34.3 & 4.12 & 4.71 \\
\hline \multirow{6}{*}{$\mathrm{C} 19$} & 0 & 0 & 10.7 & 13.11 & 13.11 \\
\hline & 25 & 25 & 11.0 & 6.91 & 9.49 \\
\hline & 50 & 25 & 12.9 & 5.25 & 7.22 \\
\hline & 77 & 27 & 12.1 & 3.70 & 4.63 \\
\hline & 99 & 22 & 12.0 & 3.29 & 4.11 \\
\hline & 116 & 17 & 10.0 & 3.08 & 3.57 \\
\hline \multirow{5}{*}{$\mathrm{C} 20$} & 0 & 0 & 27.3 & 14.66 & 14.66 \\
\hline & 18 & 18 & 15.9 & 8.15 & 9.49 \\
\hline & 43 & 25 & 17.3 & 4.74 & 6.18 \\
\hline & 63 & 20 & 9.6 & 3.91 & 4.53 \\
\hline & 87 & 24 & 15.7 & 3.08 & 3.49 \\
\hline \multirow{3}{*}{$\mathrm{C} 21$} & 0 & 0 & 25.1 & 13.11 & 13.11 \\
\hline & 13 & 13 & 24.8 & 8.53 & 9.39 \\
\hline & 35 & 22 & 31.7 & 5.89 & 7.63 \\
\hline
\end{tabular}


Table B.1. UV intensity data for cycles 16-23. Intensity data collected after cleaning the sensor's lens was modeled to obtain $\mathrm{k}_{\text {sleeve }}$ and the intensity data collected before cleaning the sensor's lens was modeled to obtain $\mathrm{k}_{\text {sesnor }}$ (continued).

\begin{tabular}{|c|c|c|c|c|c|}
\hline $\begin{array}{c}\text { Cycle } \\
\text { Number }\end{array}$ & $\begin{array}{c}\text { Time of } \\
\text { Operation } \\
(\mathbf{t})\end{array}$ & $\begin{array}{c}\text { Time between } \\
\text { Sensor Cleaning } \\
\left(\mathbf{t}^{\prime}\right)\end{array}$ & Flow & $\begin{array}{c}\text { Intensity Before } \\
\text { Sensor Cleaning }\end{array}$ & $\begin{array}{c}\text { Intensity After } \\
\text { Sensor Cleaning }\end{array}$ \\
\cline { 2 - 6 } (Hours) & $($ Hours $)$ & gpm & $\mathrm{mW} / \mathrm{cm}^{2}$ & $\mathrm{~mW} / \mathrm{cm}^{2}$ \\
\hline \multirow{4}{*}{ C21 } & 61 & 26 & 25.3 & 4.94 & 5.77 \\
\cline { 2 - 6 } & 86 & 25 & 28.5 & 4.32 & 4.53 \\
\hline \multirow{4}{*}{ C22 } & 0 & 0 & 35.1 & 11.87 & 11.87 \\
\cline { 2 - 6 } & 13 & 13 & 33.8 & 10.73 & 11.45 \\
\cline { 2 - 6 } & 25 & 12 & 34.8 & 8.77 & 9.18 \\
\cline { 2 - 6 } & 58 & 33 & 32.7 & 7.11 & 7.63 \\
\hline \multirow{4}{*}{ C23 } & 82 & 24 & 35.5 & 5.35 & 5.87 \\
\cline { 2 - 6 } & 0 & 0 & 13.0 & 12.49 & 12.49 \\
\cline { 2 - 6 } & 15 & 15 & 9.8 & 7.52 & 10.32 \\
\cline { 2 - 6 } & 38 & 23 & 10.0 & 5.25 & 7.21 \\
\cline { 2 - 6 } & 61 & 23 & 10.3 & 4.84 & 5.25 \\
\cline { 2 - 6 } & 84 & 23 & 10.5 & 3.29 & 3.80 \\
\hline
\end{tabular}


Table B.2. RMSE and CVRMSE for cycles C16 through C23.

\begin{tabular}{|c|c|c|c|c|}
\hline \multirow{2}{*}{ Cycle Number } & \multicolumn{2}{|c|}{ Before Sensor Cleaning } & \multicolumn{2}{c|}{ After Sensor Cleaning } \\
\cline { 2 - 5 } & RMSE & CVRMSE & RMSE & CVRMSE \\
\hline C16 & 0.21676 & 0.03140 & 0.25275 & 0.03407 \\
\hline C17 & 0.29296 & 0.04313 & 0.32632 & 0.0496 \\
\hline C18 & 0.30426 & 0.03879 & 0.33761 & 0.03900 \\
\hline C19 & 0.23029 & 0.03910 & 0.27529 & 0.03920 \\
\hline C20 & 0.45031 & 0.06521 & 0.48425 & 0.06313 \\
\hline C21 22 & 0.71805 & 0.09759 & 0.62753 & 0.07763 \\
\hline C23 & 0.36246 & 0.04135 & 0.41966 & 0.04562 \\
\hline
\end{tabular}


Table B.3. UV intensity data collected during C24.

\begin{tabular}{|c|c|c|c|}
\hline Time of Operation ( $t$ ) & $\begin{array}{l}\text { Time elapsed between } \\
\text { Sensor Cleanings }\left(t^{\prime}\right)\end{array}$ & Flow & Intensity \\
\hline (Hours) & Hours & gpm & $\mathrm{mW} / \mathrm{cm}^{2}$ \\
\hline 0 & 0 & 20.0 & 13.6 \\
\hline 1 & 1 & 16.3 & 13.2 \\
\hline 2 & 2 & 16.1 & 12.5 \\
\hline 3 & 3 & 16.0 & 11.9 \\
\hline 4 & 4 & 15.9 & 10.9 \\
\hline 5 & 5 & 15.7 & 11.0 \\
\hline 6 & 6 & 16.0 & 10.5 \\
\hline 7 & 7 & 15.8 & 9.8 \\
\hline 8 & 8 & 15.8 & 10.0 \\
\hline 9 & 9 & 15.7 & 9.7 \\
\hline 10 & 10 & 15.2 & 9.6 \\
\hline 11 & 11 & 15.1 & 9.6 \\
\hline 12 & 12 & 15.1 & 9.5 \\
\hline 13 & 13 & 14.7 & 9.3 \\
\hline 14 & 14 & 14.8 & 9.2 \\
\hline 15 & 15 & 14.7 & 8.9 \\
\hline 16 & 16 & 14.4 & 8.3 \\
\hline 17 & 17 & 14.0 & 8.8 \\
\hline 18 & 18 & 13.5 & 8.7 \\
\hline 19 & 19 & 13.4 & 8.4 \\
\hline 20 & 20 & 13.6 & 7.8 \\
\hline 21 & 21 & 16.4 & 8.1 \\
\hline 22 & 22 & 16.0 & 7.6 \\
\hline 23 & 23 & 15.9 & 7.1 \\
\hline 24 & 24 & 15.9 & 7.4 \\
\hline 25 & 25 & 15.8 & 7.4 \\
\hline 26 & 26 & 15.6 & 7.4 \\
\hline 27 & 27 & 15.6 & 7.5 \\
\hline 28 & 28 & 15.4 & 7.2 \\
\hline 29 & 29 & 15.9 & 6.8 \\
\hline 30 & 30 & 15.7 & 6.4 \\
\hline 31 & 31 & 15.6 & 6.7 \\
\hline 32 & 32 & 15.4 & 6.5 \\
\hline
\end{tabular}


Table B.3. UV intensity data collected during C24 (continued).

\begin{tabular}{|c|c|c|c|}
\hline Time of Operation ( $t)$ & $\begin{array}{l}\text { Time elapsed between } \\
\text { Sensor Cleanings }\left(t^{\prime}\right)\end{array}$ & Flow & Intensity \\
\hline (Hours) & Hours & gpm & $\mathrm{mW} / \mathrm{cm}^{2}$ \\
\hline 33 & 33 & 15.2 & 6.5 \\
\hline 34 & 34 & 14.2 & 6.2 \\
\hline 35 & 35 & 13.9 & 6.1 \\
\hline 36 & 36 & 14.0 & 6.0 \\
\hline 37 & 37 & 13.8 & 5.8 \\
\hline 38 & 38 & 13.7 & 5.7 \\
\hline 39 & 39 & 13.7 & 5.7 \\
\hline 40 & 40 & 13.6 & 5.4 \\
\hline 41 & 41 & 13.4 & 5.2 \\
\hline 42 & 42 & 13.3 & 5.4 \\
\hline 43 & 43 & 13.2 & 5.2 \\
\hline 44 & 44 & 13.3 & 5.0 \\
\hline 45 & 45 & 18.8 & 5.0 \\
\hline 46 & 46 & 18.6 & 4.7 \\
\hline 47 & 47 & 18.6 & 4.5 \\
\hline 48 & 48 & 18.5 & 4.2 \\
\hline 49 & 49 & 18.1 & 3.9 \\
\hline 50 & 50 & 18.0 & 3.6 \\
\hline 51 & 51 & 18.2 & 3.4 \\
\hline 52 & 52 & 18.2 & 3.4 \\
\hline 53 & 53 & 18.0 & 3.7 \\
\hline 54 & 54 & 18.0 & 3.6 \\
\hline 55 & 55 & 17.8 & 3.5 \\
\hline 56 & 56 & 18.0 & 3.4 \\
\hline 57 & 57 & 17.6 & 3.5 \\
\hline 58 & 58 & 17.5 & 3.5 \\
\hline 59 & 59 & 17.4 & 3.4 \\
\hline 60 & 60 & 17.3 & 3.3 \\
\hline 61 & 61 & 17.1 & 3.6 \\
\hline 62 & 62 & 17.3 & 3.5 \\
\hline 63 & 63 & 17.2 & 3.6 \\
\hline 64 & 64 & 16.9 & 3.5 \\
\hline 65 & 65 & 16.6 & 3.5 \\
\hline 66 & 66 & 16.7 & 3.5 \\
\hline
\end{tabular}


Table B.3. UV intensity data collected during C24 (continued).

\begin{tabular}{|c|c|c|c|}
\hline Time of Operation ( $t)$ & $\begin{array}{l}\text { Time elapsed between } \\
\text { Sensor Cleanings }\left(t^{\prime}\right)\end{array}$ & Flow & Intensity \\
\hline (Hours) & Hours & gpm & $\mathrm{mW} / \mathrm{cm}^{2}$ \\
\hline 67 & 67 & 16.7 & 3.5 \\
\hline 68 & 68 & 16.8 & 3.4 \\
\hline 69 & 69 & 16.5 & 3.4 \\
\hline 70 & 70 & 16.5 & 3.3 \\
\hline 71 & 71 & 16.7 & 3.2 \\
\hline 72 & 72 & 16.6 & 3.1 \\
\hline 73 & 73 & 16.7 & 2.9 \\
\hline 74 & 74 & 16.6 & 2.9 \\
\hline 75 & 75 & 16.7 & 2.9 \\
\hline 76 & 76 & 16.7 & 2.7 \\
\hline 77 & 77 & 16.6 & 2.8 \\
\hline 78 & 78 & 16.2 & 2.8 \\
\hline 79 & 79 & 16.4 & 2.8 \\
\hline 80 & 80 & 16.2 & 2.6 \\
\hline 81 & 81 & 16.3 & 2.6 \\
\hline 82 & 82 & 16.5 & 2.6 \\
\hline 83 & 83 & 15.9 & 2.7 \\
\hline 84 & 84 & 16.2 & 2.7 \\
\hline 85 & 85 & 16.0 & 2.8 \\
\hline 86 & 86 & 15.9 & 2.8 \\
\hline 87 & 87 & 16.0 & 2.7 \\
\hline 88 & 88 & 15.9 & 2.6 \\
\hline 89 & 89 & 15.4 & 2.7 \\
\hline 90 & 90 & 15.5 & 2.7 \\
\hline 91 & 91 & 15.4 & 2.5 \\
\hline 92 & 92 & 15.5 & 2.7 \\
\hline 93 & 93 & 15.6 & 2.6 \\
\hline 94 & 94 & 15.2 & 2.5 \\
\hline 95 & 95 & 15.7 & 2.6 \\
\hline 96 & 96 & 15.5 & 2.5 \\
\hline 97 & 97 & 15.6 & 2.5 \\
\hline 98 & 98 & 15.8 & 2.6 \\
\hline 99 & 99 & 15.7 & 2.5 \\
\hline 100 & 100 & 15.4 & 2.5 \\
\hline
\end{tabular}


Table B.3. UV intensity data collected during C24 (continued).

\begin{tabular}{|c|c|c|c|}
\hline Time of Operation ( $t)$ & $\begin{array}{l}\text { Time elapsed between } \\
\text { Sensor Cleanings }\left(t^{\prime}\right)\end{array}$ & Flow & Intensity \\
\hline (Hours) & Hours & gpm & $\mathrm{mW} / \mathrm{cm}^{2}$ \\
\hline 101 & 101 & 15.4 & 2.4 \\
\hline 102 & 102 & 15.3 & 2.3 \\
\hline 103 & 103 & 15.6 & 2.2 \\
\hline 104 & 104 & 15.6 & 1.9 \\
\hline 105 & 105 & 15.3 & 1.7 \\
\hline 106 & 106 & 15.3 & 1.7 \\
\hline 107 & 107 & 15.2 & 1.9 \\
\hline 108 & 108 & 15.6 & 2.2 \\
\hline 109 & 109 & 15.1 & 2.2 \\
\hline 110 & 110 & 14.7 & 2.2 \\
\hline 111 & 111 & 14.6 & 2.2 \\
\hline 112 & 112 & 14.5 & 2.2 \\
\hline 113 & 113 & 14.4 & 2.2 \\
\hline 114 & 114 & 14.6 & 2.2 \\
\hline 115 & 115 & 14.6 & 2.0 \\
\hline 116 & 116 & 17.0 & 2.0 \\
\hline 117 & 117 & 16.8 & 2.0 \\
\hline 118 & 118 & 17.0 & 2.0 \\
\hline 119 & 119 & 17.1 & 2.2 \\
\hline 120 & 120 & 17.2 & 1.9 \\
\hline 121 & 121 & 17.0 & 1.8 \\
\hline 122 & 122 & 16.9 & 1.6 \\
\hline 123 & 123 & 17.0 & 1.5 \\
\hline 124 & 124 & 16.8 & 1.0 \\
\hline 125 & 125 & 16.9 & 0.8 \\
\hline 126 & 126 & 17.0 & 0.8 \\
\hline 127 & 127 & 16.9 & 0.9 \\
\hline 128 & 128 & 16.9 & 0.9 \\
\hline 129 & 129 & 16.7 & 1.0 \\
\hline 130 & 130 & 16.7 & 1.1 \\
\hline 131 & 131 & 16.8 & 1.1 \\
\hline 132 & 132 & 16.5 & 1.1 \\
\hline 133 & 133 & 16.6 & 1.2 \\
\hline 134 & 134 & 16.3 & 1.3 \\
\hline
\end{tabular}


Table B.3. UV intensity data collected during C24 (continued).

\begin{tabular}{|c|c|c|c|}
\hline Time of Operation $(t)$ & $\begin{array}{l}\text { Time elapsed between } \\
\text { Sensor Cleanings }\left(t^{\prime}\right)\end{array}$ & Flow & Intensity \\
\hline (Hours) & Hours & gpm & $\mathrm{mW} / \mathrm{cm}^{2}$ \\
\hline 135 & 135 & 16.4 & 1.4 \\
\hline 136 & 136 & 16.4 & 1.4 \\
\hline 137 & 137 & 16.4 & 1.5 \\
\hline 138 & 138 & 16.3 & 1.5 \\
\hline 139 & 139 & 16.4 & 1.5 \\
\hline 140 & 140 & 16.3 & 1.5 \\
\hline 141 & 141 & 16.4 & 1.5 \\
\hline 142 & 142 & 16.5 & 1.5 \\
\hline 143 & 143 & 16.5 & 1.4 \\
\hline 144 & 144 & 16.6 & 1.4 \\
\hline 145 & 145 & 16.4 & 1.3 \\
\hline 146 & 146 & 16.3 & 1.4 \\
\hline 147 & 147 & 15.8 & 1.4 \\
\hline 148 & 148 & 15.8 & 1.5 \\
\hline 149 & 149 & 15.8 & 1.5 \\
\hline 150 & 150 & 16.0 & 1.5 \\
\hline 151 & 151 & 16.2 & 1.4 \\
\hline 152 & 152 & 16.0 & 1.4 \\
\hline 153 & 153 & 15.7 & 1.4 \\
\hline 154 & 154 & 15.6 & 1.4 \\
\hline 155 & 155 & 15.6 & 1.4 \\
\hline 156 & 156 & 15.3 & 1.3 \\
\hline 157 & 157 & 15.6 & 1.4 \\
\hline 158 & 158 & 15.5 & 1.5 \\
\hline 159 & 159 & 15.4 & 1.4 \\
\hline 160 & 160 & 15.4 & 1.5 \\
\hline 161 & 161 & 15.0 & 1.5 \\
\hline 162 & 162 & 15.4 & 1.5 \\
\hline 163 & 163 & 15.4 & 1.5 \\
\hline 164 & 164 & 15.3 & 1.4 \\
\hline 165 & 165 & 15.5 & 1.4 \\
\hline 166 & 166 & 15.5 & 1.3 \\
\hline 167 & 167 & 15.7 & 1.3 \\
\hline 168 & 168 & 15.3 & 1.2 \\
\hline
\end{tabular}


Table B.4. UV intensity data collected during C25.

\begin{tabular}{|c|c|c|c|}
\hline Time of Operation ( $t)$ & $\begin{array}{l}\text { Time elapsed between } \\
\text { Sensor Cleanings }\left(t^{\prime}\right)\end{array}$ & Flow & Intensity \\
\hline (Hours) & Hours & gpm & $\mathrm{mW} / \mathrm{cm}^{2}$ \\
\hline 0 & 0 & 25.9 & 13.4 \\
\hline 1 & 1 & 26.5 & 13.0 \\
\hline 2 & 2 & 26.2 & 13.1 \\
\hline 3 & 3 & 26.2 & 12.9 \\
\hline 4 & 4 & 26.3 & 11.8 \\
\hline 5 & 5 & 26.4 & 11.5 \\
\hline 6 & 6 & 26.1 & 10.5 \\
\hline 7 & 7 & 26.2 & 9.8 \\
\hline 8 & 8 & 25.9 & 10.1 \\
\hline 9 & 9 & 25.9 & 10.1 \\
\hline 10 & 10 & 25.8 & 10.4 \\
\hline 11 & 11 & 26.1 & 10.4 \\
\hline 12 & 12 & 25.9 & 10.3 \\
\hline 13 & 13 & 25.8 & 10.3 \\
\hline 14 & 14 & 25.8 & 10.2 \\
\hline 15 & 15 & 25.7 & 10.1 \\
\hline 16 & 16 & 26.0 & 10.0 \\
\hline 17 & 17 & 25.4 & 9.8 \\
\hline 18 & 18 & 25.5 & 9.5 \\
\hline 19 & 19 & 25.0 & 9.2 \\
\hline 20 & 20 & 24.8 & 8.5 \\
\hline 21 & 21 & 25.1 & 8.7 \\
\hline 22 & 22 & 24.7 & 8.5 \\
\hline 23 & 23 & 26.4 & 8.4 \\
\hline 24 & 24 & 26.8 & 8.1 \\
\hline 25 & 25 & 26.2 & 8.0 \\
\hline 26 & 26 & 26.7 & 7.7 \\
\hline 27 & 27 & 26.0 & 7.3 \\
\hline 28 & 28 & 26.2 & 7.1 \\
\hline 29 & 29 & 26.5 & 6.9 \\
\hline 30 & 30 & 26.4 & 6.6 \\
\hline 31 & 31 & 26.3 & 6.3 \\
\hline 32 & 32 & 26.4 & 6.2 \\
\hline
\end{tabular}


Table B.4. UV intensity data collected during C25 (continued).

\begin{tabular}{|c|c|c|c|}
\hline Time of Operation $(t)$ & $\begin{array}{l}\text { Time elapsed between } \\
\text { Sensor Cleanings }\left(t^{\prime}\right)\end{array}$ & Flow & Intensity \\
\hline (Hours) & Hours & gpm & $\mathrm{mW} / \mathrm{cm}^{2}$ \\
\hline 33 & 33 & 26.4 & 6.2 \\
\hline 34 & 34 & 26.2 & 6.3 \\
\hline 35 & 35 & 26.4 & 6.2 \\
\hline 36 & 36 & 26.3 & 6.3 \\
\hline 37 & 37 & 26.9 & 6.2 \\
\hline 38 & 38 & 26.3 & 6.1 \\
\hline 39 & 39 & 26.6 & 6.2 \\
\hline 40 & 40 & 26.3 & 6.1 \\
\hline 41 & 41 & 26.6 & 6.0 \\
\hline 42 & 42 & 26.7 & 5.9 \\
\hline 43 & 43 & 26.7 & 5.8 \\
\hline 44 & 44 & 26.9 & 5.7 \\
\hline 45 & 45 & 26.4 & 5.5 \\
\hline 46 & 46 & 26.9 & 5.3 \\
\hline 47 & 47 & 27.1 & 5.2 \\
\hline 48 & 48 & 26.6 & 5.2 \\
\hline 49 & 49 & 26.5 & 4.9 \\
\hline 50 & 50 & 26.5 & 4.8 \\
\hline 51 & 51 & 26.4 & 4.6 \\
\hline 52 & 52 & 26.3 & 4.8 \\
\hline 53 & 53 & 26.4 & 4.7 \\
\hline 54 & 54 & 26.4 & 4.6 \\
\hline 55 & 55 & 26.3 & 4.6 \\
\hline 56 & 56 & 25.9 & 4.4 \\
\hline 57 & 57 & 26.6 & 4.4 \\
\hline 58 & 58 & 26.0 & 4.4 \\
\hline 59 & 59 & 25.8 & 4.4 \\
\hline 60 & 60 & 25.8 & 4.4 \\
\hline 61 & 61 & 25.7 & 4.3 \\
\hline 62 & 62 & 25.8 & 4.2 \\
\hline 63 & 63 & 25.8 & 4.2 \\
\hline 64 & 64 & 25.8 & 4.0 \\
\hline 65 & 65 & 25.8 & 4.2 \\
\hline 66 & 66 & 25.1 & 4.2 \\
\hline
\end{tabular}


Table B.4. UV intensity data collected during C25 (continued).

\begin{tabular}{|c|c|c|c|}
\hline Time of Operation ( $t$ ) & $\begin{array}{l}\text { Time elapsed between } \\
\text { Sensor Cleanings }\left(t^{\prime}\right)\end{array}$ & Flow & Intensity \\
\hline (Hours) & Hours & gpm & $\mathrm{mW} / \mathrm{cm}^{2}$ \\
\hline 67 & 67 & 25.3 & 4.1 \\
\hline 68 & 68 & 25.2 & 4.1 \\
\hline 69 & 69 & 25.1 & 4.0 \\
\hline 70 & 70 & 25.2 & 3.9 \\
\hline 71 & 71 & 25.4 & 3.8 \\
\hline 72 & 72 & 24.8 & 3.7 \\
\hline 73 & 73 & 24.5 & 3.6 \\
\hline 74 & 74 & 24.7 & 3.5 \\
\hline 75 & 75 & 24.5 & 3.4 \\
\hline 76 & 76 & 24.4 & 3.3 \\
\hline 77 & 77 & 24.3 & 3.4 \\
\hline 78 & 78 & 24.5 & 3.3 \\
\hline 79 & 79 & 24.3 & 3.1 \\
\hline 80 & 80 & 24.1 & 3.1 \\
\hline 81 & 81 & 24.0 & 3.0 \\
\hline 82 & 82 & 23.9 & 3.1 \\
\hline 83 & 83 & 24.0 & 3.0 \\
\hline 84 & 84 & 24.1 & 3.0 \\
\hline 85 & 85 & 23.2 & 3.0 \\
\hline 86 & 86 & 23.5 & 3.0 \\
\hline 87 & 87 & 23.5 & 3.0 \\
\hline 88 & 88 & 22.9 & 3.0 \\
\hline 89 & 89 & 22.7 & 3.0 \\
\hline 90 & 90 & 22.5 & 3.0 \\
\hline 91 & 91 & 23.1 & 2.9 \\
\hline 92 & 92 & 22.9 & 2.9 \\
\hline 93 & 93 & 25.8 & 2.9 \\
\hline 94 & 94 & 26.0 & 2.9 \\
\hline 95 & 95 & 25.5 & 2.8 \\
\hline 96 & 96 & 25.2 & 2.7 \\
\hline 97 & 97 & 25.3 & 2.7 \\
\hline 98 & 98 & 25.1 & 2.6 \\
\hline 99 & 99 & 24.5 & 2.5 \\
\hline 100 & 100 & 24.8 & 2.5 \\
\hline
\end{tabular}


Table B.4. UV intensity data collected during C25 (continued).

\begin{tabular}{|c|c|c|c|}
\hline Time of Operation $(t)$ & $\begin{array}{l}\text { Time elapsed between } \\
\text { Sensor Cleanings }\left(t^{\prime}\right)\end{array}$ & Flow & Intensity \\
\hline (Hours) & Hours & gpm & $\mathrm{mW} / \mathrm{cm}^{2}$ \\
\hline 101 & 101 & 24.8 & 2.3 \\
\hline 102 & 102 & 24.7 & 2.2 \\
\hline 103 & 103 & 24.4 & 2.0 \\
\hline 104 & 104 & 24.1 & 2.0 \\
\hline 105 & 105 & 23.6 & 2.0 \\
\hline 106 & 106 & 23.9 & 2.2 \\
\hline 107 & 107 & 24.0 & 2.0 \\
\hline 108 & 108 & 23.5 & 2.2 \\
\hline 109 & 109 & 23.0 & 2.2 \\
\hline 110 & 110 & 23.2 & 2.2 \\
\hline 111 & 111 & 22.8 & 2.2 \\
\hline 112 & 112 & 22.5 & 2.2 \\
\hline 113 & 113 & 24.5 & 2.2 \\
\hline 114 & 114 & 24.8 & 2.2 \\
\hline 115 & 115 & 24.8 & 2.2 \\
\hline 116 & 116 & 28.5 & 2.3 \\
\hline 117 & 117 & 29.0 & 2.2 \\
\hline 118 & 118 & 28.5 & 2.2 \\
\hline 119 & 119 & 28.0 & 2.2 \\
\hline 120 & 120 & 27.8 & 2.0 \\
\hline 121 & 121 & 28.3 & 2.0 \\
\hline 122 & 122 & 28.2 & 2.0 \\
\hline 123 & 123 & 28.1 & 1.9 \\
\hline 124 & 124 & 27.9 & 1.9 \\
\hline 125 & 125 & 28.6 & 1.8 \\
\hline 126 & 126 & 28.2 & 1.7 \\
\hline 127 & 127 & 27.8 & 1.7 \\
\hline 128 & 128 & 28.0 & 1.6 \\
\hline 129 & 129 & 27.0 & 1.7 \\
\hline 130 & 130 & 27.5 & 1.7 \\
\hline 131 & 131 & 26.8 & 1.7 \\
\hline 132 & 132 & 27.1 & 1.8 \\
\hline 133 & 133 & 26.8 & 1.9 \\
\hline 134 & 134 & 26.8 & 1.8 \\
\hline
\end{tabular}


Table B.4. UV intensity data collected during C25 (continued).

\begin{tabular}{|c|c|c|c|}
\hline Time of Operation ( $t)$ & $\begin{array}{l}\text { Time elapsed between } \\
\text { Sensor Cleanings ( }\left(\mathbf{t}^{\prime}\right)\end{array}$ & Flow & Intensity \\
\hline (Hours) & Hours & gpm & $\mathrm{mW} / \mathrm{cm}^{2}$ \\
\hline 135 & 135 & 26.0 & 1.8 \\
\hline 136 & 136 & 26.5 & 1.9 \\
\hline 137 & 137 & 27.0 & 1.8 \\
\hline 138 & 138 & 26.9 & 1.8 \\
\hline 139 & 139 & 26.9 & 1.8 \\
\hline 140 & 140 & 26.7 & 1.8 \\
\hline 141 & 141 & 26.9 & 1.7 \\
\hline 142 & 142 & 26.9 & 1.7 \\
\hline 143 & 143 & 26.5 & 1.7 \\
\hline 144 & 144 & 26.6 & 1.7 \\
\hline 145 & 145 & 26.8 & 1.7 \\
\hline 146 & 146 & 24.8 & 1.7 \\
\hline 147 & 147 & 27.4 & 1.6 \\
\hline 148 & 148 & 27.2 & 1.6 \\
\hline 149 & 149 & 27.0 & 1.6 \\
\hline 150 & 150 & 27.3 & 1.5 \\
\hline 151 & 151 & 27.2 & 1.5 \\
\hline 152 & 152 & 27.4 & 1.5 \\
\hline 153 & 153 & 26.8 & 1.5 \\
\hline 154 & 154 & 26.5 & 1.4 \\
\hline 155 & 155 & 26.3 & 1.5 \\
\hline 156 & 156 & 26.6 & 1.5 \\
\hline 157 & 157 & 26.5 & 1.5 \\
\hline 158 & 158 & 26.7 & 1.5 \\
\hline 159 & 159 & 26.2 & 1.5 \\
\hline 160 & 160 & 26.5 & 1.5 \\
\hline 161 & 161 & 26.3 & 1.6 \\
\hline 162 & 162 & 26.2 & 1.5 \\
\hline 163 & 163 & 26.6 & 1.5 \\
\hline 164 & 164 & 25.7 & 1.5 \\
\hline 165 & 165 & 25.6 & 1.5 \\
\hline 166 & 166 & 25.8 & 1.5 \\
\hline 167 & 167 & 25.9 & 1.4 \\
\hline
\end{tabular}


Table B.5. UV intensity data collected during C26.

\begin{tabular}{|c|c|c|c|}
\hline Time of Operation $(t)$ & $\begin{array}{l}\text { Time elapsed between } \\
\text { Sensor Cleanings }\left(t^{\prime}\right)\end{array}$ & Flow & Intensity \\
\hline (Hours) & Hours & gpm & $\mathrm{mW} / \mathrm{cm}^{2}$ \\
\hline 0 & 0 & 25.5 & 12.20 \\
\hline 1 & 1 & 25.4 & 11.25 \\
\hline 2 & 2 & 25.1 & 10.94 \\
\hline 3 & 3 & 25.0 & 10.42 \\
\hline 4 & 4 & 25.0 & 10.22 \\
\hline 5 & 5 & 25.4 & 10.11 \\
\hline 6 & 6 & 24.9 & 9.91 \\
\hline 7 & 7 & 24.7 & 9.91 \\
\hline 8 & 8 & 25.1 & 9.80 \\
\hline 9 & 9 & 24.7 & 9.70 \\
\hline 10 & 10 & 24.9 & 9.60 \\
\hline 11 & 11 & 24.5 & 9.49 \\
\hline 12 & 12 & 24.4 & 9.18 \\
\hline 13 & 13 & 24.7 & 9.28 \\
\hline 14 & 14 & 24.6 & 9.29 \\
\hline 15 & 15 & 24.2 & 9.18 \\
\hline 16 & 16 & 24.0 & 8.97 \\
\hline 17 & 17 & 24.1 & 8.87 \\
\hline 18 & 18 & 24.4 & 8.66 \\
\hline 19 & 19 & 23.8 & 8.56 \\
\hline 20 & 20 & 24.0 & 8.25 \\
\hline 21 & 21 & 28.2 & 7.84 \\
\hline 22 & 22 & 28.4 & 7.63 \\
\hline 23 & 23 & 28.3 & 7.43 \\
\hline 24 & 24 & 28.4 & 7.32 \\
\hline 25 & 25 & 27.8 & 7.22 \\
\hline 26 & 26 & 28.0 & 7.01 \\
\hline 27 & 27 & 27.7 & 6.60 \\
\hline 28 & 28 & 28.2 & 6.18 \\
\hline 29 & 29 & 27.1 & 5.98 \\
\hline 30 & 30 & 27.6 & 5.87 \\
\hline 31 & 31 & 27.8 & 5.56 \\
\hline 32 & 32 & 28.0 & 5.77 \\
\hline
\end{tabular}


Table B.5. UV intensity data collected during C26 (continued).

\begin{tabular}{|c|c|c|c|}
\hline Time of Operation ( $t)$ & $\begin{array}{l}\text { Time elapsed between } \\
\text { Sensor Cleanings }\left(t^{\prime}\right)\end{array}$ & Flow & Intensity \\
\hline (Hours) & Hours & gpm & $\mathrm{mW} / \mathrm{cm}^{2}$ \\
\hline 33 & 33 & 27.6 & 5.67 \\
\hline 34 & 34 & 27.2 & 5.67 \\
\hline 35 & 35 & 27.8 & 5.67 \\
\hline 36 & 36 & 28.0 & 5.56 \\
\hline 37 & 37 & 27.1 & 5.56 \\
\hline 38 & 38 & 27.2 & 5.56 \\
\hline 39 & 39 & 27.7 & 5.56 \\
\hline 40 & 40 & 26.8 & 5.46 \\
\hline 41 & 41 & 26.9 & 5.46 \\
\hline 42 & 42 & 27.1 & 5.36 \\
\hline 43 & 43 & 27.3 & 5.36 \\
\hline 44 & 44 & 27.1 & 5.25 \\
\hline 45 & 45 & 27.1 & 5.15 \\
\hline 46 & 46 & 27.5 & 4.94 \\
\hline 47 & 47 & 27.0 & 4.84 \\
\hline 48 & 48 & 27.5 & 4.74 \\
\hline 49 & 49 & 27.6 & 4.74 \\
\hline 50 & 50 & 27.4 & 4.63 \\
\hline 51 & 51 & 27.8 & 4.63 \\
\hline 52 & 52 & 27.5 & 4.53 \\
\hline 53 & 53 & 27.1 & 4.43 \\
\hline 54 & 54 & 27.5 & 4.43 \\
\hline 55 & 55 & 27.3 & 4.43 \\
\hline 56 & 56 & 27.4 & 4.32 \\
\hline 57 & 57 & 27.2 & 4.22 \\
\hline 58 & 58 & 27.4 & 4.12 \\
\hline 59 & 59 & 27.4 & 4.12 \\
\hline 60 & 60 & 26.9 & 4.01 \\
\hline 61 & 61 & 26.8 & 4.01 \\
\hline 62 & 62 & 27.1 & 3.91 \\
\hline 63 & 63 & 27.0 & 3.91 \\
\hline 64 & 64 & 26.3 & 3.81 \\
\hline 65 & 65 & 26.4 & 3.81 \\
\hline 66 & 66 & 26.4 & 3.81 \\
\hline
\end{tabular}


Table B.5. UV intensity data collected during C26 (continued).

\begin{tabular}{|c|c|c|c|}
\hline Time of Operation (t) & $\begin{array}{l}\text { Time elapsed between } \\
\text { Sensor Cleanings }\left(t^{\prime}\right)\end{array}$ & Flow & Intensity \\
\hline (Hours) & Hours & gpm & $\mathrm{mW} / \mathrm{cm}^{2}$ \\
\hline 67 & 67 & 26.0 & 3.81 \\
\hline 68 & 68 & 26.2 & 3.70 \\
\hline 69 & 69 & 26.4 & 3.70 \\
\hline 70 & 70 & 26.3 & 3.60 \\
\hline 71 & 71 & 26.3 & 3.50 \\
\hline 72 & 72 & 23.4 & 3.39 \\
\hline 73 & 73 & 24.3 & 3.39 \\
\hline 74 & 74 & 24.5 & 3.29 \\
\hline 75 & 75 & 24.5 & 3.19 \\
\hline 76 & 76 & 24.6 & 3.08 \\
\hline 77 & 77 & 25.7 & 3.08 \\
\hline 78 & 78 & 25.7 & 3.08 \\
\hline 79 & 79 & 26.0 & 2.98 \\
\hline 80 & 80 & 25.6 & 2.98 \\
\hline 81 & 81 & 26.2 & 2.88 \\
\hline 82 & 82 & 25.9 & 2.88 \\
\hline 83 & 83 & 25.4 & 2.88 \\
\hline 84 & 84 & 25.5 & 2.77 \\
\hline 85 & 85 & 25.5 & 2.77 \\
\hline 86 & 86 & 25.8 & 2.77 \\
\hline 87 & 87 & 25.3 & 2.67 \\
\hline 88 & 88 & 25.1 & 2.67 \\
\hline 89 & 89 & 25.2 & 2.67 \\
\hline 90 & 90 & 24.9 & 2.67 \\
\hline 91 & 91 & 25.0 & 2.67 \\
\hline 92 & 92 & 24.9 & 2.67 \\
\hline 93 & 93 & 24.7 & 2.67 \\
\hline 94 & 94 & 24.9 & 2.67 \\
\hline 95 & 95 & 24.8 & 2.57 \\
\hline 96 & 96 & 24.7 & 2.57 \\
\hline 97 & 97 & 24.4 & 2.36 \\
\hline 98 & 98 & 24.7 & 2.36 \\
\hline 99 & 99 & 24.4 & 2.36 \\
\hline 100 & 100 & 24.3 & 2.36 \\
\hline
\end{tabular}


Table B.5. UV intensity data collected during C26 (continued).

\begin{tabular}{|c|c|c|c|}
\hline Time of Operation ( $\mathbf{t}$ ) & $\begin{array}{l}\text { Time elapsed between } \\
\text { Sensor Cleanings }\left(t^{\prime}\right)\end{array}$ & Flow & Intensity \\
\hline (Hours) & Hours & gpm & $\mathrm{mW} / \mathrm{cm}^{2}$ \\
\hline 101 & 101 & 24.0 & 2.26 \\
\hline 102 & 102 & 23.9 & 2.26 \\
\hline 103 & 103 & 24.0 & 2.15 \\
\hline 104 & 104 & 24.0 & 2.15 \\
\hline 105 & 105 & 23.8 & 2.05 \\
\hline 106 & 106 & 24.0 & 1.95 \\
\hline 107 & 107 & 23.8 & 1.95 \\
\hline 108 & 108 & 23.3 & 1.95 \\
\hline 109 & 109 & 23.0 & 1.84 \\
\hline 110 & 110 & 23.2 & 1.84 \\
\hline 111 & 111 & 23.3 & 1.84 \\
\hline 112 & 112 & 22.6 & 1.74 \\
\hline 113 & 113 & 22.9 & 1.74 \\
\hline 114 & 114 & 22.5 & 1.74 \\
\hline 115 & 115 & 22.7 & 1.74 \\
\hline 116 & 116 & 22.9 & 1.74 \\
\hline 117 & 117 & 22.3 & 1.64 \\
\hline 118 & 118 & 22.6 & 1.53 \\
\hline 119 & 119 & 23.2 & 1.53 \\
\hline 120 & 120 & 25.1 & 1.53 \\
\hline 121 & 121 & 24.8 & 1.43 \\
\hline 122 & 122 & 24.9 & 1.43 \\
\hline 123 & 123 & 25.0 & 1.43 \\
\hline 124 & 124 & 24.5 & 1.43 \\
\hline 125 & 125 & 25.1 & 1.43 \\
\hline 126 & 126 & 24.9 & 1.33 \\
\hline 127 & 127 & 24.4 & 1.33 \\
\hline 128 & 128 & 24.6 & 1.22 \\
\hline 129 & 129 & 24.1 & 1.22 \\
\hline 130 & 130 & 23.6 & 1.22 \\
\hline 131 & 131 & 23.6 & 1.22 \\
\hline 132 & 132 & 23.1 & 1.22 \\
\hline 133 & 133 & 23.1 & 1.33 \\
\hline 134 & 134 & 23.1 & 1.33 \\
\hline
\end{tabular}


Table B.5. UV intensity data collected during C26 (continued).

\begin{tabular}{|c|c|c|c|}
\hline Time of Operation ( $t$ ) & $\begin{array}{l}\text { Time elapsed between } \\
\text { Sensor Cleanings }\left(t^{\prime}\right)\end{array}$ & Flow & Intensity \\
\hline (Hours) & Hours & gpm & $\mathrm{mW} / \mathrm{cm}^{2}$ \\
\hline 135 & 135 & 23.1 & 1.33 \\
\hline 136 & 136 & 22.2 & 1.33 \\
\hline 137 & 137 & 22.7 & 1.33 \\
\hline 138 & 138 & 22.4 & 1.33 \\
\hline 139 & 139 & 22.7 & 1.33 \\
\hline 140 & 140 & 22.0 & 1.33 \\
\hline 141 & 141 & 21.8 & 1.33 \\
\hline 142 & 142 & 21.1 & 1.33 \\
\hline 143 & 143 & 21.6 & 1.33 \\
\hline 144 & 144 & 22.3 & 1.22 \\
\hline 145 & 145 & 21.9 & 1.22 \\
\hline 146 & 146 & 22.0 & 1.22 \\
\hline 147 & 147 & 21.6 & 1.33 \\
\hline 148 & 148 & 22.2 & 1.33 \\
\hline 149 & 149 & 21.9 & 1.33 \\
\hline 150 & 150 & 22.0 & 1.22 \\
\hline 151 & 151 & 21.6 & 1.22 \\
\hline 152 & 152 & 21.2 & 1.22 \\
\hline 153 & 153 & 21.4 & 1.22 \\
\hline 154 & 154 & 21.0 & 1.22 \\
\hline 155 & 155 & 20.4 & 1.22 \\
\hline 156 & 156 & 21.2 & 1.22 \\
\hline 157 & 157 & 20.6 & 1.22 \\
\hline 158 & 158 & 20.3 & 1.22 \\
\hline 159 & 159 & 19.9 & 1.22 \\
\hline 160 & 160 & 19.9 & 1.22 \\
\hline 161 & 161 & 19.6 & 1.22 \\
\hline 162 & 162 & 19.3 & 1.22 \\
\hline
\end{tabular}


Table B.6. UV intensity data collected during C27.

\begin{tabular}{|c|c|c|c|}
\hline Time of Operation ( $t$ ) & $\begin{array}{l}\text { Time elapsed between } \\
\text { Sensor Cleanings }\left(t^{\prime}\right)\end{array}$ & Flow & Intensity \\
\hline (Hours) & Hours & gpm & $\mathrm{mW} / \mathrm{cm}^{2}$ \\
\hline 0 & 0 & 25.0 & 10.01 \\
\hline 1 & 1 & 25.6 & 9.91 \\
\hline 2 & 2 & 25.2 & 9.49 \\
\hline 3 & 3 & 25.3 & 9.28 \\
\hline 4 & 4 & 25.3 & 9.08 \\
\hline 5 & 5 & 25.2 & 8.67 \\
\hline 6 & 6 & 25.4 & 8.36 \\
\hline 7 & 7 & 25.7 & 8.05 \\
\hline 8 & 8 & 25.1 & 7.53 \\
\hline 9 & 9 & 25.3 & 6.70 \\
\hline 10 & 10 & 25.2 & 6.49 \\
\hline 11 & 11 & 25.1 & 6.29 \\
\hline 12 & 12 & 25.4 & 5.98 \\
\hline 13 & 13 & 24.9 & 5.98 \\
\hline 14 & 14 & 24.6 & 5.87 \\
\hline 15 & 15 & 24.7 & 5.87 \\
\hline 16 & 16 & 24.7 & 5.87 \\
\hline 17 & 17 & 24.4 & 5.77 \\
\hline 18 & 18 & 24.6 & 5.77 \\
\hline 19 & 19 & 23.9 & 5.67 \\
\hline 20 & 20 & 23.8 & 5.56 \\
\hline 21 & 21 & 24.3 & 5.56 \\
\hline 22 & 22 & 23.9 & 5.56 \\
\hline 23 & 23 & 24.0 & 5.46 \\
\hline 24 & 24 & 23.9 & 5.46 \\
\hline 25 & 25 & 24.1 & 5.15 \\
\hline 26 & 26 & 24.4 & 4.74 \\
\hline 27 & 27 & 24.1 & 4.63 \\
\hline 28 & 28 & 24.2 & 4.32 \\
\hline 29 & 29 & 24.7 & 4.22 \\
\hline 30 & 30 & 24.4 & 4.12 \\
\hline 31 & 31 & 24.2 & 4.22 \\
\hline 32 & 32 & 24.7 & 4.12 \\
\hline
\end{tabular}


Table B.6. UV intensity data collected during C27 (continued).

\begin{tabular}{|c|c|c|c|}
\hline Time of Operation ( $t$ ) & $\begin{array}{l}\text { Time elapsed between } \\
\text { Sensor Cleanings ( }\left(t^{\prime}\right)\end{array}$ & Flow & Intensity \\
\hline (Hours) & Hours & gpm & $\mathrm{mW} / \mathrm{cm}^{2}$ \\
\hline 33 & 33 & 24.0 & 4.12 \\
\hline 34 & 34 & 24.4 & 4.01 \\
\hline 35 & 35 & 24.1 & 3.91 \\
\hline 36 & 36 & 23.9 & 3.81 \\
\hline 37 & 37 & 24.0 & 3.81 \\
\hline 38 & 38 & 24.0 & 3.70 \\
\hline 39 & 39 & 23.9 & 3.70 \\
\hline 40 & 40 & 23.6 & 3.70 \\
\hline 41 & 41 & 24.3 & 3.81 \\
\hline 42 & 42 & 23.9 & 3.81 \\
\hline 43 & 43 & 23.6 & 3.81 \\
\hline 44 & 44 & 24.1 & 3.81 \\
\hline 45 & 45 & 23.6 & 3.81 \\
\hline 46 & 46 & 23.6 & 3.81 \\
\hline 47 & 47 & 24.0 & 3.81 \\
\hline 48 & 48 & 23.4 & 3.60 \\
\hline 49 & 49 & 23.3 & 3.29 \\
\hline 50 & 50 & 23.5 & 3.19 \\
\hline 51 & 51 & 23.8 & 3.19 \\
\hline 52 & 52 & 23.3 & 3.19 \\
\hline 53 & 53 & 23.5 & 3.19 \\
\hline 54 & 54 & 23.8 & 3.08 \\
\hline 55 & 55 & 23.7 & 2.98 \\
\hline 56 & 56 & 23.6 & 2.88 \\
\hline 57 & 57 & 23.5 & 2.77 \\
\hline 58 & 58 & 23.5 & 2.67 \\
\hline 59 & 59 & 23.5 & 2.46 \\
\hline 60 & 60 & 23.3 & 2.36 \\
\hline 61 & 61 & 23.7 & 2.36 \\
\hline 62 & 62 & 23.9 & 2.26 \\
\hline 63 & 63 & 23.7 & 2.15 \\
\hline 64 & 64 & 24.4 & 2.05 \\
\hline 65 & 65 & 24.3 & 1.84 \\
\hline 66 & 66 & 24.2 & 1.74 \\
\hline
\end{tabular}


Table B.6. UV intensity data collected during C27 (continued).

\begin{tabular}{|c|c|c|c|}
\hline Time of Operation (t) & $\begin{array}{c}\text { Time elapsed between } \\
\text { Sensor Cleanings (t') }\end{array}$ & Flow & Intensity \\
\hline (Hours) & Hours & gpm & $\mathrm{mW} / \mathrm{cm}^{2}$ \\
\hline 67 & 67 & 23.9 & 1.84 \\
\hline 68 & 68 & 23.4 & 1.95 \\
\hline 69 & 69 & 23.1 & 2.05 \\
\hline 70 & 70 & 23.0 & 2.05 \\
\hline 71 & 71 & 22.9 & 2.05 \\
\hline 72 & 72 & 22.8 & 2.05 \\
\hline 73 & 73 & 22.9 & 2.05 \\
\hline 74 & 74 & 23.1 & 1.95 \\
\hline 75 & 75 & 22.9 & 1.95 \\
\hline 76 & 76 & 22.9 & 1.95 \\
\hline 77 & 77 & 22.8 & 1.95 \\
\hline 78 & 78 & 23.1 & 1.95 \\
\hline 79 & 79 & 22.7 & 1.95 \\
\hline 80 & 80 & 22.8 & 1.84 \\
\hline 81 & 81 & 22.8 & 1.84 \\
\hline 82 & 82 & 23.2 & 1.84 \\
\hline 83 & 83 & 23.2 & 1.74 \\
\hline 84 & 84 & 23.0 & 1.74 \\
\hline 85 & 85 & 23.0 & 1.74 \\
\hline 86 & 86 & 22.8 & 1.74 \\
\hline 87 & 87 & 24.8 & 1.74 \\
\hline 88 & 88 & 24.5 & 1.64 \\
\hline 89 & 89 & 24.7 & 1.64 \\
\hline 90 & 90 & 24.4 & 1.53 \\
\hline 91 & 91 & 24.6 & 1.53 \\
\hline 92 & 92 & 24.7 & 1.33 \\
\hline 93 & 93 & 24.2 & 1.33 \\
\hline 94 & 94 & 24.1 & 1.33 \\
\hline 95 & 95 & 23.9 & 1.43 \\
\hline 96 & 97.4 & 1.43 \\
\hline 97 & & 24.3 & 1.43 \\
\hline 98 & 24.0 & 1.53 \\
\hline 99 & 90.8 & 1.53 \\
\hline 100 & & & \\
\hline & 96.53 \\
\hline
\end{tabular}


Table B.6. UV intensity data collected during C27 (continued).

\begin{tabular}{|c|c|c|c|}
\hline Time of Operation ( $t$ ) & $\begin{array}{l}\text { Time elapsed between } \\
\text { Sensor Cleanings ( }\left(t^{\prime}\right)\end{array}$ & Flow & Intensity \\
\hline (Hours) & Hours & gpm & $\mathrm{mW} / \mathrm{cm}^{2}$ \\
\hline 101 & 101 & 24.1 & 1.53 \\
\hline 102 & 102 & 23.7 & 1.53 \\
\hline 103 & 103 & 23.7 & 1.53 \\
\hline 104 & 104 & 24.0 & 1.33 \\
\hline 105 & 105 & 23.1 & 1.33 \\
\hline 106 & 106 & 23.5 & 1.12 \\
\hline 107 & 107 & 23.4 & 1.02 \\
\hline 108 & 108 & 23.5 & 0.81 \\
\hline 109 & 109 & 23.3 & 0.71 \\
\hline 110 & 110 & 23.3 & 0.71 \\
\hline 111 & 111 & 23.2 & 0.71 \\
\hline 112 & 112 & 23.8 & 0.71 \\
\hline 113 & 113 & 23.3 & 0.71 \\
\hline 114 & 114 & 22.5 & 0.81 \\
\hline 115 & 115 & 22.6 & 0.81 \\
\hline 116 & 116 & 22.5 & 0.91 \\
\hline 117 & 117 & 22.9 & 0.91 \\
\hline 118 & 118 & 22.4 & 1.02 \\
\hline 119 & 119 & 22.4 & 1.02 \\
\hline 120 & 120 & 23.1 & 1.02 \\
\hline 121 & 121 & 22.8 & 1.02 \\
\hline 122 & 122 & 22.4 & 1.02 \\
\hline 123 & 123 & 22.3 & 1.02 \\
\hline 124 & 124 & 22.0 & 1.02 \\
\hline 125 & 125 & 22.3 & 1.02 \\
\hline 126 & 126 & 22.1 & 0.71 \\
\hline 127 & 127 & 24.5 & 0.50 \\
\hline 128 & 128 & 24.4 & 0.40 \\
\hline 129 & 129 & 24.3 & 0.40 \\
\hline 130 & 130 & 24.5 & 0.29 \\
\hline 131 & 131 & 24.3 & 0.29 \\
\hline 132 & 132 & 24.2 & 0.29 \\
\hline 133 & 133 & 24.0 & 0.29 \\
\hline 134 & 134 & 23.7 & 0.40 \\
\hline
\end{tabular}


Table B.6. UV intensity data collected during C27 (continued).

\begin{tabular}{|c|c|c|c|}
\hline Time of Operation (t) & $\begin{array}{c}\text { Time elapsed between } \\
\text { Sensor Cleanings (t') }\end{array}$ & Flow & Intensity \\
\hline (Hours) & Hours & gpm & $\mathrm{mW} / \mathrm{cm}^{2}$ \\
\hline 135 & 135 & 23.9 & 0.40 \\
\hline 136 & 136 & 24.1 & 0.40 \\
\hline 137 & 137 & 23.8 & 0.40 \\
\hline 138 & 138 & 23.8 & 0.40 \\
\hline 139 & 139 & 22.8 & 0.40 \\
\hline 140 & 140 & 22.3 & 0.50 \\
\hline 141 & 141 & 22.5 & 0.50 \\
\hline 142 & 142 & 22.8 & 0.60 \\
\hline 143 & 143 & 23.0 & 0.60 \\
\hline 144 & 144 & 23.1 & 0.60 \\
\hline 145 & 145 & 22.5 & 0.60 \\
\hline 146 & 146 & 22.7 & 0.60 \\
\hline 147 & 147 & 22.0 & 0.60 \\
\hline
\end{tabular}


Table B.7. UV intensity data collected during C28.

\begin{tabular}{|c|c|c|c|}
\hline Time of Operation ( $t$ ) & $\begin{array}{l}\text { Time elapsed between } \\
\text { Sensor Cleanings }\left(t^{\prime}\right)\end{array}$ & Flow & Intensity \\
\hline (Hours) & Hours & $\mathrm{gpm}$ & $\mathrm{mW} / \mathrm{cm}^{2}$ \\
\hline 0 & 0 & 35.5 & 13.63 \\
\hline 1 & 1 & 35.2 & 13.63 \\
\hline 2 & 2 & 34.5 & 13.43 \\
\hline 3 & 3 & 34.6 & 13.32 \\
\hline 4 & 4 & 34.5 & 12.59 \\
\hline 5 & 5 & 34.3 & 11.87 \\
\hline 6 & 6 & 34.0 & 11.35 \\
\hline 7 & 7 & 34.7 & 11.15 \\
\hline 8 & 8 & 34.7 & 10.73 \\
\hline 9 & 9 & 34.1 & 10.84 \\
\hline 10 & 10 & 33.8 & 10.01 \\
\hline 11 & 11 & 33.7 & 10.11 \\
\hline 12 & 12 & 34.2 & 10.22 \\
\hline 13 & 13 & 34.1 & 10.11 \\
\hline 14 & 14 & 33.2 & 10.32 \\
\hline 15 & 15 & 33.5 & 9.80 \\
\hline 16 & 16 & 33.0 & 9.60 \\
\hline 17 & 17 & 32.8 & 9.49 \\
\hline 18 & 18 & 33.2 & 9.39 \\
\hline 19 & 19 & 33.0 & 9.08 \\
\hline 20 & 20 & 33.1 & 8.98 \\
\hline 21 & 21 & 33.0 & 8.98 \\
\hline 22 & 22 & 33.1 & 8.56 \\
\hline 23 & 23 & 33.4 & 8.46 \\
\hline 24 & 24 & 32.8 & 8.36 \\
\hline 25 & 25 & 34.0 & 8.36 \\
\hline 26 & 26 & 33.7 & 8.05 \\
\hline 27 & 27 & 34.3 & 7.74 \\
\hline 28 & 28 & 33.7 & 7.53 \\
\hline 29 & 29 & 33.7 & 7.12 \\
\hline 30 & 30 & 33.7 & 6.70 \\
\hline 31 & 31 & 33.8 & 6.29 \\
\hline 32 & 32 & 33.7 & 6.08 \\
\hline
\end{tabular}


Table B.7. UV intensity data collected during C28 (continued).

\begin{tabular}{|c|c|c|c|}
\hline Time of Operation ( $t$ ) & $\begin{array}{l}\text { Time elapsed between } \\
\text { Sensor Cleanings }\left(t^{\prime}\right)\end{array}$ & Flow & Intensity \\
\hline (Hours) & Hours & gpm & $\mathrm{mW} / \mathrm{cm}^{2}$ \\
\hline 33 & 33 & 33.8 & 6.08 \\
\hline 34 & 34 & 33.6 & 5.98 \\
\hline 35 & 35 & 33.3 & 6.08 \\
\hline 36 & 36 & 33.2 & 5.98 \\
\hline 37 & 37 & 33.3 & 6.19 \\
\hline 38 & 38 & 33.5 & 6.39 \\
\hline 39 & 39 & 32.8 & 6.08 \\
\hline 40 & 40 & 32.9 & 6.08 \\
\hline 41 & 41 & 32.9 & 6.08 \\
\hline 42 & 42 & 33.0 & 6.08 \\
\hline 43 & 43 & 32.7 & 5.98 \\
\hline 44 & 44 & 29.1 & 5.77 \\
\hline 45 & 45 & 28.3 & 5.67 \\
\hline 46 & 46 & 30.4 & 5.57 \\
\hline 47 & 47 & 31.2 & 5.26 \\
\hline 48 & 48 & 31.3 & 4.64 \\
\hline 49 & 49 & 30.8 & 4.12 \\
\hline 50 & 50 & 34.7 & 4.22 \\
\hline 51 & 51 & 34.9 & 4.33 \\
\hline 52 & 52 & 34.6 & 4.22 \\
\hline 53 & 53 & 34.4 & 4.22 \\
\hline 54 & 54 & 34.6 & 4.22 \\
\hline 55 & 55 & 34.6 & 4.02 \\
\hline 56 & 56 & 34.8 & 3.91 \\
\hline 57 & 57 & 34.7 & 4.02 \\
\hline 58 & 58 & 33.8 & 3.91 \\
\hline 59 & 59 & 34.4 & 4.02 \\
\hline 60 & 60 & 33.8 & 4.02 \\
\hline 61 & 61 & 33.5 & 4.02 \\
\hline 62 & 62 & 33.5 & 4.02 \\
\hline 63 & 63 & 33.1 & 4.02 \\
\hline 64 & 64 & 33.1 & 4.12 \\
\hline 65 & 65 & 32.7 & 4.02 \\
\hline 66 & 66 & 32.7 & 4.01 \\
\hline
\end{tabular}


Table B.7. UV intensity data collected during C28 (continued).

\begin{tabular}{|c|c|c|c|}
\hline Time of Operation ( $t$ ) & $\begin{array}{l}\text { Time elapsed between } \\
\text { Sensor Cleanings ( }\left(t^{\prime}\right)\end{array}$ & Flow & Intensity \\
\hline (Hours) & Hours & gpm & $\mathrm{mW} / \mathrm{cm}^{2}$ \\
\hline 67 & 67 & 33.3 & 3.91 \\
\hline 68 & 68 & 33.0 & 3.91 \\
\hline 69 & 69 & 33.1 & 3.71 \\
\hline 70 & 70 & 33.2 & 3.60 \\
\hline 71 & 71 & 33.4 & 3.60 \\
\hline 72 & 72 & 33.6 & 3.60 \\
\hline 73 & 73 & 33.9 & 3.81 \\
\hline 74 & 74 & 35.0 & 3.71 \\
\hline 75 & 75 & 35.1 & 3.71 \\
\hline 76 & 76 & 35.4 & 3.60 \\
\hline 77 & 77 & 35.0 & 3.50 \\
\hline 78 & 78 & 34.8 & 3.19 \\
\hline 79 & 79 & 34.8 & 2.98 \\
\hline 80 & 80 & 34.9 & 2.98 \\
\hline 81 & 81 & 34.5 & 2.88 \\
\hline 82 & 82 & 34.4 & 2.88 \\
\hline 83 & 83 & 34.3 & 2.88 \\
\hline 84 & 84 & 34.4 & 2.98 \\
\hline 85 & 85 & 34.1 & 2.88 \\
\hline 86 & 86 & 34.0 & 2.98 \\
\hline 87 & 87 & 33.9 & 2.98 \\
\hline 88 & 88 & 33.8 & 2.88 \\
\hline 89 & 89 & 34.1 & 2.88 \\
\hline 90 & 90 & 34.2 & 3.09 \\
\hline 91 & 91 & 33.6 & 2.88 \\
\hline 92 & 92 & 33.4 & 2.77 \\
\hline 93 & 93 & 33.5 & 2.77 \\
\hline 94 & 94 & 33.4 & 2.67 \\
\hline 95 & 95 & 33.8 & 2.67 \\
\hline 96 & 96 & 33.6 & 2.57 \\
\hline 97 & 97 & 34.2 & 2.67 \\
\hline 98 & 98 & 33.6 & 2.67 \\
\hline 99 & 99 & 33.9 & 2.67 \\
\hline 100 & 100 & 33.8 & 2.57 \\
\hline
\end{tabular}


Table B.7. UV intensity data collected during C28 (continued).

\begin{tabular}{|c|c|c|c|}
\hline Time of Operation ( $t$ ) & $\begin{array}{l}\text { Time elapsed between } \\
\text { Sensor Cleanings ( }\left(t^{\prime}\right)\end{array}$ & Flow & Intensity \\
\hline (Hours) & Hours & gpm & $\mathrm{mW} / \mathrm{cm}^{2}$ \\
\hline 101 & 101 & 33.8 & 2.57 \\
\hline 102 & 102 & 33.7 & 2.67 \\
\hline 103 & 103 & 34.5 & 2.46 \\
\hline 104 & 104 & 34.2 & 2.36 \\
\hline 105 & 105 & 34.3 & 2.36 \\
\hline 106 & 106 & 34.1 & 2.46 \\
\hline 107 & 107 & 33.9 & 2.36 \\
\hline 108 & 108 & 33.9 & 2.36 \\
\hline 109 & 109 & 33.8 & 2.36 \\
\hline 110 & 110 & 33.8 & 2.36 \\
\hline 111 & 111 & 33.4 & 2.36 \\
\hline 112 & 112 & 33.1 & 2.36 \\
\hline 113 & 113 & 33.1 & 2.36 \\
\hline 114 & 114 & 33.8 & 2.36 \\
\hline 115 & 115 & 33.1 & 2.36 \\
\hline 116 & 116 & 33.2 & 2.26 \\
\hline 117 & 117 & 33.1 & 2.26 \\
\hline 118 & 118 & 33.3 & 2.15 \\
\hline 119 & 119 & 33.8 & 2.15 \\
\hline 120 & 120 & 33.3 & 1.95 \\
\hline 121 & 121 & 33.3 & 1.95 \\
\hline 122 & 122 & 33.3 & 1.95 \\
\hline 123 & 123 & 33.7 & 2.05 \\
\hline 124 & 124 & 33.5 & 2.05 \\
\hline 125 & 125 & 34.3 & 2.05 \\
\hline 126 & 126 & 34.2 & 1.95 \\
\hline 127 & 127 & 33.9 & 1.95 \\
\hline 128 & 128 & 34.0 & 1.95 \\
\hline 129 & 129 & 33.3 & 1.95 \\
\hline 130 & 130 & 33.3 & 1.95 \\
\hline 131 & 131 & 33.2 & 1.95 \\
\hline 132 & 132 & 33.3 & 1.84 \\
\hline 133 & 133 & 33.3 & 1.84 \\
\hline 134 & 134 & 33.6 & 1.84 \\
\hline
\end{tabular}


Table B.7. UV intensity data collected during C28 (continued).

\begin{tabular}{|c|c|c|c|}
\hline Time of Operation ( $\mathbf{t}$ ) & $\begin{array}{l}\text { Time elapsed between } \\
\text { Sensor Cleanings }\left(\mathbf{t}^{\prime}\right)\end{array}$ & Flow & Intensity \\
\hline (Hours) & Hours & gpm & $\mathrm{mW} / \mathrm{cm}^{2}$ \\
\hline 135 & 135 & 33.1 & 1.84 \\
\hline 136 & 136 & 33.0 & 1.84 \\
\hline 137 & 137 & 32.9 & 1.84 \\
\hline 138 & 138 & 33.1 & 1.84 \\
\hline 139 & 139 & 33.0 & 1.74 \\
\hline 140 & 140 & 33.0 & 1.74 \\
\hline 141 & 141 & 33.0 & 1.64 \\
\hline 142 & 142 & 33.0 & 1.64 \\
\hline 143 & 143 & 33.0 & 1.64 \\
\hline 144 & 144 & 33.0 & 1.53 \\
\hline 145 & 145 & 33.0 & 1.53 \\
\hline 146 & 146 & 33.0 & 1.53 \\
\hline 147 & 147 & 33.0 & 1.43 \\
\hline 148 & 148 & 33.0 & 1.43 \\
\hline 149 & 149 & 33.0 & 1.33 \\
\hline 150 & 150 & 33.0 & 1.33 \\
\hline 151 & 151 & 33.0 & 1.33 \\
\hline 152 & 152 & 33.0 & 1.33 \\
\hline 153 & 153 & 33.0 & 1.33 \\
\hline 154 & 154 & 34.2 & 1.33 \\
\hline 155 & 155 & 34.1 & 1.53 \\
\hline 156 & 156 & 33.9 & 1.43 \\
\hline 157 & 157 & 33.9 & 1.43 \\
\hline 158 & 158 & 33.8 & 1.33 \\
\hline 159 & 159 & 33.5 & 1.53 \\
\hline 160 & 160 & 33.7 & 1.53 \\
\hline 161 & 161 & 33.5 & 1.53 \\
\hline 162 & 162 & 33.8 & 1.53 \\
\hline 163 & 163 & 33.1 & 1.53 \\
\hline 164 & 164 & 33.1 & 1.53 \\
\hline 165 & 165 & 33.3 & 1.53 \\
\hline 166 & 166 & 33.2 & 1.53 \\
\hline
\end{tabular}


Table B.8. UV intensity data collected during C29.

\begin{tabular}{|c|c|c|c|}
\hline Time of Operation $(t)$ & $\begin{array}{l}\text { Time elapsed between } \\
\text { Sensor Cleanings }\left(t^{\prime}\right)\end{array}$ & Flow & Intensity \\
\hline (Hours) & Hours & gpm & $\mathrm{mW} / \mathrm{cm}^{2}$ \\
\hline 0 & 0 & 36.2 & 13.63 \\
\hline 1 & 1 & 35.3 & 13.43 \\
\hline 2 & 2 & 35.5 & 13.52 \\
\hline 3 & 3 & 35.4 & 13.11 \\
\hline 4 & 4 & 35.4 & 12.70 \\
\hline 5 & 5 & 35.4 & 11.87 \\
\hline 6 & 6 & 35.4 & 11.35 \\
\hline 7 & 7 & 34.9 & 10.94 \\
\hline 8 & 8 & 34.9 & 10.52 \\
\hline 9 & 9 & 34.9 & 10.63 \\
\hline 10 & 10 & 34.0 & 10.11 \\
\hline 11 & 11 & 34.1 & 9.90 \\
\hline 12 & 12 & 34.5 & 10.01 \\
\hline 13 & 13 & 34.9 & 9.59 \\
\hline 14 & 14 & 34.6 & 9.59 \\
\hline 15 & 15 & 34.6 & 9.49 \\
\hline 16 & 16 & 34.0 & 9.39 \\
\hline 17 & 17 & 34.0 & 8.97 \\
\hline 18 & 18 & 34.0 & 8.66 \\
\hline 19 & 19 & 34.1 & 8.97 \\
\hline 20 & 20 & 33.8 & 8.77 \\
\hline 21 & 21 & 33.8 & 8.56 \\
\hline 22 & 22 & 33.9 & 8.35 \\
\hline 23 & 23 & 34.8 & 8.04 \\
\hline 24 & 24 & 34.5 & 8.04 \\
\hline 25 & 25 & 34.1 & 7.84 \\
\hline 26 & 26 & 34.7 & 7.73 \\
\hline 27 & 27 & 34.4 & 7.53 \\
\hline 28 & 28 & 34.6 & 7.42 \\
\hline 29 & 29 & 34.3 & 7.32 \\
\hline 30 & 30 & 35.1 & 7.22 \\
\hline 31 & 31 & 27.5 & 7.11 \\
\hline 32 & 32 & 28.1 & 6.80 \\
\hline
\end{tabular}


Table B.8. UV intensity data collected during C29 (continued).

\begin{tabular}{|c|c|c|c|}
\hline Time of Operation ( $t$ ) & $\begin{array}{l}\text { Time elapsed between } \\
\text { Sensor Cleanings }\left(t^{\prime}\right)\end{array}$ & Flow & Intensity \\
\hline (Hours) & Hours & gpm & $\mathrm{mW} / \mathrm{cm}^{2}$ \\
\hline 33 & 33 & 28.8 & 6.49 \\
\hline 34 & 34 & 28.7 & 6.39 \\
\hline 35 & 35 & 28.2 & 6.18 \\
\hline 36 & 36 & 28.0 & 5.77 \\
\hline 37 & 37 & 27.7 & 5.87 \\
\hline 38 & 38 & 27.7 & 5.98 \\
\hline 39 & 39 & 27.6 & 5.77 \\
\hline 40 & 40 & 27.2 & 5.87 \\
\hline 41 & 41 & 27.2 & 5.67 \\
\hline 42 & 42 & 27.5 & 5.56 \\
\hline 43 & 43 & 27.1 & 5.56 \\
\hline 44 & 44 & 26.5 & 5.56 \\
\hline 45 & 45 & 26.4 & 5.36 \\
\hline 46 & 46 & 26.7 & 5.25 \\
\hline 47 & 47 & 26.7 & 5.15 \\
\hline 48 & 48 & 27.1 & 4.94 \\
\hline 49 & 49 & 27.8 & 4.84 \\
\hline 50 & 50 & 27.9 & 4.84 \\
\hline 51 & 51 & 27.5 & 4.84 \\
\hline 52 & 52 & 27.9 & 4.74 \\
\hline 53 & 53 & 28.0 & 4.74 \\
\hline 54 & 54 & 28.3 & 4.63 \\
\hline 55 & 55 & 28.4 & 4.63 \\
\hline 56 & 56 & 27.8 & 4.43 \\
\hline 57 & 57 & 27.6 & 4.22 \\
\hline 58 & 58 & 27.9 & 4.12 \\
\hline 59 & 59 & 27.6 & 4.01 \\
\hline 60 & 60 & 27.7 & 3.91 \\
\hline 61 & 61 & 27.5 & 4.01 \\
\hline 62 & 62 & 27.3 & 4.01 \\
\hline 63 & 63 & 27.4 & 3.91 \\
\hline 64 & 64 & 28.0 & 3.91 \\
\hline 65 & 65 & 27.3 & 3.81 \\
\hline 66 & 66 & 27.3 & 3.81 \\
\hline
\end{tabular}


Table B.8. UV intensity data collected during C29 (continued).

\begin{tabular}{|c|c|c|c|}
\hline Time of Operation (t) & $\begin{array}{l}\text { Time elapsed between } \\
\text { Sensor Cleanings }\left(t^{\prime}\right)\end{array}$ & Flow & Intensity \\
\hline (Hours) & Hours & gpm & $\mathrm{mW} / \mathrm{cm}^{2}$ \\
\hline 67 & 67 & 27.1 & 3.70 \\
\hline 68 & 68 & 26.7 & 3.70 \\
\hline 69 & 69 & 26.7 & 3.70 \\
\hline 70 & 70 & 26.8 & 3.60 \\
\hline 71 & 71 & 26.6 & 3.60 \\
\hline 72 & 72 & 26.9 & 3.50 \\
\hline 73 & 73 & 27.0 & 3.39 \\
\hline 74 & 74 & 27.2 & 3.29 \\
\hline 75 & 75 & 26.8 & 3.29 \\
\hline 76 & 76 & 27.1 & 3.29 \\
\hline 77 & 77 & 26.9 & 3.29 \\
\hline 78 & 78 & 26.8 & 3.18 \\
\hline 79 & 79 & 26.9 & 3.08 \\
\hline 80 & 80 & 26.9 & 3.08 \\
\hline 81 & 81 & 26.9 & 2.87 \\
\hline 82 & 82 & 27.5 & 2.77 \\
\hline 83 & 83 & 26.8 & 2.77 \\
\hline 84 & 84 & 26.7 & 2.67 \\
\hline 85 & 85 & 26.6 & 2.67 \\
\hline 86 & 86 & 26.2 & 2.67 \\
\hline 87 & 87 & 26.3 & 2.56 \\
\hline 88 & 88 & 26.0 & 2.67 \\
\hline 89 & 89 & 25.9 & 2.67 \\
\hline 90 & 90 & 25.9 & 2.56 \\
\hline 91 & 91 & 26.0 & 2.49 \\
\hline
\end{tabular}


Table B.9. UV intensity data collected during C30.

\begin{tabular}{|c|c|c|c|}
\hline Time of Operation ( $t$ ) & $\begin{array}{l}\text { Time elapsed between } \\
\left.\text { Sensor Cleanings ( } \mathbf{t}^{\prime}\right)\end{array}$ & Flow & Intensity \\
\hline (Hours) & Hours & gpm & $\mathrm{mW} / \mathrm{cm}^{2}$ \\
\hline 0 & 0 & 35.9 & 11.66 \\
\hline 1 & 1 & 35.6 & 11.77 \\
\hline 2 & 2 & 35.5 & 11.87 \\
\hline 3 & 3 & 35.3 & 11.45 \\
\hline 4 & 4 & 35.2 & 11.04 \\
\hline 5 & 5 & 35.7 & 10.63 \\
\hline 6 & 6 & 35.4 & 10.52 \\
\hline 7 & 7 & 34.9 & 10.52 \\
\hline 8 & 8 & 34.9 & 10.52 \\
\hline 9 & 9 & 35.1 & 10.42 \\
\hline 10 & 10 & 34.8 & 10.11 \\
\hline 11 & 11 & 34.9 & 10.01 \\
\hline 12 & 12 & 34.5 & 9.90 \\
\hline 13 & 13 & 34.9 & 9.80 \\
\hline 14 & 14 & 35.1 & 9.90 \\
\hline 15 & 15 & 35.2 & 9.70 \\
\hline 16 & 16 & 34.6 & 9.39 \\
\hline 17 & 17 & 34.0 & 9.28 \\
\hline 18 & 18 & 34.1 & 9.39 \\
\hline 19 & 19 & 33.9 & 9.18 \\
\hline 20 & 20 & 34.1 & 9.18 \\
\hline 21 & 21 & 34.1 & 8.97 \\
\hline 22 & 22 & 34.0 & 9.08 \\
\hline 23 & 23 & 34.2 & 8.66 \\
\hline 24 & 24 & 34.0 & 8.56 \\
\hline 25 & 25 & 34.5 & 8.46 \\
\hline 26 & 26 & 34.3 & 8.25 \\
\hline 27 & 27 & 34.1 & 8.25 \\
\hline 28 & 28 & 33.8 & 8.25 \\
\hline 29 & 29 & 34.0 & 8.25 \\
\hline 30 & 30 & 33.8 & 8.04 \\
\hline 31 & 31 & 34.2 & 7.94 \\
\hline 32 & 32 & 34.2 & 7.84 \\
\hline
\end{tabular}


Table B.9. UV intensity data collected during C30 (continued).

\begin{tabular}{|c|c|c|c|}
\hline Time of Operation ( $t$ ) & $\begin{array}{l}\text { Time elapsed between } \\
\text { Sensor Cleanings ( }\left(t^{\prime}\right)\end{array}$ & Flow & Intensity \\
\hline (Hours) & Hours & gpm & $\mathrm{mW} / \mathrm{cm}^{2}$ \\
\hline 33 & 33 & 34.2 & 7.53 \\
\hline 34 & 34 & 34.1 & 7.22 \\
\hline 35 & 35 & 34.1 & 7.11 \\
\hline 36 & 36 & 34.3 & 6.91 \\
\hline 37 & 37 & 34.1 & 6.91 \\
\hline 38 & 38 & 34.2 & 6.80 \\
\hline 39 & 39 & 34.2 & 6.80 \\
\hline 40 & 40 & 34.7 & 6.80 \\
\hline 41 & 41 & 34.3 & 6.80 \\
\hline 42 & 42 & 34.2 & 6.49 \\
\hline 43 & 43 & 33.8 & 6.49 \\
\hline 44 & 44 & 34.0 & 6.49 \\
\hline 45 & 45 & 34.3 & 6.29 \\
\hline 46 & 46 & 33.6 & 6.18 \\
\hline 47 & 47 & 33.7 & 6.08 \\
\hline 48 & 48 & 34.0 & 5.77 \\
\hline 49 & 49 & 34.2 & 5.67 \\
\hline 50 & 50 & 34.1 & 5.56 \\
\hline 51 & 51 & 34.0 & 5.56 \\
\hline 52 & 52 & 34.7 & 5.56 \\
\hline 53 & 53 & 34.1 & 5.56 \\
\hline 54 & 54 & 33.9 & 5.56 \\
\hline 55 & 55 & 33.9 & 5.46 \\
\hline 56 & 56 & 33.8 & 5.46 \\
\hline 57 & 57 & 34.0 & 5.15 \\
\hline 58 & 58 & 34.4 & 4.84 \\
\hline 59 & 59 & 34.0 & 4.74 \\
\hline 60 & 60 & 33.9 & 4.63 \\
\hline 61 & 61 & 34.3 & 4.63 \\
\hline 62 & 62 & 34.2 & 4.63 \\
\hline 63 & 63 & 34.2 & 4.63 \\
\hline 64 & 64 & 33.8 & 4.43 \\
\hline 65 & 65 & 33.5 & 4.53 \\
\hline 66 & 66 & 33.5 & 4.43 \\
\hline
\end{tabular}


Table B.9. UV intensity data collected during C30 (continued).

\begin{tabular}{|c|c|c|c|}
\hline Time of Operation ( $t$ ) & $\begin{array}{l}\text { Time elapsed between } \\
\text { Sensor Cleanings ( }\left(t^{\prime}\right)\end{array}$ & Flow & Intensity \\
\hline (Hours) & Hours & gpm & $\mathrm{mW} / \mathrm{cm}^{2}$ \\
\hline 67 & 67 & 33.6 & 4.43 \\
\hline 68 & 68 & 33.9 & 4.43 \\
\hline 69 & 69 & 33.7 & 4.22 \\
\hline 70 & 70 & 34.3 & 4.16 \\
\hline 71 & 71 & 33.9 & 4.16 \\
\hline 72 & 72 & 33.8 & 4.12 \\
\hline 73 & 73 & 34.4 & 4.01 \\
\hline 74 & 74 & 34.3 & 4.01 \\
\hline 75 & 75 & 34.1 & 3.91 \\
\hline 76 & 76 & 33.7 & 3.81 \\
\hline 77 & 77 & 34.3 & 3.81 \\
\hline 78 & 78 & 34.3 & 3.50 \\
\hline 79 & 79 & 34.3 & 3.50 \\
\hline 80 & 80 & 34.0 & 3.29 \\
\hline 81 & 81 & 34.0 & 3.19 \\
\hline 82 & 82 & 33.6 & 3.18 \\
\hline 83 & 83 & 33.6 & 3.19 \\
\hline 84 & 84 & 33.7 & 3.08 \\
\hline 85 & 85 & 33.6 & 3.08 \\
\hline 86 & 86 & 33.8 & 3.08 \\
\hline 87 & 87 & 33.4 & 3.08 \\
\hline 88 & 88 & 33.1 & 2.98 \\
\hline 89 & 89 & 33.3 & 2.98 \\
\hline 90 & 90 & 33.4 & 2.98 \\
\hline 91 & 91 & 33.3 & 2.98 \\
\hline 92 & 92 & 33.3 & 2.98 \\
\hline 93 & 93 & 33.3 & 2.88 \\
\hline 94 & 94 & 33.7 & 2.88 \\
\hline 95 & 95 & 33.6 & 2.98 \\
\hline 96 & 96 & 33.3 & 2.98 \\
\hline 97 & 97 & 35.3 & 2.98 \\
\hline 98 & 98 & 34.6 & 2.98 \\
\hline 99 & 99 & 34.5 & 2.87 \\
\hline 100 & 100 & 34.4 & 2.98 \\
\hline
\end{tabular}


Table B.9. UV intensity data collected during C30 (continued).

\begin{tabular}{|c|c|c|c|}
\hline Time of Operation (t) & $\begin{array}{c}\text { Time elapsed between } \\
\text { Sensor Cleanings (t') }\end{array}$ & Flow & Intensity \\
\hline (Hours) & Hours & gpm & mW/cm \\
\hline 101 & 101 & 34.5 & 2.87 \\
\hline 102 & 102 & 34.1 & 2.87 \\
\hline 103 & 103 & 34.1 & 2.67 \\
\hline 104 & 104 & 34.3 & 2.67 \\
\hline 105 & 105 & 34.0 & 2.67 \\
\hline 106 & 106 & 34.3 & 2.46 \\
\hline 107 & 107 & 33.7 & 2.57 \\
\hline 108 & 108 & 34.0 & 2.57 \\
\hline 109 & 109 & 34.3 & 2.36 \\
\hline 110 & 110 & 33.7 & 2.36 \\
\hline 111 & 111 & 33.5 & 2.36 \\
\hline 112 & 112 & 33.7 & 2.36 \\
\hline 113 & 113 & 33.3 & 2.25 \\
\hline 114 & 114 & 33.2 & 2.36 \\
\hline 115 & 115 & 33.4 & 2.36 \\
\hline 116 & 116 & 33.6 & 2.36 \\
\hline 117 & 117 & 33.4 & 2.20 \\
\hline
\end{tabular}


Table B.10. RMSE and CVRMSE for cycles C24 through C30.

\begin{tabular}{|c|c|c|}
\hline Cycle Number & RMSE & CVRMSE \\
\hline C24 & 0.53233 & 0.13878 \\
\hline C25 & 0.46144 & 0.10781 \\
\hline C26 & 0.29196 & 0.07475 \\
\hline C27 & 0.36308 & 0.13008 \\
\hline C28 & 0.52603 & 0.12226 \\
\hline C29 & 0.30866 & 0.05044 \\
\hline C30 & 0.19825 & 0.03479 \\
\hline
\end{tabular}




\section{APPENDIX C. PILOT UNIT PERFORMANCE RUNS DATA}

Table C.1. Intensity data collected after cleaning the sensor's lens during performance runs.

\begin{tabular}{|c|c|c|c|c|}
\hline \multirow{2}{*}{$\begin{array}{l}\text { Run } \\
\text { Number }\end{array}$} & $\begin{array}{l}\text { Time of } \\
\text { Operation }\end{array}$ & Flow & UVT & Intensity \\
\hline & (Hours) & (gpm) & $(\%)$ & $\left(\mathrm{mW} / \mathrm{cm}^{2}\right)$ \\
\hline \multirow{5}{*}{$\mathrm{R} 1$} & 0 & 15 & 56.6 & 13.17 \\
\hline & 18 & 15 & 54.1 & 9.35 \\
\hline & 43 & 15 & 55.9 & 6.01 \\
\hline & 63 & 15 & 53.1 & 4.43 \\
\hline & 87 & 15 & 52 & 3.45 \\
\hline \multirow{5}{*}{$\mathrm{R} 2$} & 0 & 25 & 52 & 12.8 \\
\hline & 13 & 25 & 53.7 & 9.18 \\
\hline & 35 & 25 & 51.2 & 7.53 \\
\hline & 61 & 25 & 54.7 & 5.61 \\
\hline & 86 & 25 & 56.9 & 4.47 \\
\hline \multirow{4}{*}{$\mathrm{R} 3$} & 0 & 35 & 52.8 & 11.6 \\
\hline & 14 & 35 & 54.8 & 9 \\
\hline & 38 & 35 & 54.2 & 7.4 \\
\hline & 62 & 35 & 53.5 & 5.73 \\
\hline \multirow{5}{*}{$\mathrm{R} 4$} & 0 & 10 & 53.90 & 12.40 \\
\hline & 16 & 10 & 53.60 & 9.88 \\
\hline & 40 & 10 & 55.30 & 7.03 \\
\hline & 64 & 10 & 54.10 & 5.20 \\
\hline & 88 & 10 & 53.70 & 3.70 \\
\hline \multirow{4}{*}{ R5 } & 0 & 20 & 51.9 & 12.15 \\
\hline & 16 & 20 & 50.6 & 8.7 \\
\hline & 30 & 20 & 54.1 & 6.38 \\
\hline & 40 & 20 & 53.0 & 4.71 \\
\hline \multirow{2}{*}{ R6 } & 0 & 15 & 52.7 & 12.45 \\
\hline & 14 & 15 & 54.2 & 10.7 \\
\hline
\end{tabular}


Table C.2. Influent and effluent E. coli data collected during the first performance run.

\begin{tabular}{|c|c|c|c|c|c|}
\hline \multirow{2}{*}{$\begin{array}{l}\text { Performance } \\
\text { Test Number }\end{array}$} & \multicolumn{4}{|c|}{$\begin{array}{c}\text { E. coli } \\
(\text { MIPN/100ml) }\end{array}$} & \multirow{2}{*}{$\begin{array}{c}\begin{array}{c}\text { E. coli } \\
\text { Survival }\end{array} \\
\left(\mathrm{N} / \mathrm{N}_{\mathrm{o}}\right)\end{array}$} \\
\hline & $\begin{array}{c}\text { Influent } \\
\text { Count } \\
\left(\mathrm{N}_{\mathrm{o}}\right)\end{array}$ & $\begin{array}{c}\text { Influent } \\
\text { Geo } \\
\text { Mean }\end{array}$ & $\begin{array}{c}\text { Effluent } \\
\text { Count }(\mathrm{N})\end{array}$ & $\begin{array}{c}\text { Effluent } \\
\text { Geo } \\
\text { Mean }\end{array}$ & \\
\hline \multirow{2}{*}{ PT1 } & 11060 & \multirow{2}{*}{12536} & 17.9 & \multirow{2}{*}{15} & \multirow{2}{*}{$1.2 \mathrm{E}-03$} \\
\hline & 14210 & & 12.2 & & \\
\hline \multirow{2}{*}{ PT2 } & 3970 & \multirow{2}{*}{6253} & 86 & \multirow{2}{*}{121} & \multirow{2}{*}{$1.94 \mathrm{E}-02$} \\
\hline & 9850 & & 196.4 & & \\
\hline \multirow{2}{*}{ PT3 } & 9590 & \multirow{2}{*}{9464} & 54.4 & \multirow{2}{*}{108} & \multirow{2}{*}{$1.14 \mathrm{E}-02$} \\
\hline & 9340 & & 214.3 & & \\
\hline \multirow{2}{*}{ PT4 } & 17930 & \multirow{2}{*}{17273} & 195.6 & \multirow{2}{*}{376} & \multirow{2}{*}{$2.18 \mathrm{E}-02$} \\
\hline & 16640 & & 721.5 & & \\
\hline \multirow{2}{*}{ PT5 } & 5570 & \multirow{2}{*}{8748} & 1299.7 & \multirow{2}{*}{774} & \multirow{2}{*}{ 8.85E-02 } \\
\hline & 13740 & & 461.1 & & \\
\hline
\end{tabular}

Table C.3. Influent and effluent E. coli data collected during the second performance run.

\begin{tabular}{|c|c|c|c|c|c|}
\hline \multirow{2}{*}{$\begin{array}{l}\text { Performance } \\
\text { Test Number }\end{array}$} & \multicolumn{4}{|c|}{$\begin{array}{c}\text { E. coli } \\
(\mathrm{MPN} / 100 \mathrm{ml})\end{array}$} & \multirow{2}{*}{$\begin{array}{c}\begin{array}{c}\text { E. coli } \\
\text { Survival }\end{array} \\
\left(\mathrm{N} / \mathrm{N}_{\mathrm{o}}\right)\end{array}$} \\
\hline & $\begin{array}{c}\text { Influent } \\
\text { Count } \\
\left(\mathrm{N}_{\mathrm{o}}\right)\end{array}$ & $\begin{array}{c}\text { Influent } \\
\text { Geo } \\
\text { Mean }\end{array}$ & $\begin{array}{l}\text { Effluent } \\
\text { Count }(\mathrm{N})\end{array}$ & $\begin{array}{c}\text { Effluent } \\
\text { Geo } \\
\text { Mean }\end{array}$ & \\
\hline \multirow{2}{*}{ PT1 } & 7270 & \multirow{2}{*}{10139} & 85.2 & \multirow{2}{*}{129} & \multirow{2}{*}{$1.27 \mathrm{E}-02$} \\
\hline & 14140 & & 195.6 & & \\
\hline \multirow{2}{*}{ PT2 } & 5730 & \multirow{2}{*}{6079} & 501.2 & \multirow{2}{*}{441} & \multirow{2}{*}{$7.25 \mathrm{E}-02$} \\
\hline & 6450 & & 387.3 & & \\
\hline \multirow{2}{*}{ PT3 } & 10470 & \multirow{2}{*}{9631} & 721.5 & \multirow{2}{*}{644} & \multirow{2}{*}{ 6.69E-02 } \\
\hline & 8860 & & 574.8 & & \\
\hline \multirow{2}{*}{ PT4 } & 7540 & \multirow{2}{*}{7404} & 579.4 & \multirow{2}{*}{779} & \multirow{2}{*}{$1.05 \mathrm{E}-01$} \\
\hline & 7270 & & 1046.2 & & \\
\hline \multirow{2}{*}{ PT5 } & 9080 & \multirow{2}{*}{8939} & 2205.9 & \multirow{2}{*}{1599} & \multirow{2}{*}{$1.74 \mathrm{E}-01$} \\
\hline & 8800 & & 1158.8 & & \\
\hline
\end{tabular}


Table C.4. Influent and effluent E. coli data collected during the third performance run.

\begin{tabular}{|c|c|c|c|c|c|}
\hline \multirow{2}{*}{$\begin{array}{l}\text { Performance } \\
\text { Test Number }\end{array}$} & \multicolumn{4}{|c|}{$\begin{array}{c}\text { E. coli } \\
(\text { MPN/100ml) }\end{array}$} & $\begin{array}{l}\text { E. coli } \\
\text { Survival }\end{array}$ \\
\hline & $\begin{array}{c}\text { Influent } \\
\text { Count } \\
\left(\mathrm{N}_{\mathrm{o}}\right)\end{array}$ & $\begin{array}{c}\text { Influent } \\
\text { Geo } \\
\text { Mean }\end{array}$ & $\begin{array}{l}\text { Effluent } \\
\text { Count }(\mathrm{N})\end{array}$ & $\begin{array}{c}\text { Effluent } \\
\text { Geo } \\
\text { Mean }\end{array}$ & $\left(\mathrm{N} / \mathrm{N}_{\mathrm{o}}\right)$ \\
\hline \multirow{2}{*}{ PT1 } & 7380 & \multirow{2}{*}{8952} & 1030.05 & \multirow{2}{*}{1113} & \multirow{2}{*}{$1.24 \mathrm{E}-01$} \\
\hline & 10860 & & 1203.3 & & \\
\hline \multirow{2}{*}{ PT2 } & 7330 & \multirow{2}{*}{6871} & 1540 & \multirow{2}{*}{1684} & \multirow{2}{*}{$2.45 \mathrm{E}-01$} \\
\hline & 6440 & & 1842 & & \\
\hline \multirow{2}{*}{ PT3 } & 3730 & \multirow{2}{*}{3613} & 1551.6 & \multirow{2}{*}{1304} & \multirow{2}{*}{$3.61 \mathrm{E}-01$} \\
\hline & 3500 & & 1096.2 & & \\
\hline \multirow{2}{*}{ PT4 } & 8200 & \multirow{2}{*}{8524} & 2442 & \multirow{2}{*}{2586} & \multirow{2}{*}{ 3.03E-01 } \\
\hline & 8860 & & 2737.5 & & \\
\hline
\end{tabular}

Table C.5. Influent and effluent E. coli data collected during the fourth performance run.

\begin{tabular}{|c|c|c|c|c|c|}
\hline \multirow{2}{*}{$\begin{array}{l}\text { Performance } \\
\text { Test Number }\end{array}$} & \multicolumn{4}{|c|}{$\begin{array}{c}\text { E. coli } \\
(\mathrm{MPN} / 100 \mathrm{ml})\end{array}$} & \multirow{2}{*}{$\begin{array}{c}\text { E. coli } \\
\text { Survival } \\
\left(\mathrm{N} / \mathrm{N}_{0}\right)\end{array}$} \\
\hline & $\begin{array}{c}\text { Influent } \\
\text { Count } \\
\left(\mathbf{N}_{\mathrm{o}}\right)\end{array}$ & $\begin{array}{c}\text { Influent } \\
\text { Geo } \\
\text { Mean }\end{array}$ & $\begin{array}{l}\text { Effluent } \\
\text { Count }(\mathrm{N})\end{array}$ & $\begin{array}{c}\text { Effluent } \\
\text { Geo } \\
\text { Mean }\end{array}$ & \\
\hline \multirow{2}{*}{ PT1 } & 22820 & \multirow{2}{*}{21881} & 8.2 & \multirow{2}{*}{7} & \multirow{2}{*}{$3.20 \mathrm{E}-04$} \\
\hline & 20980 & & 6.3 & & \\
\hline \multirow{2}{*}{ PT2 } & 12360 & \multirow{2}{*}{12937} & 31.1 & \multirow{2}{*}{44} & \multirow{2}{*}{$3.40 \mathrm{E}-3$} \\
\hline & 13540 & & 62 & & \\
\hline \multirow{2}{*}{ PT3 } & 9900 & \multirow{2}{*}{12247} & 101.9 & \multirow{2}{*}{83} & \multirow{2}{*}{$6.78 \mathrm{E}-03$} \\
\hline & 15150 & & 67.7 & & \\
\hline \multirow{2}{*}{ PT4 } & 10460 & \multirow{2}{*}{11476} & 613.1 & \multirow{2}{*}{359} & \multirow{2}{*}{$3.13 \mathrm{E}-02$} \\
\hline & 12590 & & 209.8 & & \\
\hline \multirow{2}{*}{ PT5 } & 15000 & \multirow{2}{*}{12363} & 249.6 & \multirow{2}{*}{204} & \multirow{2}{*}{$1.65 \mathrm{E}-02$} \\
\hline & 10190 & & 167 & & \\
\hline
\end{tabular}


Table C.6. Influent and effluent E. coli data collected during the fifth performance run.

\begin{tabular}{|c|c|c|c|c|c|}
\hline \multirow{2}{*}{$\begin{array}{l}\text { Performance } \\
\text { Test Number }\end{array}$} & \multicolumn{4}{|c|}{$\begin{array}{c}\text { E. coli } \\
(\text { MPN/100ml) }\end{array}$} & $\begin{array}{c}\text { E. coli } \\
\text { Survival }\end{array}$ \\
\hline & $\begin{array}{c}\text { Influent } \\
\text { Count } \\
\left(\mathrm{N}_{\mathrm{o}}\right)\end{array}$ & $\begin{array}{c}\text { Influent } \\
\text { Geo } \\
\text { Mean }\end{array}$ & $\begin{array}{l}\text { Effluent } \\
\text { Count }(\mathrm{N})\end{array}$ & $\begin{array}{c}\text { Effluent } \\
\text { Geo } \\
\text { Mean }\end{array}$ & $\left(\mathrm{N} / \mathrm{N}_{\mathrm{o}}\right)$ \\
\hline \multirow{2}{*}{ PT1 } & 8600 & \multirow{2}{*}{5188} & 517.2 & \multirow{2}{*}{371} & \multirow{2}{*}{$7.16 \mathrm{E}-02$} \\
\hline & 3130 & & 266.6 & & \\
\hline \multirow{2}{*}{ PT2 } & 10980 & \multirow{2}{*}{11906} & 444.8 & \multirow{2}{*}{417} & \multirow{2}{*}{$3.50 \mathrm{E}-02$} \\
\hline & 12910 & & 391.2 & & \\
\hline \multirow{2}{*}{ PT3 } & 6130 & \multirow{2}{*}{5140} & 1226.2 & \multirow{2}{*}{1261} & \multirow{2}{*}{$2.45 \mathrm{E}-01$} \\
\hline & 4310 & & 1297.6 & & \\
\hline \multirow{2}{*}{ PT4 } & 16070 & \multirow{2}{*}{14308} & 896.8 & \multirow{2}{*}{1049} & \multirow{2}{*}{ 7.33E-02 } \\
\hline & 12740 & & 1226.2 & & \\
\hline
\end{tabular}

Table C.7. Influent and effluent E. coli data collected during the sixth performance run.

\begin{tabular}{|c|c|c|c|c|c|}
\hline \multirow{2}{*}{$\begin{array}{l}\text { Performance } \\
\text { Test Number }\end{array}$} & \multicolumn{4}{|c|}{$\begin{array}{c}\text { E. coli } \\
(\mathrm{MPN} / 100 \mathrm{ml})\end{array}$} & $\begin{array}{c}\text { E. coli } \\
\text { Survival }\end{array}$ \\
\hline & $\begin{array}{c}\text { Influent } \\
\text { Count } \\
\left(\mathbf{N}_{\mathrm{o}}\right)\end{array}$ & $\begin{array}{c}\text { Influent } \\
\text { Geo } \\
\text { Mean }\end{array}$ & $\begin{array}{c}\text { Effluent } \\
\text { Count }(\mathrm{N})\end{array}$ & $\begin{array}{c}\text { Effluent } \\
\text { Geo } \\
\text { Mean }\end{array}$ & $\left(\mathrm{N} / \mathrm{N}_{\mathrm{o}}\right)$ \\
\hline \multirow{2}{*}{ PT1 } & 22820 & \multirow{2}{*}{23794} & 69.6 & \multirow{2}{*}{39} & \multirow{2}{*}{$1.64 \mathrm{E}-3$} \\
\hline & 24810 & & 21.3 & & \\
\hline \multirow{2}{*}{ PT2 } & 11530 & \multirow{2}{*}{10657} & 613.1 & \multirow{2}{*}{525} & \multirow{2}{*}{ 4.93E-02 } \\
\hline & 9850 & & 449.4 & & \\
\hline
\end{tabular}




\section{APPENDIX D. EFFLUENT WATER QUALITY DATA}

Table D.1. Unfiltered water quality data.

\begin{tabular}{|c|c|c|c|c|c|c|c|}
\hline \multirow{2}{*}{$\begin{array}{c}\text { Test } \\
\text { Number }\end{array}$} & \multirow[t]{2}{*}{ Test Date } & $\begin{array}{c}\text { Water } \\
\text { Temperature }\end{array}$ & COD & TSS & Turbidity & UVT & \multirow{2}{*}{ pH } \\
\hline & & $\left({ }^{\circ} \mathrm{C}\right)$ & $(\mathrm{mg} / \mathrm{L})$ & $(\mathrm{mg} / \mathrm{L})$ & (NTU) & $(\%)$ & \\
\hline Test \#1 & $3 / 8 / 2016$ & 14.6 & 55 & 17.5 & 12.8 & 50.6 & - \\
\hline Test \#2 & $3 / 22 / 2016$ & 14.4 & 52 & 12.5 & 10.5 & 53.9 & - \\
\hline Test \#3 & $3 / 24 / 2016$ & 14.4 & 54 & 11.0 & 11.5 & 51.4 & - \\
\hline Test \#4 & $3 / 29 / 2016$ & 14.7 & 53 & 16.0 & 10.6 & 53.7 & 7.07 \\
\hline Test \#5 & $4 / 5 / 2016$ & 14.3 & 49 & 16.5 & 11.1 & 54.5 & 7.25 \\
\hline Test \#6 & $4 / 7 / 2016$ & 14.4 & 50 & 12.0 & 8.4 & 56.1 & 7.30 \\
\hline Test \#7 & $4 / 12 / 2016$ & 14.0 & 63 & 14.0 & 10.7 & 54.0 & 7.34 \\
\hline Test \#8 & $4 / 14 / 2016$ & 15.2 & 55 & 17.0 & 11.8 & 53.0 & 7.22 \\
\hline Test \#9 & $4 / 19 / 2016$ & 15.2 & 57 & 24.5 & 11.6 & 51.6 & 7.08 \\
\hline Test \#10 & $4 / 21 / 2016$ & 15.2 & 53 & 15.0 & 11.8 & 53.2 & 7.06 \\
\hline Test \#11 & $4 / 26 / 2016$ & 14.2 & 54 & 19.5 & 15.1 & 49.0 & 7.28 \\
\hline Test \#12 & $4 / 28 / 2016$ & 14.9 & 54 & 15.0 & 12.2 & 55.0 & 7.37 \\
\hline Test \#13 & $5 / 3 / 2016$ & 16.0 & 52 & 15.5 & 12.0 & 53.2 & 7.29 \\
\hline Test \#14 & $5 / 5 / 2016$ & 16.1 & 35 & 13.5 & 9.6 & 55.8 & 7.18 \\
\hline Test \#15 & $5 / 10 / 2016$ & 16.3 & 41 & 13.0 & 8.8 & 54.7 & 7.18 \\
\hline Test \#16 & $5 / 12 / 2016$ & 16.3 & 58 & 15.2 & 9.5 & 54.4 & 7.35 \\
\hline Test \#17 & $5 / 16 / 2016$ & 13.3 & 28 & 19.5 & 11.8 & 54.8 & 7.23 \\
\hline Test \#18 & $5 / 17 / 2016$ & 16.5 & 31 & 22.5 & 14.0 & 53.5 & 7.24 \\
\hline Test \#19 & $5 / 18 / 2016$ & 16.7 & 43 & 13.2 & 11.3 & 52.6 & 7.07 \\
\hline Test \#20 & $5 / 19 / 2016$ & 16.8 & 49 & 17.5 & 9.5 & 55.3 & 7.17 \\
\hline Test \#21 & $5 / 23 / 2016$ & 17.6 & 56 & 14.5 & 12.2 & 52.3 & 7.06 \\
\hline Test \#22 & $5 / 24 / 2016$ & 17.7 & 61 & 11.0 & 7.9 & 55.1 & 7.18 \\
\hline Test \#23 & $5 / 25 / 2016$ & 17.5 & 44 & 16.5 & 12.0 & 52.4 & 7.13 \\
\hline Test \#24 & $5 / 26 / 2016$ & 17.6 & 85 & 12.0 & 12.6 & 42.6 & 7.02 \\
\hline Test \#25 & $5 / 27 / 2016$ & 18.1 & 64 & 19.0 & 15.5 & 51.6 & 7.05 \\
\hline Test \#26 & $5 / 31 / 2016$ & 18.0 & 72 & 20.8 & 14.0 & 49.5 & 7.33 \\
\hline Test \#27 & $6 / 1 / 2016$ & 17.3 & 62 & 9.6 & 8.2 & 51.7 & 7.44 \\
\hline Test \#28 & $6 / 2 / 2016$ & 17.7 & 66 & 22.4 & 12.1 & 54.9 & 7.51 \\
\hline Test \#29 & $6 / 3 / 2016$ & 17.7 & 52 & 11.6 & 9.6 & 56.0 & 7.37 \\
\hline Test \#30 & $6 / 6 / 2016$ & 17.4 & 55 & 16.4 & 9.1 & 54.8 & 7.61 \\
\hline
\end{tabular}


Table D.1. Unfiltered water quality data (continued).

\begin{tabular}{|c|c|c|c|c|c|c|c|}
\hline \multirow{2}{*}{$\begin{array}{c}\text { Test } \\
\text { Number }\end{array}$} & \multirow[t]{2}{*}{ Test Date } & \multirow{2}{*}{$\begin{array}{c}\text { Water } \\
\text { Temperature } \\
\left({ }^{\circ} \mathrm{C}\right)\end{array}$} & \multirow{2}{*}{$\frac{\text { COD }}{(\mathrm{mg} / \mathrm{L})}$} & \multirow{2}{*}{$\begin{array}{c}\text { TSS } \\
(\mathrm{mg} / \mathrm{L})\end{array}$} & \multirow{2}{*}{$\begin{array}{c}\text { Turbidity } \\
\text { (NTU) }\end{array}$} & \multirow{2}{*}{$\begin{array}{l}\text { UVT } \\
(\%) \\
\end{array}$} & \multirow[t]{2}{*}{ pH } \\
\hline & & & & & & & \\
\hline Test \#31 & $6 / 7 / 2016$ & 18.0 & 67 & 10.0 & 8.1 & 55.3 & 7.45 \\
\hline Test \#32 & $6 / 9 / 2016$ & 18.6 & 52 & 16.8 & 11.8 & 52.2 & 7.27 \\
\hline Test \#33 & $6 / 14 / 2016$ & 19.6 & 55 & 14.0 & 6.8 & 55.0 & 7.28 \\
\hline Test \#34 & $6 / 16 / 2016$ & 19.0 & 56 & 18.8 & 11.2 & 53.5 & 7.30 \\
\hline Test \#35 & $6 / 21 / 2016$ & 19.3 & 49 & 14.0 & 9.2 & 53.9 & 7.33 \\
\hline Test \#36 & $6 / 23 / 2016$ & 19.9 & 47 & 15.7 & 10.0 & 54.9 & 7.31 \\
\hline Test \#37 & $6 / 27 / 2016$ & 18.9 & 36 & 10.0 & 7.8 & 56.3 & 7.59 \\
\hline Test \#38 & $7 / 1 / 2016$ & 19.0 & 57 & 17.2 & 8.3 & 51.2 & 7.23 \\
\hline Test \#39 & $7 / 11 / 2016$ & 19.3 & 55 & 26.4 & 19.5 & 52.0 & 7.05 \\
\hline Test \#40 & $7 / 13 / 2016$ & 19.6 & 82 & 10.3 & 9.9 & 40.2 & 7.66 \\
\hline Test \#41 & $7 / 18 / 2016$ & 20.1 & 61 & 20.0 & 14.1 & 51.7 & 7.12 \\
\hline Test \#42 & $7 / 21 / 2016$ & 20.8 & 45 & 12.0 & 8.9 & 57.4 & 7.18 \\
\hline Test \#43 & $7 / 26 / 2016$ & 20.9 & 39 & 9.0 & 6.6 & 57.0 & 7.19 \\
\hline Test \#44 & $7 / 27 / 2016$ & 20.7 & 65 & 19.3 & 13.3 & 39.5 & 7.08 \\
\hline Test \#45 & $8 / 2 / 2016$ & 21.3 & 46 & 15.3 & 9.2 & 56.1 & 7.25 \\
\hline Test \#46 & $8 / 4 / 2016$ & 21.3 & 47 & 17.0 & 10.5 & 55.1 & 7.35 \\
\hline Test \#47 & $8 / 9 / 2016$ & 21.4 & 48 & 23.7 & 9.6 & 52.2 & 7.31 \\
\hline Test \#48 & $8 / 11 / 2016$ & 21.2 & 44 & 14.0 & 9.6 & 50.6 & 6.97 \\
\hline Test \#49 & $8 / 16 / 2016$ & 21.8 & 46 & 22.3 & 12.4 & 53.2 & 7.08 \\
\hline Test \#50 & $8 / 18 / 2016$ & 21.2 & 48 & 15.0 & 9.1 & 53.7 & 6.99 \\
\hline Test \#51 & $8 / 22 / 2016$ & 21.1 & 50 & 18.3 & 6.3 & 53.7 & 7.15 \\
\hline Test \#52 & $8 / 24 / 2016$ & 21.3 & 46 & 10.0 & 8.1 & 55.7 & 7.07 \\
\hline Test \#53 & $8 / 29 / 2016$ & 21.3 & 60 & 23.6 & 10.8 & 52.7 & 7.17 \\
\hline Test \#54 & $8 / 31 / 2016$ & 21.3 & 52 & 8.0 & 8.3 & 53.3 & 6.82 \\
\hline Test \#55 & $9 / 7 / 2016$ & 21.3 & 46 & 10.3 & 9.2 & 54.3 & 7.02 \\
\hline Test \#56 & $9 / 21 / 2016$ & 21.1 & 47 & 20.7 & 8.5 & 55.9 & 7.61 \\
\hline Test \#57 & $9 / 23 / 2016$ & 20.9 & 69 & 18.4 & 8.7 & 50.8 & 7.31 \\
\hline Test \#58 & $9 / 26 / 2016$ & 20.2 & 49 & 12.0 & 8.7 & 54.7 & 7.47 \\
\hline Test \#59 & $9 / 28 / 2016$ & 20.7 & 36 & 15.6 & 4.7 & 56.9 & 7.5 \\
\hline Test \#60 & $10 / 5 / 2016$ & 20.1 & 55 & 13.6 & 10.2 & 53.6 & 7.09 \\
\hline Test \#61 & $10 / 7 / 2016$ & 19.2 & 60 & 14.4 & 8.1 & 54.1 & 7.54 \\
\hline Test \#62 & $10 / 17 / 2016$ & 19.9 & 44 & 14 & 13.4 & 51.9 & 7.25 \\
\hline
\end{tabular}


Table D.1. Unfiltered water quality data (continued).

\begin{tabular}{|c|c|c|c|c|c|c|c|}
\hline \multirow{2}{*}{$\begin{array}{c}\text { Test } \\
\text { Number }\end{array}$} & \multirow{2}{*}{ Test Date } & $\begin{array}{c}\text { Water } \\
\text { Temperature }\end{array}$ & COD & TSS & Turbidity & UVT & pH \\
\cline { 3 - 8 } & & $\left({ }^{\circ} \mathrm{C}\right)$ & $(\mathrm{mg} / \mathrm{L})$ & $(\mathrm{mg} / \mathrm{L})$ & $(\mathrm{NTU})$ & $(\%)$ & \\
\hline Test \#63 & $10 / 21 / 2016$ & 19.3 & 73 & 10.4 & 8.9 & 52.4 & 7.32 \\
\hline Test \#64 & $10 / 24 / 2016$ & 18.8 & - & - & 9.3 & 55.1 & 7.24 \\
\hline
\end{tabular}


Table D.2. Filtered water quality data.

\begin{tabular}{|c|c|c|c|c|c|c|c|}
\hline \multirow{3}{*}{$\begin{array}{c}\text { Test } \\
\text { Number }\end{array}$} & \multirow{3}{*}{ Test Date } & \multirow{2}{*}{\multicolumn{2}{|c|}{$\frac{\text { UVT }}{(\%)}$}} & \multirow{2}{*}{\multicolumn{2}{|c|}{$\begin{array}{c}\text { Turbidity } \\
\text { (NTU) }\end{array}$}} & \multirow{2}{*}{\multicolumn{2}{|c|}{$\frac{\text { COD }}{(\mathrm{mg} / \mathrm{L})}$}} \\
\hline & & & & & & & \\
\hline & & $\begin{array}{l}1.2 \mu \mathrm{m} \\
\text { Filt. }\end{array}$ & $\begin{array}{c}0.45 \mu \mathrm{m} \\
\text { Filt. }\end{array}$ & $\begin{array}{l}1.2 \mu \mathrm{m} \\
\text { Filt. }\end{array}$ & $\begin{array}{c}0.45 \mu \mathrm{m} \\
\text { Filt. }\end{array}$ & $\begin{array}{c}1.2 \mu \mathrm{m} \\
\text { Filt. }\end{array}$ & $\begin{array}{c}0.45 \mu \mathrm{m} \\
\text { Filt. }\end{array}$ \\
\hline Test \#7 & $4 / 12 / 2016$ & 57.4 & - & 2.91 & - & - & - \\
\hline Test \#8 & $4 / 14 / 2016$ & 59.1 & - & 1.98 & - & - & - \\
\hline Test \#9 & $4 / 19 / 2016$ & 55.1 & 60.6 & 2.16 & 1.07 & - & - \\
\hline Test \#10 & $4 / 21 / 2016$ & 58.8 & 62 & 1.73 & 1.02 & - & - \\
\hline Test \#11 & $4 / 26 / 2016$ & 55.6 & 56.4 & 1.71 & 1.07 & - & - \\
\hline Test \#12 & $4 / 28 / 2016$ & 60.9 & 63.4 & 1.68 & 0.94 & - & 34 \\
\hline Test \#13 & $5 / 3 / 2016$ & 59.9 & 60.9 & 1.47 & 0.9 & - & 30 \\
\hline Test \#14 & $5 / 5 / 2016$ & 61.7 & 63 & 1.3 & 0.95 & - & 11 \\
\hline Test \#15 & $5 / 10 / 2016$ & 60.8 & 62.1 & 1.4 & 0.82 & - & 6 \\
\hline Test \#16 & $5 / 12 / 2016$ & 58.7 & 59.8 & 1.25 & 0.9 & - & 53 \\
\hline Test \#17 & $5 / 16 / 2016$ & 64.1 & 65.5 & 1.35 & 0.75 & - & 14 \\
\hline Test \#18 & $5 / 17 / 2016$ & 62.5 & 65.4 & 1.82 & 0.84 & - & 27 \\
\hline Test \#19 & $5 / 18 / 2016$ & 59.8 & 62.4 & 2.87 & 1.21 & - & 24 \\
\hline Test \#20 & $5 / 19 / 2016$ & 60.7 & 63 & 1.87 & 0.99 & - & 34 \\
\hline Test \#21 & $5 / 23 / 2016$ & 61.4 & 64.2 & 1.81 & 1.03 & - & 29 \\
\hline Test \#22 & $5 / 24 / 2016$ & 60 & 62.8 & 1.54 & 0.94 & - & 38 \\
\hline Test \#23 & $5 / 25 / 2016$ & 59.7 & 61.6 & 2.61 & 1.2 & - & 27 \\
\hline Test \#24 & $5 / 26 / 2016$ & 50.1 & 53.6 & 1.95 & 1.11 & - & 83 \\
\hline Test \#25 & $5 / 27 / 2016$ & 60.1 & 62.5 & 1.4 & 0.93 & - & 53 \\
\hline Test \#26 & $5 / 31 / 2016$ & 59.4 & 63.6 & 1.57 & 0.67 & - & 37 \\
\hline Test \#27 & $6 / 1 / 2016$ & 56.8 & 60.3 & 1.69 & 0.73 & - & 46 \\
\hline Test \#28 & $6 / 2 / 2016$ & 62.6 & 65.7 & 1.54 & 0.66 & - & 43 \\
\hline Test \#29 & $6 / 3 / 2016$ & 62 & 70.6 & 1.48 & 0.98 & - & 39 \\
\hline Test \#30 & $6 / 6 / 2016$ & 63.2 & 64.7 & 1.49 & 0.8 & - & 45 \\
\hline Test \#31 & $6 / 7 / 2016$ & 62.7 & 63.7 & 1.87 & 0.95 & - & 43 \\
\hline Test \#32 & $6 / 9 / 2016$ & 60.5 & 61.8 & 1.47 & 0.85 & - & 36 \\
\hline Test \#33 & $6 / 14 / 2016$ & 61.5 & 62.1 & 1.54 & 0.67 & - & 45 \\
\hline Test \#34 & $6 / 16 / 2016$ & 61.4 & 64.3 & 1.04 & 0.64 & - & 33 \\
\hline Test \#35 & $6 / 21 / 2016$ & 59.4 & 62.9 & 1.14 & 0.82 & - & 35 \\
\hline Test \#36 & $6 / 23 / 2016$ & 62 & 65.4 & 1.24 & 0.72 & - & 33 \\
\hline Test \#37 & $6 / 27 / 2016$ & 63.3 & 70 & 1.31 & 0.78 & - & 15 \\
\hline
\end{tabular}


Table D.2. Filtered water quality data (continued).

\begin{tabular}{|c|c|c|c|c|c|c|c|}
\hline \multirow{3}{*}{$\begin{array}{c}\text { Test } \\
\text { Number }\end{array}$} & \multirow{3}{*}{ Test Date } & \multirow{2}{*}{\multicolumn{2}{|c|}{$\begin{array}{c}\text { UVT } \\
(\%)\end{array}$}} & \multirow{2}{*}{\multicolumn{2}{|c|}{$\begin{array}{c}\text { Turbidity } \\
\text { (NTU) }\end{array}$}} & \multirow{2}{*}{\multicolumn{2}{|c|}{$\frac{\text { COD }}{(\mathrm{mg} / \mathrm{L})}$}} \\
\hline & & & & & & & \\
\hline & & $\begin{array}{l}1.2 \mu \mathrm{m} \\
\text { Filt. }\end{array}$ & $\begin{array}{l}0.45 \mu \mathrm{m} \\
\text { Filt. }\end{array}$ & $\begin{array}{c}1.2 \mu \mathrm{m} \\
\text { Filt. }\end{array}$ & $\begin{array}{c}0.45 \mu \mathrm{m} \\
\text { Filt. }\end{array}$ & $\begin{array}{l}1.2 \mu \mathrm{m} \\
\text { Filt. }\end{array}$ & $\begin{array}{l}0.45 \mu \mathrm{m} \\
\text { Filt. }\end{array}$ \\
\hline Test \#38 & $7 / 1 / 2016$ & 58.8 & 59.6 & 1.39 & 0.77 & - & 45 \\
\hline Test \#39 & $7 / 11 / 2016$ & 67 & 69.3 & 1.62 & 0.78 & - & 35 \\
\hline Test \#40 & $7 / 13 / 2016$ & 45.6 & 47.6 & 1.71 & 0.85 & - & 71 \\
\hline Test \#41 & $7 / 18 / 2016$ & 60.6 & 62.7 & 1.36 & 0.79 & - & 38 \\
\hline Test \#42 & $7 / 21 / 2016$ & 63.5 & 65.8 & 1.38 & 0.74 & - & 32 \\
\hline Test \#43 & $7 / 26 / 2016$ & 62.8 & 65.2 & 1.34 & 0.73 & - & 18 \\
\hline Test \#44 & $7 / 27 / 2016$ & 46 & 48.8 & 1.52 & 0.82 & - & 43 \\
\hline Test \#45 & $8 / 2 / 2016$ & 64.3 & 66.1 & 1.09 & 0.69 & - & 26 \\
\hline Test \#46 & $8 / 4 / 2016$ & 62.6 & 64.9 & 1.53 & 0.7 & - & 30 \\
\hline Test \#47 & $8 / 9 / 2016$ & 61.1 & 63 & 1.27 & 0.81 & - & 31 \\
\hline Test \#48 & $8 / 11 / 2016$ & 57.9 & 60.7 & 1.64 & 1.07 & - & 40 \\
\hline Test \#49 & $8 / 16 / 2016$ & 62.4 & 64.3 & 1.51 & 0.73 & - & 34 \\
\hline Test \#50 & $8 / 18 / 2016$ & 60.8 & 64.2 & 1.64 & 0.89 & - & 32 \\
\hline Test \#51 & $8 / 22 / 2016$ & 62.7 & 64.4 & 1.28 & 0.73 & - & 30 \\
\hline Test \#52 & $8 / 24 / 2016$ & 60.8 & 63.4 & 1.37 & 0.6 & - & 23 \\
\hline Test \#53 & $8 / 29 / 2016$ & 63.2 & 65.4 & 1.18 & 0.61 & - & 26 \\
\hline Test \#54 & $8 / 31 / 2016$ & 59.7 & 62.3 & 1.53 & 0.64 & - & 36 \\
\hline Test \#55 & $9 / 7 / 2016$ & 60.2 & 62.6 & 1.49 & 0.62 & - & 36 \\
\hline Test \#56 & $9 / 21 / 2016$ & 58 & 64.3 & 1.2 & 0.59 & - & 27 \\
\hline Test \#57 & $9 / 23 / 2016$ & 55.2 & 56.7 & 1.28 & 0.73 & - & 48 \\
\hline Test \#58 & $9 / 26 / 2016$ & 62.9 & 65.7 & 1.75 & 0.71 & - & 33 \\
\hline Test \#59 & $9 / 28 / 2016$ & 62.7 & 65.4 & 1.71 & 0.74 & - & 23 \\
\hline Test \#60 & $10 / 5 / 2016$ & 63 & 65.5 & 1.69 & 0.89 & - & 40 \\
\hline Test \#61 & $10 / 7 / 2016$ & 59.9 & 61.2 & 1.51 & 0.75 & - & 36 \\
\hline Test \#62 & $10 / 17 / 2016$ & 58.9 & 61 & 1.48 & 0.88 & - & 19 \\
\hline Test \#63 & $10 / 21 / 2016$ & 58.7 & 60.9 & 1.49 & 0.86 & - & 58 \\
\hline Test \#64 & $10 / 24 / 2016$ & 59.5 & 64 & 2.61 & 0.83 & - & - \\
\hline
\end{tabular}


Table D.3. Total and soluble iron monitoring.

\begin{tabular}{|c|c|c|c|}
\hline Test & \multirow{2}{*}{ Test Date } & \multicolumn{2}{|c|}{ Iron (mg/L) } \\
\cline { 3 - 4 } Number & & Total & Soluble \\
\hline Test \#1 & $5 / 3 / 2016$ & 0.76 & 0.371 \\
\hline Test \#2 & $5 / 18 / 2016$ & 0.986 & 0.291 \\
\hline Test \#3 & $6 / 1 / 2016$ & 0.833 & - \\
\hline Test \#4 & $6 / 2 / 2016$ & 1.18 & - \\
\hline Test \#5 & $6 / 3 / 2016$ & 0.83 & - \\
\hline Test \#6 & $6 / 6 / 2016$ & 1.01 & - \\
\hline Test \#7 & $6 / 7 / 2016$ & 0.7 & 0.195 \\
\hline Test \#8 & $6 / 8 / 2016$ & 1.22 & - \\
\hline Test \#9 & $6 / 9 / 2016$ & 0.81 & - \\
\hline Test \#10 & $6 / 10 / 2016$ & 0.96 & - \\
\hline Test \#11 & $6 / 13 / 2016$ & 1.06 & - \\
\hline Test \#12 & $6 / 14 / 2016$ & 0.738 & 0.188 \\
\hline Test \#13 & $6 / 15 / 2016$ & 0.73 & - \\
\hline Test \#14 & $6 / 16 / 2016$ & 0.91 & - \\
\hline Test \#17 & $6 / 21 / 2016$ & 0.64 & - \\
\hline Test \#18 & $6 / 22 / 2016$ & 1.08 & - \\
\hline Test \#19 & $6 / 23 / 2016$ & 0.941 & 0.206 \\
\hline Test \#20 & $6 / 24 / 2016$ & 0.75 & - \\
\hline Test \#21 & $6 / 27 / 2016$ & 0.751 & 0.167 \\
\hline Test \#22 & $6 / 29 / 2016$ & 0.85 & - \\
\hline Test \#23 & $6 / 30 / 2016$ & 0.8 & - \\
\hline Test \#24 & $7 / 1 / 2016$ & 0.72 & 0.21 \\
\hline Test \#25 & $7 / 11 / 2016$ & 1.24 & 0.17 \\
\hline Test \#26 & $7 / 12 / 2016$ & 0.75 & - \\
\hline Test \#27 & $7 / 13 / 2016$ & 0.593 & 0.264 \\
\hline Test \#28 & $7 / 14 / 2016$ & 0.41 & - \\
\hline Test \#29 & $7 / 15 / 2016$ & 0.6 & 0.07 \\
\hline Test \#30 & $7 / 18 / 2016$ & 0.673 & 0.17 \\
\hline Test \#31 & $7 / 19 / 2016$ & 0.47 & - \\
\hline Test \#32 & $7 / 20 / 2016$ & 0.54 & - \\
\hline Test \#33 & $7 / 21 / 2016$ & 0.51 & 0.18 \\
\hline Test \#34 & $7 / 26 / 2016$ & 0.56 & - \\
\hline
\end{tabular}


Table D.3. Total and soluble iron monitoring (continued).

\begin{tabular}{|c|c|c|c|}
\hline \multirow{2}{*}{$\begin{array}{c}\text { Test } \\
\text { Number }\end{array}$} & \multirow{2}{*}{ Test Date } & \multicolumn{2}{|c|}{ Iron (mg/L) } \\
\cline { 3 - 4 } Test \#35 & $8 / 2 / 2016$ & 0.73 & - \\
\hline Test \#36 & $8 / 4 / 2016$ & 0.6 & 0.23 \\
\hline Test \#37 & $8 / 9 / 2016$ & 0.91 & 0.03 \\
\hline Test \#38 & $8 / 11 / 2016$ & 0.61 & 0.21 \\
\hline Test \#39 & $8 / 16 / 2016$ & 0.89 & - \\
\hline Test \#40 & $8 / 18 / 2016$ & 0.61 & 0.22 \\
\hline Test \#41 & $8 / 22 / 2016$ & 0.81 & - \\
\hline Test \#42 & $8 / 24 / 2016$ & 0.64 & 0.21 \\
\hline Test \#43 & $8 / 29 / 2016$ & 1.04 & 0.18 \\
\hline Test \#44 & $8 / 31 / 2016$ & 0.59 & 0.21 \\
\hline Test \#45 & $9 / 7 / 2016$ & 0.51 & 0.2 \\
\hline Test \#46 & $9 / 9 / 2016$ & 0.5 & 0.19 \\
\hline Test \#47 & $9 / 12 / 2016$ & 0.51 & 0.14 \\
\hline Test \#48 & $9 / 21 / 2016$ & 0.89 & \\
\hline Test \#49 & $9 / 23 / 2016$ & 0.74 & 0.16 \\
\hline Test \#50 & $9 / 26 / 2016$ & 0.5 & 0.17 \\
\hline Test \#51 & $9 / 28 / 2016$ & 0.28 & 0.13 \\
\hline Test \#52 & $10 / 5 / 2016$ & 0.63 & \\
\hline Test \#53 & $10 / 7 / 2016$ & 0.57 & \\
\hline Test \#54 & $10 / 17 / 2016$ & 0.76 & \\
\hline Test \#55 & $10 / 21 / 2016$ & 0.64 & \\
\hline Test \#56 & $10 / 24 / 2016$ & 0.63 & \\
\hline & & & \\
\hline
\end{tabular}


U.S. Department of Commerce Netional Oceanic \& Amospheric Adm

Elev: $900 \mathrm{ft}$. Lat: $46.925^{\circ} \mathrm{N}$ Lon: $96.811^{\circ} \mathrm{W}$

Station: FARGO HECTOR INTERNATIONAL AIRPORT, ND US GHCND:USW00014914

Record of Climatological Observations
These data are quality controlled and may not be identical to the original observations.
id

entical to the original observ

National Centers for Environmental Information 151 Patton Avenue
Asheville, North Carolina 28801

\begin{tabular}{|c|c|c|c|c|c|c|c|c|c|c|c|c|c|c|c|c|c|c|c|}
\hline \multirow{3}{*}{\begin{tabular}{|c|}
$\mathrm{P}$ \\
$\mathrm{r}$ \\
$\mathrm{r}$ \\
$\mathrm{i}$ \\
$\mathrm{i}$ \\
$\mathrm{m}$ \\
$\mathrm{i}$ \\
$\mathrm{n}$ \\
$\mathrm{a}$ \\
$\mathrm{a}$ \\
$\mathrm{r}$ \\
$\mathrm{y}$
\end{tabular}} & \multirow[b]{3}{*}{$\begin{array}{l}\mathbf{Y} \\
\mathbf{e} \\
\mathrm{a} \\
\mathrm{r}\end{array}$} & \multirow[b]{3}{*}{$\begin{array}{l}\mathrm{M} \\
\circ \\
n \\
\mathrm{t} \\
\mathrm{h}\end{array}$} & \multirow[b]{3}{*}{$\begin{array}{l}\mathrm{D} \\
\mathrm{a} \\
\mathrm{y}\end{array}$} & \multicolumn{3}{|c|}{ Temperature (F) } & \multicolumn{5}{|c|}{ Precipitation } & \multicolumn{2}{|c|}{ Evaporation } & \multicolumn{6}{|c|}{ Soil Temperature (F) } \\
\hline & & & & \multicolumn{2}{|c|}{$\begin{array}{l}24 \mathrm{hrs} \text {. ending } \\
\text { at observation } \\
\text { time }\end{array}$} & \multirow{2}{*}{$\begin{array}{l}\text { at } \\
\text { o } \\
\text { b } \\
\text { s } \\
\text { e } \\
r \\
v \\
\text { a } \\
\text { t } \\
i \\
o \\
n\end{array}$} & \multicolumn{4}{|c|}{$\begin{array}{l}24 \text { Hour Amounts ending } \\
\text { at observation time }\end{array}$} & \multirow{2}{*}{\begin{tabular}{|c|} 
At Obs \\
Time \\
Snow, ice \\
pellets, \\
hail, ice \\
on \\
ground \\
(in)
\end{tabular}} & \multirow[b]{2}{*}{$\begin{array}{c}24 \text { Hour } \\
\text { Wind } \\
\text { Moveme } \\
\text { nt } \\
(\mathrm{mi})\end{array}$} & \multirow[b]{2}{*}{$\begin{array}{l}\text { Amount } \\
\text { of Evap. } \\
\text { (in) }\end{array}$} & \multicolumn{3}{|c|}{4 in depth } & \multicolumn{3}{|c|}{8 in depth } \\
\hline & & & & Max. & Min. & & $\begin{array}{l}\text { Rain, } \\
\text { melted } \\
\text { snow, } \\
\text { etc. } \\
\text { (in) }\end{array}$ & $\begin{array}{l}F \\
I \\
a \\
g\end{array}$ & \begin{tabular}{|c|} 
Snow, ice \\
pellets, \\
hail \\
(in)
\end{tabular} & $\begin{array}{l}F \\
\text { I } \\
a \\
g\end{array}$ & & & & $\begin{array}{l}\text { Ground } \\
\text { Cover } \\
\text { (see *) }\end{array}$ & Max. & Min. & $\begin{array}{l}\text { Ground } \\
\text { Cover } \\
\text { (see ") }\end{array}$ & Max. & Min. \\
\hline & 2016 & 7 & 1 & 75 & 45 & & 0.00 & & 0.0 & & 0.0 & & & & & & & & \\
\hline & 2016 & 7 & 2 & 81 & 62 & & T & & 0.0 & & 0.0 & & & & & & & & \\
\hline & 2016 & 7 & 3 & 83 & 61 & & $T$ & & 0.0 & & 0.0 & & & & & & & & \\
\hline & 2016 & 7 & 4 & 90 & 65 & & 0.26 & & 0.0 & & 0.0 & & & & & & & & \\
\hline & 2016 & 7 & 5 & 80 & 60 & & 0.00 & & 0.0 & & 0.0 & & & & & & & & \\
\hline & 2016 & 7 & 6 & 84 & 59 & & $T$ & & 0.0 & & 0.0 & & & & & & & & \\
\hline & 2016 & 7 & 7 & 80 & 63 & & 0.43 & & 0.0 & & 0.0 & & & & & & & & \\
\hline & 2016 & 7 & 8 & 80 & 60 & & 0.00 & & 0.0 & & 0.0 & & & & & & & & \\
\hline & 2016 & 7 & 9 & 83 & 57 & & 1.37 & & 0.0 & & 0.0 & & & & & & & & \\
\hline & 2016 & 7 & 10 & 84 & 64 & & 0.01 & & 0.0 & & 0.0 & & & & & & & & \\
\hline & 2016 & 7 & 11 & 74 & 62 & & 2.11 & & 0.0 & & 0.0 & & & & & & & & \\
\hline & 2016 & 7 & 12 & 83 & 61 & & 0.00 & & 0.0 & & 0.0 & & & & & & & & \\
\hline & 2016 & 7 & 13 & 76 & 63 & & 0.07 & & 0.0 & & 0.0 & & & & & & & & \\
\hline & 2016 & 7 & 14 & 65 & 59 & & 0.17 & & 0.0 & & 0.0 & & & & & & & & \\
\hline & 2016 & 7 & 15 & 78 & 52 & & $T$ & & 0.0 & & 0.0 & & & & & & & & \\
\hline & 2016 & 7 & 16 & 78 & 58 & & $T$ & & 0.0 & & 0.0 & & & & & & & & \\
\hline & 2016 & 7 & 17 & 82 & 62 & & $\mathrm{~T}$ & & 0.0 & & 0.0 & & & & & & & & \\
\hline & 2016 & 7 & 18 & 86 & 57 & & 0.00 & & 0.0 & & 0.0 & & & & & & & & \\
\hline & \begin{tabular}{|l|}
2016 \\
\end{tabular} & 7 & 19 & 88 & 66 & & $T$ & & 0.0 & & 0.0 & & & & & & & & \\
\hline & 2016 & 7 & 20 & 89 & 69 & & 0.04 & & 0.0 & & 0.0 & & & & & & & & \\
\hline & 2016 & 7 & 21 & 90 & 67 & & 0.01 & & 0.0 & & 0.0 & & & & & & & & \\
\hline & 2016 & 7 & 22 & 92 & 63 & & 0.00 & & 0.0 & & 0.0 & & & & & & & & \\
\hline & 2016 & 7 & 23 & 84 & 70 & & 0.15 & & 0.0 & & 0.0 & & & & & & & & \\
\hline & 2016 & 7 & 24 & 83 & 62 & & 0.00 & & 0.0 & & 0.0 & & & & & & & & \\
\hline & 2016 & 7 & 25 & 91 & 57 & & 0.00 & & 0.0 & & 0.0 & & & & & & & & \\
\hline & \begin{tabular}{|l|}
2016 \\
\end{tabular} & 7 & 26 & 86 & 65 & & $\begin{array}{l}1.34 \\
\end{array}$ & & 0.0 & & 0.0 & & & & & & & & \\
\hline & 2016 & 7 & 27 & 79 & 63 & & 0.02 & & 0.0 & & 0.0 & & & & & & & & \\
\hline & 2016 & 7 & 28 & 81 & 62 & & T & & $\mid 0.0$ & & $\begin{array}{l}0.0 \\
\end{array}$ & & & & & & & & \\
\hline & 2016 & 7 & 29 & 81 & 58 & & $\mathrm{~T}$ & & 0.0 & & 0.0 & & & & & & & & \\
\hline & 2016 & 7 & 30 & 81 & 66 & & 0.00 & & 0.0 & & 0.0 & & & & & & & & \\
\hline & 2016 & 7 & 31 & 85 & 66 & & 0.00 & & 0.0 & & 0.0 & & & & & & & & \\
\hline & & & Summary & 82 & 61 & & 5.98 & & 0.0 & & & & & & & & & & \\
\hline
\end{tabular}

The "' hags in Preliminary indicate the data have not completed processing and qualitycontrol and may not be identical to the original observation

Empty, or blank, cells indicate that a data observation was not reported.
- Ground Cover: $1=$ Grass; $2=$ Fallow; $3=$ Bare Ground; $4=B$ Brome grass; $5=$ Sod; $6=$ Straw mulch; $7=$ Grass muck; $8=B$ Bare muck; $0=U$ Unknown

"s" This data value failed one of NCDC's quality control tests.

"T" values in the Precipitation category above indicate a TRACE value was recorded.

"Alus

Figure D.1. Precipitation data (Source: Record of Climatological Observations). 
Table D.4. Precipitation and plant's flow for days prior to July $13^{\text {th }}$ and July $27^{\text {th }}$ of 2016 .

\begin{tabular}{|c|c|c|}
\hline \multirow{2}{*}{ Date } & Precipitation & Flow \\
\cline { 2 - 3 } inches & MGD \\
\hline $7 / 11 / 16$ & 2.11 & 22.54 \\
\hline $7 / 12 / 16$ & & 20.27 \\
\hline $7 / 13 / 16$ & 0.07 & 15.54 \\
\hline $7 / 14 / 16$ & 0.17 & 15.10 \\
\hline $7 / 15 / 16$ & & 14.98 \\
\hline $7 / 16 / 16$ & & 13.76 \\
\hline $7 / 17 / 16$ & & 14.00 \\
\hline $7 / 18 / 16$ & & 14.87 \\
\hline $7 / 19 / 16$ & & 14.55 \\
\hline $7 / 20 / 16$ & 0.04 & 14.44 \\
\hline $7 / 21 / 16$ & 0.01 & 15.41 \\
\hline $7 / 22 / 16$ & & 14.23 \\
\hline $7 / 23 / 16$ & 0.15 & 12.94 \\
\hline $7 / 24 / 16$ & & 12.81 \\
\hline $7 / 25 / 16$ & & 14.38 \\
\hline $7 / 26 / 16$ & 1.34 & 15.06 \\
\hline $7 / 27 / 16$ & 0.02 & 15.83 \\
\hline $7 / 28 / 16$ & & 13.99 \\
\hline $7 / 29 / 16$ & & 13.86 \\
\hline $7 / 30 / 16$ & & 12.59 \\
\hline $7 / 31 / 16$ & & 12.97 \\
\hline $8 / 1 / 16$ & & 14.72 \\
\hline $8 / 2 / 16$ & & 13.84 \\
\hline $8 / 3 / 16$ & & 13.50 \\
\hline $8 / 4 / 16$ & & 13.50 \\
\hline & & \\
\hline
\end{tabular}




\section{APPENDIX E. CB TEST LOG INACTIVATION DATA}

Table E.1. CB test log inactivation data.

\begin{tabular}{|c|c|c|c|c|}
\hline \begin{tabular}{c} 
Dose \\
\cline { 1 - 3 }$\left(\mathrm{mJ} / \mathrm{cm}^{2}\right)$
\end{tabular} & $\begin{array}{c}\text { CBT1 Log } \\
\text { Inactivation }\end{array}$ & $\begin{array}{c}\text { CBT2 Log } \\
\text { Inactivation }\end{array}$ & $\begin{array}{c}\text { CBT3 Log } \\
\text { Inactivation }\end{array}$ & $\begin{array}{c}\text { CBT4 Log } \\
\text { Inactivation }\end{array}$ \\
\hline 0 & 0.0 & 0.0 & 0.0 & 0.0 \\
\hline 5 & 1.0 & 1.2 & 1.4 & 0.6 \\
\hline 7.5 & - & 1.7 & - & - \\
\hline 10 & 1.9 & 1.8 & 2.0 & 1.2 \\
\hline 20 & 2.0 & - & 2.2 & - \\
\hline 30 & - & 2.2 & - & 1.8 \\
\hline 40 & 2.4 & - & 2.7 & 2.2 \\
\hline 80 & 3.0 & 2.7 & 3.0 & 2.4 \\
\hline
\end{tabular}

